\title{
A Design Guide for Energy-Efficient Research Laboratories
}

Prepared By:

Lawrence Berkeley National Laboratory

Center for Building Science

Applications Team

Principal Investigator:

Evan Mills, Ph.D.

Authors:

Geoffrey C. Bell, P.E.

with

Evan Mills, Ph.D.

Dale Sartor, P.E.

Doug Avery

Michael Siminovitch, Ph.D.

Mary Ann Piette

DISTRIBUTION OF THIS DOCUNENT IS UNUMTED
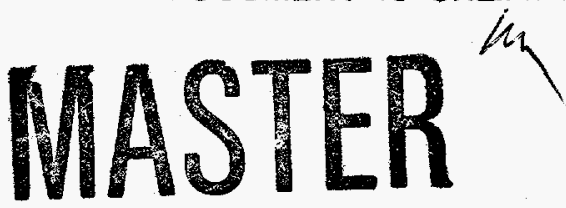


\section{DISCLAIMER}

Portions of this document may be illegible in electronic image products. Images are produced from the best available original document. 


\section{DISCLAIMER}

This report was prepared as an account of work sponsored by an agency of the United States Government. Neither the United States Government nor any agency thereof, nor any of their employees, makes any warranty, express or implied, or assumes any legal liability or responsibility for the accuracy, completeness, or usefulness of any information, apparatus, product, or process disclosed, or represents that its use would not infringe privately owned rights. Reference herein to any specific commercial product, process, or service by trade name, trademark, manufacturer, or otherwise does not necessarily constitute or imply its endorsement, recommendation, or favoring by the United States Government or any agency thereof. The views and opinions of authors expressed herein do not necessarily state or refiect those of the United States Government or any agency thereof. 


\section{A Design Guide for Energy-Efficient Research Laboratories}

\section{Prepared By:}

Lawrence Berkeley National Laboratory, Center for Building Science, Applications Team

University of California, Berkeley, CA 94720

Acknowledgments:

Authors: Geoffrey C. Bell, P.E.

with: Evan Mills, Ph.D., Dale Sartor, P.E., Doug Avery, Michael Siminovitch, Ph.D., Mary Ann Piette

Technical Review:

Victor A. Neuman, P.E., Doug Lockhart, P.E., Steve Greenberg, P.E., Kifah Jayyousi, P.E.

Editors:

Nancy Wishner, Allan Chen, Laural Cook

CIEE Technical Liaison:

Karl Brown

Special Thanks to:

Southern California Edison Company

John Bunnell

Michael Sullivan

University of California at Irvine

Wendell Brase

Vice Chancellor, Administrative and Business Services

Rebekah G. Gladson, AlA

Assistant Vice Chancellor, Design and Construction Services

Larry R. Givens, P.E.

Assistant Vice Chancellor, Facilities Management Department

for technical contributions including arranging participation in the value engineering process for the $\mathrm{UCI}$

Medical Center, Academic Laboratory Building

This work was supported by the California Institute for Energy Efficiency (CIEE), a research unit of the University of California, through the U.S. Department of Energy under contract No. DE-AC03-76SF00098 


\section{FOREWORD}

A Design Guide for Energy-Efficient Research Laboratories -- is intended to assist facility owners, architects, engineers, designers, facility managers, and utility demand-side management specialists in identifying and applying advanced energy-efficiency features in laboratory-type environments. This Guide focuses comprehensively on laboratory energy design issues with a "systems" design approach. Although a laboratory-type facility includes many sub-system designs, e.g., the heating system, we believe that a comprehensive design approach should view the entire building as the essential "system." This means the larger, macro energy-efficiency considerations during architectural programming come before the smaller, micro component selection such as an energy-efficient fan. We encourage readers to consider the following four points when utilizing the Guide.

1. Since the Guide's design recommendations focus upon energy efficiency, it is best used in conjunction with other design resources, manuals, handbooks, and guides. This Guide is not meant to supplant these resources but rather to augment them by facilitating the integration of energyefficiency considerations into the overall design process.

2. Though the Guide may seem to push the envelope of traditional engineering design practice, its recommendations are widely used in actual installations in the United States and abroad. We believe that successful design teams build from the members' combined experience and feedback from previous work. Each team should incorporate energy efficiency improvements, as appropriate, by considering their interactions and life-cycle costs. We also recognize that there is no single design solution for all situations; thus, the Guide focuses on conceptual approaches rather than prescriptive measures.

3. We have performed an extensive literature search and present brief excerpts from many excellent publications. We encourage readers to obtain the full citation of interesting and pertinent documents.

4. The next generation of this Guide will be available both in "hypertext" through the Internet and in a format for "local" use with a computer. Consequently, the current organization of the Guide is optimized for these electronic media. The "home page" for the hypertext version will be: http://eande.lbl.gov/CBS/Ateam/Ateam.html.

We hope the reader will find the Guide to be a useful tool in their laboratory design process and benefit from the work completed by so many energy-efficiency specialists.

Recommended Citation:

Bell, G.C., P.E., E. Mills, Ph.D., D. Sartor, P.E., D. Avery, M. Siminovitch, Ph.D., M. A. Piette. A Design Guide for Energy-Efficient Research Laboratories, LBNL-PUB-777, Lawrence Berkeley National Laboratory, Center for Building Science, Applications Team. September 1996. 


\section{Contents}

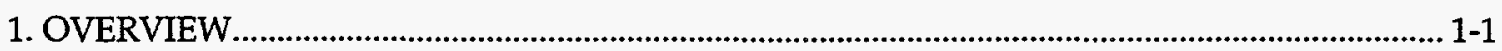

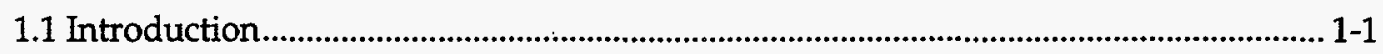

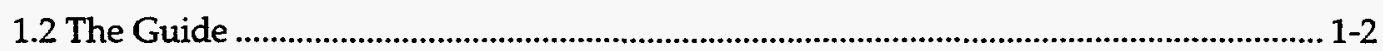

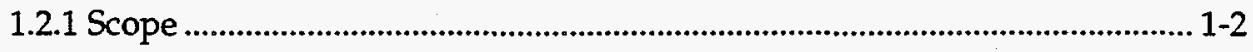

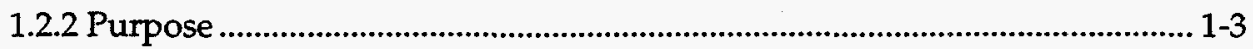

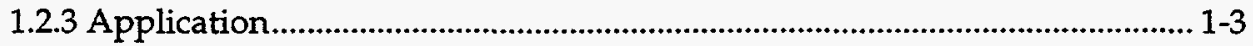

1.2.4 How to use the guide ........................................................................................ 1-3

1.3 The Energy-Efficient Design Process ......................................................................... 1-5

1.3.1 Barriers to energy-efficient laboratory design................................................... 1-6

1.3.2 Example of an integrated energy concept...................................................... 1-7

1.4 "Hot Topics" .............................................................................................................. 1-8

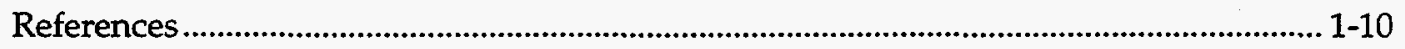

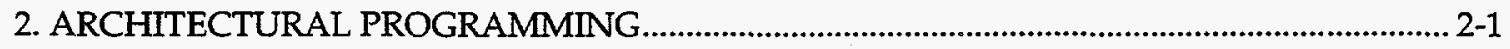

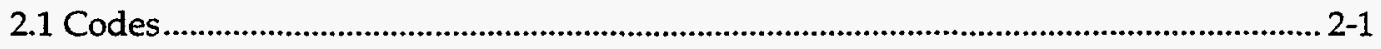

2.1.1 California Health and Safety Code ................................................................... 2-1

2.1.1.1 Code excerpt ....................................................................................... 2-2

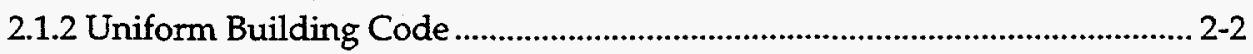

2.1.2.1 Code excerpt ................................................................................... 2-3

2.1.3 Uniform Fire Code ...................................................................................... 2-7

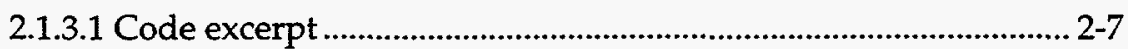

2.1.4 California Code of Regulations ................................................................... 2-8

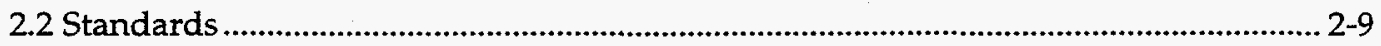

2.2.0.1 Laboratory type definitions .............................................................. 2-9

2.2.1 OSHA - 29 CFR - Part 1910.1450 ..................................................................... 2-10

2.2.2 ANSI - Laboratory Ventilation Standard - Z9.5 - 1992 ............................... 2-11

2.2.3 ASHRAE - 1991 Applications Handbook - Ch. 14 - Laboratories............. 2-11

2.2.4 ACGIH - Industrial Ventilation - 22nd Ed. - 1995 ....................................... 2-12

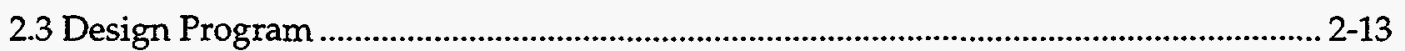

2.3.1 Functional differences in laboratories ..................................................... 2-14

2.3.1.1 The basic science lab ......................................................................... 2-14 
2.3.1.2 The applied science lab .............................................................. 2-14

2.3.1.3 The invention lab...................................................................... 2-14

2.3.1.4 The analysis lab ............................................................................ 2-15

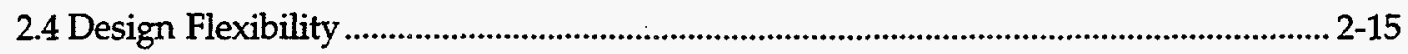

2.4.1 Design flexibility impacts ............................................................................. 2-15

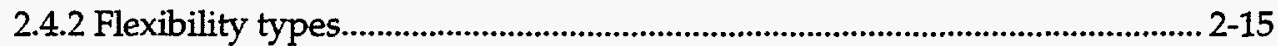

2.4.2.1 Adaptability ................................................................................... 2-15

2.4.2.2 Adjustability ................................................................................. 2-16

2.4.2.3 Expandability............................................................................... 2-16

2.4.3 Operational classifications .......................................................................... 2-16

2.4.3.1 Independent discovery laboratory.................................................. 2-16

2.4.3.2 Interactive commercial laboratory ............................................. 2-17

2.4.4 Conflicts among flexibility types............................................................... 2-17

2.4.4.1 Physical conflicts ............................................................................... 2-17

2.4.4.2 Safety conflicts ........................................................................... 2-17

2.4.5 Flexibility and planning............................................................................ 2-17

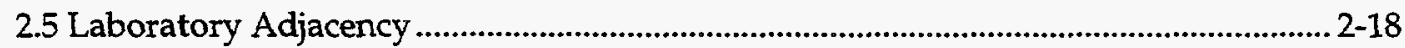

2.5.1 Support activity integration ........................................................................... 2-18

2.5.1.1 Support spaces............................................................................... 2-18

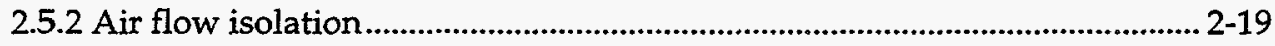

2.5.3 Hazardous isolation .......................................................................................... 2-19

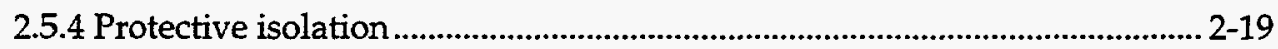

2.5.4.1 Sterile manufacturing operations............................................... 2-20

2.5.4.2 Solids manufacturing environment ............................................. 2-20

2.5.5 Air balancing ........................................................................................... 2-20

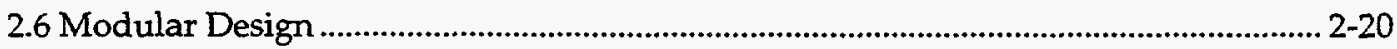

2.6.1 Laboratory modules .............................................................................................. 2-20

2.6.2 Fume hoods and laboratory modules............................................................. 2-21

2.6.3 Cleanroom modules ......................................................................................... 2-21

2.6.3.1 Modular clean bay .......................................................................... 2-21

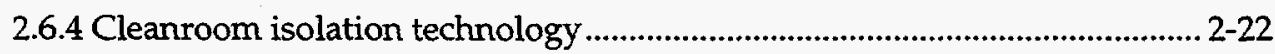

2.6.4.1 Ballroom-style cleanrooms............................................................. 2-22

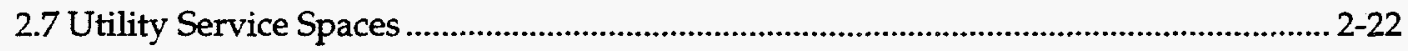

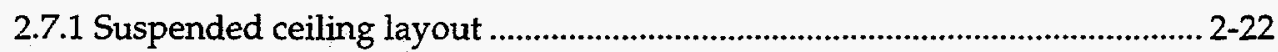

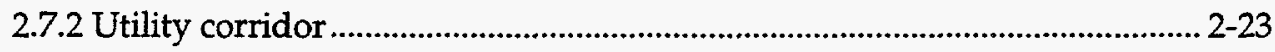

2.7.3 Interstitial space ......................................................................................... 2-23

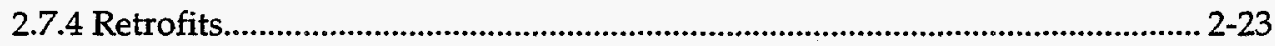

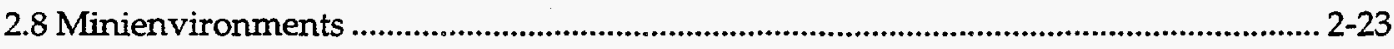

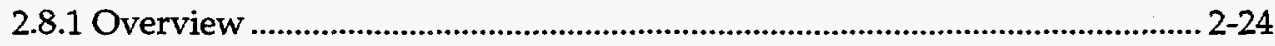




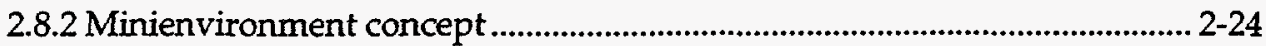

2.8.2.1 Minienvironment enclosure........................................................... 2-24

2.8.2.2 Inert gas microenvironment .......................................................... 2-25

2.8.3 Minienvironment benefits .................................................................................. 2-25

2.8.4 Mini-environments air supply.......................................................................... 2-25

2.8.5 Barrier isolation and the mini-environment ............................................... 2-25

2.8.5.1 Minienvironments hard wall enclosures ...................................... 2-26

2.8.5.2 Minienvironments air curtain enclosures ...................................... 2-26

2.8.5.3 Automation and the minienvironment ...................................... 2-26

2.8.5.4 Minienvironment results/case studies............................................ 2-26

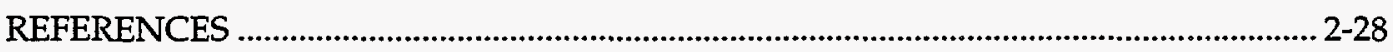

3. RIGHT SIZING: CHOOSING AN ENERGY-EFFICIENT DESIGN ......................................... 3-1

3.1 Life-Cycle Cost Analysis.................................................................................................... 3-2

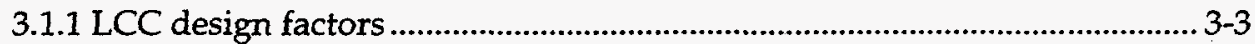

3.1.1.1 LCC techniques .................................................................................3-3

3.1.1.2 LCC and adequate space................................................................... 3-4

3.1.2 LCC economic factors ..................................................................................... 3-4

3.1.3 LCC performance factors ......................................................................... 3-5

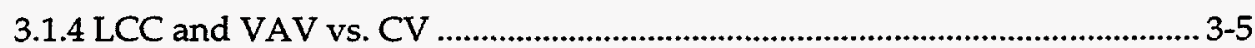

3.1.4.1 Life-cycle cost model study-VAV vs. CV ................................. 3-6

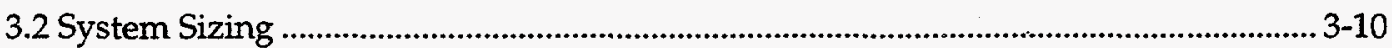

3.2.1 Optimum mechanical system ......................................................................... 3-11

3.2.1.1 Decision-making analysis methodology .........................................3-11

3.2.1.2 Equipment temperature ranges ........................................................ 3-13

3.2.2 Room air change rates.................................................................................... 3-13

3.2.2.1 Computational fluid dynamics (CFD) research project...............3-14

3.2.2.2 Animal facilities.................................................................................. 3-15

3.2.2.3 Ventilation system overview ............................................................ 3-15

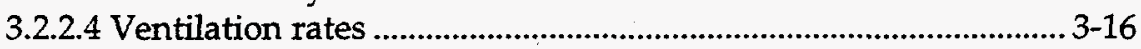

3.2.3 Fume hood face velocity ........................................................................3-16

3.2.3.1 Face velocity - a historical review …...............................................3-17

3.2.3.2 Measured face velocity ................................................................. 3-17

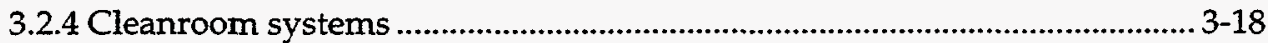

3.2.4.1 Cleanroom exhaust devices .............................................................3-18

3.2.4.2 Optimization in cleanroom systems ............................................... 3-19

3.2.4.3 Cleanroom optimization-case study ........................................... 3-19

3.2.4.4 Cleanroom efficiency - case study ............................................. 3-20

3.2.5 Packaged Air Conditioning.......................................................................... 3-22

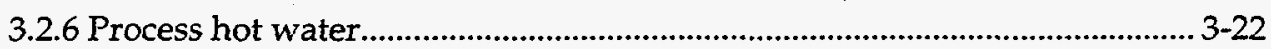

3.2.6.1 Domestic hot water systems ................................................... 3-22

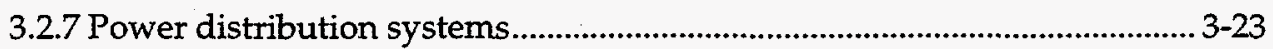

3.2.7.1 Electric load estimation ................................................................. 


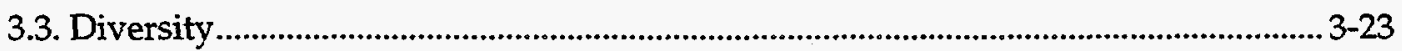

3.3.1 Survey questionnaire ........................................................................................... 3-24

3.3.1.1 Survey example............................................................................. 3-24

3.3.1.2 Survey example \#2 ...................................................................... 3-25

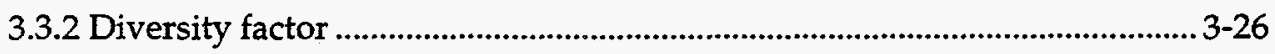

3.3.2.1 Operating cycle............................................................................ $3-26$

3.3.2.2 Diversity calculation .......................................................................... 3-27

3.3.2.3 Diversity factor - a case study ........................................................ 3-27

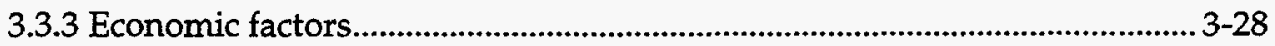

3.3.3.1 Downsizing .......................................................................................... 3-28

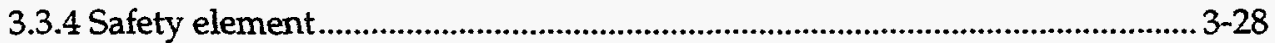

3.3.4.I Facility vs. local diversity ................................................................ 3-29

3.3.5 Diversity and VAV systems ............................................................................... 3-29

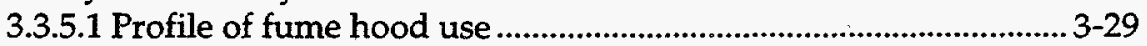

3.4 Load Management......................................................................................................... 3-29

3.4.1 Peak load identification ........................................................................... $3-30$

3.4.2 Demand-controlled ventilation .................................................................... 3-30

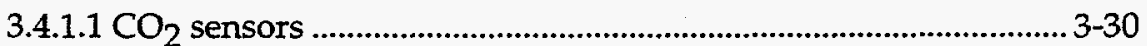

3.4.1.2 Particle counters .................................................................................. 3-31

3.4.1.3 Other gas sensors ................................................................................... 3-31

3.4.1.4 Nonlaboratory applications ............................................................... 3-31

3.4.3 User energy practices....................................................................................... 3-32

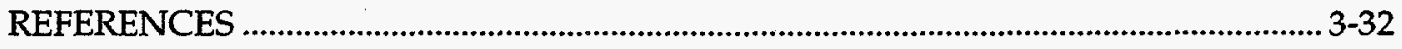

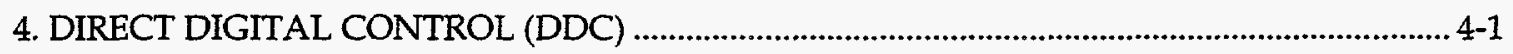

4.1 DDC Implementation ...................................................................................................... 4-1

4.1.1 EMCS acceptance ........................................................................................... 4-2

4.1.2 Control industry ............................................................................................. 4-2

4.1.2.1 An EMCS alternative ................................................................... 4-2

4.1.3 EMCS Pyramid structure ................................................................................ 4-2

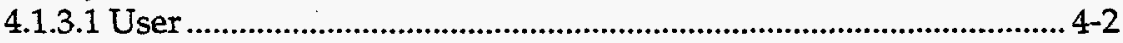

4.1.3.2 Analyst.................................................................................. 4-2

4.1.3.3 Operator ….............................................................................................. 4-3

4.1.3.4 Manager........................................................................................... 4-3

4.1.3.5 Control logic ....................................................................... 4-3

4.1.3.6 Devices.............................................................................................. 4-3

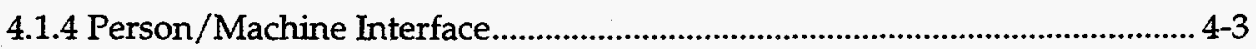

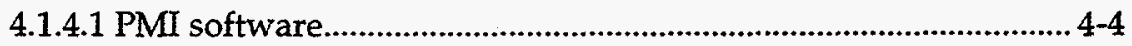

4.1.4.2 EMCS coordinator....................................................................... 4-4

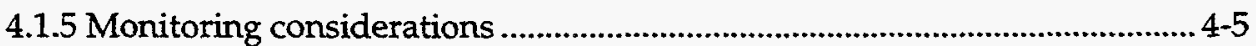

4.1.5.1 Particle counters ...................................................................... 4-5

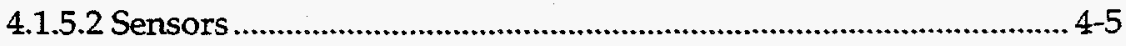

4.1.5.3 Sensor location ............................................................................... 4-5 


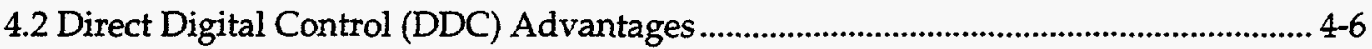

4.2.1 DDC vs. conventional pneumatic controls ................................................ 4-6

4.2.1.1 Dynamic system response.......................................................... 4-6

4.2.1.2 DDC system startup............................................................................... 4-7

4.2.1.3 DDC and pneumatics combined ................................................ 4-7

4.2.2 DDC control integration ........................................................................................ 4-7

4.2.2.1 Optimum start ................................................................................... 4-7

4.2.2.2 Diversity analyses ............................................................................... 4-7

4.2.3 Monitoring and maintenance...................................................................... 4-7

4.2.3.1 Graphical User Interface (GUI) ...................................................... 4-8

4.2.3.2 Combined monitoring application................................................... 4-8

4.2.4 Reporting ................................................................................................. 4-8

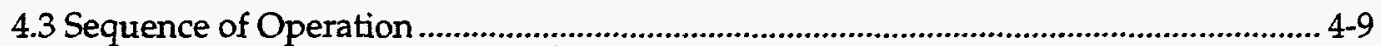

4.3.1 Facility control sequences............................................................................. 4-9

4.3.1.1 Sequence implementation .............................................................. 4-9

4.3.1.2 Control block algorithms.................................................................. 4-10

4.3.1.3 Tuning aids .................................................................................... 4-11

4.3.1.4 Pressure isolation ............................................................................. 4-11

4.3.2 Control strategy overview................................................................................ 4-11

4.3.3 Global zone control .................................................................................. 4-12

4.3.4 Air-handling unit control ......................................................................... 4-12

4.3.5 Economizer operational routines ............................................................ 4-12

4.3.6 Occupancy-based controls ........................................................................... 4-12

4.3.7 Peak electrical demand control.......................................................................... 4-13

4.4 Total Laboratory Energy Management (TLEM) …......................................................... 4-13

4.4.1 EMCS enhancements .............................................................................................. 4-14

4.4.2 Real-time energy evaluations ......................................................................... 4-14

4.4.2.1 Enthalpy stabilization ....................................................................... 4-14

4.4.3 Multivariable control strategies.............................................................. 4-15

4.4.3.1 Multivariable control-case study.............................................. 4-15

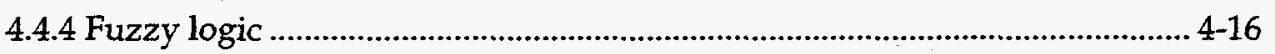

4.4.5 Artificial neural networks .......................................................................... 4-16

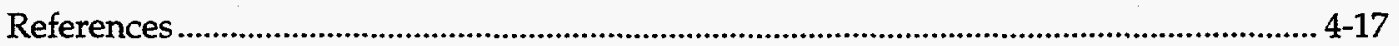

5. SUPPLY SYSTEMS

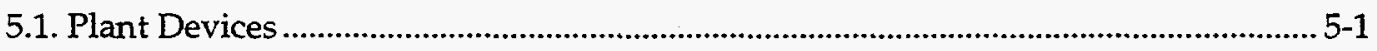

5.1.1 Chillers........................................................................................... 5-2

5.1.1.1 Two-temperature systems........................................................... 5-3

5.1.1.2 Centrifugal refrigeration ............................................................5-3

5.1.1.3 Compressor motors................................................................. 5-4

5.1.1.4 Internal pressure drop.............................................................. 5-4 
5.1.1.5 Cold condenser water.....................................................................

5.1.1.6 Cooling tower capacity................................................................. 5-5

5.1.1.7 Cooling tower fans............................................................................ 5-5

5.1.1.8 VFD cooling tower operation ....................................................... 5-5

5.1.1.9 Optimum operating point................................................................ 5-5

5.1.1.10 Part-load conditions..................................................................... 5-6

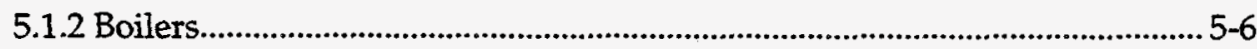

5.1.3 Free cooling ......................................................................................... 5-6

5.1.3.1 Stabilized temperature control ..................................................... 5-7

5.1.3.2 Blended tower water ................................................................... 5-7

5.1.3.3 Tower water isolation .................................................................... 5-7

5.1.3.4 Additional refrigerant ................................................................ 5-8

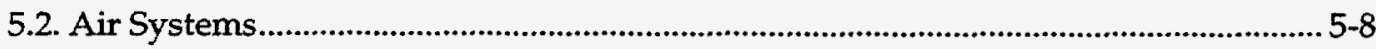

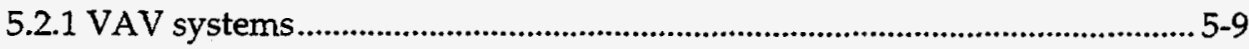

5.2.1.1 VAV terminal devices................................................................... 5-9

5.2.1.2 VAV relative humidity............................................................ 5-9

5.2.1.3 VAV comparison case study ............................................................ 5-9

5.2.1.4 Constant-volume reheat comparison ...........................................5-10

5.2.1.5 Double-duct VAV .................................................................... 5-10

5.2.1.6 VAV retrofit example ................................................................. 5-10

5.2.2 Make-up air systems ................................................................................. 5-10

5.2.2.1 Make-up air components ................................................................. 5-11

5.2.2.2 Cleanroom make-up air ................................................................ 5-11

5.2.2.3 Make-up system acoustics and vibration....................................... 5-12

5.2.3 Air recirculation systems.......................................................................... 5-12

5.2.3.1 Filter fan units (FFU) ........................................................... 5-12

5.2.3.2 Recirculation and make-up air combined.................................... 5-13

5.2.3.3 Recirculation system acoustics and vibration .............................. 5-13

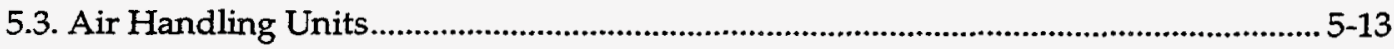

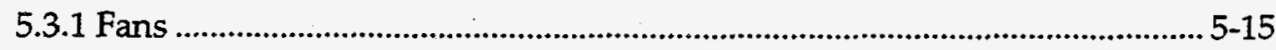

5.3.1.1 Selection and optimum BHP .................................................. 5-16

5.3.1.2 Fan selection evaluation ............................................................. 5-17

5.3.1.3 System effect ................................................................................ 5-18

5.3.1.4 Variable frequency drive (VFD) application ............................... 5-18

5.3.1.5 Drive and motor efficiency ............................................................. 5-19

5.3.1.6 Synchronous belts ..................................................................... 5-19

5.3.1.7 Scroll housing effects .......................................................................... 5-19

5.3.1.8 Manufacturers' data.................................................................... 5-19

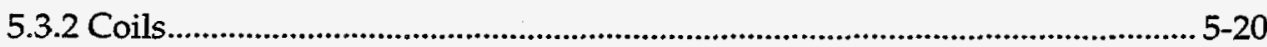

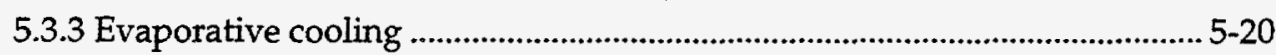

5.3.3.1 Evaporative cooler configuration............................................... 5-21

5.3.3.2 Humidity control.......................................................................... 5-21

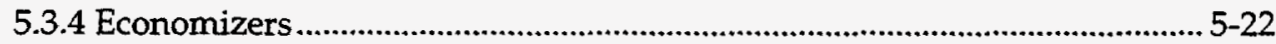

5.3.4.1 Mixing box efficiency............................................................... 5-23

5.3.4.2 Air blenders ................................................................................... 5-23

5.3.4.3 Economizer case study …………............................................... 5-23 


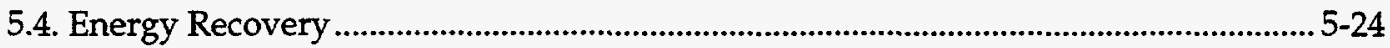

5.4.0.1 Laboratory energy recovery selection factors ............................. 5-25

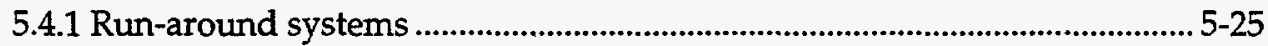

5.4.1.1 Manifolded exhaust and energy recovery ....................................... 5-26

5.4.1.2 Run-around vs. indirect evaporative precooling .......................... 5-26

5.4.1.3 Condenser water heat recovery .................................................... 5-27

5.4.1.4 Coupling fluid glycol concentration.............................................. 5-27

5.4.1.5 Simulation model ............................................................................. 5-27

5.4.1.6 Cooling load reduction....................................................................... 5-27

5.4.1.7 Run-around system commissioning ......................................... 5-28

5.4.1.8 Run-around system limitations ...................................................... 5-28

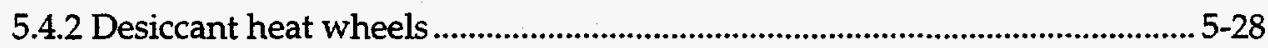

5.4.2.1 Heat wheel operation .................................................................. 5-29

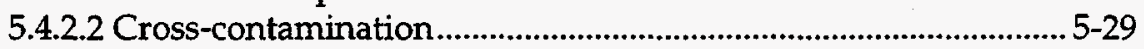

5.4.2.3 AHU installation ........................................................................ 5-30

5.4.3 Heat pipes.............................................................................................................. 5-30

5.4.4 Fixed-plate systems ............................................................................... 5-30

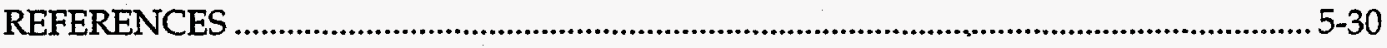

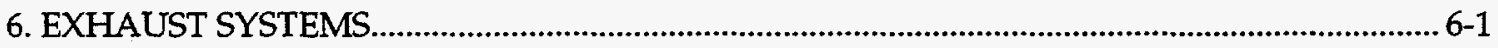

6.1 Overview of Exhaust Systems....................................................................................... 6-1

6.1.1 Configuration .................................................................................................... 6-1

6.1.2 Exhaust air cleaning systems …................................................................. 6-1

6.1.3 Specialized exhaust systems ............................................................................... 6-2

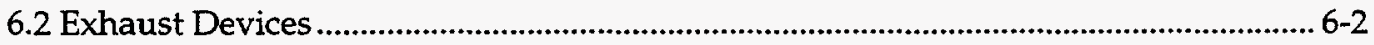

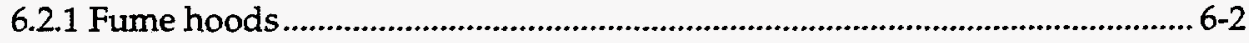

6.2.1.1 Fume hood types............................................................................ 6-3

6.2.1.2 Vertical sash ........................................................................................ 6-3

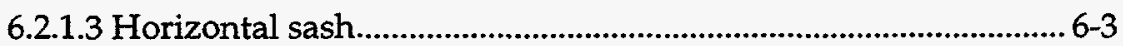

6.2.1.4 Horizontal/vertical sash ................................................................ 6-4

6.2.1.5 Hood testing .................................................................................. 6-4

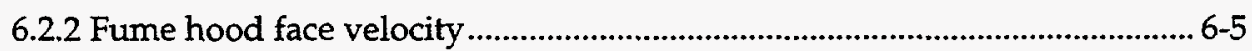

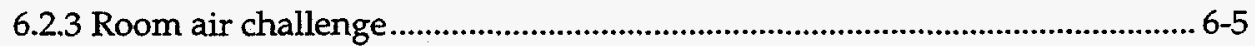

6.2.3.1 Room airflow recommendations................................................. 6-5

6.2.3.2 Fume hood location .................................................................. 6-6

6.2.4 Biological safety cabinets.................................................................................. 6-6

6.2.4.1 Types of biological safety cabinets...................................................6-7

6.2.4.2 BSC type selection............................................................................ 6-7

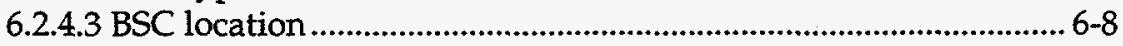

6.2.4.4 Exhaust air requirements ............................................................. 6-8

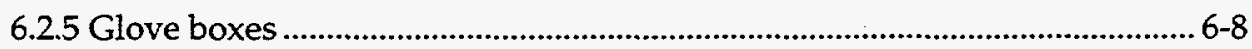

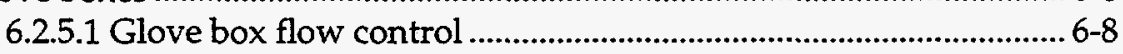

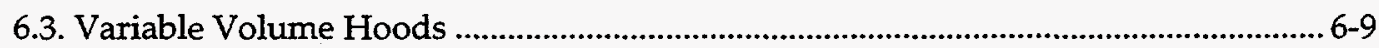




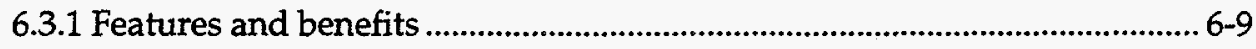

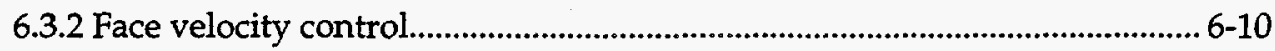

6.3.2.1 Electronic velocity sensing ..............................................................6-10

6.3.2.2 Sash position sensor........................................................................... 6-10

6.3.2.3 Velocity controller ......................................................................... 6-10

6.3.2.4 Response time...................................................................... 6-10

6.3.2.5 Face velocity control - A case history........................................... 6-11

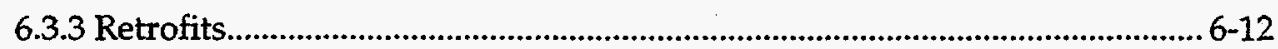

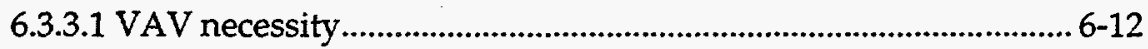

6.3.3.2 VAV organic chemistry research laboratory .............................. 6-12

6.3.3.3 Analytical chemical laboratory ………......................................... 6-13

6.3.3.4 VAV technology research center.................................................... 6-14

6.3.3.5 VAV chemistry building ............................................................. 6-16

6.3.3.6 VAV alternative .................................................................................. 6-17

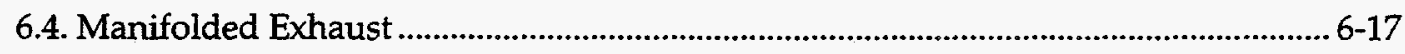

6.4.1 Overview of manifold exhaust systems ................................................. 6-17

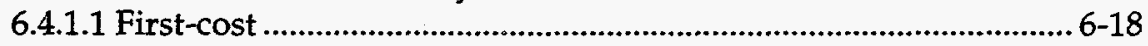

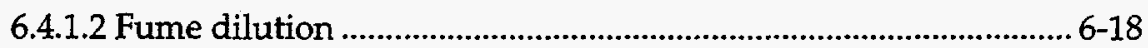

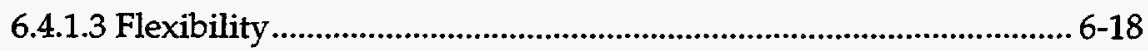

6.4.1.4 Manifold limitations ...................................................................... 6-18

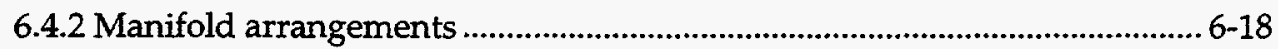

6.4.2.1 Manifold duct work ........................................................................... 6-19

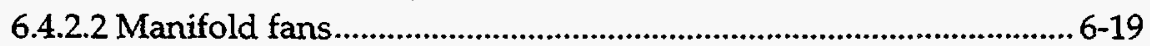

6.4.2.3 Manifold dampers....................................................................6-19

6.4.2.4 Manifolded biological safety cabinets .......................................... 6-20

6.4.3 Duct static pressure control...........................................................................20

6.4.3.1 Suggested sequence of operation................................................ 6-20

6.4.3.2 Example sequence specification.................................................... 6-20

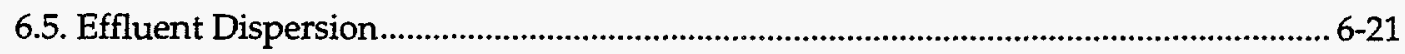

6.5.1 Overview of effluent dispersion.................................................................. 6-21

6.5.1.1 Available dilution concept ........................................................... 6-22

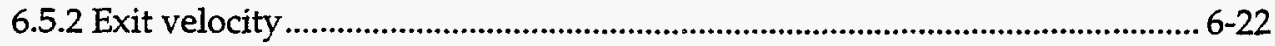

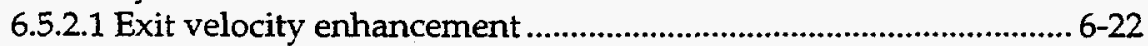

6.5.2.2 VAV exit velocity .......................................................................... 6-23

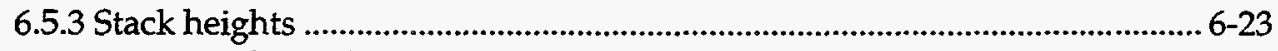

6.5.3.1 Stack downwash....................................................................... 6-23

6.5.3.2 Manifolded vs. individual exhausts ............................................. 6-23

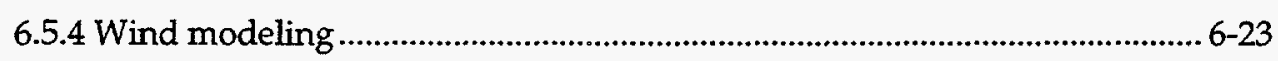

6.5.4.1 Wind model input criteria ............................................................ 6-23

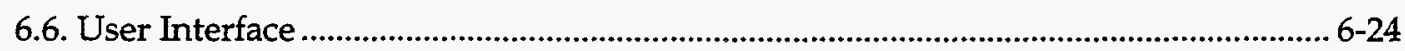

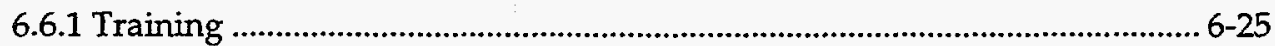

6.6.1.1 Sash function.............................................................................. 6-25

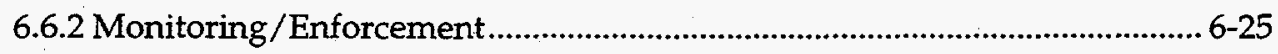

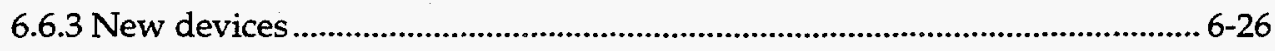




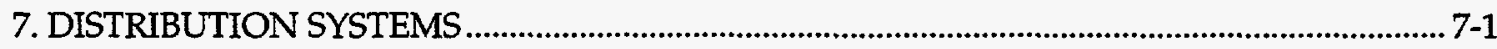

7.1. Air Distribution....................................................................................................................... 7-1

7.1.1 Duct work design methods ............................................................................... 7-2

7.1.2 Low-velocity duct design ................................................................................... 7-2

7.1.3 Duct work ............................................................................................................. 7-2

7.1.3.1 Animal room distribution system: case study............................. 7-3

7.1.4 Displacement flow ................................................................................................ 7-4

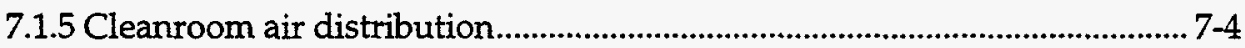

7.1.5.1 Laminar flow cleanroom ............................................................. $7-4$

7.1.5.2 Vertical laminar flow cleanroom.................................................. 7-5

7.1.5.3 Horizontal laminar flow cleanroom ............................................. 7-5

7.1.5.4 Modular laminar flow systems .................................................. 7-6

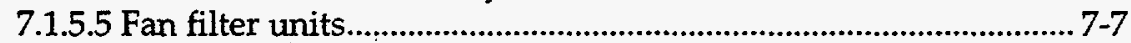

7.1.5.6 Nonlaminar flow cleanroom...................................................... 7-7

7.1.6 Cleanrooms-Pressurized plenum vs. ducted designs.................................. 7-7

7.1.6.1 High- and low-velocity cleanrooms .................................................. 7-7

7.1.6.2 Cleanroom laminar flow velocity …................................................. 7-7

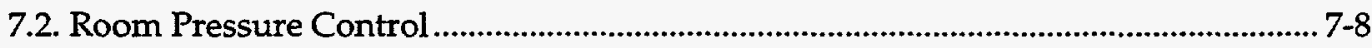

7.2.1 Laboratory pressure control objectives .......................................................... 7-8

7.2.1.1 Static pressure relationships and pressurization .......................... 7-9

7.2.1.2 Temperature control considerations............................................ $7-9$

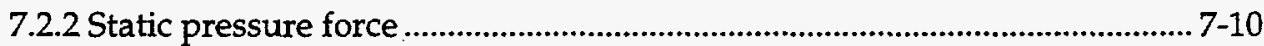

7.2.2.1 Air lock entry ................................................................................... 7-10

7.2.3 VAV and laboratory pressure control .......................................................... 7-10

7.2.4 Application of pressure sensing .......................................................................... 7-11

7.2.4.1 Pressure sensing control................................................................. 7-11

7.2.5 Application of air-flow tracking .................................................................... 7-12

7.2.5.1 Air-flow tracking control ............................................................... 7-12

7.2.6 Combined pressure sensing and air-flow tracking..................................... 7-13

7.2.6.1 Air-flow tracking and pressure sensing - case study................. 7-13

7.2.7 Enthalpy stabilization .................................................................................. 7-14

7.2.7.1 Combined control with enthalpy stabilization................................ 7-14

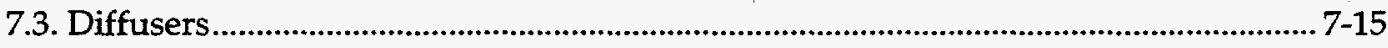

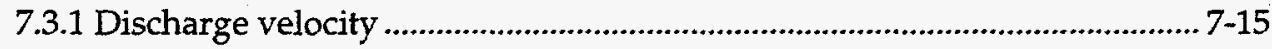

7.3.2 Diffuser placement................................................................................................. 7-15

7.3.2.1 Animal room diffuser systems - case study .............................. 7-16

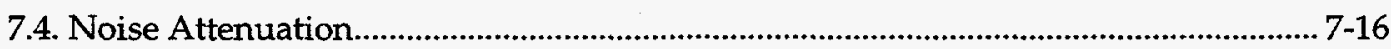

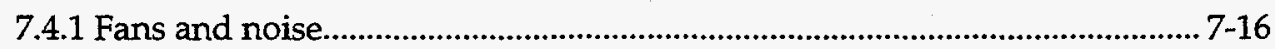

7.4.2 Fume hoods and exhaust duct work noise .................................................. 7-16 


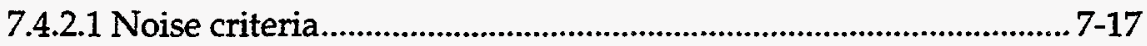

7.4.2.2 General laboratory noise minimization........................................... 7-18

7.4.2.3 Noise attenuation - case study ................................................... 7-18

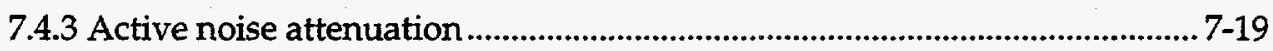

7.4.3.1 Adaptive signal processing.......................................................... 7-19

7.4.3.2 Active noise attenuation in cleanrooms - case study ................ 7-19

7.5. Pumping Systems ...................................................................................................

7.5.1 Variable speed pumping …............................................................................ 7-20

7.5.1.1 Pump selection ................................................................................ 7-21

7.5.1.2 Variable speed pumping-case study............................................. 7-21

7.5.2 Primary/secondary/tertiary loops ................................................................... 7-21

7.5.3 Piping pressure drop .................................................................................. 7-22

7.5.4 Coil pressure drops ........................................................................................... 7-22

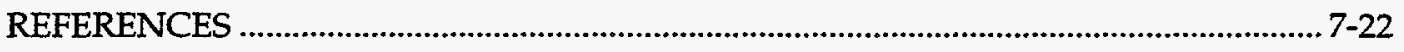

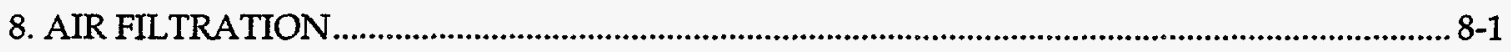

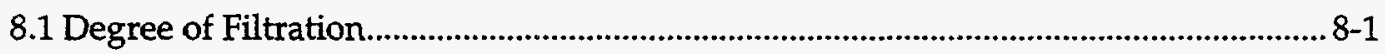

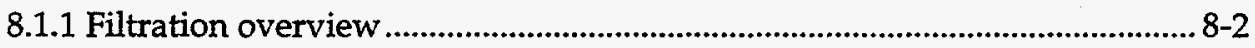

8.1.1.1 Filter processes .............................................................................. 8-2

8.1.1.2 Filter performance................................................................................ 8-3

8.1.1.3 Filter power calculation.............................................................. 8-4

8.1.1.4 Filter construction ........................................................................ 8-5

8.1.1.5 Impingement filters........................................................................... 8-5

8.1.1.6 Extended surface filters.................................................................... 8-5

8.1.1.7 HEPA filters .................................................................................... 8-6

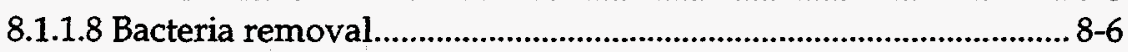

8.1.1.9 Mounting and location .................................................................. 8-6

8.1.1.10 Filtration application-chicken house case study ...................... 8-7

8.1.1.11 Filtration arrangement-case study ........................................... 8-7

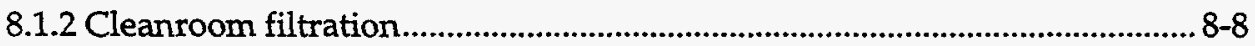

8.1.2.1 Cleanroom prefilter............................................................................ 8-8

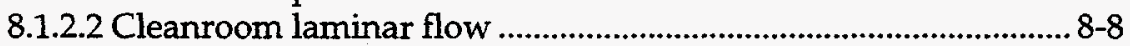

8.1.2.3 ULPA and SULPA filters ............................................................ 8-9

8.1.2.4 Impurity ion removal ........................................................................ 8-9

8.1.2.5 Sodium elimination..................................................................... 8-10

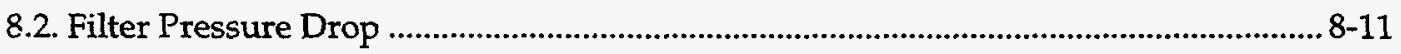

8.2.1 Optimizing final pressure drop: analysis method ..................................... 8-12

8.2.2 HEPA filter pressure drop ............................................................................ 8-12

8.2.2.1 Arc-shaped filter - case study .................................................. 8-12

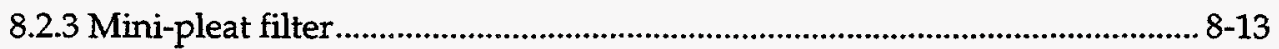

8.2.4 Membrane filtration ............................................................................................... 8-13

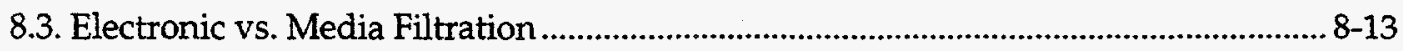

8.3.1 Efficiency of electronic air cleaners .................................................................... 8-13 
8.3.1.1 Electronic air cleaner design.......................................................... 8-14

8.3.1.2 Electronic air cleaner prefiltration ............................................. 8-15

8.3.1.3 Airborne microorganisms .......................................................... 8-15

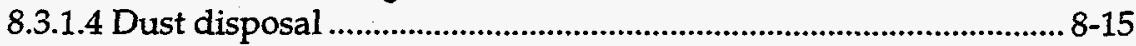

8.3.1.5 Historical background ........................................................................ 8-16

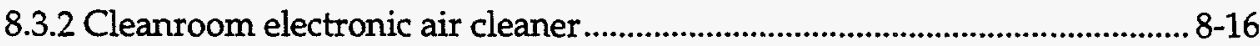

8.3.2.1 Two-stage filtration......................................................................... 8-16

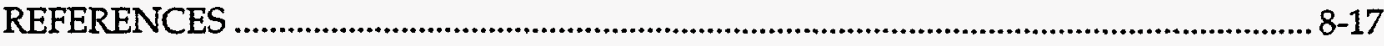

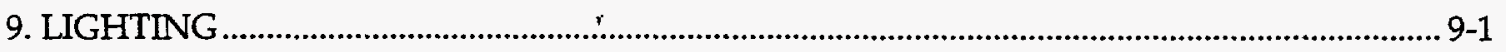

9.1 Lighting Design............................................................................................................... 9-1

9.1.1 Task identification ..................................................................................... 9-1

9.1.2 General lighting design ............................................................................ 9-1

9.1.2.5 Luminance levels....................................................................... 9-2

9.1.3 Task-ambient lighting ..................................................................................... 9-3

9.1.3.1 Lighting calculation methods .......................................................... 9-4

9.1.3.2 Lighting quality computations ...................................................... 9-5

9.1.3.3 Inputs for lighting quality computations ......................................... 9-5

9.1.3.4 Point calculation considerations........................................................9-6

9.1.3.5 Lighting calculation programs and resources ................................ 9-6

9.1.3.6 Task/ambient lighting example....................................................... 9-8

9.2 High-Efficiency Lighting Components .................................................................. 9-9

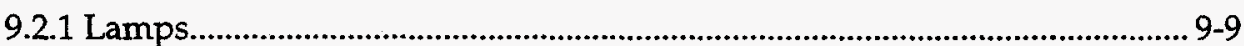

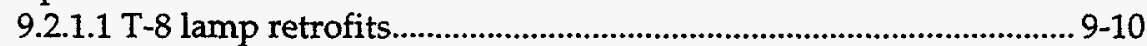

9.2.1.2 History and problems of T12 fluorescent lamps.......................... 9-10

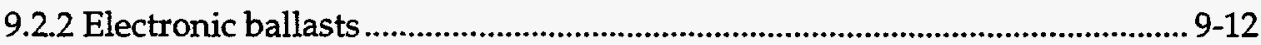

9.2.2.1 Ballast factor ...................................................................................... 9-12

9.2.2.2 Rapid-start ballasts ...................................................................... 9-13

9.2.2.3 Instant-start ballasts.......................................................................... 9-14

9.2.2.4 Harmonic distortion and electronic ballasts................................ 9-14

9.2.2.5 Reliability of electronic ballasts........................................................ 9-15

9.2.2.6 Electronic vs. Magnetic ballasts ...................................................... 9-15

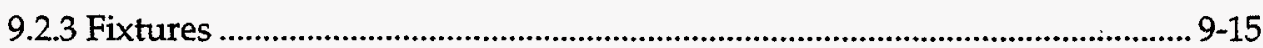

9.2.3.1 Cleanroom fixture considerations.................................................. 9-16

9.2.3.2 Animal room fixture considerations............................................... 9-16

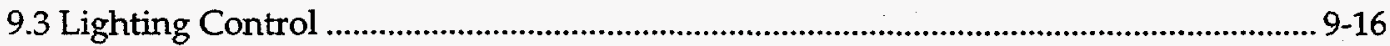

9.3.1 Occupancy sensors ............................................................................................. 9-17

9.3.2 Dimmable ballasts ............................................................................................. 9-18

9.3.3 Lumen maintenance......................................................................................... 9-18

9.4 Remote Lighting Systems ............................................................................................. 9

9.4.1 Remote lighting systems............................................................................. 9-19

9.4.2 Remote lighting sources ......................................................................... 9-20

9.4.2.1 Future remote lighting sources ................................................... 9-20 
9.4.3 Remote lighting optics and distribution...........................................................9-21

9.4.3.1 Hollow light guides ........................................................................... 9-21

9.4.3.2 Hollow light guide test installations................................................ 9-22

9.4.3.3 Reflector-based distribution test installation..................................9-22

9.4.3.4 Fiber optic systems............................................................................ 9-23

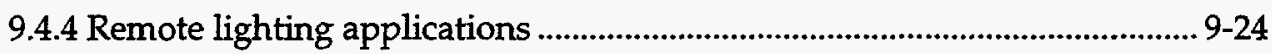

9.4.4.1 Fiber optic flux calculation.............................................................. 9-25

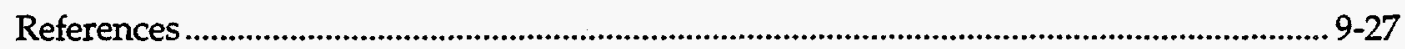

10. COMMISSIONING

10.1 Introduction to Commissioning ............................................................................ 10-1

10.1.1 Commissioning Overview............................................................................... 10-4

10.1.1.1 Related Commissioning Programs ................................................ 10-5

10.1.1.2 The Cost of Commissioning ........................................................... 10-5

10.1.1.3 Commissioning Mockups .......................................................... 10-6

10.1.2 Commissioning (Cx) Team......................................................................... 10-8 10.1.2.1 Cx Team Commitment, Responsibility, Oversight - case study10-8

10.1.3 Operations and Maintenance Hand-off.................................................... 10-10

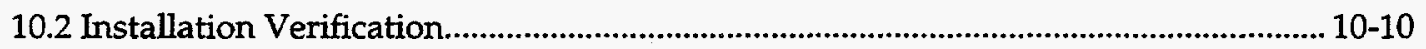

10.2.1 Submittal review ..................................................................................... 10-10

10.2.2 Construction inspection............................................................................... 10-10

10.2.3 As-built conditions .................................................................................. 10-11

10.2.4 Test reports ......................................................................................................... 10-11

10.3 Operational Assessment ........................................................................................... 10-11

10.3.1 EMCS operational assessment................................................................. 10-11

10.3.2 Operational testing....................................................................................... 10-12

10.3.2.1 Operational Testing - case study................................................... 10-14

10.3.3 Operational balancing................................................................................... 10-16

10.3.4 Operational calibration .............................................................................10-16

10.3.4.1 Operational Assessment Process.....................................................10-16

10.3.4.2 Accurate Airflow Sensing …....................................................... 10-17

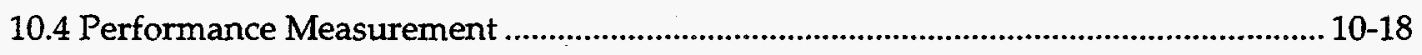

10.4.1 Design compliance ............................................................................... 10-18

10.4.2 Dynamic measurements ........................................................................ 10-18

10.4.2.1 Measuring equipment .................................................................. 10-18

10.4.3 Performance challenge........................................................................... 10-19

10.4.4 Fume hood containment verification....................................................... 10-19

10.4.4.1 Fume Hood Performance measurement example ...................... 10-20

10.4.5 Room pressure control verification.................................................................10-21

10.4.5.1 VAV Flow Tracking Cx - case study............................................. 10-21 


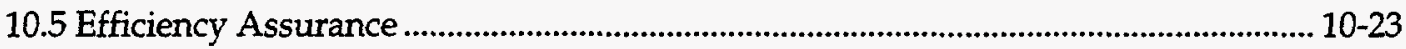

10.5.1 Baseline energy use ........................................................................................ 10-23

10.5.2 EMCS and efficiency assurance........................................................................ 10-24

10.5.3 Verification of EEMs ...................................................................................... 10-24

10.5.4 Estimating energy savings ............................................................................ 10-24

10.5.5 Determining monitoring intervals .............................................................. 10-24

10.5.5.1 Periodic report tasks ........................................................................ 10-25

10.5.5.2 M\&V options ....................................................................... 10-25

10.5.5.3 M\&V activities................................................................... 10-28

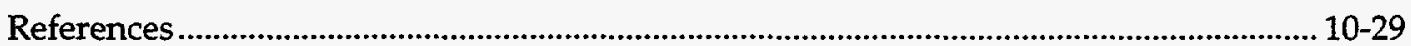




\section{OVERVIEW}

This document--A Design Guide for Energy-Efficient Research Laboratories-provides a detailed and holistic framework to assist designers and energy managers in identifying and applying advanced energyefficiency features in laboratory-type environments. The Guide fills an important void in the general literature and compliments existing in-depth technical manuals. Considerable information is available pertaining to overall laboratory design issues, but no single document focuses comprehensively on energy issues in these highly specialized environments. Furthermore, practitioners may utilize many antiquated rules of thumb, which often inadvertently cause energy inefficiency. The Guide helps its user to: introduce energy decision-making into the earliest phases of the design process, access the literature of pertinent issues, and become aware of debates and issues on related topics. The Guide does focus on individual technologies, as well as control systems, and important operational factors such as building commissioning. However most importantly, the Guide is intended to foster a systems perspective (e.g. "right sizing") and to present current leading-edge, energy-efficient design practices and principles.

Laboratory-type facilities represent an important segment of the building stock, especially when considered in terms of energy intensity and overall consumption. In California, for example, there are over 50 million square feet of laboratory-type space. Energy intensities are often five-times higher than those found in ordinary (non-laboratory) buildings, such as offices. In the case of cleanrooms, intensities are 10-100-times higher, depending on classification. In 1993, California laboratory facilities were responsible for 8.8 billion kilowatt-hours of electricity demand (2100 megawatts) and 21 trillion BTUs of natural gas demand. In the absence of energy-efficiency improvements, projected growth is $131 \%$ (3.9\%/year) to the year 2015. The corresponding energy cost in 1993 was $\$ 700$ million annually, growing to $\$ 1640$ million by the year 2015 . We estimate an overall savings potential of $50 \%$ in new and existing laboratory facilities. [Mills et al., 1996]

\subsection{Introduction}

Energy-efficient laboratories offer the research community cost savings and safer working conditions in addition to serving the larger social good of reducing energy consumption. The laboratory designer with expertise in energy-efficient design will remain competitive in a world that increasingly values energy savings (and the resulting cost savings). Although the recommendations in this guide may seem new, they are valid when applied systematically, and the field of energy efficient design continues to move ahead. We hope design teams use this guide as a starting point, moving beyond the information presented here to read in depth and stay current with energy-efficiency developments in their fields.

Research laboratories are sophisticated and complex environments that are designed to meet the special demands of experimental study, testing, and analysis and to provide safe environments for workers. This double mission means that laboratories must provide levels of safety, space conditioning, and indoor air quality not usually maintained in conventional office buildings. To this end, designs of research laboratories typically have minimal regard for energy use.

A research laboratory environmental conditioning system must also provide protection and comfort for occupants of the laboratory building, including those in associated non-research spaces. The integration of dissimilar types of spaces increases the potential for energy waste.

The weight given to energy use in the design of a building is determined by the building owners/operators and the design team. Owners and designers should be aware that energy-efficient designs can increase worker safety and are more easily adapted in response to the facility's evolving needs. 
Numerous texts and guides deal with design and engineering of laboratory facilities. However, little information is centrally available on energy-efficient research laboratory design. This design guide has been compiled as a comprehensive information source emphasizing the ranges and advantages of energyefficiency measures (EEM's) that can be included in a new facility design, or into an existing facility, and the savings that can result.

\subsection{The Guide}

This design guide for research laboratories compiles information from an extensive literature search of more than 150 research papers, conference proceedings, design texts, case studies, recommended practice, and manufacturers' experience. We gathered additional information from the practicing engineering community; and from energy systems specialists, including scientists and in-house energy managers at the United States Department of Energy's Ernest Orlando Lawrence Berkeley National Laboratory (LBNL). The In-House Energy Management (IHEM) section at LBNL has implemented more than \$14 million worth of energy-efficiency retrofit projects and contributed to the design of numerous, new laboratory facilities.

\subsubsection{Scope}

The guide is designed to address multiple audiences: building owners, planners, architects, and engineers, as well as energy utility personnel interested in demand-side management for their customers with laboratory-type facilities. Ideally, the building owner(s) will explicitly require the building design team to make energy efficiency a design priority and request an "energy engineer" be included as a team member. However, at a minimum, we believe the design team should designate an existing member, usually the mechanical engineer, to focus on energy efficiency. In either case, throughout the Guide, this design engineer will be referred to as the "energy engineer."

The guide provides information at four increasingly technical levels, as described below in Section 1.2.4, "How to Use the Guide." The Guide is not meant to be a resource for all design elements of a laboratory facility and does not deal with specific elements, e.g., fan selection, in depth. Instead, this work is intended to complement existing publications by focusing on energy efficiency. The Guide discusses the design of new facilities and the retrofit of existing facilities. The chapters consider energy efficiency in the following areas:

- Chapter 2: Architectural Programming

- Chapter 3: Integrated System Design: Right-Sizing for Energy Efficiency

- Chapter 4: Direct Digital Control Systems

- Chapter 5: Supply Systems

- Chapter 6: Exhaust Systems

- Chapter 7: Distribution Systems

- Chapter 8: Filtration Systems

- Chapter 9: Lighting Systems

- Chapter 10: Commissioning 
Although economics is a prime driver of energy-efficient investments, given the enormous variation in the pertinent factors among laboratory-type environments, we do not emphasize specific quantitative examples in this Guide. Rather, we discuss the concept and the application of life-cycle cost analysis in some depth, with special consideration for conducting the analysis properly in laboratory-type facilities.

\subsubsection{Purpose}

The Guide's primary purpose is to foster energy efficiency in research laboratories. There are many highly qualified design engineers in the construction industry interested in energy-efficient design, and application of the Guide will be enhanced and focused by their individual experiences. There are various shades of gray involved in engineering judgments and the phrase, "It depends..." will be with us always. Therefore, the Guide's recommendations should be taken in the context of project specifics and individual experiences.

The Guide's chapters consider all phases of the design process that influence a laboratory facility's energy consumption, including design solutions that directly or indirectly affect energy use. An example of a solution with direct impact is the specification of fume hood face velocity; the amount of exhausted conditioned air is proportional to this value. A solution with an indirect impact is selection of supply diffuser throw velocity near a fume hood; this choice influences the performance of an energy-efficient fume hood with a lower than normal face velocity. A design decision that would adversely affect energy efficiency (and safety) is to assume that a high value (greater than $125 \mathrm{fpm}$ ) for the fume hood face velocity increases the operator's safety, without considering the throw velocity of a supply diffuser near the fume hood.

\subsubsection{Application}

This design guide is intended for laboratory-type facilities, such as those found in universities, and for commercial and industrial research facilities, including laboratories and cleanrooms. These facilities typically have Uniform Building Code (UBC) occupancy classifications of B-2, H-8, or H-7. When we use the word "cleanroom," we mean a research and not a production scale facility. We anticipate that future versions of this guide will cover related production and manufacturing-scale laboratory-type facilities. We remind the reader that this guide is intended to complement existing laboratory design manuals and references by describing the ramifications of Energy Efficiency Measures (EEMs) that could be incorporated. This guide does not provide calculation methods to determine energy savings of a design. However, references to in-depth calculation procedures are given.

\subsubsection{How to use the guide}

This guide is arranged in a hierarchical format moving from the macro to the micro levels. The broadest issues, a building's architectural configuration and its UBC code classification, are reviewed first, in the expectation that input from the energy engineer can influence the overall design configuration and possibly this building occupancy and safety classification. The micro issues are quite specific-the impact of air filtration on energy efficiency, for example. The selection of an air filter has a large influence on energy use, particularly in high-air-quality laboratories. Figure 1-1 depicts the design philosophy and decision-making process by illustrating the specific case of fan selection. 
Figure 1-1

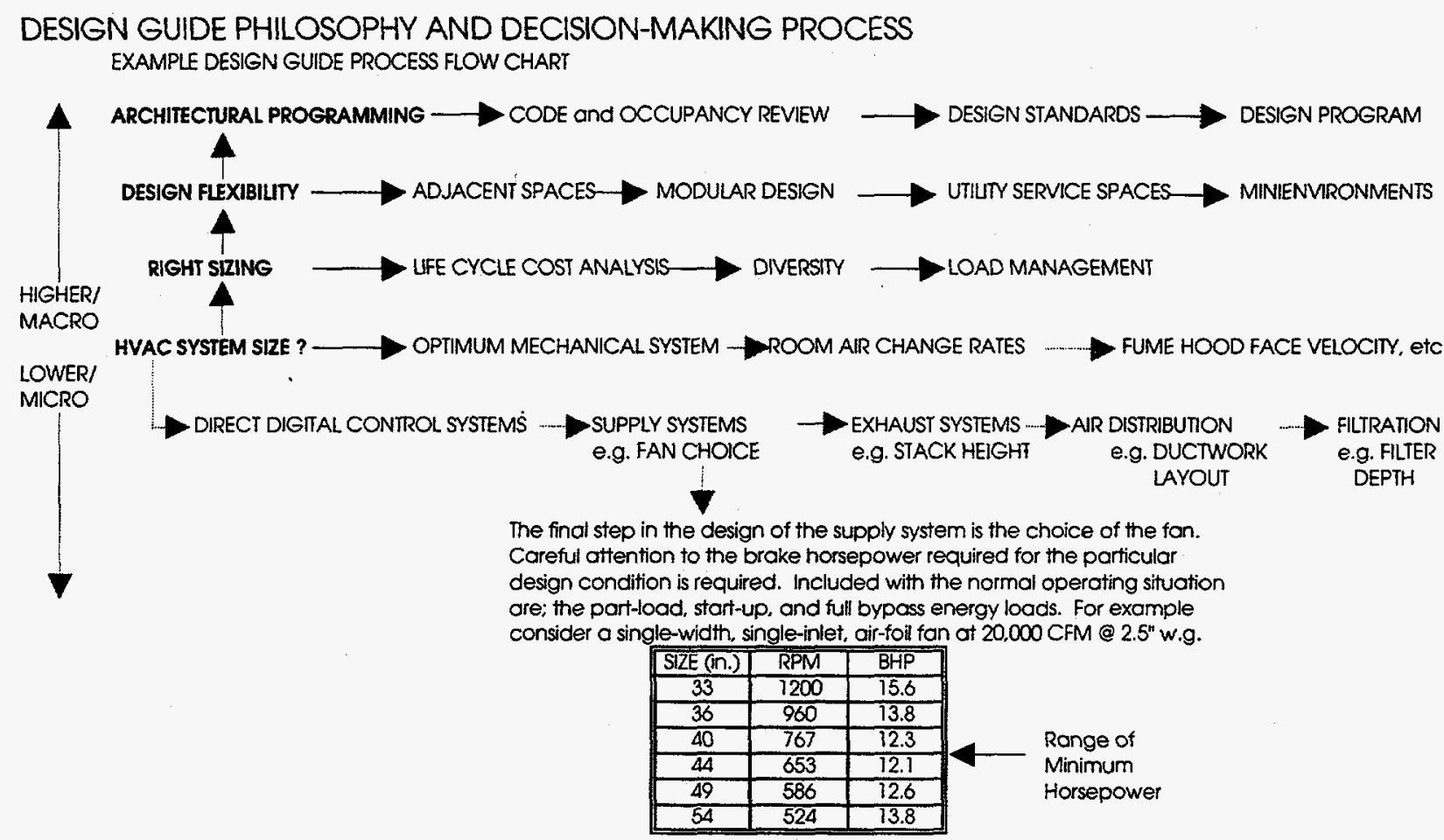

- Chapter Levels

In each chapter of the guide, information about design issues is presented at four increasingly technical levels of detail. This hierarchical presentation is designed to permit readers to choose how much detail they wish to read. The hierarchy is as follows:

- The first level of information in each chapter is a section identified by one number (e.g., 6.) and is immediately followed by the title beginning with, Abstract: Energy Efficiency and..., for example, Abstract: Energy Efficiency and Exhaust Systems, specifically. This level of information presents an abstract of the material covered in the chapter on that topic, highlighting and summarizing key points only. Reading this level alone provides a general overview of the topic.

- The second level of information in each chapter is in sections identified by two numbers (e.g., 6.3) and each is begins with, Energy Efficiency and..., for example specifically, Energy Efficiency and Variable Volume Hoods. This information level presents significant sub-topics contained within the body of each chapter that is more specific than the first level, offering techniques for energyefficient designs. The second level is meant for readers who want a somewhat more particular overview of the topics.

- The third level of information in each chapter is in sections identified by three numbers (e.g., 6.3.2) that describe specific energy-efficiency considerations that should be included in a system/component design/specification. This level presupposes the reader is familiar with the systems/components being analyzed. Level three contains "nuts-and-bolts" information for engineers and designers. 
- The fourth level of each chapter is in sections identified by four numbers (e.g., 6.3.2.4) that present very specific background and support information regarding the energy-efficiency measure under discussion, including case studies and examples. References are given at this level to enable engineers and designers to obtain all particulars on a topic.

\section{- Chapter Bibliography}

Each chapter's references appear at the end in alphabetical order. A complete list of citations is included in a bibliography at the end of the Guide. Footnotes are used to provide immediate clarification of information. Although in many cases excerpts from these sources are provided, the reader is strongly encouraged to obtain the entire document to benefit from their complete scope of work.

\subsection{The Energy-Efficient Design Process}

Energy-efficient design is an iterative process that begins with the establishment of communication among all members of the design team. Each design discipline has an impact on the energy load. On a macro scale, the flexibility of the architectural design permits or presents such features as a modular laboratory size. On a micro scale, the choice of a lighting system can affect sensible heat gain and transformer sizing, for example. Energy-efficient design solutions in laboratories determine the potential variability of a minimized load and match the load with flexible, adjustable electrical and mechanical conditioning system(s). This "systems approach" is fundamental to an integrated system design and "Right-Sizing" (See Chapter 3). The process can be outlined as follows:

\section{- Determine Potential Load Variability}

Laboratory facilities are very energy intensive, primarily because of the large volumes of conditioned air necessary for safety and process ventilation. Therefore, the energy engineer must determine the potential variation of energy loads on hourly, daily, annual, and life-cycle bases. The engineer is encouraged to use the principles of diversity; see Chapter 3 . Each laboratory facility will be operated in a unique manner, commonly referred to as the "Profile of Use," that may or may not vary during a given time frame. For example, some highly specialized research requires a 24 -hour-a-day commitment. When this kind of research is located in a mild climate, the variability of the environmental conditioning load is likely to be small. By contrast, the operation of a laboratory in a university environment may be extremely variable because of odd-hour use, class sizes, and academic-term cycles. Ideally, the analysis of load variability is performed for each energy-consuming device or system within the laboratory.

\section{- Minimize the Load}

While potential variability of energy load is being identified, the design team must focus on minimizing potential energy load. Research laboratories have been compared to wind tunnels because of the large volumes of air moved through them, typically ten times greater than in an office building. Minimizing this air volume substantially reduces energy consumption; however, because of the volume of air flow, traditional energy-saving measures like wall and roof insulation will not have a big effect on energy efficiency. The main air-volume energy loads that need to be minimized are provided by an environmental conditioning system: [Ruys, 1990]

- thermal (sensible), e.g., heating and cooling;

- latent, e.g., humidification or dehumidification;

- air movement, e.g., fans and motors/drives;

- circulation, e.g., pumps and motors/drives; and

- miscellaneous support and peripheral equipment (i.e., those that create internal heat gains). 
The energy engineer should first qualify and then quantify the load as follows:

- qualify the load with researchers and owner(s) to: inform them of the energy-use implications of all choices they make regarding lab environmental conditions, determine the range of acceptable lab environment conditions, specify the tolerance to which the lab environment must be held, and involve the client in selecting the largest possible "comfort envelope" in consideration of the energy consumed to maintain restrictive temperature and humidity conditions. For instance, an excessively tight relative humidity (R.H.) range consumes a large amount of energy and may require cooling and re-heating coils in the air supply system.

- quantify the load by: complying with the code requirements; providing certification when necessary, as in the case of biological safety cabinets; maintaining required researcher/user safety and environmental conditions; employing computer-based simulation tools to analyze life-cycle cost benefits of alternative designs. "Rule-of-Thumb" calculations should be questioned; climate and user operation should be thoroughly considered in all load calculations.

\section{- Match Variable Load with an Adjustable System}

A flexible, adjustable environmental system should be designed in concert with all of the design steps in this section, so that the system can match load variations to achieve maximum energy efficiency. A flexible, adjustable system adapts by means of staged operation of modules and devices that can be operated to satisfy the current load. Engineers must consider the part-load efficiency of an environmental conditioning system.

\section{- Understand Barriers}

The goal of the energy-efficient design process is to have considered all energy-efficiency options and incorporate the best into the final design. However, numerous real and perceived barriers exist, such as higher than normal first costs and out-of-date design standards. Creating an energy-efficient laboratory design requires an understanding of and a willingness to surmount these barriers; with persistence, an energy engineer can optimize system performance and individual components to produce an effective, integrated, energy-efficient design. A list of barriers is given in Section 1.3.1 below.

\section{- Use an Integrated Energy Engineering Approach}

The Integrated Energy Engineering or "Right-Sizing" approach to laboratory facility design considers interdisciplinary and interactive energy relationships among: architecture, facility programming and planning, electrical and mechanical engineering, and facility operation and maintenance. Energy engineers should promote and share design ideas directed toward minimizing a facility's total energy use, not just the energy consumed by its environmental conditioning system. The interrelationship of an electrical system design provides a good example of this interactive design methodology. When closely analyzed, an energy-efficient lighting system reduces the waste heat within a facility which, in turn, means a smaller HVAC system is needed. A smaller HVAC system permits a reduced transformer size and a smaller emergency generator.

\subsubsection{Barriers to energy-efficient laboratory design}

A comprehensive list of barriers to energy-efficiency improvements was compiled at a workshop that focused on cleanroom design; the list applies to other research laboratory facilities. The barriers to energy-efficient design that were identified include: 
- Standard design practices are based on old technologies or inaccurate assumptions. These include: sizing air-side pressure drops for a fixed static pressure; sizing water systems for a fixed amount of head; using high coil and filter face velocities.

- Considerable emphasis is placed on system first cost although lower first cost may result in higher life-cycle costs. Design teams need to consider life-cycle costs, which often justify higherfirst-cost, energy-efficient equipment.

- Time and priority need to be given to working out new, nontraditional designs. Energy-efficient designs may require additional staff time or consultants.

- The conservative facility building culture often resists new ideas. Innovators carry a heavy burden to prove the efficacy of new design concepts; in addition, designers may risk legal consequences if the laboratory's operation does not meet design specifications/design basis documents.

- Benchmarking of energy costs is lacking. If an existing facility does not already track what it costs to operate each component, management has little information on which to base decisions about possible improvements in energy use.

- Size limitations for code requirements may adversely affect environmental conditioning system designs. For example, limiting the height of the penthouse where the air handlers are located may prevent optimal configurations of systems.

- Inadequate space may be available for energy-efficient equipment. Currently, the architect often designs the facility and then tells the engineers how much space they have. Early cooperation among design team members is necessary to devise optimum configurations.

- Performance envelope specifications may limit possibilities for energy efficiency. When the performance envelope or operating range of the facility can be expanded-for example, increasing the allowable relative humidity-lower first costs and operational energy costs may result. Owners and occupants need to clearly understand the impacts that design tolerances have on facility energy performance.

- Designers who are familiar with energy-efficiency concerns in laboratory-type environments are in short supply. [Micro-Electronics Facility Efficiency Workshop, 1995]

\subsubsection{Example of an integrated energy concept}

The example below illustrates some of the energy-efficient design process and its incorporation into an overall facility design. The example describes the energy-efficient design of a research institute specializing in the development of special-purpose microelectronic components.

A central plant with constant air flow rate was chosen for the air conditioning of the multi-story building. At the entrance of each story, the HEPA filters are grouped centrally in easily accessible compact filter boxes according to zones, so that monitoring and maintenance work can be carried out, without need to enter the research rooms. An air distribution system, which is designed so that later modifications can be made without difficulty, conveys the supply air to custom-designed clean air distribution elements. The size and arrangement of the distribution elements, the direction of air flow and the air flow velocity are exactly tailored to the individual requirements of each work station....In some cases the apparatus is protected by the use of horizontal unidirectional flow, in others by vertical unidirectional flow.

The work stations are thus isolated from the surroundings by the use of the principle of spot protection. The remaining room areas of the laboratory are air conditioned merely by spill-over flow from the clean zones, and additional supply air devices have not been 
necessary. This allows both the desired room air conditions to be maintained and an air cleanliness corresponding to cleanliness Class 10,000 according to US Federal Standard $209 \mathrm{D}$, to be ensured-at no additional cost as far as air engineering is concerned.

The velocity of the air emerging from the clean air distributing elements was set individually within the range 0.25 to $0.4 \mathrm{~m} / \mathrm{s}$ ( $\sim 50$ to 80 feet per minute) and is subsequently kept constant by means of automatic air volume control devices.

Minimization both of the spatial extent of the area protected by unidirectional flow and of the flow velocity are (sic) therefore used to keep down the air flow rate to the very minimum possible. [Schicht, 1991]

\section{4 "Hot Topics"}

\section{Energy Efficiency and "Hot Topics"}

When the energy engineer is familiar with the Hot Topics of energy-efficient laboratory design, solutions will develop to overcome many of the barriers noted above. Current solutions include right-sizing techniques, diversity appraisal, DDC systems, VAV systems, modular boiler plants, chiller turn-down ratios, minienvironments, indirect-direct evaporative cooling, and heat recovery. A comprehensive design process combines measures to create a smoothly operating facility with low life-cycle costs.

\section{- Integrated System Design: Right-Sizing for Energy Efficiency}

The techniques of right-sizing integrate the many interactive relationships that influence the capacity of the environmental conditioning system. The goal of right-sizing is to prevent over design of the spaceconditioning system; excessive capacity in a large system wastes energy and increases first costs. The engineering team must determine whether the facility's design conditions are overstated; typically, the specified comfort envelope can be enlarged, reducing the required conditioning system capacity. Another Right-Sizing technique is appraisal of conditioning system diversity, which is based on the assumption that all laboratory equipment is unlikely to operate simultaneously; a diversity analysis determines the average system capacity that will accommodate part-load operation. A Variable Air Volume (VAV) system can efficiently accommodate part-load operation. Chapter 3 elaborates diversity design principles. For analysis of safe, energy-efficient application of VAV supply systems, see Chapter 5; for VAV exhaust systems, see Chapter 6.

\section{- Energy Monitoring and Control System with Direct Digital Control}

An Energy Monitoring and Control System (EMCS) that incorporates direct digital control (DDC) is a key element to an energy-efficient research laboratory. If it is properly designed, installed, and maintained the EMCS insures energy-efficient operation of the facility by monitoring, controlling, and tracking energy consumption. Traditionally, EMCSs have been provided to facilities by manufacturers with little input from design team engineers. It is strongly recommended that energy engineers take a more proactive role in EMCS selection from the design of the sequence of operations to the specification of the kinds of sensors and operators to be installed. See Chapter 4.

\section{- Variable Frequency Drives (VFDs) and Air Flow Rates}

Air handling equipment is typically sized so that it operates at only 70 percent of its full-load rating. Incorporating a variable frequency drive (VFD) that uses duct static pressure as a control input can pay for itself in less than two years. The VFD's lower air velocity reduces pressure loss and increases operating efficiency of a heat recovery device if one is present; these improvements more than compensate for higher system first costs. When the laboratory is unoccupied, the rate could be reduced to 
$50 \%$ of the nominal value, decreasing the energy consumption of the entire air handling system to less than $25 \%$ of that required for a conventional system, provided safe minimum ventilation is maintained. See Chapters 3, 5, and 6. [Schicht, 1991]

\section{- Modularized Plant Devices}

Conditioning equipment can be designed in modules that can operate singly or together to meet part or full loads. Modules include multiple boilers and chillers that can have their operation staged to meet the load. Devices whose operation can be ranged include Variable Air Volume (VAV) supply and fume hood exhaust systems and Variable Frequency Drives (VFDs) on fans and pumps. EMCSs can modulate heating and cooling temperatures with real-time precision. All of these modules and devices take advantage of the facility's diversity and maximize system part-load efficiency. See Chapter 5.

\section{- Segregating Tasks with Minienvironments}

Laboratory temperature and humidity design conditions are typically specified to satisfy both process and human comfort needs. Segregating the more tightly controlled areas from other non-critical areas saves energy. One method is to subdivide systems and zones with minienvironments, see Chapter 2.

\section{- Indirect-Direct Evaporative Cooling}

The greater the range of allowable humidity, the greater the energy savings. As the allowable humidity range increases, the use of energy-efficient indirect-direct evaporative cooling becomes more appropriate. Depending upon climate, when a laboratory's required relative humidity range is 45 to 50 percent, evaporative cooling can be used. This approach can consume as little as two-thirds of the energy necessary to provide a range of 40 to 45 percent R.H., assuming this lower humidity range requires the use of a chiller. Laboratories in warmer climates benefit from raising the allowable R.H.; laboratories in colder climates benefit most from lower minimum R.H. specifications as well as a wider range. See Chapter 3 and 5. [Lynn, 1991]

\section{- Other Measures}

Numerous other measures can be employed in an energy-efficient laboratory conditioning system. The list below provides a quick overview of some additional energy-efficient solutions:

- recover heat from the exhaust air or process cooling water with run-around coils; recover both sensible and latent energy with heat wheels

- incorporate low-face-velocity coils and filters

- choose the lowest pressure drop filter for the efficiency required

- utilize free cooling with a plate-and-frame heat exchanger instead of the chiller and oversized cooling towers

- minimize energy-intensive air cooling and humidification by using evaporative cooling

- use premium efficiency equipment when selecting motors, lamps, boilers, chillers, fans, etc.

- use variable outside air for support spaces that have economizers

- reuse air from office/support spaces to reduce the need for mechanical cooling in the laboratories

- use chiller waste heat for heating purposes. 


\section{References}

Lynn, Charles A.P. "Impact of Cleanroom Concepts on Energy Consumption." 1991.

Micro-Electronics Facility Efficiency Workshop: Meeting Report, Northwest Power Planning Council, Portland, Oregon, 1995.

Mills, E., G. Bell, D. Sartor, A. Chen, D. Avery, M. Siminovitch, S. Greenberg, G. Marton, A. de Almeida, and L.E. Lock. "Energy Efficiency in California Laboratory-Type Facilities." 1996. Lawrence Berkeley National Laboratory Report 39061.

Ruys, T., AIA. Handbook of Facilities Planning, Vol. One, Laboratory Facilities. ISBN 0-442-31852-9. Ruys, Theodorus, AIA, ed. New York: Van Nostrand Reinhold, 1990.

Schicht, H.H. "Cost-Efficiency and Energy-saving Concepts for Cleanrooms." Cleanroom Design, Chapter 6. Whyte, W., ed., London, England: John Wiley \& Sons, Ltd., 1991. 


\title{
2. ARCHITECTURAL PROGRAMMING
}

\author{
Abstract: Energy Efficiency and Architectural Programming
}

Modern research facilities provide usable space for laboratories, laboratory support areas, offices, and interactive spaces for formal and informal gatherings. The special equipment and environments required for research make these facilities complex and expensive to build and operate. Complying with building codes and considering building standards are part of the architectural programming process. The research organization priorities will set the tone for the incorporation of the energy-efficiency measures (EEMs) for the facility. It is important that the facility be able to accommodate changes in use by including flexibility in the original design. However, the facility's near-term energy use must not be overlooked even though the facility may plan for larger system capacity in the future. Architectural arrangements that provide laboratory isolation can result in energy efficiency benefits by using a design concept that includes modular degrees of isolation for the required controlled environments. The modular research laboratory provides an opportunity to arrange the environmental conditioning systems efficiently. Utility service coordination, by providing orderly pathways and routing, will reduce energy use by streamlining their layout and configuration. Minienvironments can reduce energy consumption greatly with their ability to confine energy-intense environments to small volumes.

\subsection{Codes}

\section{Energy Efficiency and Codes}

While it is a fact that codes and energy efficiency are inexorably linked, the codes have few requirements that affect the facility's energy efficiency directly. Recommended standards (see below) have a greater influence on the energy consumption of the laboratory facility. The building standards that apply to all occupancies throughout the state of California appear in the California Code of Regulations and the California Health and Safety Code. Laboratory facilities, per the Uniform Building Code (UBC), typically fall into one of three classifications; $\mathrm{B}-2, \mathrm{H}-8$, or $\mathrm{H}-7$.

The occupancy classification is the key to any impacts of a building standard on the facility's energy efficiency. The energy engineer rarely will have a say in the determination of the facility's UBC classification. However, the indirect benefits of a less stringent classification can reduce energy consumption, e.g., by allowing the recirculation of air within a laboratory rather than requiring $100 \%$ outside air at all times. Therefore, the energy engineer should study the requirements of each classification to be familiar with their potential energy impacts and relate these findings to the project design team.

\subsubsection{California Health and Safety Code}

The California Health and Safety Code is the document that stipulates which building standards shall be applied to all of the occupancies throughout the state. The reference is:

\author{
California Health and Safety Code \\ Division 13 - Housing \\ Part 2.5 - State Building Standards \\ Chapter 4 - The California Building Standards Code \\ SECTIONS 18935-18944.7
}


Under section 18938 (b), the standards that influence energy efficiency considerations are in: the Uniform Building Code of the International Conference of Building Officials; the Uniform Fire Code (UFC) of the International Conference of Building Officials and the Western Fire Chiefs Association, Inc.; and the Uniform Mechanical Code (UMC) of the International Conference of Building Officials and the International Association of Plumbing and Mechanical Officials.

\subsubsection{Code excerpt}

The application of the California Health and Safety Code is defined in Division 13 (Housing), Part 2.5 (State Building Standards), Chapter 4, Section 18938 of the code:

(b) The building standards contained in the Uniform Fire Code of the International Conference of Building Officials and the Western Fire Chiefs Association, inc., the Uniform Building Code of the International Conference of Building Officials, Appendix Chapter 1 of the Uniform Code for Building Conservation of the International Conference of Building Officials, the Uniform Plumbing Code of the International Association of Plumbing and Mechanical Officials, the National Electrical Code of the National Fire Protection Association, and the Uniform Mechanical Code of the Intemational Conference of Building Officials and the Intemational Association of Plumbing and Mechanical Officials, as referenced in the California Building Standards Code, shall apply to all occupancies throughout the state and shall become effective 180 days after publication in the California Building Standards Code by the California Building Standards Commission or at a later date after publication established by the commission.

\subsubsection{Uniform Building Code}

The requirements for the typical laboratory facility occupancy were reviewed for special provisions that would influence their energy efficiency. Ventilation rates are a primary driver in the energy consumption of the laboratory-type facility. However, the building codes do not make large demands for high ventilation rates.

The California version of the UBC includes a special hazardous occupancy, $\mathrm{H}-8$, for "laboratories and similar areas used for scientific experimentation or research." This classification fits between the typical university classification of B-2 and the more hazardous $\mathrm{H}-7$.

The sections that list the requirements of each occupancy (B-2, H-8, H-7) state that light, ventilation, and sanitation are to be provided "in accordance with" Chapter 12 of the UBC. Chapter 12 (Interior Environment) requires only "a minimum of $15 \mathrm{cfm}$ of outside air per occupant in all portions of the building during such time as the building is occupied." In addition, for "Group B Occupancies or portions thereof where Class I, II or III-A liquids are used, a mechanically operated exhaust ventilation shall be provided sufficient to produce six air changes per hour." Only when the occupancy classification reaches the hazard level of H-6 does the following ventilation requirement become necessary:

1202.2.5 Group H, Division 6 Occupancies. In Group H, Division 6 Occupancies, mechanical ventilation, which may include recirculated air, shall be provided throughout the fabrication area at the rate of not less than $1 \mathrm{cfm} / \mathrm{sq}$.ft. of floor area. The exhaust air duct system of one fabrication area shall not connect to another duct system outside that fabrication area within the building. 


\subsubsection{Code excerpt}

The California Uniform Building Code occupancy requirements for laboratories are as follows:

UCB Section 304 - Requirements for Group B Occupancies

304.1 Group B Occupancies Defined

14. Laboratories - testing and research

[Laboratories - testing and research; Universities]

\subsubsection{Special Provisions}

304.2.2.1 Laboratories and vocational shops [Universities]

Laboratories and vocational shops in buildings used for educational purposes, and similar areas containing hazardous materials... The code includes tables showing amounts of hazardous materials and corresponding requirements]. When the quantities of hazardous materials in such uses exceed those listed... [the code refers to tables corresponding to particular occupancy designations].

304.5 Light, Ventilation and Sanitation. Light, ventilation and sanitation shall be accordance with Chapters 12 and 29 [see the complete code] and this section.

304.5.1 Ventilation of flammable vapors. See Section 1202.2.2 for ventilation of flammable vapors.

UCB Section 306 - Requirements for Group F Occupancies

306.1 Group F Occupancies Defined

306.1 General. Group F.....

Division 1.

17. Electronics assembly

20. Food processing

30. Optical goods

306.5 Light, Ventilation and Sanitation. In Group F Occupancies, light, ventilation and sanitation shall be accordance with Chapters 12 and 29 [see the complete code] and this section.

UCB Section 307 - Requirements for Group H Occupancies

307.1 Group H Occupancies Defined.

Division 6. Semiconductor fabrication facilities and comparable research and development areas in which hazardous production materials (HPM) are used and the aggregate quantity of materials are in excess of... [see the complete code for cited tables and sections]. Such facilities and areas shall be designed and constructed in accordance with... [see the complete code for cited tables and sections].

Division 7. Occupancies having quantities of materials in excess of those listed... [the code refers to tables corresponding to particular occupancy designations] that are health hazards, including:

1. Corrosives. 
2. Toxic and highly toxic materials.

3. Irritants.

4. Sensitizers.

5. Other health hazards.

Division 8. (For SFM) Laboratories and similar areas used for scientific experimentation or research having quantities of materials not in excess of those listed... and not otherwise classified as Group B, Division 2 Occupancies. Such laboratories may be classified as Group B, Division 2 Occupancies when quantities of materials are not in excess of those listed... Laboratories having quantities of materials in excess of those listed... and which are located below the fourth story may be classified as a Group H, Division 7 Occupancy... [see complete code for the tables and sections cited].

\subsubsection{Special Provisions for Group H, Division 8 Occupancies.}

...The interstitial space above the lab shall be separated from the corridor by one-hour construction.

...Fume hood exhaust ducts exposed to fire-resistive exit corridors shall be separated from the corridor by one-hour fire-resistive construction.

307.5 Light, Ventilation, and Sanitation.

307.5.2 Ventilation in hazardous locations. See Section 1202.2.3 for ventilation requirements in hazardous locations.

307.5.5 Ventilation in Group $H$, Division 8 Occupancies. In all Group $H$, Division 8 Occupancies, exhaust streams when combined shall not create a physical hazard or react to degrade the contained material. The building official may require a technical report in accordance with Section 307.1.6 [see the complete code for section cited].

Fire dampers in fume hood exhaust ducts are expressly prohibited.

Ducts from laboratory hoods and local exhaust systems shall be constructed entirely of noncombustible material.

\section{Exceptions:}

1. Flexible ducts for special local exhausts used within a laboratory area.

2. Combustible ducts with flame-spread index less than 75 located within a shaft of noncombustible construction where passing through areas other than the laboratory units they serve and provided with intemal fire sprinklers.

3. Combustible ducts or duct linings having a flame spread of 25 or less.

Exhaust ducts from each laboratory unit shall be separately ducted to a point outside the building, to a mechanical space or to a shaft. Connection to a common duct may occur at those points. Exhaust ducts within the same laboratory unit may be combined within that laboratory unit.

Perchloric acid hoods and exhaust ducts shall be constructed of materials that are acid resistant, nonreactive, and impervious to perchloric acid. A water-spray system shall be provided for washing down the hood interior behind the baffle and the entire duct system. 
Ductwork shall provide a positive drainage slope back to the hood and shall consist of sealed sections. The hood baffle shall be removable for inspection.

307.11 Group H, Division 6 Occupancies.

307.11.2 Fabrication area.

307.11.2.4 Ventilation. See Section 1202.2.5 for ventilation requirements. $=>1202.2 .1$ and 1202.2.3 and 1202.2.5

307.11.2.6 Electrical. ... The requirements for.hazardous locations need not be applied when the average air change is at least four times that set forth in Section 307.11.2.4 [see the complete code for sections cited] and when the number of air changes at any location is not less than three times that required by Section 307.11.2.4 and the Fire Code [see the complete code for sections cited].

307.11.5 Storage of hazardous production materials [HPM].

307.11.5.4 Ventilation. Mechanical exhaust ventilation shall be provided in storage rooms at the rate of not less than $1 \mathrm{cfm} / \mathrm{sq}$.ft. of floor area or six air changes per hour, whichever is greater, for all categories of materials.

$$
\begin{array}{ll}
\text { Group B or F-1 } & <\text { Table } 3 D \text { or }<\text { Table } 3 E \\
\text { Group H-8 } & \text { See UBC <Table 3D.1 or <Table 3I } \\
\text { Group H-7 } & \text { See UBC <Table 3D or }>\text { Table 3E } \\
\text { Group H-6 } & \text { See UBC > Table 3D or }>\text { Table 3E }
\end{array}
$$

[see the complete code for table sited].

\section{Table 3D.1 footnotes}

\#1. A laboratory suite is a space up to 10,000 square feet... Up through the third floor and down through the first basement floor, the quantity in this table shall apply. Fourth, fifth and sixth floors and the second and third basement floor level quantity shall be reduced to 75 percent of this table. The seventh through 10th floor and below the third basement floor level quantity shall be 50 percent of this table.

\#2. Quantities may be increased 100 percent when stored in approved exhausted gas cabinets, exhausted enclosures or fume hoods.

\section{Table $3 /$ footnotes}

\#1. A laboratory suite is a space up to 10,000 square feet... Up through the third floor and down through the first basement floor, the quantity in this table shall apply. Fourth, fifth and sixth floors and the second and third basement floor level quantity shall be reduced to 75 percent of this table. The seventh through 10th floor and below the third basement floor level quantity shall be 50 percent of this table.

\#2. Permitted only when stored or used in approved exhausted gas cabinets, exhausted enclosures or fume hoods. Quantities of high toxics in use in open systems need not be 
reduced above the third floor or below the first basement floor level. Individual container size shall be limited to 2 pounds $(0.91 \mathrm{~kg})$ for solids and $1 / 4$ gallon $(0.95 \mathrm{~L})$ for liquids.

Table 3D footnotes

\#6. Quantities may be increased 100 percent in sprinklered buildings. When Footnote 7 [see complete code for footnote 7] [10] also applies, the increase for both footnotes may be applied.

\#10. Quantities may be increased 100 percent when stored in approved storage cabinets, gas cabinets or exhausted enclosures as specified in the Fire Code. When Footnote 6 also applies, the increase for both footnotes may be applied.

Table 3E footnotes

\#5. Quantities may be increased 100 percent in sprinklered buildings. When Footnote 6 also applies, the increase for both footnotes may be applied.

\#6. Quantities may be increased 100 percent when stored in approved storage cabinets, gas cabinets or exhausted enclosures as specified in the Fire Code. When Footnote 5 also applies, the increase for both footnotes may be applied.

UCB Chapter 12 - Interior Environment

Section 1202 - Light and Ventilation in Groups $A, B, E, F, H, I, M$, and S Occupancies

1202.2 Ventilation.

1202.2.1 General. All enclosed portions of Groups $A, B, E, F, H, I, M$, and S Occupancies customarily occupied by human beings shall be provided...with a mechanically operated ventilation system. ...Such a mechanically operated ventilation system shall be capable of supplying a minimum of $15 \mathrm{cfm}$ of outside air per occupant in all portions of the building during such time as the building is occupied.

1202.2.2 Group B Occupancies. In all buildings classified as Group B Occupancies or portions thereof where Class I, II or III-A liquids are used, a mechanically operated exhaust ventilation shall be provided sufficient to produce six air changes per hour. Such exhaust ventilation shall be taken from a point at or near the floor level.

1202.2.3 Group H Occupancies. ...Ducts conveying explosives or flammable vapors, fumes or dusts shall extend directly to the exterior of the building without entering other spaces. ...

EXCEPTION: Ducts conveying vapor or fumes having flammable constituents less than 25 percent of their lower flammability limit may pass through other spaces.

1202.2.5 Group H, Division 6 Occupancies. In Group H, Division 6 Occupancies, mechanical ventilation, which may include recirculated air, shall be provided throughout the fabrication area at the rate of not less than $1 \mathrm{cfm} / \mathrm{sq}$.ft. of floor area. The exhaust air duct system of one fabrication area shall not connect to another duct system outside that fabrication area within the building.

...automatic shutoffs need not be installed on air-moving equipment. 
Except for exhaust systems, at least one manually operated remote control switch that will shut down the fabrication area ventilation system shall be installed at an approved location outside the fabrication area. =>control system

1202.2.5.1 \{For State Fire Marshall\} Ventilation in Group H, Division 8 Occupancies. In all Group $H$, Division 8 Occupancies, exhaust streams when combined shall not create a physical hazard or react to degrade the contained material. The building official may require a technical report in accordance with Section 707.1 .6 [see the complete code for section cited].

Fire dampers in fume hood exhaust ducts are expressly prohibited.

Ducts from laboratory hoods and local exhaust systems shali be constructed entirely of noncombustible material.

Exceptions: 1. Flexible ducts for special local exhausts used within a laboratory area.

2. Combustible ducts with flame-spread index less than 75 located within a shaft of noncombustible construction where passing through areas other than the laboratory units they serve and provided with internal fire sprinklers.

3. Combustible ducts or duct linings having a flame spread of 25 or less.

Exhaust ducts from each laboratory unit shall be separately ducted to a point outside the building, to a mechanical space or to a shaft. Connection to a common duct may occur at those points. Exhaust ducts within the same laboratory unit may be combined within that laboratory unit.

Perchloric acid hoods and exhaust ducts shall be constructed of materials that are acid resistant, nonreactive, and impenvious to perchloric acid. A water-spray system shall be provided for washing down the hood interior behind the baffle and the entire duct system. Ductwork shall provide a positive drainage slope back to the hood and shall consist of sealed sections. The hood baffle shall be removable for inspection.

\subsubsection{Uniform Fire Code}

The Uniform Fire Code refers to the UBC for specific ventilation rates except in the case of an H-6 occupancy, which is not a likely designation for a research laboratory facility. Therefore, the UFC does not specify particular ventilation rates that would reduce the effectiveness of energy-efficient environmental conditioning systems.

\subsubsection{Code excerpt}

UFC - Article 51 - Semiconductor Fabrication Facilities

5103 - Fabrication Areas.

5103.4 Ventilation Requirements.

5103.4.1 General. Exhaust ventilation shall be provided to produce not less than $1 \mathrm{cfm} / \mathrm{sq} . \mathrm{ft}$. exhaust of floor over the design area... 
5103.4.2 Separate systems. The return-air system of one fabrication area [vs. storage area] shall not connect to another system within the building.

5103.4.3 Ventilation controls. There shall be a manual control switch for supply or recirculation air systems, or both, located outside fabrication area...

5104 - Workstations within Fabrication Areas.

5104.3 Exhaust Ventilation.

5104.3.1 Design criteria. A ventilation system shall be provided to capture and exhaust fumes and vapors at workstations.

\subsubsection{Duct systems}

5104.3.2.2 Reactives. Two or more operations shall not to be connected to the same exhaust system when either one or the combination of the substances removed could constitute a fire, explosion, or chemical reaction reaction hazard within the duct system.

5104.3.3 Ventilation power and controls - emergency power. The exhaust ventilation system shall have an emergency source of power. [Group H-6 and H-7; see UBC 307.2.8].

5105 - Storage and Dispensing of HPM within Fabrication Areas.

5105.1 General. The storage of HPM liquids, gases, and solids shall be within fully enclosed storage cabinets or within a workstation. ...

5105.2 Special Requirements for HPM Gases.

5105.2.3 Ventilation. Gas cabinets shall be provided with ventilation. When a gas cabinet contains highly toxic or toxic gases, the average velocity of ventilation at the face of the access ports shall be not less than $200 \mathrm{fpm}$ with a minimum of $150 \mathrm{fpm}$ at any point of the access port.

Gas cabinets shall be operated at a negative pressure in relation to the surrounding area...

5108 - Storage of HPM.

5108.2 Storage of HPM within Buildings.

5108.2.5 Ventilation requirements. Ventilation shall be provided in accordance with Section 5103.4.1.

\subsubsection{California Code of Regulations}

The California Code of Regulations includes two Titles that affect the energy efficiency of the laboratory facility. They are Title 8 and Title 24 .

- Title 8, Section 5154.1. and 5209.

Section 5154.1. Ventilation Requirements for Laboratory-Type Hood Operations. Under Part (c), Ventilation Rates, a fume hood must have an "...average face velocity of at least 100 linear feet per minute [lfm] with a minimum of $70 \mathrm{lfm}$ at any point..." except for the handling of special hazardous materials. A 
more stringent face velocity rate is stipulated under Section 5209. Carcinogens, Part (b) (11) of $150 \mathrm{lfm}$ with a minimum of $125 \mathrm{lfm}$ [see the complete code for section cited].

- $\quad$ Title 24

Title 24 includes sections that influence the energy efficiency of the laboratory facility, including design requirements for energy-using systems and components, and the building envelope. This code is already familiar to and utilized by the energy engineer. A comprehensive Title 24 review is beyond the scope of this design guide. Therefore, no attempt is made to enumerate its many energy-efficiency requirements.

\subsection{Standards}

\section{Energy Efficiency and Standards}

There are many published design standards and guidelines that inform the design engineer about the health and physical hazards of the laboratory environment. This guide focuses on four publications to summarize recommendations that pertain to the energy efficiency of the laboratory. They are:

- Occupational Safety and Health Administration (OSHA) - 29 CFR - Part 1910.1450

- "American National Standard for Laboratory Ventilation." ANS/AIHA Z9.5 1992 [King, 1992]

- American Society of Heating, Refrigeration, and Air-conditioning Engineers (ASHRAE), 1991 Applications Handbook. Atlanta, GA.: ASHRAE, 1994. [1991 Applications Handbook, 1994]

- Industrial Ventilation: A Manual of Recommended Practice - 22nd Edition. ISBN: 1-882417-09-7 (ACGIH). The American Conference of Governmental Industrial Hygienists, Inc., eds. City, State: Publisher, 1995. [Industrial Ventilation: A Manual of Recommended Practice - 22nd Edition, 1995]

These standards include a wealth of information with which the energy engineer should become familiar to produce safe and energy-efficient laboratory design. However, some recommendations are not supported by the current research and some conflict with other standards. Resolving conflicting recommendations is complex and challenging. Information in this design guide can help the energy engineer qualify and quantify the spectrum of considerations and offer the most appropriate energyefficient resolution.

\subsubsection{Laboratory type definitions}

In the Handbook of Facilities Planning (1990), Lindner distinguishes among types of laboratories and typical activities in each. [Lindner, 1990]

- Chemistry Laboratories

Chemistry laboratories tend to break down into the following generic spaces: organic chemistry, inorganic chemistry, physical chemistry and analytical chemistry.

- Biosciences Laboratories

These laboratories, sometimes also called life sciences laboratories, serve as work spaces for a host of special research interests reflecting the investigators' research direction. They are distinguished by the support space that is required for each laboratory or group of laboratories. 
In most ceases, such support space houses: shared equipment, such as centrifuges, freezers, or gas chromatograhs; spaces that need to be separated and enclosed for environmental reasons, such as cold rooms, warm rooms or containment laboratories; or spaces that house specialized functions, such as flow cytometry, tissue culture or autoclaving.

Fume hoods, as well as biosafety cabinets and laminar flow hoods, are used in all areas of bioscience research. Storage for chemicals (solvents and acids) must be provided in accordance with applicable codes.

\section{- Physical Sciences Laboratories}

Physical science laboratories are distinguished from other types of laboratories in a number of ways.

First, there is only a small amount of built-in furniture.

Second, there is an abundance and a variety of electrical power. This, of course, is due to the fact that in most physical sciences research labs the floor space is occupied by an array of mindboggling apparatus and instrumentation, both home-built and store bought. Almost all of this equipment requires power of varying voltage and amperage... Power and piped services are usually provided from an overhead suspended service carrier.

The scientists will then build the experiment within the empty floor space, connect to the overhead services and provide additional work surfaces with movable tables that can easily be rearranged... [Lindner, 1990]

\subsubsection{OSHA - 29 CFR - Part 1910.1450}

As noted in OSHA-29 CFR, the following two points relate to energy efficiency. See Appendix A, Part C. The Laboratory Facility, Section 4. Ventilation $(\mathrm{f})$ and $(\mathrm{g})$. All quotes below are from OSHA-29 CFR.

\section{- Ventilation performance}

The code specifies a room ventilation rate of four to 12 air changes per hour, which "is normally adequate general ventilation if local exhaust systems such as hoods are used as the primary method of control."

This range of air changes per hour is excessively broad and gives the energy engineer little guidance. Many factors affect the best air change rate for the laboratory, and new design methods are in development and testing. Chapter 3 of this guide treats the issue of air changes per hour.

\section{- Ventilation quality}

The recommendation is: insure that "airflow into and within the hood not be excessively turbulent; hood face velocity should be adequate (typically 60-100 lfm)." This guidance is commensurate with energyefficient design practice.

The appropriate fume hood face velocity is an issue of considerable debate. Substantive work to determine safe fume hood face velocity began in 1978 by Caplan and Knutson, et. al. 


\subsubsection{ANSI - Laboratory Ventilation Standard - Z9.5 - 1992}

See Sections: 4.8 Exhaust stack discharge; 4.9 Combined stack gas; 4.11.4 Differential pressure and airflow between rooms; 5.7 Face velocities.

\section{- Exhaust stack discharge}

The recommended discharge velocity is 3000 feet per minute (fpm) for stacks without internal condensation.

This velocity is based most likely on the expected average wind speed. Wind modeling and staged exhaust fan operation can offer reductions in the energy consumed to produce this velocity. See Chapter 6.

- Combined stack gas

Two or more exhaust streams can be combined with this recommendation.

This translates into an energy-efficient design solution that will take advantage of diversity. See Chapters 3 and 6.

\section{- Differential pressure and air flow between rooms}

A pressure differential between the supply and exhaust air flows to and from the laboratory creates the driving force that isolates the laboratory. The recommendation is that "...specifying quantitative pressure differential is a poor basis for design. What really is desired is an air-flow velocity (usually 50 to $100 \mathrm{fpm}$ ) through any openings...".

While this 50 to $100 \mathrm{fpm}$ air-flow velocity is desirable from an energy-use point of view, this value is quite difficult to obtain and maintain in the "real world." The velocity pressure differential to create 50 fpm is only 0.00015 inches W.G. Typically, a laboratory maintains a differential of 0.01 to 0.02 inches W.G. Further discussion is presented in Chapter 3. [Roberts et al., 1992]

\section{- Face velocities}

"...80 to $120 \mathrm{fpm}$ with no face velocity measurement more than plus or minus $20 \%$ of the average" is the suggested range of face velocity (OSHA-29 CFR).

This recommendation is slightly higher than the OSHA suggestion and, when applied, will lead to higher energy consumption. See Chapter 3 and 6.

\subsubsection{ASHRAE - 1991 Applications Handbook - Ch. 14 - Laboratories}

The ASHRAE Applications Handbook chapter on laboratory design has many well-designed recommendations that will increase energy efficiency. This document should be studied in preparation for the design process. However, there is updated information for some of the recommendations included in the ASHRAE handbook chapter, as noted below. Further detail on the updates is available in the specified chapters.

\section{- Design conditions and thermal loss}

Two recommendations in this section of the chapter require further analysis. The recommended design temperature conditions... should be reviewed with the researchers using the laboratory since 
"expanding" the comfort "window" for both temperature and humidity will result in significant savings in energy. See Chapter 3.

The recommendation for a separate thermostat in each laboratory is expanded. It now recommends the inclusion of an Energy Monitoring and Control System (EMCS) that uses Direct Digital Control (DDC). See Chapter 4.

\section{- Supply systems - filtration}

The filtration efficiency should be verified with the researcher, and the pressure drop of the filter should be minimized. The energy-efficiency impacts of these two features of the filtration system are especially important in research cleanrooms. See Chapters 3,5 , and 8.

\section{- Exhaust systems, air balance and flow patterns}

Two statements in the original ASHRAE standard need revision: "many research laboratories require 20 to 30 per hour air change rates," and "generally, minimum rates must be within the range of 6 to 10 air changes per hour of $100 \%$ outside air." These are not supported by recent studies and calculations. Note that in the ASHRAE Applications Handbook section under Flow Patterns, the recommended minimum ranges from four to 20 air changes per hour. This approach of making a laboratory "safe" with high air change rates is not an exact science and is extremely energy inefficient. See Chapters 3,5,6,7, and 8 .

\section{- Laboratory animal rooms}

The table in the ASHRAE handbook for Recommended Ventilation for Laboratory Animal Rooms, compiled by the Institute of Laboratory Animal Resources, dates back to 1977. More recent studies and evaluations have examined the benefits of ventilating cages directly and using computational fluid dynamics to understand the room's air circulation patterns more clearly. Energy savings are increased when these techniques are used in the design process. See Chapter $3,5,6$, and 7 .

\subsubsection{ACGIH - Industrial Ventilation - 22nd Ed. - 1995}

The ACGIH Manual of Recommended Practice should be used as a contemporary source of best design practices for the range of design configurations likely to be encountered in the laboratory facility. This manual is a great resource for air-flow rates needed in an energy-efficient laboratory. See Sections: 2.2 Dilution Ventilation Principles; 7.7 Air Changes; and 10.35.1 Laboratory Hoods.

\section{- Dilution ventilation principles}

These dilution ventilation principles use equations to more accurately predict the hazardous effluent concentrations that are found in laboratory facility exhausts. The application of these principles can affect the exhaust stack design and its exit velocity and consequently the energy required to create a safe dispersion of the pollutants. See Chapter 6.

\section{- Air changes}

The issue of air changes is analyzed correctly. The standard states that "Air changes per hour' or 'air changes per minute' is a poor basis for ventilation criteria where environmental control of hazards, heat, and/or odors is required." The impact of the laboratory's ceiling height is identified correctly as one of the reasons that the air change approach does not address adequately the required contamination control. Dilution of these environmental conditions is the alternative method. See Chapter 3, 5, and 6. 


\section{- Laboratory hoods}

This section of the ACGIH manual references the best available research on fume hood face velocities. Table 10.35.1 gives a comprehensive review of the arrangements for incorporating fume hood face velocities from 60 to $100 \mathrm{fpm}$. See Chapter 3.

Table 10.35-1.

\begin{tabular}{|c|c|}
\hline Condition & $\begin{array}{c}\mathrm{cfm} / \mathrm{ft}^{2} \\
\text { Open Hood Face }\end{array}$ \\
\hline $\begin{array}{l}\text { 1. Ceiling panels properly located with average panel face velocity } \\
<40 \mathrm{fpm} \text {. Horizontal sliding sash hoods. No equipment in hood closer } \\
\text { than } 12 \text { inches to face of hood. Hoods located away from doors and } \\
\text { traffic ways.* }\end{array}$ & 60 \\
\hline $\begin{array}{l}\text { 2. Same as } 1 \text { above; some traffic past hoods. No equipment in hoods closer } \\
\text { than six inches to face of hood. Hoods located away from doors and } \\
\text { traffic ways.* }\end{array}$ & 80 \\
\hline $\begin{array}{l}\text { 3. Ceiling panels properly located with average panel face velocity }<60 \mathrm{fpm} \\
\text { or ceiling diffusers properly located; no diffuser immediately in front of } \\
\text { hoods; quadrant facing hood blocked; terminal throw velocity }<60 \mathrm{fpm} \text {. } \\
\text { No equipment in hood closer than six inches to face of hood. Hoods } \\
\text { located away from doors or traffic ways.* }\end{array}$ & 80 \\
\hline $\begin{array}{l}\text { 4. Same as } 3 \text { above; some traffic past hood. No equipment in hood closer } \\
\text { than six inches to face of hood. }\end{array}$ & 100 \\
\hline $\begin{array}{l}\text { 5. Wall grilles are possible but not recommended for advance planning of } \\
\text { new facilities. }\end{array}$ & \\
\hline
\end{tabular}

*Hoods near doors are acceptable if 1) there is a second safe egress from the room, 2) traffic past hood is low, and 3) door is normally closed.

\subsection{Design Program}

\section{Energy Efficiency and the Design Program}

As part of the design basis document, the research organization and design team should prepare an "energy efficiency mission statement" to outline the goals, methods, evaluation criteria, and constraints of the facility's energy efficiency measures (EEMs). Establishing priorities and communicating them among all parties must be the first step in the design process.

\section{- Innovative concepts}

Even experienced individuals have a natural tendency to repeat what works rather than test new ideas rigorously. The design team should not have prejudices about the laboratory design. Creative energy engineers will use the "mission statement" to find ways of developing opportunities out of challenges. Innovative concepts must be explored at the micro and macro levels as a collaborative effort among the energy engineer, research scientist, and the design team. [Wodka, 1990; Cooper, 1994] 
- User's ideas

Excellent ideas for design concepts often come from a facility's eventual users. However, caution is advised since laboratory users have a hard time imagining facilities they have not experienced.

- Changing research

Many laboratory activities are on the cutting edge of technology. The goal of research is to make new discoveries and develop better processes. Because change is inevitable, flexibility is an asset in laboratory-type facilities. [Wodka, 1990; Cooper, 1994]

\subsubsection{Functional differences in laboratories}

A brief overview of the functional differences in laboratories is presented for orientation. Based on differences in scientific objectives rather than the more usual distinction of field of practice, laboratories can be divided into four categories: basic science, applied science, invention, and analysis. Each represents a different goal of the laboratory's output and requires a different classification. In the Handbook of Facilities Planning (1990), Wodka distinguishes various general categories of laboratories and describes the types of research done in each.

\subsubsection{The basic science lab}

This lab's activities are dedicated to advancing understanding and pure scientific knowledge. Its output is judged by scientific peers, and the value of the work done is seen in very academic terms. To allow this to occur, with the high quality and thoroughness demanded by good scientific practice, there is much individual control of projects following personally chosen objectives. Lab work is usually bench scale, and the facility is often broken into ownership of individual labs by the scientist in charge. [Wodka, 1990]

\subsubsection{The applied science lab}

This lab uses the techniques and methods of science to produce practical, useful results. These results may be in the form of a concept or a verification of a hypothesis in order to solve a stated problem. In this case, the work is judged by those who stated the problem, and these persons are often not scientists. This is an important distinction because the concept of a client enters the picture at this level of science. In basic science, the client can be viewed as science itself. In applied science, there is a definite judgment made by outsiders. Quality is based on the success of the solution proposed. This naturally leads to less control over one's work, since fitting the solution and the problem together demands a different approach to lab practice compared to pure discovery for its own sake. Work here ranges from a high degree of bench-scale activity to larger functions that may include pilot production spaces. [Wodka, 1990]

\subsubsection{The invention lab}

Even more responsive to external pressures is the lab where actual products are invented. These places are part of classic corporate R\&D operations. The problem here is often defined in terms of taking an applied science finding or principle and making it practical for the marketplace. In these situations the issues relate to how to make it, and success is clearly defined by sales and profits. These labs usually have real products or subcomponents requiring space that supports everything from bench scale activity to hangers for huge objects or pilot production. [Wodka, 1990] 


\subsubsection{The analysis lab}

The analytical lab supports the other labs by providing service. The focus here is producing data, as opposed to providing basic understanding, useful concepts or hardware. Analytical lab personnel usually make no judgments as to the value of the data they produce. Therefore, like basic science labs, these labs are concemed with accuracy, truth and specific knowledge. However, they are also responsible to outside customers who judge their output and set their problems, which makes their accountability more like that of applied or invention labs. While the work is most likely to be bench scale in size, repetitive operation and high efficiency are the key goals. [Wodka, 1990]

\subsection{Design Flexibility}

\section{Energy Efficiency and Design Flexibility}

In the design process, the energy engineer is most likely to encounter a desire for adjustability and expandability of the laboratory's energy-using systems, notably its environmental conditioning (HVAC) system. Planning for facility flexibility, in the form of future expansion by the design group, will push the sizing of these systems to larger capacities. To accommodate these capacities it is important to apply a "right-sizing" systems approach. This will ensure that the near-term system usage will be efficient.

\subsubsection{Design flexibility impacts}

The impacts of the laboratory's design flexibility on its energy efficiency are significant and subtle. They are significant because the survivable nature of a flexible design allows investments in energy-efficiency features to provide a positive payback over the long term, and subtle because of the ease with which they can be overlooked in the early stages of the design process. The diverse and often conflicting interpretations of flexibility must be examined, in some functional way, before flexibility can be converted into a working plan. [Lindner, 1990]

\subsubsection{Flexibility types}

The term "flexibility" will lack consistent meaning among the various participants in the planning and design process. The work of three authors has been compiled below to clarify the term "flexibility" as it relates to the design process for energy-efficient research laboratories. Their work and that of others, e.g., Pena et al. (1977), develops some useful distinctions to help understand alternative types of flexibility. The distinctions are the following: Watson, 1990 and Lindner, 1990, make the distinctions in the sections below.

\subsubsection{Adaptability}

The first level of flexibility is a laboratory's ability to adapt to different uses without requiring physical changes. For instance, a "fiexible" laboratory could accommodate microbiology studies during one year and analytical chemistry studies during another year without any changes to benching, hoods, utilities, walls, or ceilings. The only changes would be in the type of science being practiced, the equipment brought in, and the people doing the work. Adaptations would be limited to moving and rearranging furnishings such as tables, chairs, computers, and carts. 


\subsubsection{Adjustability}

The second level of a laboratory's flexibility is its ability to adjust and redirect function with minimum disruption of operations. Trades personnel, using common hand tools, may be required to remove or install new equipment and attach to building services and utilities in a reasonable amount of time. Examples of adjustments include adding or removing sections of lab counter tops, rearranging casework and shelving, and adding or removing a fume hood or a biological safety cabinet. When a fume hood or a biological safety cabinet that has dedicated exhaust is changed, adjustments to the entire facility's HVAC balance and EMCS will be required to presenve user safety and comfort. Fume hood removal or installation and casework changes must take place without impacting adjoining lab operations or disrupting building services.

\subsubsection{Expandability}

The third level of a laboratory's flexibility is its capacity for renovations that reassemble interchangeable subcomponents into new spatial configurations or new functional assemblies. Products such as system furniture, modular walls, modular utility systems, and modular ceilings can change size, shape, capacity, and location. Expandable modular laboratory components allow for changes in fenestration, interior walls, door placement, HVAC zoning, and utility distribution with the addition, subtraction, and relocation of the modular subcomponents. For instance, a modular ceiling allows the number and or placement of HVAC registers and light fixtures to change. Expandable modular building components allow for changes in the capacity and location of major building elements, such as the mechanical, HVAC, and plumbing services.

Laboratories should be designed to one of the above flexibility levels. In most cases flexibility options are mixed, based on the future needs of the facility.

\subsubsection{Operational classifications}

An operational classification matrix includes the functional distinctions described above as well as process complexity which reflects the project mix and the procedure mix in the laboratory. The project mix is an indicator of the variety of the research conducted in the laboratory. The procedure mix is the number of experimental or analytical protocols used in a single type of research in the laboratory. This "matrix" of operational and physical similarities then describes what well-planned laboratories have in common. Two important 'types' of research laboratories can now be described as follows.

\subsubsection{Independent discovery laboratory}

This type of laboratory includes all basic science research laboratories that have both single and multiple projects and procedures. This type of laboratory also includes applied science laboratories that have only single projects but include both single and multiple procedures. Individual projects typically remain independent to maintain scientific purity and personal control with a minimum of project cross-fertilization. This type of laboratory is usually designed to be adaptive and adjustable (see Sections 2.4.2.1 and 2.4.2.2 for definitions). Large-scale expandability is a secondary consideration, occurring at intervals of up to 10 years.

Independent discovery laboratories often need only limited plumbing (plumbed utilities), which suggests that conventional redundant distribution may not be the most appropriate technique. This type of laboratory has a moderate need for widely distributed electrical service. Change... when it occurs, is usually precipitated by a change in research method rather than by a change in timing or in a field of study, which is best supported by local revision of the space and key components rather than by wholesale remodeling. These types of laboratories are presently acquiring large pieces of computerized equipment, which is causing an increase in bench changes. The most significant renovation activity is the addition of ventilation and the trade of bench top space for hood space or for floor space to accommodate electronic equipment and computer space. This renovation often results from the 
increasing need in an independent discovery lab to investigate nature by making ever smaller measurements, which require more sophisticated equipment and environmental contamination control. [Wodka, 1990]

\subsubsection{Interactive commercial Jaboratory}

Interactive commercial laboratories include all invention research laboratories that have both single and multiple projects and procedures. This type of laboratory also includes applied science laboratories that have multiple projects including both single and multiple procedures. These laboratories rely on information exchange among employees and project cross-fertilization and often have parallel programs, with scientists working on segments of the same problem. Interaction among these programs is essential in solving large, complex problems. [Wodka, 1990]

These laboratories use a limited number of utility services that are typically plumbed into the laboratory. Like independent discovery laboratories, above, they need new approaches to utility service distribution. These laboratories use electrical service extensively. Change here is precipitated by changes in program and timing, which feed the need for expandability.

Because these laboratories have either multiple processes or programs, the open-plan or ballroom lab has been the design choice. Like the independent discovery laboratories, these laboratories are now also using more computerized equipment to expedite work, and bench rearrangement is common. Investment in this equipment is seen as a step toward productivity.

\subsubsection{Conflicts among flexibility types}

Flexibility in the laboratory design offers the chance to deal with organizational change effectively. However, conflicts may occur during planning that can render flexibility choices useless unless the conflicts are resolved. For the energy engineer, those conflicts fall into two categories: physical and safety. [Ruys, 1990]

\subsubsection{Physical conflicts}

A singular flexibility type may be selected for a lab; problems may result from attempts to blend flexibility types. These problems develop when the interaction, assembly arrangement, and fit tolerance of the building systems are at odds with one another. Assembly methods must allow the altered system to be relocated or reconfigured quickly when it must work within other system elements that are slow and difficult to change.

\subsubsection{Safety conflicts}

The energy engineer must consider potential safety conflicts that will arise from flexible laboratory designs. Although easily relocated and convertible components like hoods and wall systems give flexibility, changes should not become easy enough for individual users to do on their own. There can never be enough built-in safety controls to ensure proper application and connection if changes are made by untrained personnel. [Ruys, 1990] .

\subsubsection{Flexibility and planning}

Flexibility is often substituted for comprehensive planning. If time is available in the design process, the energy engineer should propose scenarios describing how the progress of research in the lab space can lead to renovation, major or minor. Alternatively, scientists who will use the laboratory can describe how the progress of their research projects will create new design requirements in the space, or how their past work evolved to require new changes in existing lab spaces. All of these scenarios should include the best projections of the likely changes through the life of the facility. [Ruys, 1990] 
New facilities will be flexible, more heavily equipped, more sterile, more secure, and more expensive and they will be operated by more highly skilled and educated personnel. The challenge to laboratory facility designers is to build a strong knowledge base of general science, become informed about the successes and failures of today's energy-efficient laboratories, assist in the development and analysis of the clients' laboratory performance requirements, and synthesize this information into a design solution. [Watson, 1990]

Ruys (1990) admonishes:

Finally, keep in mind that on this subject, the last word is: there is no last word. This is true because lab planning and design are based on the unpredictability of science and technology.

Tested and workable solutions are not constants to be applied to the design process. Engineers should review these solutions each time and must update them continuously to help guide the process of providing laboratories that will work efficiently now and in the future.

\subsection{Laboratory Adjacency}

\section{Energy Efficiency and Laboratory Adjacency}

Eliminating cross-contamination between laboratories is a primary consideration in designing safe and productive laboratory facilities. Energy efficiency can be accomplished with a design concept that includes modular degrees of isolation for the required controlled environments. Laboratories that contain individual processing rooms can modulate the isolation pressures more accurately, increasing both energy efficiency and safety. By designing the facility with multiple degrees of isolation, several processes can be maintained concurrently. [Bossert et al., 1994]

According to Cooper (1994):

The pace of discovery and the potential hazards of research have dictated that sophisticated mechanical and electrical systems and services are available to create pleasant, productive, and safe environments for scientific inquiry. It is not unusual for the building volume devoted to systems and services to exceed the usable, or served spaces.

\subsubsection{Support activity integration}

Support activities include spaces for special equipment or work tasks that require unique environments such as animal control rooms, tissue culture, or darkrooms. Noisy, vibrating, and high-heat-generating equipment such as freezers and centrifuges are better located slightly remote from the laboratory bench area. Here again, it is not unusual for this laboratory support space to equal or exceed the area of the research laboratories. [Cooper, 1994]

\subsubsection{Support spaces}

Laboratory support activities should occur away from the "bench area," but close by. The UCB Department of Physics Facilities Planning Study Technical Appendix (1993) points out that,

Theoretical research offices and the associated research laboratories provide an example of this need for proximity. Support space typically includes computer rooms (no raised floor required; 
cooling required) and conference rooms. Theoreticians typically work in their offices with direct access to a utility corridor preferred. The office size for theoreticians and experimenters should be the same. Research space for each group's experimenters should be contiguous.

\subsubsection{Air flow isolation}

Laboratories are spaces where testing and analyses take place, for observation, experimentation, and scientific practice. These practices involve handling hazardous, toxic, precious, or delicate materials. The authority that has code jurisdiction or certification requires these practices be performed in isolation from normal facility workplaces and conditions.

\section{- Pressure relationship}

This isolation is accomplished through the air balance/pressure relationship to adjacent areas. The pressure relationship is either:

a. negative in the case of hazardous isolation for handling hazardous or toxic operations (a.k.a. dirty operations), or

b. positive in the case of protective isolation for handling precious or delicate operations (a.k.a. clean operations).

\section{- Isolated operations}

Laboratory-type facilities are buildings that contain areas where "isolated operations" are performed with hazardous, toxic, precious, or delicate materials. The air balancing within the facility requires coordination between the facility's individual air-handling units to maintain the directional air flow between rooms. Users should be restricted from accessing any air balancing devices since changes affect the air balance of the entire facility.

\subsubsection{Hazardous isolation}

Hazardous isolation air should flow from areas surrounding the laboratory operation to areas of most critical (dirty) operation inside the laboratory. The laboratory must have a negative pressure differential relative to cleaner, adjacent spaces. Therefore, air flows to the most hazardous area of the laboratory from the external hallway, through the adjacent laboratories by which the most hazardous laboratory is accessed. An acceptable (minimum) pressure differential would be 0.02 in. W.G. [Bossert et al., 1994]

\subsubsection{Protective isolation}

Protective isolation air should flow from areas of critical (clean) operation inside laboratories to areas of less critical operation, such that each laboratory has a positive pressure differential relative to less clean, adjacent rooms. Air flows from the laboratory to the external hallway from which the laboratory is accessed. A pressure differential between spaces of $0.05 \mathrm{in}$. of water gauge (with doors closed) is acceptable (FDA 1987; CFR 1986). Air flow between spaces must be maintained so that even when doorways are opened, outward air flow restricts the introduction of contamination into the cleaner area. While a pressure differential of $0.05 \mathrm{in.}$ W.G. is acceptable, the design of the system to maintain air flow between rooms is critical and may require a higher pressure differential because of openings between rooms. [Bossert et al., 1994] 


\subsubsection{Sterile manufacturing operations}

Bossert and McGinley (1994) describe some of the ways in which sterile manufacturing environments are unique.

Sterile manufacturing operations are arguably the most closely scrutinized manufacturing activities in either a production facility or a clinical supply laboratory. Because of the nature of sterile products (must be free from all viable and nonviable contamination), the areas of operation in a sterile suite require separation and control, and each area requires different degrees of air quality, depending on the intended use of the area. [Bossert, 1994]

\subsubsection{Solids manufacturing environment}

In their paper, "Design Characteristics of Clinical Supply Laboratories Relative to HVAC Systems" (1990), Bossert and McGinley distinguish solids manufacturing environments from sterile manufacturing environments.

... Unlike sterile manufacturing, where restricted introduction of particulates is a key consideration, in a solids manufacturing environment, particulates are readily introduced into the manufacturing area by the nature of the starting and in-process materials and the processes. In a solids facility, then, the "dirtiest" areas are those in which manufacturing operations occur, and the cleaner areas are those adjacent to the manufacturing rooms. As such, the aifflow should be from the cleaner, adjacent hallways or access rooms toward the more central manufacturing rooms. [Bossert, 1994]

\subsubsection{Air balancing}

The air balancing is complicated since general room exhaust and fume hoods are typically on the same system. Operation of the fume hoods will alter the air balance if the system is not properly designed. Room pressure control must be maintained automatically. When the fume hoods are adjusted, they should only affect the air within an individual laboratory room and not the adjacent laboratories. To achieve a specific pressure differential, additional sealing of walls, doors, windows, and ceilings may be required [Bossert, 1994]

\subsection{Modular Design}

\section{Energy Efficiency and Modular Design}

One of the most important strategies to incorporate flexibility in a laboratory-type facility is to provide modular systems. The main energy-use benefit of the modular research laboratory is the flexibility it provides to arrange the environmental conditioning systems efficiently. The modules can accommodate a wide range of mechanical and electrical systems with a broad variety of energy-efficiency features. These modules can expand incrementally to provide enough physical space for initial use, and for future growth. [Lindner, 1990; Cooper, 1994]

\subsubsection{Laboratory modules}

A laboratory module is the three-dimensional planning unit composed of a specific floor space for laboratory work that is repeated throughout the facility. The module is related proportionally to other building systems. Modules are combined and divided into viable units to satisfy the researchers' programmatic needs. They have planned and identified locations for partitions, ceiling and lighting systems, supply and exhaust air systems, plumbing and piping systems, and electric power distribution. The energy engineer should make modular space planning decisions by applying the principles of value 
engineering. The energy-efficiency considerations in the selection of a planning module include but are not limited to the following aspects:

- access, egress, and internal traffic patterns,

- location of the offices and support spaces,

- location of the hoods,

- accommodation of process equipment, and

- the number of people in the space. [Lindner, 1990]

Laboratory modules are intended to facilitate safe, cost-effective modification of support systems when the inevitable changes to the space occur. The mark of a good laboratory design is that its energy efficiency, safety and economy complement the modular nature of the design. [Lindner, 1990; Cooper, 1994]

\subsubsection{Fume hoods and laboratory modules}

Although the choice of whether or not to use the laboratory module concept is based on many factors, it should be noted that relatively small laboratory modules with multiple fume hoods impose more stringent requirements on the ventilation system design. Fume hoods have a major impact on the design and configuration of the laboratory ventilation systems, and their impact will be greatest in rooms where the amount of air flow through the fume hood is large in comparison to the normal ventilation requirements of the room itself. In other words, a fume hood which can consume as much or more air as is required to ventilate the room itself will create a need for a precise and highly responsive room ventilation control system. This also translates into the need for accuracy and precision in the design of the ventilation systems themselves. In contrast, larger laboratory rooms (e.g., in a teaching laboratory) will be less impacted by the changing air flow of a single fume hood and will be able to better absorb the effects of changing fume hood airflow. [Landis and Gyr, 1994]

\subsubsection{Cleanroom modules}

Along with the ever-increasing cost of cleanrooms, a design trend has developed to reduce the area of the cleanroom by placing the process equipment outside the clean room envelope into modular "gray" areas. The use of gray areas reduces the volume of the actual cleanroom proper and modularizes the tasks necessary to operate the cleanroom. This leads to a downsizing of the environmental conditioning systems and a commensurate lowering of their operating costs. Much of the normal maintenance and chemical distribution can now be done in the gray area instead of in a cleanroom area. This helps lower the number of people in the cleanroom, further reducing the operating costs by controlling contamination. Another side benefit is that adjustment and maintenance activities can now be done in the gray area more quickly and efficiently. [Briner, 1986]

\subsubsection{Modular clean bay}

Another modular layout approach places processing equipment into a "clean bay," which acts as a cleanroom when the product is present and as a "gray" area when production is shut down for maintenance or engineering. A closed door isolates the "clean bay" from the cleanroom. Service access is accomplished through another door between the "clean bay" and the "gray" area. The temporary isolation of process equipment in a clean bay preserves the integrity of the cleanroom because all servicing is done from the gray area. Service personnel have unhindered access to the processing system, tools, parts, and service facilities, and only qualified operators work inside the cleanroom. [Briner, 1986] 


\subsubsection{Cleanroom isolation technology}

Isolation technology can reduce further the cost of cleanroom operation in a variety of industries where rooms of various areas utilizing isolation techniques can replace large-scale cleanrooms, sometimes referred to as "ballrooms." The large-scale cleanroom should be a thing of the past; a blend of isolation techniques, robotics, and automation will be the way of the future. [Mcllvaine et al., 1992]

\subsubsection{Ballroom-style cleanrooms}

Ballroom-style cleanrooms are arranged with all operations, routine servicing, chemical distribution and maintenance completed inside the ballroom space. System accessibility is relatively good, but all adjustments and maintenance are carried out in the cleanroom itself, which causes unpredictable interruptions that generate high levels of particulate contamination. Ballroom-style flexibility is limited because process equipment must be removed or installed on off-shifts when "particle storms" can be tolerated. [Briner, 1986]

\subsection{Utility Service Spaces}

\section{Energy Efficiency and Utility Service Spaces}

There are many utilities, ducts, and electrical services that must be distributed throughout the laboratory facility. Providing orderly pathways and routing for these will reduce energy use and space requirements and make future maintenance easier..

\section{- Utility coordination}

To provide efficient horizontal and vertical pathways for the ducts and pipes required for HVAC, plumbing, communications, and electric power requires a great deal of coordination among the researchers, designers, and engineers. The location of these pathways is normally determined by the facility's function, systems access, and first cost and does not consider the energy waste incurred by inefficient routing of these services.

\section{- Access space}

All designs require access space during the original installation and for maintenance and remodeling during the life of the facility. Energy engineers should be involved in the design of access spaces as early as possible. There are many ways of servicing or providing pathways for services in laboratory buildings, but only a few basic approaches ensure an energy-efficient design. The energy engineer should keep in mind that the laboratory planning module and the structural system could be in conflict with energyefficient utility design, which would impair the efficient routing of utility services during original installation, as well as during future renovations. [Ruys, 1990]

\subsubsection{Suspended ceiling layout}

A generous vertical floor-to-floor dimension is essential in research laboratories to provide adequate space for the horizontal mechanical and electrical distribution systems. These systems can be placed above a suspended, accessible ceiling. The floor-to-floor height typically includes the functional space, as well as mechanical, electrical, and structural systems. The energy engineer should track space assumptions constantly as the structural and mechanical engineers refine their calculations. Frequently these refinements lead to floor-to-floor height contractions that will "squeeze" the efficient sizing of the HVAC systems. [Cooper, 1994] 
Early designs probably will be based on an assumed ceiling height or on the height of the light fixture above the finished floor. This height varies from $8 \mathrm{ft} .0 \mathrm{in}$. to $11 \mathrm{ft} .0 \mathrm{in}$. above the finished floor. The low ceiling height of $8 \mathrm{ft} .0 \mathrm{in}$. will depend largely on the size of the space and will reduce the volume of air when ventilation rates are based on air change rates. Heights of $11 \mathrm{ft} .0 \mathrm{in}$. and higher will depend on the size of the space as well and will affect lighting calculations in the energy use of the space. [Lindner, 1990]

\subsubsection{Utility corridor}

In another approach, the engineer can site the distribution system between laboratories instead of above them. Here, the laboratory spaces are adjacent to an accessible utility corridor which houses horizontal duct and pipe runs above head height. The ducts and pipe distribute horizontally into individual laboratories through their ceiling space. Laboratory benches are serviced through the wall from the utility corridor. The design still requires vertical shafts for ducts and pipes to rise or drop to mechanical spaces. The advantages of the utility corridor approach are smooth routing for energy efficiency and easy access for changes and maintenance. The disadvantages are the additional floor area required and a constraint on the ability of the back-to-back laboratories to communicate or expand. [Ruys, 1990; Cooper, 1994]

\subsubsection{Interstitial space}

This arrangement uses an accessible space above the ceiling plane with a floor for access and a low vertical height to accomplish a horizontal distribution of systems. The HVAC and services drop (or rise) vertically from this space into the laboratory envelope and connect to the benches and equipment. Ventilation air is typically distributed from above the laboratory space it serves. Interstitial space or a mechanical loft space have excellent advantages to provide energy-efficient layouts of the services required for laboratory-type facilities. They provide excellent access for maintenance personnel. Vertical shafts at the perimeter or in a central core connect interstitial space services with the entire building. The disadvantage compared to other approaches is the high cost, but use of interstitial space provides good long-term adaptability and a more efficient maintenance program. [Ruys, 1990; Cooper, 1994]

\subsubsection{Retrofits}

Two of the most successful methods of modernizing an older building are to use the interstitial or "exostitial" mechanical/electrical service space. The interstitial space concept may require appropriating existing usable space. A modification of this approach requires building a floor mezzanine between other floors to locate new equipment and networks.

Exostitial space is the addition of service space to the building volume at the perimeter or on top of existing space. Although the cost of providing this service space is high, there may be no other options available when retrofitting certain facilities. There is significant flexibility to this method.

Either concept permits the installation of energy-efficient "plug-in" laboratory adaptations which reduce the expense of repeated system modifications. [Cooper, 1994]

\subsection{Minienvironments}

\section{Energy Efficiency and Minienvironments}

The layout of a cleanroom has an impact on its energy consumption. The layout that requires the lowest quantity of recirculation air within the cleanroom will result in the lowest energy consumption using 
minienvironments, or locally isolated environments, can have a significant impact on the energy consumption of a laboratory-type facility containing a cleanroom. The greatest benefit of minienvironments is that they enable the laboratory to operate at much lower power consumption levels by decreasing the air volume that must be conditioned and reducing the installed air handling capacity.

\subsubsection{Overview}

Cleanrooms in laboratory-type facilities used for research require the control of particle sensitivities that approach the 0.01 micron size. In these facilities and in microelectronics production facilities, costs, expressed as a function of silicon wafers, are increasing dramatically. Researchers and manufacturers are concerned that this escalation rate will exceed the rate of device integration, a trend that threatens to reverse traditional economics and increase the cost per function of the silicon wafer. Additionally, when the production of new devices moves from the research laboratory to large cleanrooms, these production facilities cannot purge particles this small. Increased silicon wafer costs are driven by: process complexity, escalating equipment costs, facility construction costs, and operating costs, which address the increasingly stringent contamination requirements. Energy-efficient laboratory-type facilities incorporating minienvironments can help contain these costs by reducing the first costs of construction and the life-cycle energy use of the facility. [O'Reilly and Rhine, 1995]

\subsubsection{Minienvironment concept}

The mini-environment is a class 1,000 ballroom environment with locally isolated environments of class 1 or better. The idea is to reduce the volume of ultra-clean areas to a minimum by enclosing only the immediate environment of the contamination-sensitive products. During the whole production cycle, the products remain completely isolated from personnel and the surrounding environment by either a physical barrier or an air curtain. The minienvironment has three advantages:

- reduction of ultra-clean areas minimizes the investment and operational costs of the environmental conditioning systems,

- isolation of the product provides contamination control at the product level, and

- the minimum enclosure size of the minienvironment maximizes flexibility. [Gath et al., 1995]

\subsubsection{Minienvironment enclosure}

The minienvironment encloses each piece of process equipment or tool in a local Class 1 ultra-clean area; continuous positive pressure in the enclosure prevents influx from the less stringently maintained ambient atmosphere. The ultra-clean air for the minienvironment can be provided either by integrated fitter-fan units on top of the enclosure or through connections to the plenum of the cleanroom ceiling. [Mcllvaine, 1992]

In general, the minienvironment is composed of three elements:

1. An isolation enclosure for the process or measurement tool, coupled with a source of clean air for the enclosure,

2. A container to hold and transport the product, and

3. An Input/Output device to extract parts from the container and present them to the process tool. [Bonora, 1993] 
Originally, minienvironments were designed to enclose the whole process tool, resulting in a "tool in the box.". Minienvironments have become smaller and now typically only enclose the product handling area of the process tool. Smaller environments decrease air circulation volumes and improve maintenance access to the tool. [Gath, 1995]

\subsubsection{Inert gas microenvironment}

A minienvironment is very clean space in which a physically-isolated manufacturing tool operates; it may include a single tool or a cluster. In minienvironments, such as clean hoods or environmentally controlled enclosures around tools, tool adjustments or maintenance intrude into the controlled area, which can lead to a gradual degradation in cleanliness. A step beyond the minienvironment is the so-called microenvironment, which isolates the clean space with an inert gas, such as ultra-pure nitrogen, rather than air. A microenvironment encloses only the area necessary for successful processing of the product; most of the tool remains outside the microenvironment for ease of maintenance operations. [Mclivaine, 1992]

\subsubsection{Minienvironment benefits}

Minienvironments have proven to substantially reduce capital and operating costs while improving cleanliness. The direct benefits of minienvironments include the following:

- reduced air handling capacity,

- reduced power consumption,

- decreased particle contamination, and

- reduced gowning requirements. [O'Reilly and Rhine, 1995]

An indirect benefit is the superior contamination control performance of the minienvironment, which eliminates the need for new air-handling and contamination control systems with each generation of processing tools. Thus, it is now possible to develop laboratory-type facilities that bridge several generations of device technology. The success of older-generation cleanrooms validates this capability. Other cleanrooms with minienvironments have made successful transitions to submicron processing. [Bonora, 1993]

\subsubsection{Mini-environments air supply}

Early in their development, minienvironments used the same supply of clean air from the filter ceiling as the conventional cleanroom. Ultra-clean air was supplied through the ULPA filters suspended from the existing ceiling grid minienvironment. The trend toward stand-alone mini-environments, as well as the requirement of optimized flexibility in tool layout, has led to the use of dedicated fan filter units as air supply sources. [Gath et al., 1995]

Only air volumes within the clean air enclosure need to be controlled to desired class specifications, typically $20 \%$ or less of the total cleanroom air volume. The air outside the enclosures can be maintained at Class 1,000 and Class 10,000, while the air within is at Class 1 and Class 10 environments. [Briner, 1986]

\subsubsection{Barrier isolation and the mini-environment}

Minienvironment isolation enclosures can be grouped into four primary types:

- canopy enclosures constructed of clear plastic panels with localized clean air source, 
- wall enclosures with ceiling clean air source (the "clean bay" approach),

- hanging curtain enclosures with ceiling clean air source,

- air curtain containment systems. [Briner, 1986]

\subsubsection{Minienvironments hard wall enclosures}

Hard wall enclosures are not always used to create minienvironments. Modules can be furnished with HEPA-filtered air curtains utilizing direct-drive motor blowers to provide portable Class 100 areas. The units may be self-contained modules with their own motors and blowers or terminal modules on the central air supply. Self-contained units are recommended because the majority of air is recirculated, which reduces energy costs. Self-contained units are equipped with a separate motor/blower with speed control to obtain control of air velocity. Air curtain directional adjustments can be made easily; directional mass control of laminar air flow can be manipulated. [Mclivaine, 1992]

\subsubsection{Minienvironments air curtain enclosures}

The air curtain, in addition to providing a minienvironment barrier, produces an important side benefit. The lowpressure area created by the air curtain starts a slight horizontal component to the vertical air flow in the minienvironment. The effect of this horizontal component is to create a sweeping action whenever the vertical air contacts a horizontal or irregular surface within the minienvironment. This horizontal flow serves to evacuate particles. [Schneider, 1995]

\subsubsection{Automation and the minienvironment}

The more that the process equipment and materials handling systems are automated, the less need for human operators. Therefore, state-of-the-art processing equipment is designed to require little or no operator presence in the cleanroom during normal device production. The Standard Mechanical interface (SMIF) wafer-handling system is a method developed by the microelectronics industry for wafer transport between minienvironments. [Mcllvaine, 1992; Briner, 1986; Dooley, 1986]

Robot arms are the most flexible way of handling products, with an interequipment transfer system between the process machines and the storage areas. Robot arms transport products in and out of the minienvironments in sealed, ultra-clean cassette containers.

An automated environment SMIF environment incorporates the use of the following features, according to King (1986):

1. Isolation of process equipment using protective clean air enclosures,

2. SMIF pods to house and transport products,

3. SMIF robots to provide protected transfers between SMIF pods and process equipment.]

\subsubsection{Minienvironment resu/ts/case studies}

Minienvironments cost significantly less to construct than full-scale cleanroom facilities.

In 1970, the initial cost of building and equipping a high-volume, state-of-the-art production cleanroom was $\$ 30$ million. By 1990 , this cost had increased tenfold to $\$ 300$ million. The use of the minienvironment can offer savings in reduced initial construction costs for environmental conditioning systems, commensurate reduced annual operating costs, a highly flexible equipment layout, and reduced costs for personnel and operator gowning procedures. [Mcllvaine, 1992] 
The volume of clean air required to maintain acceptable contamination levels in the cleanroom is dramatically reduced. According to Cleanrooms - 1992-2000, Rooms and Components Vol. Three (1992) to maintain

... a conventional cleanroom of 40,000 square feet uniformly clean to Class 1 standards requires the recirculation, conditioning, and filtration of over four million cubic feet of clean air per minute. Operating the required air handling equipment consumes approximately ten million $\mathrm{kWh}$ per year of electricity. This can cost as much as $\$ 1$ million per year at an assumed cost of $\$ 0.10 / \mathrm{kWh}$. A [small] fraction of the ... clean air volume is required in an equivalent minienvironment cleanroom because, while the local environment around the product and the processing equipment is kept ultra-clean, the rest of the room is kept at a much lower level of cleanliness. [The Mcllvaine Co., Illinois, Correspondence, October 1995]

Different cleanroom design concepts and their energy consumption have been compared by Lynn (1991). All four of the concepts studied are currently being used in industry to obtain Class 1 Performance.

1. Clean Bay Return Chase (This concept is a common configuration in Class 10 or better cleanrooms.),

2. Clean Bay/Supply Air to Chase,

3. Ballroom, and

4. Minienvironments.

To compare these concepts on equal terms, the process equipment load and building exhaust flow were held constant; the only variation among the four concepts came from varying air-flow rates for the cleanroom recirculation systems.

Total energy consumption varied by site location, but energy consumption for the minienvironment was the lowest for both locations modeled: New England and San Jose, CA. While the percent differentials among concepts varied by location, the minienvironment concept ranked the lowest in each location.

The San Jose location yielded a variation of $29 \%$ between the annual maximum and minimum total energy consumption. [Lynn, 1991]

Fan energy consumes a greater percentage of the total energy in San Jose than in New England, resulting in a wider variation in energy use between these two geographic locations. Colder climates require more heating energy; therefore, the total energy impact of fan energy savings is reduced. Cost savings for reducing fan energy can be significant in milder climates. Minimizing total cleanroom air flow directly affects the operating costs of a facility. [Lynn, 1991]

In another case study, a 50,000 sq. ft. cleanroom was designed to produce 30,000 wafers per month. According to O'Reilly and Rhine (1995), "the design used Class 1000 open ballroom, with minienvironments to provide Class 0.1 where wafers were exposed." [O'Reilly and Rhine, 1995]

In this case study, savings were found in both construction and operating costs. The final design reduced the number of air handling units by 52 percent, reduced the number of ULPA filters required by 54 percent, and reduced the clean air volume flow-rate by 49 percent. "Savings for operating costs were calculated at $\$ 2$ per wafer," according to O'Reilly and Rhine (1995) and an additional benefit that was not foreseen "was the increase in ramp-up of the process, which gave them a 4 month advance on getting product to the market."

In another case study noted by O'Reilly and Rhine (1995), "the requirement was for a Class 100 cleanroom for development of optical devices." However, because of a limited budget, "[a] general Class 10,000 cleanroom [was 
designed instead] with minienvironments. The air handling volume was reduced by $75 \%$ with a better than Class 10 level for the equipment was maintained."

\section{REFERENCES}

American Society of Heating, Refrigeration, and Air-conditioning Engineers (ASHRAE), 1991 Applications Handbook. Atlanta, GA.: ASHRAE, 1994.

Bonora, Anthony C. Technology Topics: "Minienvironments and Their Place in the Lab of the Future." Solid State Technology September 1993.

Bossert, K.A., Ph.D., R.Ph. and S.M. McGinley. "Design Characteristics of Clinical Supply Laboratories Relating to HVAC Systems." ASHRAE Technical Data Bulletin, Vol. 10, No. 1, 1994.

Briner, Don, PE. "Section 4: Clean Room Layout Considerations." Semiconductor International, November 1986.

Caplan, K.J., and Knutson, G.W., "Laboratory fume hoods: A performance test." ASHRAE Transactions, Vol. 84, Part1. Atlanta, GA: ASHRAE, 1978a.

Caplan, K.J., and Knutson, G.W., "Laboratory fume hoods 1978b: Influence of Room Air Supply." ASHRAE Transactions, Vol. 84, Part2. Atlanta, GA: ASHRAE, 1978b.

Cooper, E. Crawley. Laboratory Design Handbook. ISBN 0-8493-8996-8. Boca Raton, FL: CRC Press, 1994.

Gath, H.C., A. Honold, and P. Csatary. "Trends in Recent Minienvironment Installations." Proceedings Institute of Environmental Sciences, 1995.

American Society of Heating, Refrigeration, and Air-conditioning Engineers, The (ASHRAE), 1991 Applications Handbook. Atlanta, GA.: ASHRAE, 1994.

Industrial Ventilation: A Manual of Recommended Practice - 22nd Edition. ISBN: 1-882417-09-7 (ACGIH). The American Conference of Governmental Industrial Hygienists, Inc., eds. City, State: Publisher, 1995.

King, Bruce W., CIH. "American National Standard for Laboratory Ventilation." ANS/AIHA Z9.5 1992.

King, J. Gordon. "Designing for SMIF." Semiconductor International, November 1986.

Laboratory Control and Safety Solutions Application Guide-Rev. 2. Buffalo Grove, IL: Landis and Gyr Powers, Inc., 1994.

Lindner, U.M. "Modular Design," Handbook of Facilities Planning. Ruys, Theodorus, AIA, ed. New York: Van Nostrand Reinhold, 1990.

Lynn, Charles A. P. "Impact of Cleanroom Concepts on Energy Consumption." Cleanroom Technology Forum Proceedings, 1991.

McIlvaine, Robert W. Cleanrooms 1992-2000, Rooms and Components Vol. Three. Mcllvaine, Robert W., Sally Halderman, Alpa Bagga, and Joseph Schwartz, eds. Northbrook, IL.: The McIlvaine Co., 1992. Chapter 1, Rooms; Chapter 4, Engineering \& Design. 
O'Reilly, Hugh and Bruce Rhine. "The Role of Minienvironments in Redefining Microelectronic Manufacturing Economics." Proceedings - Institute of Environmental Sciences, 1995.

Roberts, P., Girard, P.V., Remiarz, and Troy M. Tillman. "Measuring Safety in the Laboratory." TSI Incorporated, 1992.

Ruys, T., AIA. Handbook of Facilities Planning, Vol. One, Laboratory Facilities. ISBN 0-442-31852-9. Ruys, Theodorus, AIA, ed. New York: Van Nostrand Reinhold, 1990.

Schneider, Mlene. "Special Report: Barrier Isolation Technologies." Cleanrooms, May, 1995.

UCB Department of Physics Facilities Planning Study Technical Appendix. Mc Lellan and Copenhagen, Inc., eds. Cupertino, CA: McLellan and Copenhagen, Inc., 1993.

Watson, N. "Research Types," Handbook of Facilities Planning. Ruys, Theodorus, AIA, ed. New York: Van Nostrand Reinhold, 1990.

Wodka, M. "Characteristics of Laboratories," Handbook of Facilities Planning. Ruys, Theodorus, AIA, ed. New York: Van Nostrand Reinhold, 1990. 


\title{
3. RIGHT SIZING: CHOOSING AN ENERGY-EFFICIENT DESIGN
}

\author{
Abstract: Energy Efficiency and Environmental Design
}

Research laboratories exist to provide the precise environmental conditions required for research. These conditions require sophisticated, expensive, energy-intensive HVAC systems. Laboratories typically consume 300,000 to 400,000 BTUs per square foot per year or more, six to 10 times the number of BTUs consumed in a typical office building. However, energy consumption and operating costs can be reduced through "right sizing," choosing the most efficient and cost effective combinations of equipment and equipment sizes as well as managing the laboratory load, all to achieve energy efficiency. Right sizing is an iterative process; although new techniques are developed continuously, the basic elements are:

- Life-Cycle Cost Analysis,

- Conditioning System Capacity Analysis,

- Diversity Analysis, and

- Load Management Analysis. [Cooper, 1994]

- Life-cycle cost analysis

Energy intensive environmental conditioning systems have high operational and first costs. Therefore, it is very important for the energy engineer to consider the optimum mix of operational and first costs to determine the system's life-cycle cost. Life-cycle cost (LCC) analysis accounts for all costs incurred for the HVAC system from installation through a chosen period of time, usually 20 years. Life-cycle cost analysis is a "yard stick" to measure the relative benefits of the choices available to the design team. When an energy-efficiency measure (EEM) happens to have the lowest first cost, an LCC analysis is not necessary.

\section{- Conditioning system capacity analysis}

Estimating the conditioning capacity necessary for a laboratory includes a myriad of choices to determine the laboratory's HVAC system type and size. To make these choices intelligently, the engineer must understand the variability of the laboratory facility's load profile. Air-flow rate through the facility is a subject of considerable debate that is primarily driven by the air change rate per hour $(\mathrm{ACH})$ and the design fume hood face velocity.

\section{- Diversity analysis}

Diversity analysis in a laboratory ventilation system accounts for the fact that not all laboratory spaces or fume hoods are operated at 100 percent, 24 hours per day. The larger the facility, the smaller the probability of simultaneous use of all available capacity. Studies and practical experience have shown that, for large laboratories with many fume hoods, at least 20 to 30 percent are closed or only partially used at any one time. Therefore, HVAC systems can be sized for 70 to 80 percent of peak ventilation capacity. Sizing the HVAC system at 70 percent of peak load decreases operational and first costs, gives better system control, increases system stability, and reduces mechanical space requirements. Taking advantage of diversity is particularly valuable when retrofitting existing facilities where available space is limited. Therefore, it is very important to consider diversity when sizing a large laboratory HVAC system. Small, single-room laboratories should always be sized for full 100 percent capacity without downsizing. [Lentz and Smith, 1989; Cooper, 1994] 
A comprehensive analysis of the laboratory loads should include an interview between the researchers and the energy engineer. Such interviews often produce unexpected results and increased energy efficiency; identification of equipment and occupancy schedules helps clarify system capacity needs, and, in some cases, reveals that demand-controlled ventilation is a viable option.

Finally, control is the single most important design variable in an HVAC system that meets a laboratory's exacting environmental requirements. The control scheme must address temperatures as well as safe ventilation and stable control of building pressures, duct static pressures, and air migration patterns. An in-depth examination of control systems is presented in Chapter 4. [Lentz, and Smith, 1989]

\subsection{Life-Cycle Cost Analysis}

\section{Energy Efficiency and Life-Cycle Cost Analysis}

Life-cycle cost (LCC) analysis is the most rational, objective method for selecting the optimum HVAC system for a laboratory facility. Through LCC analysis, all factors that influence total system cost can be identified and quantified. Subjective factors such as fuel cost adjustments, component reliability, and maintenance costs are also included. LCC analysis can be used to assess the economic consequences of any decision by comparing two or more alternatives. [Lacey, 1993; Matson, 1990]

\section{- Annual cost comparison}

Review of the annual cost of space conditioning for a laboratory or cleanroom shows the high impact of energy costs. A Class 10,000 cleanroom system costs five to 10 times as much to operate annually as the conditioning system for the facility's office spaces; a Class 100 laboratory cleanroom system will cost 50 times as much. In either case, however, the contributions to total cost are:

- energy costs, contributing 65-75 percent;

- capital costs, i.e. interest plus depreciation, contributeing 15-25 percent; and

- maintenance costs, contributing 10 percent. [Schicht, 1991]

A life-cycle cost analysis does not need to be extremely complex to yield reasonably accurate figures for first and operational costs. A modified LCC, similar to a simple payback, does not account for inflation or cost of money; this modified LCC can give an order-of-magnitude appraisal to help determine whether or not to add an EEM to a system. [Kruse, 1991; Lacey, 1993]

If LCC computations are easily understood, the analysis is more likely to be used by design teams and accepted by researchers/owners. One approach to simplifying life-cycle cost analysis is to convert facility operating costs to an equivalent annual expense per fume hood. This number can serve as a common denominator for comparing the composite performances of various system designs and for examining the sensitivity of each design alteration. The energy engineer should concentrate on determining realistic values for the most sensitive design factors before selecting the HVAC system type. [Lacey, 1993]

\section{- LCC factors}

LCC factors that influence a laboratory's HVAC system design can be broken into three categories: design factors, economic factors, and performance factors. Sometimes other factors must be considered; for example, a functional-use factor may be developed based on efficiency studies of personnel in the operations of different laboratory systems or components. Because laboratory personnel LCCs are very high, the more functional a design or system is, the more LCC savings are possible. An example is the 
workspace flexibility and reduced costs of space planning that can be afforded by a raised floor system. (see Chapter 2) [Matson, 1990; Lacey, 1993; "Minimizing Life-Cycle Costs-and First Costs-of New Building Systems," 1994]

\subsubsection{LCC design factors}

LCC design factors include: design temperature and humidity; room air-flow rate (air change rate); hood size and number; face velocity; and climate. Other design parameters include laboratory and office support spaces, and the number of fixed-rate exhaust systems per laboratory. All design factors are subject to review, including climate data, e.g., which meteorological year to choose, and design temperature and humidity, e.g., which indoor and outdoor design temperature levels are appropriate. [Lacey, 1993]

\subsubsection{LCC techniques}

According to Matson (1990), life-cycle cost analysis (LCC):

... offers project owners and architects techniques to make investment tradeoff decisions. To better comprehend LCC techniques, the following concepts must be understood.

Life: The life expectancy of a building. Does the building need to last 10,40 or 60 years? This must be considered when establishing project objectives and goals, as it will affect the cost and design of the facility. Factors affecting the determination of a facility's life for calculation purposes are many. They relate to projected ownership, expected use, applicability of depreciation, financing sources and the purpose of the project.

Cycle: The building's yearly or monthly cycle in terms of operation and maintenance, and its expected cycle for remodeling and replacement.

Costs: All present and future costs associated with the project projected over the life of the facility. These costs are factored using projected inflation, interest rates and depreciation, and other factors affecting the cost of money in the future.

It combines the initial project development costs (construction, project and capital costs) with the projected continuing occupancy or use costs (operating and maintenance renewal and long-term financing costs, i.e., interest payments). These combined costs are projected over the life of the building. They are analyzed in terms of both present worth and future worth so that a realistic comparison can be achieved. LCCs can be analyzed for various alternatives for comparative purposes. With this information, the most advantageous return or investment can be determined for a given project or project component.

\section{Operating Costs}

Operating or use costs are customarily estimated on an annual basis. Operating costs are the owner's total building costs for supplies, utilities and building services, excluding any tenant's share of the costs. These costs project the annual costs for supplies that the building needs to operate, such as cleaning supplies, toilet supplies and small tools. Operating costs also project the annual costs for utilities such as electricity, gas, oil, water, telephone bills, garbage collection fees and sewer fees. Finally, operating costs include fees for services such as security, maintenance, and janitorial and cleaning services. For example, security service may cost $\$ 250,000$ per year. This cost is then projected to the total security service costs based on the life 
expectancy of the building. When all the annual operating costs are projected throughout the life of the building, this total will be the total operating costs of the life cycle of the building.

\section{Cyclical Maintenance Costs}

Maintenance Costs, including renewal costs, are costs associated with repainting, remodeling, repairing and replacing. These costs are projected on a cycle. For example, fixed lab casework may have to be replaced every 5 years. These costs for replacing the lab casework every 5 years are projected to a total replacement cost based on the life expectancy of the building. When all the cyclical maintenance costs are projected throughout the life of the building, this total will be the total maintenance costs of the building.

\section{Annual Interest Costs}

The building's annual interest costs and financing fees are projected throughout the life of the debt. These may be increased as a part of initial construction or renewal costs. These costs then become the total interest costs.

\section{Total LCCs}

Total LCCS are the total operating costs plus the total maintenance costs plus the total interest costs plus all of the project's initial costs... Replacement or disposal costs may also be included, depending on the ownership and goals of the project.

Lacey (1993) adds the following note regarding a laboratory's energy costs:

The energy costs of a laboratory facility can be calculated by examining the energy requirement of outside air flow through the building. In buildings ventilated at eight air changes per hour (ach) and higher, the energy transfer through the building skin is insignificant. It is also present, regardless of whether the mechanical system is constant or variable volume, and can be neglected for comparative studies.

\subsubsection{LCC and adequate space}

Steere (1990) points out the relationship between space for the laboratory's ventilation system and life-cycle costs:

Since adequate space for ventilation ductwork and equipment is absolutely crucial for its maintenance, modification and economical operation, the laboratory planner needs to be sure that the budget is adequate and that no last-minute cost cutting is allowed to reduce the size or height of areas needed for the ventilation system. Such changes will increase the life-cycle cost of the building by permanently increasing the difficulty and hazards of servicing the equipment and by decreasing the performance and cost effectiveness of the system.

\subsubsection{LCC economic factors}

Economic factors are generally more accurately known than the other LCC factors. Economic factors include: present fuel costs for heating and cooling; fuel cost adjustments over the life of the facility; and incremental cost for EEMs, service life, and interest rates. The installed cost of EEMs should be estimated using costs from recent projects in the same region as the facility being designed and a contingency factor should be included to account for future expansion and cost overrun possibilities. Preliminary discussions with construction contractors and vendors should be completed and included in LCC data. [Lacey, 1993] 
Complete, installed VAV systems for laboratories with chemical fume hoods can be as much as $\$ 5,000$ per hood. When a simple Class 10,000 laboratory cleanroom system is used as a reference point, a sophisticated Class 10,000 cleanroom may cost five times as much, a unidirectional air-flow system for Class 100 may cost 20 to 30 times as much, and a unidirectional air-flow system for Class 1 may cost 30 to 50 times as much. [Saunders, 1993; Schicht, 1991]

\subsubsection{LCC performance factors}

Laboratory performance factors are the most difficult to quantify. This important group includes: HVAC system diversity; laboratory heat gain from process loads; fume hood user energy-efficiency practices; maintenance costs; system failure rate; and heat recovery and free-cooling effectiveness. [Lacey, 1993]

To calculate the LCC economics of a VAV system, a diversity value is necessary. Diversity values can range from 0.02 to 0.60 . HVAC system diversity is reviewed extensively later in this chapter. [Lacey, 1993]

Process heat gain from laboratory equipment is in many facilities the major source of heat gain but is difficult to define. Little information has been published that provides guidance on this subject to energy engineers. [Lacey, 1993]

Good energy and safety practice mandates that fume hood sashes be lowered when hoods are in use and be closed when hoods are not in use. An off-hour setback that allows the ventilation system to go into a reduced volume mode when labs are not occupied is also a part of a complete energy use program. [Saunders, 1993]

\subsubsection{LCC and VAV vs. CV}

A simple life-cycle cost model can be analyzed with a computer spreadsheet. The model can account for the marginal construction cost differences for Variable Air Volume (VAV) systems and other EEMs in comparison to a base Constant Volume (CV) system. Typically, an HVAC system is assumed to condition 100 percent outside air to a supply temperature between $55^{\circ} \mathrm{F}\left(13^{\circ} \mathrm{C}\right)$ and $65^{\circ} \mathrm{F}\left(18.3^{\circ} \mathrm{C}\right)$, depending upon climate.

According to Lacey (1993), each laboratory system needs to be evaluated individually. However, it is instructive to review some typical differences between VAV and CV systems, which Lacey describes as follows:

VAV systems are most economical when operated at low diversity factors. At a diversity factor of $75 \%$, the fixed-cost of a VAV system usually surpasses the cost of a CV system with or without heat recovery.

The VAV system operational cost is generally insensitive to heating degree-days. The annual energy cost of a CV system increases rapidly as the climate becomes more severe. In mild climates, the $C V$ system can offer lower life-cycle cost than a CV system with heat recovery.

The life-cycle cost of a CV system is more sensitive to heating fuel cost; only peak heat gain and hood airflow volume are more important factors. CV systems that employ heat recovery are less sensitive to heating fuel costs than $\mathrm{CV}$ systems without heat recovery. VAV systems are less sensitive to both heating and cooling costs than CV systems. 
Generally, a CV system has the best life-cycle cost during five years. The VAV equipment usually produces the lowest life-cycle cost during fifteen years and less especially in new installations.

The first-cost of control systems has a relatively minor impact on the life-cycle cost of a VAV system.

Life-cycle operating costs of CV and VAV systems are not highly sensitive to the average heat gain that is part of operating laboratories. [Lacey, 1993]

\subsubsection{Life-cycle cost model study-VAV vs. CV}

Lacey (1993) has written about the selection of mechanical systems for laboratories. He describes the process in general and refers to a base case in particular which provides an exacting review of the design considerations, economic factors, and performance evaluations of VAV vs. CV systems.

\section{Design factors}

Design heat gain. Design heat gain in a laboratory is the total cooling load resulting from equipment, lighting, people, insulation and conduction. The design engineer must calculate this load using information supplied by the owner and experience with previous lab buildings.

The 1989 ASHRAE Handbook of Fundamentals states that heat gain from equipment commonly ranges from 15 to $70 \mathrm{Btu} / \mathrm{h}$. $\mathrm{t}^{2}$ (50 to $250 \mathrm{~W} / \mathrm{m}^{2}$ ). It also points out that this can be as much as four times the heat gain from all other sources. Chapter 14 of the ASHRAE Handbook HVAC Applications includes a table of recommended heat gain figures for various pieces of equipment. This is a valuable guide in designing a specific laboratory room but often the future equipment of a new facility is unknown. The laboratories of a new high technology building may hold devices (such as DNA synthesizers) that were not commercially available when design of the facility began.

Three factors lead designers to overestimate the peak heat gain.

- First, future laboratory users are likely to be optimistic about the amount of equipment they will obtain.

- Second, researchers and lab equipment vendors are accustomed to defining equipment power draw in full load or nameplate amperage. Conversion of these power flows to thermal gain without adjusting for power factor duty cycle or water cooling will lead to an excessive heat gain.

- The third force pushing design heat gains higher is conservatism. Future occupants and the design consultant want to be certain future cooling loads are met and large safety factors are common.

The economic response of VAV [steady] and constant volume [rising] systems to design heat gain is very different.

In the variable flow system design heat gain is used to size the VAV supply boxes to each room and, with diversity, the supply duct work and air handlers. In operation, room flow will modulate to meet the greater of hood flow or required cooling flow. The operating costs are insensitive to design heat gain. 
The impact on constant volume systems is very different and extremely dramatic. At low design heat gains (less than $10 \mathrm{~W} / \mathrm{ft}^{2}\left(108 \mathrm{~W} / \mathrm{m}^{2}\right)$ for the base case, design room flow will be determined by the exhaust need of the fume hood. In [this situation], installation cost and operating cost are insensitive to design heat gain. More commonly, design heat gain will exceed $10 \mathrm{~W} / \mathrm{ft}^{2}$ (108 $W / m^{2}$ ), and the flow requirement for peak heat gain will be greater than hood flow. In this condition, operating cost is directly related to design heat gain.

\section{Maximum hood flow}

The maximum hood flow is the product of hood width, maximum sash opening, design face velocity and the number of hoods per laboratory. As one would expect, the maximum hood flow is a very strong factor for both constant volume and VAV system cost. Hood face area is the mathematical product of hood width, sash height and the number of hoods per laboratory. If hoods are very small or few in number, heat gain in the laboratories will determine the required air flow and cost is insensitive to hood size. In the base case [example], face velocity is $100 \mathrm{fpm}(0.5 \mathrm{~m} / \mathrm{s})$ and the cost break occurs at a hood width of $3 \mathrm{ft}(1 \mathrm{~m})$ for VAV systems and $6 \mathrm{ft}(2 \mathrm{~m})$ for constant volume systems. When hoods are larger than these threshold widths, operating cost is essentially proportional to maximum hood flow.

\section{Climate}

Sites throughout North America experience a very wide range of climate. The amount of energy required to condition outside air to a supply temperature also varies. In [the example] analysis, climate is quantified as the number of heating and cooling degree days based on $55^{\circ} F\left(\begin{array}{lll}13 & C\end{array}\right)$. This value can be derived from a bin analysis, or the computations presented by Erbs [1983] can be used to shift degree days values based on other temperatures. In climates where the $55^{\circ} \mathrm{F}\left(13^{\mathrm{c}}\right.$ C) base heating degree days exceed 3,000, the energy saved by the heat recovery system is enough to result in a system life cycle cost that is lower than a constant volume system without heat recovery.

\section{Economic factors}

\section{Heating cost}

The cost of heating fuel varies greatly between laboratory facilities. Large complexes with district heating and cooling systems may elect to examine alternatives using only the marginal fuel cost, which can be $\$ 3$ per million Btu or less. In contrast, owners without central utility systems might pay up to five times this amount for purchased energy.

\section{Cooling cost}

The impact of cooling energy cost is much less severe than heating energy for the base case [example]. This is because all systems included a supply temperature of $55^{\circ} \mathrm{F}\left(13^{\circ} \mathrm{C}\right)$, with reheat coils at each room. Less energy was required for cooling ambient air to this temperature, on an annual basis, than to preheat.

\section{VAV control cost}

This [example] model includes hood face velocity controls with the VAV system that are capable of varying hood flow in response to sash position. There are several manufacturers of equipment that will control the variable volume air flow through a laboratory, and this is an increasingly competitive field. Controls should be selected that have proven dependability. Unit cost should be considered secondary. This [example] case included an allowance of $\$ 4,000$ per hood for VAV controls and boxes. However, this cost could increase to nearly $\$ 10,000$ before the life-cycle cost 
of VAV was challenged by a constant volume system. (Costs for these systems change constantly. The designer is advised to obtain most current costs.)

\section{Heat recovery cost}

The installation of a heat recovery system also requires additional equipment cost. As with VAV components, the cost of heat recovery requirement does not strongly affect life-cycle cost. However, because the life-cycle costs of constant volume systems with and without heat recovery are very close, the cost of heat recovery equipment can be enough to determine which is not desirable.

\section{Interest rate}

Systems that reduce energy consumption usually require increased capital investment in anticipation of future savings. This is the case for laboratory buildings that include VAV or heat recovery systems. Such investments are sensitive to interest rates, although the impact is less than most other factors.

\section{Service Life}

Between universities and development industries, there is a very different perspective of a facility's functionality. This model [example] includes only the incremental first cost of VAV and heat recovery systems above a constant volume building. The building structure and basic mechanical system are common to all [buildings] and are not included in the life-cycle cost analysis. The service life is defined not as the life of the structure, but as the operating period between major renovations of the facility. As with the interest rate, constant volume systems are not affected. The life-cycle costs of VAV and heat recovery systems show moderate, inverse relationship to increased senvice life.

\section{Performance factors}

\section{Hood diversity}

Hood diversity is defined as the average sash opening for all hoods in a facility as a percentage of the full open height. Hood diversity has also been defined by some as the percentage of hoods in use. However, that definition may not properly quantify air flow through a VAV building. Generally, VAV hoods are always on at some flow and the amount of exhaust is determined by sash height. Modern VAV hood controls modulate air flow to track sash height independent of activity in the hood. This is the most important design [aspect] for variable volume systems because a system that controls face velocity will reduce the volumetric flow as sash height is lowered.

Air flow through the room (and the cost to condition outside air) reduces proportionally until the room flow meets the requirement for space cooling. The effect of this parameter in a VAV system in extreme. If all sashes are full open, the building flow is equal to that of a constant volume facility, with no savings realized from VAV equipment that controls variable flow. With all sashes closed, the building behaves like a VAV system in a dry laboratory or office building, and flow then responds to heat gain in the space.

[In one example] [The break-even point for VAV occurred in the base model at a diversity of $70 \%$. At higher hood use factors, constant volume offers the lowest life-cycle cost. In an operating facility, it is certain that the average sash height will not be $0 \%$ or $100 \%$. However, very little has been published to assist designers with an informed estimate. In any particular project, the designer must estimate how cooperative the user group will be in keeping sashes as low as 
possible. This will depend on the group's familiarity with variable volume systems and the ability of the facility operator to solicit their support. It is expected that the users' behavior will not be consistent between private facilities and academic institutions because private facilities can maintain tighter control of hood use.

In a striking contrast, the economics of constant volume systems are insensitive to hood diversity. In these laboratories, room flow will be constant, with exhaust air moving through the hood face, through a bypass grille or through a room exhaust grille. In reality, the flow of a constant flow or bypass hood is not constant and varies somewhat with sash position. This variation has not been considered in this model.

\section{Average heat gain}

Average heat gain is the cooling load, on average, that is realized in the operating laboratories. Surprisingly, the life-cycle operating costs of constant and variable volume systems are not highly sensitive to this factor.

Generally, the air flow required for fumehood exhaust exceeds that necessary for cooling. In the unusual cases where low hood diversity (less than 25 percent) or high average heat gain (above 8 $\mathrm{W} / \mathrm{tt}^{2} ; 90 \mathrm{~W} / \mathrm{m}^{2}$ ) occur, VAV systems are sensitive to average heat gain.

The operating cost of constant volume systems [with reheat] is actually inversely related to average heat gain, because higher space gain results in less reheat energy. The reduction in system energy for reheat is offset by increased electrical consumption by equipment in the laboratory, which has not been included in this [example].

\section{Maintenance}

Increased maintenance cost due to active components of a VAV or heat recovery system must be included in the life-cycle analysis. While this cost must be fully anticipated by facility operators, it has only a small impact on the life-cycle cost of either system.

\section{VAV failure rate}

Most VAV systems are designed to provide full flow if a component of the control system fails. In a very large facility, it is expected that some percentage of the hoods will be in a failed mode at any time. One study found that nearly $20 \%$ of the observed sample had failed and were operating as constant volume hoods. The impact of this characteristic can be included in the life-cycle cost analyses of VAV systems. However, it is found to have a very minimal effect.

\section{Heat recovery effectiveness}

The effectiveness of a heat recovery system is defined as the ratio of the recovered energy to the total energy difference between the exhaust and supply air streams. For this [example], the energy penalty for auxiliary requirements such as increased pump and fan energy are incorporated in the overall effectiveness factor.

\section{Cost sensitivities}

One interesting way to examine the impact of various factors on system cost is to graph the lifecycle cost while varying one parameter at a time. [T] he sensitivity of cost in a VAV system [is related] to five parameters. 
[D]iversity is the [most sensitive] factor. Also, at some low value, diversity has no impact because the flow requirement for cooling has taken control. This break occurs at about 0.5 times the base [example] value, or a diversity of $25 \%$. Such breakpoints in a sensitivity curve are important in establishing when various laboratory factors will drive the cost function.

The sensitivities of a constant volume system are somewhat different than for VAV systems. Annualized cost is insensitive to peak heat gain at low values where hood exhaust need will determine flow rate. Above a breakpoint of about 0.9 to $1.0 \mathrm{~W} / \mathrm{t}^{2}\left(108 \mathrm{~W} / \mathrm{m}^{2}\right)$, design heat gain becomes the most dominant action. Constant volume systems are not affected by hood diversity and are more sensitive to fuel cost than climate. This is because reheat will be necessary in any climate in addition to preheat energy.

Many other laboratory design and operating factors have much less impact. It is interesting to note that on any particular project, the design team can do nothing to change climate and energy cost, and little is documented regarding hood use and peak heat gain.

\subsection{System Sizing}

\section{Energy Efficiency and System Sizing}

In this section, the major energy consuming components of air and water systems are reviewed (See Ch. 9 for Lighting Systems). Supply fan energy for air handlers can account for one-third or more of a laboratory's operating energy. Boilers, chillers, pumps, and cooling towers can account for up to one-half of the cost, and exhaust fans and accessories can account for the remainder. However, from another perspective, the single greatest influence on a laboratory facility's energy consumption is the size, type, and number of fume hoods and exhaust connections. These components also affect the design of air distribution, mechanical shafts, and ceiling space conditions, which in turn determine the height and overall configuration of the facility. [Kruse, 1991; Lyons et al., 1990]

One of an energy engineer's most important decisions is the choice of a mechanical system for the laboratory. Discussions regarding the relative merits of VAV and heat recovery systems should always be part of the conceptual design and value engineering process that occurs between designers and researchers/owners. Designers may prefer VAV because it is state-of-the-art, self-balancing, and reduces energy costs. Conservative researchers/owners might be nervous about VAV because they fear increased construction costs, higher maintenance costs, and questionable dependability. [Lacey, 1993]

The energy engineer cannot rely completely on regulatory or consensus standards for energy design guidance. These standards often cannot keep pace with laboratories' scientific and technological innovations and the safety and health problems that may accompany these innovations. Two design issues that directly relate to regulatory standards or consensus standard are the room air change rate and the fume hood face velocity. The most current figures for these airflows are subjects of intense debate and scrutiny. [Steere, 1990]

In analyses of research laboratory cleanroom HVAC systems, two energy-use factors dominate: the size of overall pressure drops in the system and the amount of air that is exhausted and must be replaced. When these factors are optimized, the energy effect ripples through the facility's system design. In these cleanrooms, the exhaust may only be about six to 10 percent of the air recirculated. However, for sophisticated research, recirculated air flow of 700 or more air changes per hour may be required, representing 42-70 cfm of wasted air per square foot of area per hour. At an energy and maintenance cost of $\$ 6-\$ 10$ per cubic foot of air per year, this is an expense of $\$ 250-\$ 700$ per square foot of research laboratory cleanroom area per year. [Patel et al., "Designing...", 1991; Patel et al., "Constructing...", 1991; Patel et al., "High Performance...", 1991] 


\subsubsection{Optimum mechanical system}

The selection of the laboratory mechanical system depends primarily on the variability of laboratory's load. Three major variable load factors are: fume hood use, process heat gain, and climate. These factors determine how much air must be moved through the laboratory; in combination with the cost of energy, they also determine the cost of conditioning this air flow. Optimizing these load factors will result in the optimum mechanical system for the facility when the cost of energy is also taken into account. [Lacey, 1993]

VAV systems offer an alternative that is often more energy efficient than the conventional CV systems. VAV systems are more efficient when large amounts of variable heat gain are anticipated, the climate has large diurnal temperature swings, and utility costs include peak demand and time-of-day use charges. CV systems are preferred when fume hood diversity is high, financing is at high interest rates, and a short service life is anticipated. However, VAV systems alone are not necessarily the best laboratory HVAC design. Many energy-efficient components and auxiliary systems can enhance the performance of VAV systems. For instance, the choice of the control system that will operate the VAV system is critically important for optimum function. A heat recovery system can also help provide the lowest life-cycle cost in certain system configurations. Four factors that will improve heat recovery systems are:

- More than 3,000 heating degree-days at the base temperature,

- Hood diversity factor greater than 75 percent,

- Service life greater than 15 years, and

- Interest rates less than 5 percent. [Lacey, 1993]

However, even in the most advanced research laboratory projects, a CV system can have the least lifecycle cost and therefore be the best choice. The new Human Genome Research facility being constructed at LBNL will have a CV system with some elements of a VAV system, including VFD on supply fans, to account for filter loading, zone heating and cooling coils for laboratories only, and laboratory room pressure monitors for safety. The factors that contributed to the choice of the $\mathrm{CV}$ system included a mild climate, 24-hour-per-day use, low fume hood density ( 16 hoods in a 40,000 sq. ft. area), many robotic and automatic research devices, and shifting of operation to flatten peak electrical demand (a decision made after a comprehensive load management study was conducted with the researchers by the energy engineer).

\subsubsection{Decision-making analysis methodology}

Doyle et al. (1993) describe the decision-making process that led to the choice of a VAV system for retrofit project in an "industrial research facility located in the midwestern United States":

According to the client's direction, each alternative was analyzed based on the Kepner-Tregoe decision-making analysis methodology, which attempts to take into account the wishes and desires of each member of the entire project team, quantify qualitative wants and desires, and reach a decision that best satisfies the whole of the project team rather than one specific department or individual.

\section{Decision-Making methodology}

The evaluation of key design modifications was undertaken at the study stage in three phases. The first dealt with the desired fume hood sash position at which to re-balance air systems. The system control strategy was the target of the second phase. The third focused on various other independent options. 
The decision-making methodology employed forced the decision makers to separate "musts" from "wants." "Must" objectives required that the option (1) improve the safety of the employee lover existing conditions); (2) comply with building codes, govemmental regulations, and industryaccepted and corporate engineering standards; and (3) be applicable to other buildings on the campus. Since most of the research laboratory buildings on the campus were originally designed by the same architectural and engineering firms, at about the same time, the HVAC systems are similar throughout the campus, making the third "must" objective a valid desire. If an option fails to satisfy any one "must" objective, the option is not considered. "Want" objectives considered the degree of safety improvement, reliability, ease of researcher use, maintenance operations, environmental (temperature, humidity, etc.) control, energy costs, construction disruption, expandability, flexibility to changing laboratory requirements, construction time, remote monitoring capabilities, use of proven products and technology, capitalization requirements, central heating and cooling plant impact, architectural impact, and reuse of existing systems.

Each team member provided an opinion of the weighting factor for each "want" objective. Skewing of weights was evident for some of them, depending upon individual bias and work function. As a consequence, averaging of weights was used. Next, selected team members scored each option. This was performed without knowledge of the resulting weights to prevent biasing scores based on weights. Again, there were differences between members and averages were used. The total score for each option was the sum of each "want" objective's weight times the option's score for that objective. The "ideal" project would score 1,120 points. It is important to note that financial issues (construction cost, annual operating and energy costs) account for less than $20 \%$ of the total possible points! This project represented a dramatically different approach from more traditional system selection methodologies (lowest first cost, shortest payback period, highest return on investment, etc.).

The weighted average diversity of fume hood sash position was $36.5 \%$ during weekdays and $17.6 \%$ during weeknights and weekends. In addition, we found that some hoods were partially open when no one was actively working on them, so there existed even more potential for higher diversity of fume hood use. Assuming that the unused open hoods were closed to $10 \%$ of the maximum open area yielded a potential average fume hood diversity of $16.6 \%$ during the weekdays and $11.6 \%$ on the weeknights and weekends.

Flexibility and future expansion capabilities [of a constant volume system] are poor. This option scored in the middle ... with the highest energy costs of $\$ 770,000$ but the lowest capital cost at $\$ 1,700,000$.

However, a two-position control option was defined and analyzed. This option, which is a compromise between full variable air volume and constant volume, requires a switch or sensor to close exhaust and supply dampers to minimum (non-zero) positions when the sash is less than $25 \%$ to $30 \%$ open. If the sash is open above this trigger level, full air would be supplied and exhausted.

The projected annual energy savings are $\$ 50,000$ when compared to the constant-volume option. The two-position option required installation of fume hood exhaust dampers and supply and auxiliary air dampers. Its construction cost of $\$ 4,600,000$ is $\$ 2.9$ million more than the constantvolume option and is almost as high as the full variable-volume option.

The main advantage of all variable air volume lies in its capability to match aiflow delivery with the needs of each individual laboratory and fume hood. The constant tracking of fume hood use and diversity that is inherent with the variable-volume controls results in a $\$ 370,000$ reduction in annual energy costs when compared with the constant-volume option. This savings is more than seven times the savings of the two-position option. in addition, the fume hood diversity allows some future expansion capabilities to be easily designed into the system and, as previously discussed, 
flexibility to changes is inherent to VAV... [This option requires the installation of dampers in all supply and exhaust ducts serving the laboratories, fume hood modifications, and variablefrequency drives at the fans. Also, additional controls are required, bringing the projected costs to $\$ 5$ million, which is $\$ 3.3$ million over the constant-volume option. The $\$ 370,000$ energy savings result in a projected nine-year payback of the first cost of the full VAV conversion on energy savings.

\subsubsection{Equipment temperature ranges}

Matson (1990) discusses laboratory equipment temperature ranges.

More and more laboratory equipment is affected by fluctuations in room temperature. At the same time, there is a greater concern to conserve energy. In order to keep temperatures within an acceptable range, it is important to know what those ranges are. Table [3.2.1] was provided by product manufacturers as a guide. Many instruments are internally cooled by chilled water that is recirculated or disposed to the drain to prevent overheating. These are not affected by room temperature fluctuations.

Table [3.2.1] Acceptable Temperature Range for Laboratory Equipment

\begin{tabular}{lcl}
\hline Equipment & Range $(\mathrm{F})$ & Remarks \\
\hline Most instruments & $59-100$ & Below $85 \%$ RH \\
Electron microscope & $68-74$ & $\begin{array}{l}45 \% \text { RH } \pm 10 \% \text {; Rate change not to exceed } 5.4^{\circ} \mathrm{F} \text { per } \\
\text { hour; no drafts }\end{array}$ \\
Scintillation counter & $54-86$ & Below $85 \%$ RH \\
Research microscope & $70-76$ & $50 \%$ RH optimum; no drafts \\
Microtome & - & Depends on use \\
Spectrophotometer & $64-86$ & $\begin{array}{l}\text { Rate change not to exceed } 1.8^{\circ} \mathrm{F} \text { per hour; } 50 \% \text { RH or } \\
\text { less }\end{array}$ \\
Gas chromatography/mass & $20-90 \%$ RH \\
spectrometer (GC/MS) & $50-85$ & 20
\end{tabular}

(Matson, 1990)

\subsubsection{Room air change rates}

Effective air circulation is essential for safe laboratory operation. The rate of air circulation has recently been a subject of discussion not only with reference to potential energy efficiency but safety and efficacy as well.

\section{- Recommended standards}

The conventional, "national consensus standard" has been four to six outside air changes per hour recommended for a "safe" B-2 occupancy laboratory; in laboratories that routinely use more hazardous material, such as known carcinogens, 10 to 12 outside air changes per hour have been recommended. Some publications simply recommend four to 12 air changes per hour; such generalized recommendations represent engineering by "rule-of-thumb" at its worst. 
Studies of laboratory facilities have demonstrated that the room air change rate had less effect on environmental conditions in the laboratories surveyed than did the room air diffusing system and other ventilation characteristics. More scientific data are needed to form a basis for laboratory air circulation guidelines because many conventional design parameters and recommendations are not directly related to microenvironmental (e.g., cage) conditions in the laboratory. For example, it has been demonstrated that air dilution or replacement does not protect personnel from exposure to concentrated bursts of aerosols in biological laboratories. In fact, Crane (1994) quotes Chatigny and West (1976), who say that, "increasing ventilation rates from six to 30 air changes per hour (ACH) has a minimal effect on aerosol concentration of microorganisms in the first few minutes after release." [Zhang et al., 1992; McDiamid, 1988]

\section{- Code compliance}

As described in Chapter 2, in California, laboratory-type facilities will usually fall into one of three California Uniform Building Code (CAL/UBC) classifications: B-2, $\mathrm{H}-8$, or H-7. The Uniform Building Code (UBC), Uniform Fire Code (UFC), NFPA 45, and Uniform Mechanical Code (UMC) do not specify the air change rate of B-2 (except in certain cases of flammable liquid storage) or H-7. The special California H-8 occupancy also does not specify an air change rate. In an H-6 occupancy (restrictive classification for large semiconductor fabrication facilities), an exhaust air-flow rate of one cfm (which may include recirculated air) per square foot $\left(0.044 \mathrm{~L} / \mathrm{s} / \mathrm{m}^{2}\right)$ of fabrication area is specified by the code. [Uniform Building Code, 1994]

A laboratory space with a 10-foot-high ceiling and a one cfm per square foot exhaust air-flow rate will result in six air changes per hour. However, if the ceiling height is greater, a ventilation rate based on air changes will result in air flows in excess of what even the H-6 occupancy requires and will consequently waste energy for less hazardous activities. Therefore, in the absence of better information, it is recommended that the air-flow rate through the laboratory space be set not at a particular air change rate but at one cfm per square foot (and not less than six air changes per hour in B-2 laboratories where Class I, II, or III-A liquids are used) and for B-2, H-8, or H-7 occupancies. [California Uniform Building Code, 1994; California Uniform Fire Code, 1994]

\section{- Computational fluid dynamics}

The relatively new area of Computational Fluid Dynamics may provide the energy engineer with information to help make laboratories safer and more energy efficient. Room geometry, HVAC system equipment, diffuser placement, and laboratory operational procedures all influence air movement around the fume hood sash opening and thus affect hood performance. The Computational Fluid Dynamics computer model is an attempt to simulate the interaction of all of these variables impacting hood contaminant performance. The National Institutes of Health, Division of Engineering Services, is working with Flomerics Ltd., the Building Services Research and Information Association (BSRIA), and the American Society of Heating, Refrigerating and Air-Conditioning Engineers (ASHRAE) to develop Computational Fluid Dynamics-based (CFD-based) models that will predict the ventilation performance of different laboratory configurations. [Hayner, 1995]

\subsubsection{Computational fluid dynamics (CFD) research project}

Hayner (1995) describes a project at the National institutes of Health (NIH) to develop a computational fluid dynamics (CFD) based model to "predict the ventilation performance of different laboratory configurations":

The research project, which has reached its halfway mark, will first develop the CFD models, then verify their validity in the field. Results are due in January, 1996. Current literature on the subject 
does not deal with the complexities of laboratory layout and equipment placement; issues that confront facilities like NIH. The sophisticated research labs at NIH contain a lot of equipment. This equipment degrades the ability of the hoods to perform satisfactorily. It also tends to limit the design effectiveness of supply diffusers, thus aggravating the problem. The CFD project will give NIH the ability to test multiple configurations of laboratory ventilation and assess their effectiveness. It will not look at the design of fume hoods themselves. Information derived from the CFD models will be the basis of design guidelines for controlling ventilation performance, maximizing local containment, and minimizing the risk of contaminant dispersion within a laboratory.

\subsubsection{Animal facilities}

Zhang et al. (1992) describe a survey of U.S. facilities that house laboratory rats.

Data are needed to quantify laboratory animal environmental conditions so as to improve animal well-being, facility design, and energy efficiency. Seven laboratory rat facilities at a U.S. university were surveyed. Temperature, humidity, air velocity, and ammonia levels in rooms and selected cages within the rooms were measured and analyzed... Ventilation recommendations are based on room air exchanges, but air exchanges in the animals' microenvironments can be inadequate or excessive depending on the cage and facility design. The room air-diffusing system, cage type, and other room characteristics generally may be more important than room air exchanges in their impact on the animals' microenvironmental conditions... The principal index for quality animal microenvironments -ammonia level-varied widely among cages even though room air exchange rates were similar...micronenvironmental conditions can be improved by increasing the cage ventilation rates. Achieving this, however, was more dependent on cage design, room ventilation system design, and animal management practices than on room air exchanges.

\subsubsection{Ventilation system overview}

The Laboratory Control and Safety Solutions Application Guide (1994) summarizes the key elements of a laboratory ventilation system:

Laboratory ventilation system design is one of the most important specialties associated with the health and safety of laboratory occupants. The primary elements of a laboratory ventilation system are listed here as part of overall facility design considerations. A proper laboratory ventilation system should:

- Provide the necessary laboratory room ventilation rate to ensure proper indoor air quality (typically expressed as air changes per hour).

- Remove chemical fumes and biological airborne substances and contaminants that pose a health or safety hazard to the building occupants.

- Provide a proper face velocity for fume hoods and other apparatus that is intended to prevent worker contact with fumes or hazardous airborne substances.

- Ensure that laboratory room air and exhaust air are not recirculated or allowed to migrate into other areas of the facility.

- Supply conditioned air to laboratory rooms in a manner that does not cause drafts or air currents. Strong air currents could adversely affect the safety of fume hoods or other provisions for exhausting potentially hazardous fumes or airborne substances. 
- Provide the required laboratory room environment (temperature and humidity) required to maintain occupant comfort or whatever environmental constraints are necessary for the purpose and processes taking place within a particular laboratory.

- Provide special modes of operation to maximize and possibly redirect the laboratory exhaust capability and ventilation air in response to a variety of emergencies including a laboratory fire, explosion, chemical spill, release of toxic fumes, etc.

- Provide the proper level of indoor air quality and comfort desired for non-laboratory areas within the same building (administrative offices, support facilities, lobbies, lunchrooms, etc.).

- Operate at an acceptable sound level so as not to be an annoyance or interfere with sounds emanating from the laboratory activities.

\subsubsection{Ventilation rates}

Crane (1994) writes about ventilation and safety in laboratories.

Ventilation rates increase safety by exchanging and diluting contaminated air in a space with noncontaminated air. However, higher ventilation rates are effective in reducing odor, long-term exposure to chemicals and long-term sensitization to potentially allergic [sic] materials produced in large quantities in pilot plants. Sufficient ventilation must be provided for proper operation of local exhaust systems.

Based on Pike's (1976) studies of 4,000 laboratory-acquired infections, Barkely (1976) concluded that the factors listed below may have reduced the number of infection as follows:

- ventilation rates - 0 infections, i.e., no reductions of lab-acquired infections

- general exhaust air treatment -- 0 infections,

- directional airflow -- 100 to 300 infections, and

- biological safety cabinets -- 500 to 3,000 infections.

From this, one can see that of all factors reducing risk, use of a biological safety cabinet is the most significant.

\subsubsection{Fume hood face velocity}

Fume hood face velocity directly affects the laboratory's energy efficiency. Higher face velocities increase exhaust air-flow rates and consequently increase the volume of conditioned air expelled, requiring more fan energy. In other words, reducing the fume hood face velocity increases a laboratory's energy efficiency.

The safest fume hood face velocity has been the subject of numerous studies and evaluations that have produced the following two criteria:

- Face velocities in the 60 to $100 \mathrm{fpm}$ range provide acceptable and safe hood operating conditions.

- Room air patterns can account for at least 50 percent of unsafe hood performance. [Saunders, 1993; Lyons et al., 1990] 
These data were reviewed and published in 1982 by the American Conference of Governmental Industrial Hygienists (ACGIH). This endorsement by a society of health professionals, of the criteria, which are substantiated by excellent research, made a definitive statement regarding hood safety and face velocities. Some fume hood manufacturers' catalogs still reflect parameters as outlined in SAMA Standard LF 101980 , where so-called class $A, B$, and $C$ hoods are represented with face velocities up to $150 \mathrm{fpm}$. In view of more current data, these A, B, and C classifications and their implied face velocities should be ignored. Relying upon this increased face velocity rather than considering hood and room ventilation design wastes energy. [Saunders, 1993]

\subsubsection{Face velocity-a historical review}

Saunders (1993) describes "some of the historical events that have shaped today's understanding of fume hood face velocities":

Fume hood face velocity has been a very lively and controversial subject for health professionals and engineers since the 1930s and 1940s. In the early days of the Atomic Energy Commission $(A E C)$ a hood face velocity of $50 \mathrm{fpm}$ was considered adequate and safe. These were also the years of a widely and wildly expanding hood population.

Advanced hood design was just beginning in the 1940s and many questions were arising as to what was a safe face velocity. Unfortunately, the "more is better" fraternity became very vocal and convinced the majority of fume hood users that much higher face velocities were safer. At that time air velocity was the only parameter that could be measured objectively. There was some use of smoke wands and smoke bombs, but the results were more subjective than objective, and the face velocity was the primary focus of so called hood safety.

As the 1950s, 1960s and 1970s came and went, these "experts" were increasing the face velocity as rapidly as possible. From $50 \mathrm{fpm}$ they had gone to 75,100 , and finally to $150 \mathrm{fpm}$ and higher before some calmer heads prevailed. Some members of the fume hood community recognized that the increased velocities had not fostered safety and were driving the cost of building and operating laboratory buildings out of reach. In the late 1970s the American Society of Heating, Ventilating and Air Conditioning Engineers (ASHRAE) instituted a monumental research project. Dr. G. W. Knutson and K.J. Caplan undertook a project to establish a method of quantitatively testing fume hoods.

\subsubsection{Measured face velocity}

Saunders (1993) talks about recommendations for the measured face velocity of fume hoods:

To be on the safe side, the measured face velocity of the hood, at a partial opening, should be close to what the velocity should be with the sash fully open. Remember the American Conference of Governmental Industrial Hygienists (ACGIH) set $60 \mathrm{fpm}$ as an accepted minimum. As an example, if we have a hood with a 30-inch available sash opening, but want to use 18 inches as the restricted size opening then the ratio of 18 to 30 inches is 60 percent so the velocity at the 18-inch opening should be $60 \mathrm{fpm}(60 \%$ of $100 \mathrm{fpm})$. If you are not comfortable with a minimum velocity of $60 \mathrm{fpm}$, you will have to insert a value that you prefer. Remember that overall sash opening height varies with manufacturer and with model, so you have to accommodate whatever the overall size actually is. 


\subsubsection{Cleanroom systems}

Many factors contribute to the overall energy consumed by air-handling systems in a laboratory or cleanroom. First is the total quantity of air to be moved, then the amount of exhaust air, and the temperature and humidity requirements for the conditioned air. An entire design industry has been created for cleanrooms. Many creative engineering designs have been directed towards the most energyefficient way to minimize air-flow rate. Energy-efficient clean room technology incorporates the following principle: [Schicht, 1991]

- Using a "minienvironment" approach to reduce to a minimum the room areas where unidirectional air flow is required by the process technology. These areas are typically protected with plastic curtains or dividing walls.

- Lowering the flow velocity to the minimum necessary to overcome thermal up-currents or flow instabilities caused by process-related heat sources. [Schicht, 1991]

We present estimates of potential energy savings for various laboratory cleanroom design choices. These estimates are based on the total savings that can be realized by choosing the energy-efficient option instead of a conventional option. [Patel et al., "Designing..." 1991]

- Open-air returns versus ducted returns

- Solid versus flex duct

- Low-pressure drop HEPA filters

- Open side-wall returns versus 100 percent grills

- Single-row coils versus double-row

- Open-ended make-up air duct

- Energy-efficient motors

$$
\begin{aligned}
& 60-95 \text { percent } \\
& 60-90 \text { percent } \\
& 30-90 \text { percent } \\
& 40-80 \text { percent } \\
& 40-70 \text { percent } \\
& 10-25 \text { percent } \\
& 8-12 \text { percent }
\end{aligned}
$$

\subsubsection{Cleanroom exhaust devices}

Patel et al. in their report "High Performance, Low Energy Cost Cleanroom A Case Study" describe the choice of exhaust devices at a semiconductor firm in the late 1980's:

By utilizing special exhaust conservation methods, a series of "hi-low" wet stations was developed, featuring low exhaust volume at all times, except high exhaust volume during work loading and unloading. Special design features included an aerodynamically configured "fansition" with splitter vanes, elimination of the typical "slot" type exhaust distribution system, and auto dampers. All auto etch stations featured a flat open deck, with just the recessed dual process tank/DI rinse system covered by an extended hi-low box, containing a single front access door. For standard wet stations, a flat-top edge vented deck with recessed tanks, multiple process doors, and a process flow opening were utilized in a majority of cases. In a few instances, predominant for maintenance type stations, a triple track interlocked sliding door system was utilized. In all cases, the key was in designing and developing the stations to allow even distribution of exhaust at low velocities. The typical "slot" method of equalizing exhaust requires a slot velocity approximately equal to the duct velocity in order for the equalization across the station to take place. This method results in high pressure losses. The reduction of the velocity to $150 \mathrm{fpm}$ results in a much lower hood loss (0.5 in. W.G. vs. 2.0 - 3.-0 in.W.G.) and an additional savings in exhaust energy requirements.

All systems were developed and tested first in a special shop area, and later in actual production conditions before the designs were approved for extensive use on this project. The development 
team included safety, environmental, production and shop personnel, as well as engineering, in order to satisfy a variety of needs. The results were that the stations were judged much safer, easier to use, less contaminating, more environmentally sound and slightly cheaper to build than standard wet stations! All of this was bonus when final tests showed a $72 \%$ reduction in exhaust usage.

\subsubsection{Optimization in cleanroom systems}

Lyons et al. (1990) discuss the use of multiple fans: "Most labs require some form of standby equipment. Although this is often critical for hood exhaust, it is often a requirement for the supply equipment as well. A simple method is to provide multiple fans in parallel, sized so that if one fails the remaining fans can continue to operate until a safe shutdown time can be scheduled."

Schicht (1982) points out that:

In addition to the possible methods... [of] restricting the air flow rate to a minimum, there are numerous other measures which can be employed to reduce the energy consumption and therefore the operating costs of cleanroom systems. Particularly good results are achieved by using a combination of measures which integrate a number of the individual steps listed below to form a harmonized whole:

- variable outside air/recirculated air proportion in order to reduce the need for the mechanical chilling by utilizing the principle of free cooling;

- use of waste heat for heating purposes;

- recovery of heat from the exhaust air with the aid of recuperation and reverse cycle heat pumps;

- minimal air humidification;

- appropriate system and zone subdivision, in line with the required room air conditions;

- application of the variable air volume principle whenever suitable;

- reduction of the air flow rate outside production hours;

- strict and comprehensive criteria for the selection of the components of the system.

In addition to these possibilities, a whole series of further savings can be achieved, when planning air conditioning and cleanroom systems, by exhaustive use of the energy management potential of modern automatic control systems, especially when, by making use of micro-processor and personal computer technology, they are upgraded into a complete building management system.

\subsubsection{Cleanroom optimization-case study}

Schicht (1982) presents a case study that is an "example of a fully integrated energy concept."

In the example given below an illustration will be provided of the way in which ... energy-saving measures listed above [Section 3.2.4.2] can be integrated to form an overall solution. The premises in question are those of a research institute specializing in the development of special purpose components for micro-electronics. 
A central plant with constant air flow rate was chosen for the air conditioning of the multi-story building. At the entrance of each story, the HEPA filters are grouped centrally in easily accessible compact fitter boxes according to zones, so that monitoring and maintenance work can be carried out, without need to enter the research rooms. An air distribution system, which is designed so that later modifications can be made without difficulty, conveys the supply air to custom-designed clean air distribution elements. The size and arrangement of the distribution elements, the direction of air flow and the air flow velocity are exactly tailored to the individual requirements of each work station. [Lab equipment] is kept under clean air conditions of Class 100 in accordance with US Federal Standard 209D on this job. In some cases the apparatus is protected by the use of horizontal unidirectional flow, in others by vertical unidirectional flow.

The work stations are thus isolated from the surroundings by the use of the principle of spot protection. The remaining room areas of the laboratory are air conditioned merely by spill-over flow from the clean zones, and additional supply air devices have not been necessary. This allows both the desired room air conditions to be maintained and an air cleanliness corresponding to cleanliness Class 10000 according to US Federal Standard 209D, to be ensured-at no additional cost as far as air engineering is concerned

The velocity of the air emerging from the clean air distributing elements was set individually within the range 0.25 to $0.4 \mathrm{~m} / \mathrm{s}$ [ 50 to $90 \mathrm{fpm}]$ and is subsequently kept constant by means of automatic air volume control devices

Minimization both of the spatial extent of the area protected by unidirectional flow and of the flow velocity are therefore used to keep down the air flow rate to the very minimum possible.

The air handling equipment is operated at only $70 \%$ of its rating. The reduction of the pressure loss and the higher degree of efficiency of the heat exchangers as a result of the lower air velocity more than compensate for the somewhat higher purchase costs of the units. Outside working hours the air flow rate is reduced to $50 \%$ of the nominal value, with the result that the energy consumption of the system for conveying the air decreases to less than $25 \%$.

Air circulation is by means of high-performance fans with an efficiency at the point of operation of over $80 \%$. This lowers the energy costs in comparison with a solution based on clean work benches even further, since that type of concept would require numerous small, decentralized fans with a relatively low efficiency.

Heat is recovered in three ways: the heat in the exhaust air is transmitted to the incoming outside air by means of finned heat exchangers made of stainless steel (stainless steel is essential because of the vapors of acids and solvents contained in the exhaust air); the cooling water, removing the waste heat from the equipment in the laboratory rooms is used to further warm the entering outside air, and the waste heat of the water chillers is used to produce hot water for the sanitary installations and for the low temperature heating system of the offices, and to supply the necessary heat for the multi-zone reheaters of the air conditioning system.

\subsubsection{Cleanroom efficiency-case study}

Patel et al. ("Constructing..." 1991) analyze the energy-saving approaches used in a new cleanroom in the semiconductor industry.

Incorporating Energy-Conservation Measures

Many factors influence the overall air-related energy costs in a cleanroom, including the total quantity of air moved, the equipment used, the temperature and humidity requirements, and 
ambient conditions. However, two factors dominate: the size of the pressure drops in the system and the amount of air that must be replaced. If both pressure drop and exhaust volume can be minimized and serious consideration is given to the incremental savings possible through careful specification of the room parameters and process equipment, considerable savings can be realized.

\section{Lowering Pressure Drops.}

In [this] cleanroom project the key to reducing the overall system pressure drops was opening up the air returns. [In this] Class 100 air-handling system, the service bays and interstitial spaces ... are continuous open areas. The side-wall returns ... are continuous openings that are 27-33 in. high. Airflow direction and pressurization are controlled by two types of portable panels, solid and louvered. The return air required by the makeup air handler for temperature and humidity control is returned directly to the mixing chamber through a grille in the roof ...; that for the local tunnel modules is returned directly to the modules through the service bays.... The tunnel modules were designed to minimize electrical-energy requirements through the use of low-pressure-drop, singlerow, sensible-heat cooling coils ...; energy-efficient motors ...; and low-pressure-drop HEPA filters ... Makeup air is supplied to these local tunnels ... via solid (rather than flex) ducts ... that are not connected directly to the units but that terminate in close proximity to the prefilters. (In the Class 1000 areas, air is delivered in the same manner to self powered, $2 \times 4$-ft drop-in ceiling units.) Because no solid connections are used between the makeup air handler and the final filter units at any point, pressure drop in the delivery duct system is minimized. Even more importantly, however, this feature permits the delivery system to remain balanced when small changes are made anywhere in the fab area. The optimized design of the tunnel modules resulted in an average electrical-energy requirement of $33 \mathrm{~W} / \mathrm{sq}$. $\mathrm{ft}$, which is $10 \%$ below that of a similar wafer fab cleanroom.

Reducing Replacement-Air Requirements.

A typical fab will exhaust $6-10 \%$ of the air supplied through the local units. Assuming approximately 700 air changes occur per hour, this exhaust adds up to $42-70 \mathrm{cu} f t / m i n$. of wasted air per square foot of fab per hour. At an annual energy maintenance cost of $\$ 6$ to $\$ 10 / \mathrm{cu} \mathrm{ft}$ of air, this represents an expense of $\$ 50$ to $\$ 700 / s q$. ft of fab area per year and an initial capital equipment cost of about the same magnitude.

In most fabs, wet-chemical process stations account for $75 \%$ or more of the replacement-air requirements. Thus, ... a series of "high-low exhaust" wet stations was developed. The exhaust volumes of these units are kept low at all times except during work loading and unloading. Other special design features include an aerodynamically configured "fansition" with splitter vanes, elimination of the typical slot-type exhaust distribution system, and automatic dampers. All automatic etch stations feature a flat, open deck, with only the recessed dual process-tank Deionized [water] (DI)-rinse system covered by an extended box containing a single front access door. Most standard wet stations have a flattop, edge-vented deck with recessed tanks; multiple process doors; and a process flow opening, although in a few instances, predominantly for maintenance-type stations, a triple-track interlocked sliding-door system is featured. In all cases, the key in designing and developing the stations was to allow an even distribution of exhaust at low velocities.

The typical slot method of equalizing exhaust requires a slot velocity approximately equal to the duct velocity in order for equalization to take place across the station, resulting in high pressure losses. By reducing the velocity to $60 \mathrm{ft} / \mathrm{min}$., the high-low design achieves much lower hood losses (0.5 versus 2.0-3.0 in. of water gage) and an additional savings in energy requirements. The estimated cost savings that resulted from this design were $\$ 120,000$ in capital expenditures for air-handling equipment and $\$ 32,000$ in annual operating costs. 


\subsubsection{Packaged Air Conditioning}

Occasionally, a laboratory space will not be part of a larger centralized HVAC system, e.g., in a temporary trailer that will house a short-term research project. However, short-term research projects often last longer than anticipated. Therefore, it is useful to consider ways to enhance energy efficiency in small, separate laboratory spaces:

- Install an air conditioner that is deliberately undersized relative to the anticipated peak cooling load. Thermal comfort is maintained by running the unit full-time, day and night, during the hottest days. Energy efficiency results from reduced cycling losses. [Andrews et al., 1993]

- Utilize a variable-speed air conditioner and restrict it to run on low speed during the peak periods. Energy savings result from the higher overall efficiency of the variable-speed unit and the limiting of peak energy consumption. [Andrews et al., 1993]

- Stage the operation of multiple room units, permitting only a limited number to operate during peak periods. Energy savings result from zoning strategies and limiting peak energy consumption. [Andrews et al., 1993]

\subsubsection{Process hot water}

Process hot water systems for a laboratory facility usually do not significantly affect total energy consumption. However, some opportunities for increasing energy efficiency include central vs. point-ofuse heaters, recovery of heat from chillers, and fuel and equipment selection. [Nelson, 1990]

\subsubsection{Domestic hot water systems}

Nelson (1990) discusses hot water systems:

Many larger laboratory buildings have large domestic hot water distribution systems that consist of heater(s), storage tank(s), distribution piping and a circulation pump(s). The pump should be controlled by a time clock and a temperature sensor. The time clock allows the pump to operate according to the schedule set on the clock, and the temperature sensor located in the return line energizes the pump when the water temperature drops below the set point. The system provides a single-temperature hot domestic water supply for the various users.

In contrast to the central system, the point-of-use system provides a supply of hot water where needed. This type of system is normally considered when:

- There is a great distance between points of use.

- The water temperature requirements vary

- The schedule of water needs varies, so that large systems must remain operating for small hot water demands.

An LCC analysis will allow comparison of installation, operating and maintenance costs. Many types of domestic water heaters are available. Each type has its own operating efficiency and may use a different fuel type. 


\subsubsection{Power distribution systems}

There are numerous opportunities to save electrical energy in new and existing laboratories. Many energy engineers overlook the original design of electrical distribution systems, especially in facilities that have been retrofitted extensively since the original installation. Some simple ways to save energy are:

- Use 277VAC for lighting circuits,

- Oversize electrical wiring relative to applicable codes,

- Use high voltage feeds to switch gear,

- Use efficient transformers and do not greatly oversize,

- Provide correctly sized, premium efficiency $(90+$ percent) motors,

- Correct the facililty's power factor. [Nelson, 1990]

\subsubsection{Electric load estimation}

Cooper (1994) discusses the choice of laboratory air conditioning equipment based on estimated heat load.

Estimating the heat loads for a laboratory is crucial to the design of the air conditioning capacity. Besides the normal heat gain calculations for the building skin, the interior heat gain from lighting, people, and especially lab equipment must be considered. Lighting loads for offices and conference rooms normally run in the 1-2 watts/[square foot] range. Laboratories tend to have greater lighting loads, averaging in the 2-3 watts/SF range. Laboratory power requirements can vary significantly. Biomedical labs will use 8-10 watts/FS, except for certain equipment rooms which may be as high as 40-50 watts/SF. On the other hand, electro-optical labs can average 2025 watts/SF, with some concentrations at much higher levels. In order to select the most appropriate central air conditioning equipment, the engineer must carefully analyze the anticipated total load and the expected diversity.

\subsection{Diversity}

\section{Energy Efficiency and Diversity}

Diversity in laboratory design can permit downsizing of equipment, reducing capital and operating costs. The diversity factor is used when considering all of the HVAC system components for the laboratory including: boilers, chillers, cooling towers, pumps, air-handling units, ductwork, heat recovery, and mechanical spaces. Diversity allows the designer to downsize a VAV system in order to make it more life-cycle cost effective when compared to a CV system. [Rabiah and Welkenbach, 1993]

\section{- Downsizing equipment}

The diversity factor must be carefully evaluated for downsizing equipment. Diversity varies in each facility depending on the type of research done there, among other factors. For large systems, a diversity factor calculation will generally increase the opportunity to use smaller air-handling systems. HVAC systems have been reduced 30 percent and more in large facilities with high levels of exhaust relative to thermal ventilation rates. [Rabiah and Welkenbach, 1993; Lentz and Smith, 1989] 


\section{- Fume hood diversity}

Fume hood diversity is the percentage of hoods in a laboratory facility that are being used simultaneously. Seventy-five percent diversity means that 75 percent of the total installed fume hood air flow is occurring simultaneously. This results from a combination of fume hood sashes being only partly open to fume hoods being turned off while others are wide open. Energy engineers have used a range 65 to 75 percent for the initial estimate of a diversity factor in sizing total facility exhaust air volume. With good researcher energy practices in the right facility, diversity factors of 49 to as low as 41 percent have been documented. It is suggested that the fume-hood-to-personnel ratio may predict the facility diversity if the motivators listed below are present. [Saunders, 1993; Hitchings and Shull, 1993]

\section{- Key motivators to capitalizing on diversity}

Capitalizing upon diversity depends mainly on three key motivators: overall facility design and function, operator training, and monitoring and enforcement. [Hitchings and Shull, 1993]

\section{- Brief diversity evaluation}

According to Lentz and Seth (1989), the following points need to be evaluated before diversity is considered in sizing the HVAC system:

- The ventilation system must be large enough to warrant diversification. There is little point in using this technique on small projects with only a few fume hoods. Simultaneous usage of the fume hoods is more likely in a small facility.

- The minimum level of air flow allowed by users, safety officials, and owners must be significantly lower than the maximum fume hood exhaust flow. There is debate over whether or not exhaust air-flow rates can be diversified.

- System oversizing in anticipation of future expansion limits the reduction of installed system capacity.

\subsubsection{Survey questionnaire}

An effective method to determine the diversity factor is to conduct a survey of researchers to identify a realistic pattern of fume hood use. This survey can be conducted both in person and with a questionnaire. The energy engineer will often be surprised by the results; researchers themselves often do not notice how often they use their fume hoods and for what purposes.

\subsubsection{Survey example}

Rabiah and Welkenbach (1993) describe the use of a survey to "provide an analysis in determining 'diversity factor' for fume hood use in six major buildings on a university campus." Each fume hood user received a questionnaire.

Varley (1993) explains a study to determine fume hood diversity.

Fume hood use in one wing of the research center of a Midwest-based paints and coatings manufacturer was measured using a simple survey form attached to the front of each fume hood. For a period of one month, fume hood users logged the time they began work in the hood, the approximate sash height, the procedure performed in the hood, and the time of departure from the hood. In addition, a remarks column allowed the user to note any unusual conditions at the hood. Fifty-six fume hoods were evaluated. The data were correlated to show the following: 
- mean aiflows for a given day

- mean airflows at given times during a day.

- peak airflow use, and

- significant behavior patterns of hood users.

Though simple in concept, this procedure will provide a basis for the design of planned exhaust systems at this research center. The survey forms to be filled out were to include the following:

- Date the fume hood was used.

- The duration of time the fume hood was used.

- The procedure performed in the hood.

- The sash height during and after hood use.

- Comments.

The collected data may contain considerable error due to a number of factors related to the survey method, including the following.

- Non participation of the researchers.

- Inconsistent reporting among survey participants.

- Inaccuracies in reportage.

- Misinterpretation of the collected data during transfer of the data from the survey form to the computerized spreadsheet.

\subsubsection{Survey example \#2}

Rabiah and Welkenbach (1993) point out that:

Laboratory fume hood operations vary widely, depending primarily upon the level of activity required for the hood and the work practices of the individuals using the hoods. In an attempt to address these issues, the facilities planning office of a large university initiated a study. This study followed a protocol intended to determine a diversity factor to be used in downsizing the mechanical equipment and establish the concept of a diversity in variable-air-volume system design for laboratory buildings. This diversity factor will provide the backup support to reduce the capital cost of installing VAV laboratory controls.

The study involved six major recently built or renovated research buildings. A total of 300 fume hoods, equipped with variable air volume exhaust/make-up air systems, were randomly selected in the study, and a questionnaire was filled out by each fume hood user. Statistical data, derived from questionnaire answers by students, researchers, and professors, were established on the basis of percent sash opening of each fume hood in hours per day. 


\subsubsection{Diversity factor}

\section{- Diversity types}

It is important to note that there are two types of diversity in a laboratory facility:

- An HVAC diversity factor, which relates to the thermal characteristics of the facility envelope, diurnal temperature swings, and occupancy of support spaces.

- A fume hood diversity factor, which relates directly to the demand characteristically placed on the ventilation system. [Rabiah and Welkenbach, 1993; Lentz and Smith, 1989]

The fume hood diversity factor is the percentage that is used from the maximum amount of exhaust airflow available from the laboratory ventilation system at a moment in time. Therefore, the fume hood diversity factor relates directly to the percentage of fume hood sashes that are open in operating hoods. This diversity factor is also a function of the hood users' work loads, research functions, and work habits. [Varley, 1993]

\section{- Fume hood ratio}

The fume hood diversity factor has been thought to be associated with the number fume hoods in the facility per total building area. Studies have shown that this assumption is not correct in all cases. The ratio of hoods to laboratory personnel contributes more to the diversity factor. Linear regressions were performed on plots of diversity factors against hood/personnel ratios; the regressions showed a strong correlation between the diversity and the number of hoods per user. "This makes sense, since one would expect hood utilization to increase as more personnel were required to share the available hoods." [Rabiah and Welkenbach, 1993; Hitchings and Shull, 1993]

Naturally the energy engineer must exercise caution before attempting to apply these findings. Extrapolation to facilities with small numbers of people or hoods is not recommended, for example. This procedure does not account for a lower diversity limit that requires a specific exhaust rate fraction of the total be maintained. [Hitchings and Shull, 1993; Rabiah and Welkenbach, 1993]

\section{- Lower diversity limit}

The lower diversity limit is a minimum value determined by a variety of factors including control set points, envelope and system leakage rates, heating and cooling loads, and indoor air quality standards. Leakage rates around dampers or at duct connections will influence the minimum value. Depending upon the climate, the air required to remove sensible heat gain may limit the diversity factor. [Rabiah and Welkenbach, 1993]

\subsubsection{Operating cycle}

Rabiah and Welkenbach (1993) emphasize that:

Another economic benefit may be achieved through the application of the diversity factor to the operating cycle of the VAV system. The VAV system can be programmed to accommodate for these different diversity levels during its 24-hour cycle. If, for example, the majority of the fume hood users in the chemistry building had an eight-hour workday from 8 a.m. to 5 p.m., then it might be appropriate to program the VAV system to operate based on the 8-hour diversity factor during this period but to taper to the 24-hour diversity factor toward the very late hours in the night when fume hood use can be expected to be at its lowest. The system must, of course, be initially designed and sized for the expected peak load, which is likely to occur in the six-hour period. 


\subsubsection{Diversity calculation}

Hitchings and Shull (1993) discuss the calculations of laboratory exhaust diversity.

Total installed exhaust capacity:

The sum of the maximum operational fume hood and specific exhaust flow rates for all sources in the facility is the total installed exhaust capacity. This should not be confused with the installed exhaust system capacity, which may be greater or less than this sum. For fume hoods with sash stops, the maximum operating flow rate is determined when the sash is open[ed] to [the] stop. For fume hoods without sash stops, the maximum operating flow rate is determined with the sash fully open. For specific exhaust sources, the maximum operating flow rate is determined when the damper is full open. The volume flow rate for all fume hoods is based on the normal operating face velocity for the facility in which they are used. In the three cases cited in this paper, the face velocity is $100 \mathrm{fpm}(0.51 \mathrm{~m} / \mathrm{s})$.

Diversity $=\frac{\text { Actual volume Flow Rate }}{\text { Total Installed Exhaust Capacity }} \times 100 \%$

Minimum possible operating diversity:

The diversity that occurs when all the fume hoods are closed and the specific exhausts are at their minimum is the minimum possible operating diversity.

99\% design diversity:

The diversity of the system that was exceeded by only $1 \%$ of the observations in the adjusted diversity data set. The number can also be interpreted as the upper control limit for a process with a $1 \%$ rejection rate. The classical statistical quality control methods of determining upper control limits assume normal distribution of the data. However, the laboratory exhaust diversity data collected were not normally distributed. In a non-normal distribution, the variance or standard deviation of the sample does not describe the distribution adequately enough to allow mathematical calculation of the control limit. To allow for non-normal distributions, the method used in this paper to determine the upper control limit was to record each observation in bins of $1 \%$ diversity increments and generate a frequency distribution. These frequencies are then summed to produce cumulative percentages for each bin. The diversity at which the cumulative percentage reaches $99 \%$ is the $99 \%$ design diversity. This approach is only valid with large numbers of obsenations, as was the case with all three facilities described in this paper.

Lentz and Smith (1989) point out that:

While the extent of diversity will be driven by the function of a facility and the character of its use, diversity of fume hood exhaust aifflow will occur if fume hoods are not of the bypass type, some method of automatic capacity control is provided, and fume hoods are not used primarily for flammable chemical or other function requiring fixed quantities of air for dilution purposes.

\subsubsection{Diversity factor-a case study}

Lentz and Smith (1989) report on a "study performed at a large medical research facility in New England" that "demonstrated that the diversified electrical load on that laboratory was between $50 \%$ and $55 \%$ of the total connected electrical load. Designers must be cautioned not to use this example figure carelessly, since use characteristics will vary with facility character and type. Intuitively, however, it should be obvious that it is very unlikely that all equipment will be needed and operated simultaneously in any but the very smallest facility." 


\subsubsection{Economic factors}

The economic advantages of designing with diversity in a VAV laboratory are great. VAV systems are highly sensitive to the fume hood diversity factor. When the diversity in the laboratory facility is great enough, the first-cost of a VAV system will be less than that of a CV system. [Rabiah and Welkenbach, 1993]

\subsubsection{Downsizing}

Rabiah and Welkenbach (1993) discuss downsizing of VAV system components:

Components of the VAV laboratory system, such as sensors, hood monitors, and make-up air control panels with related tubing and wiring, seem to make the VAV system higher in cost than a constant volume laboratory system. However, these components will provide an upgraded system with regard to safety, monitoring, control, operating cost, and efficiency. Downsizing the major components of the laboratory VAV system, such as the supply fan, exhaust fan, ductwork with related accessories, coils, space above the ceiling, and mechanical shafts, can have a heavy impact on major savings for the building structure. Of course, downsizing the components of the VAV system will lead to downsizing components of the building mechanical system, such as chillers, pumps, boilers, air-handling units, humidifiers, and associated mechanical piping.

For the purpose of future expansion, redundancy, and unusual weather conditions, downsizing should be done carefully to ensure the necessary capacities, as this is vital for the building's environmental safety. At the same time, it must be understood by building owners and users that the designer of a VAV laboratory building will expect a commitment that some of the building fume hood sashes will be partly or fully closed. This will give the designer the confidence to implement the diversity factor in the downsizing of the building's mechanical system. Airtight sealing of ductwork is essential to ensure that air delivered to or exhausted from areas is compatible with fan capacity.

\subsubsection{Safety element}

The safety ramifications of using diversity to size the laboratory HVAC system must be thoroughly considered. Diversity should not be used to size the exhaust fan capacity because of overriding safety concerns. Total installed fume hood and specified exhaust capacity must be provided. [Hitchings and Shull, 1993; Lentz and Smith, 1989]

Energy efficiency results from the exhaust system arrangement. For instance, a VFD on the exhaust fan can normally operate at the lower volume rate that is indicated by the diversity factor. The exhaust stack would be designed to maintain the required discharge velocity at this "diversified" speed. During an emergency situation, the VFD would go to full speed with an automatic bypass to provide the total exhaust system capacity, and a resulting increase in the stack discharge velocity. Instead of a VFD, a multiple-fan installation can also be arranged. The difference between the total installed exhaust capacity and the "diversity capacity" provides a safety factor.

Diversity factors should be used only for mechanical systems supporting heating, cooling, humidification, and other nonsafety functions, such as air distribution duct systems, central fan systems, and primary heating and cooling systems. A diversified exhaust rate should never be used when sizing terminal air distribution units serving any individual laboratory. [Hitchings and Shull, 1993; Lentz and Smith, 1989] 


\subsubsection{Facility vs. local diversity}

Hitchings and Shull (1993) discuss diversities that "apply to the facility as a whole. Thus, only the equipment supporting the whole facility can take advantage of this diversity. While local diversity may occur in various parts of the facility, the local diversity may differ substantially from the diversity of the whole. Therefore, care must be taken when sizing ducts, pipes, and other equipment serving only a subset of the facility."

\subsubsection{Diversity and VAV systems}

VAV systems can reduce both operating and first costs of the laboratory HVAC system. Operating costs are reduced because of the part-load operation of the VAV system; system diversity is the main reason for the reduction in first cost. [Parker et al., 1993]

A laboratory VAV system responds to both thermal and demand diversity characteristics. VAV systems match the facility's base thermal load and adjust for the variable nature of activity in the laboratory. The laboratory VAV system will also most often operate at levels significantly below an undiversified peak demand. The range of modulation required for laboratory VAV systems is much larger than that typically required in common, office-type VAV systems. This range is needed because exhaust make-up ventilation requirements could overwhelm thermal ventilation requirements and fume hood diversity. [Lentz and Smith, 1989]

In contrast, $\mathrm{CV}$ system designs are defined by the peak design characteristics of loads that are undiversified. $\mathrm{CV}$ ventilation systems must be sized to operate at this artificially defined level of ventilation, regardless of actual demand requirements, for the life of the system. [Lentz and Smith, 1989]

\subsubsection{Profile of fume hood use}

Parker et al. (1993) explain that fume hood use profiles can reveal a wealth of information:

The opportunity for cost reduction seems attractive in labs due to the high ventilation loads that are a result of the safety requirements. The ventilation loads are mainly driven by the operation of the local exhaust equipment, i.e., fume hoods. The profile of fume hood use essentially dictates both the part-load and the system diversity. Additionally, the profiles can be used to determine other important characteristics of a lab. An on-line determination of fume hood diversity provides a simple yet effective indication of the lab's load pattern. In addition, by knowing how the fume hood is being used (open or closed), the safety features of the fume hood may be assumed. Conversely, the fume hood open area also indicates how actively they are being used. In essence, by monitoring both the fume hood open area and exhaust flow rate, significant insight may be gained regarding characteristics of the fume hood's activity, safety, and use.

\subsection{Load Management}

\section{Energy Efficiency and Load Management}

Load management can have significant impacts on a laboratory's energy efficiency. The greatest efficiency and economic impact can result from evaluation of the timing of the laboratory's peak process load. New considerations are being given to managing a facility's load by controlling the ventilation rate on demand. Researchers who use a laboratory must also be made to realize that their impact on energy consumption is the "final word" on how well an expensive and sophisticated HVAC system will perform. 


\subsubsection{Peak load identification}

During the conceptual design of the LBNL Human Genome Research Facility, a detailed analysis was made of the laboratory's operation and its numerous pieces of laboratory process equipment. This effort yielded surprising energy-efficiency increases that not only contributed to the selection of the HVAC system but will also reduce operating costs by at least 50 percent compared to standard design practices.

LBNL's simple evaluation procedure included interviewing the principal facility researcher to tally: the number and type of equipment and its total energy use at full load; the percentage of capacity at which each device would perform, for how long, and at what time of the day; whether the device could be operated during a different time period; how much of the dissipated heat could be rejected to outside the laboratory space; and an estimate of future additions of equipment.

Even though the researcher was trying to be energy aware in the choice of equipment, the profile of use that was generated from the survey indicated that peak energy consumption would occur between 4 and 5 p.m., exactly during the day's highest peak demand charge period. When the researcher learned this, the peak was shaved by rescheduling some automatic equipment to operate during the early morning hours of the day. Flattening the peak in turn influenced the choice of a central HVAC system for the facility.

\subsubsection{Demand-controlled ventilation}

During periods of nonoccupancy or low level of process activity in research laboratory or cleanroom facilities, recirculation ventilation rates can be reduced. Sensors can monitor and control ventilation rates, meeting occupant safety and process requirements and minimizing energy consumption. [De Almeida, 1995]

Demand-controlled ventilation can limit the amount of outside air admitted into cleanrooms when exterior pollutants, e.g. volatile organic compounds (VOCs), would harm the research in progress. This limit also results in space cooling/heating energy savings. [De Almeida, 1995]

Typically when laboratory or cleanroom facilities are not occupied, pollutants are generated at a small rate. During these periods, exhaust air may be reduced to $25-50$ percent of daytime rate. [De Almeida, 1995]

\subsubsection{1 $\mathrm{CO}_{2}$ sensors}

Houghton (1995) describes the use of $\mathrm{CO}_{2}$ sensors in Demand Controlled Ventilation (DCV):

Perhaps the most significant limitation of controlled ventilation (CV) is that using $\mathrm{CO}_{2}$ sensors to indicate or control ventilation rate (the most common approach) does not alone guarantee good indoor air quality (IAQ). Ventilation control based on $\mathrm{CO}_{2}$ levels is an important tool that can help control occupant-related pollutants and satisfy occupant-based ventilation standards. However, a thorough IAQ strategy also should involve a complete audit of potential pollutant sources in the building, such as vapors from copiers and cleaning solutions. Ventilation control based on $\mathrm{CO}_{2}$ levels may do nothing to control these pollution sources. Measurement of volatile organic compounds (VOCs) with a VOC sensor can help complete the IAQ picture, but these sensors have significant limitations.

The most common application of Demand Controlled Ventilation (DCV) involves measurement of indoor air for $\mathrm{CO}_{2}$ concentration, which is typically less than 1,000 PPM in properly ventilated buildings. The level of $\mathrm{CO}_{2}$ is a good indicator of the per-person ventilation rate, since its 
presence depends on the number of people in a space and the rate at which the air in the space is being diluted with outdoor air.

\subsubsection{Particle counters}

Faulkner (1995) describes the results of a study using a particle counter in a cleanroom.

Data acquisition using a new particle counter is complete. A new control scheme was tried that proportionally increased the fan speeds based upon the magnitude of measured particle concentrations. The previous control scheme always increas[ed] the fan speeds by $10 \%$ whenever the particle concentration was above a set limit. The new control routine increased fan speeds by more than $10 \%$ in proportion to the amount that the particle concentration was beyond the limit. Thus if the particle concentration was just beyond the limit, then the fan speeds would be increased by $10 \%$. Whereas if the particle concentration was far above the limit, then the fan speeds would be increased by 30 to $40 \%$.

The energy savings with the new control routine are ... $60 \%$ savings ... This energy savings of $60 \%$ may be the maximum possible for our cleanroom, particle counter, data acquisition and control system. With the control schemes that we have tried, the particle concentration in the cleanroom has gone outside Class 100 criteria occasionally. Usually the particle concentration is outside Class 100 status for one minute or less and will occur 3-7 times per day. We are not sure if this will be viewed as a problem for industry cleanroom users. We have had no complaints from users.

\subsubsection{Other gas sensors}

De Almeida (1995) points out that:

Chemical gas sensors can be supplied as mixed gas sensors and specific sensors. Mixed gas sensors are sensitive to a combination of volatile organic compounds (VOCs). In contact with a hot semiconductor metal oxide (e.g. tin oxide) VOCs are oxidized, decreasing the resistance of the sensor. VOC sensors are inexpensive (typically in the range \$30-\$50) but their response is of qualitative-type and is not specific to a particular chemical, and their sensitivity is not adequate for all applications. Additionally, the sampling chamber needs to be flushed periodically with clean air in order to restore the zero.

\subsubsection{Nonlaboratory applications}

Houghton emphasizes the benefits of Demand Controlled Ventilation (DCV):

For many building operators, improving air quality by correcting under ventilation is the most important benefit of demand-controlled ventilation. But correcting over ventilation also can provide large energy savings-in some cases up to 80 percent of HVAC energy. DCV offers the greatest potential for energy savings on buildings with wide or unpredictable swings in occupancy such as auditoriums, cafeterias, theaters, retail stores, classrooms, and conference rooms. Potential energy savings from DCV depend on several factors, including:

- Baseline ventilation rate. Most buildings are set up to supply enough fresh air to satisfy the design occupancy whenever the building is occupied. (In practice, it is difficult to measure how well this is achieved.) Compared to this arrangement, DCV will reduce energy whenever actual occupancy is less than design occupancy-as long as outdoor air requires heating or cooling. If a building is under supplying outside air, a DCV system may actually increase 
energy use-but it will also bring the building into compliance with accepted practice, and do so more efficiently than a simple increase in the constant ventilation rate.

- Occupancy. Buildings with predictable near-design occupancy will save less energy from a DCV system than buildings with highly variable occupancy, or buildings which never reach design occupancy.

- Climate. Buildings in extreme heating or cooling climates will benefit most from DCV, while those in moderate climates where economizer operation is common will achieve relatively little benefit. However, it may be worthwhile to install $\mathrm{CO}_{2}$ sensors in buildings in moderate climates to document ventilation performance.

- Control setpoint. Building operators can choose to keep indoor $\mathrm{CO}_{2}$ concentrations very close to the 1,000 parts per million (PPM) target referenced in ASHRAE Standard 62-1989, or use a lower setpoint, such as 700 PPM, to intentionally provide more outside air per person. Lower setpoints will yield less energy savings than higher setpoints, but may still save energy compared to constant ventilation.

\subsubsection{User energy practices}

Current OSHA regulations for laboratories address fume hood safety and mandate a comprehensive training program for laboratory personnel. These training sessions can help increase the energy-efficient use of laboratory fume hoods as well. However, proper techniques often do not get emphasized after initial training classes at many labs. Periodic refresher courses can have a positive influence on the continuing energy-efficient performance of fume hoods; users should be trained to ask themselves the following questions:

- Is the vertical sash closed to a point below the operator's shoulders when the hood is in use?

- Is the horizontal sash partially closed to obtain the smallest possible opening?

- Is the front plane of the hood influenced by cross drafts or traffic flow? [Saunders, 1993]

Attention to these three questions helps insure that the sophisticated HVAC system achieves its energyefficiency potential.

\section{REFERENCES}

Andrews, J.W., Ph.D.; M. Piraino, and J. Strasser, "Laboratory Testing of Control Strategies to Reduce Peak Air-Conditioning Loads." ASHRAE Technical Data Bulletin, Vol. 9, No. 1, Optimal Control Strategies,1993:33-43.

Barkley, W. E., "Issues in laboratory ventilation for hazard control." Proceedings of the Symposium on Laboratory Ventilation Hazard Control, Frederick, MD. 1976.

Cooper, E. Crawley. Laboratory Design Handbook. ISBN 0-8493-8996-8. Boca Raton, FL: CRC Press, 1994.

Crane, J.T. "Biological Laboratory Ventilation and Architectural and Mechanical Implications of Biological Safety Cabinet Selection, Location, and Venting." ASHRAE Technical Data Bulletin, Vol. 10, No. 1, 1994. 
De Almeida, Anibal T. "Demand Controlled Ventilation in Lab-Type Facilities." Personal Correspondence, 1995.

Doyle, D.L., P.E., R.D. Benzuly, P.E., and J.M. O'Brien, P.E. "Variable-Air-Volume Retrofit of an Industrial Research Laboratory." ASHRAE Transactions: Symposia, 1993.

Erbs, D., et al. "Estimation of degree-days and ambient temperature bin data from monthly-average temperatures." ASHRAE Journal. Atlanta, GA. Vol. 25, No. 6, 1983.

Faulkner, David. "Quarterly Report for Energy Management in Cleanrooms Expanded Scope (CIEE Account 8853-01, Project \# BG-94-201(00)." Personal Correspondence, October 1995.

Handbook of Facilities Planning, Vol. One Laboratory Facilities. ISBN 0-442-31852-9. Ruys, Theodorus, AIA, ed. New York: Van Nostrand Reinhold, 1990.

Hayner, Anne M. "Laboratory Design, NIH Project Focuses on Lab Safety." Engineered Systems, September 1995.

Hitchings, Dale T., P.E., Richard S. Shull, P.E. "Measuring and Calculating Laboratory Exhaust Diversity-Three Case Studies." ASHRAE Transactions, Laboratory HVAC, 1993.

Houghton, David, P.E. “Demand-Controlled Ventilation Teaching Buildings to Breathe." E-Source, Inc., Tech Update, 1995.

Kruse, Robert K., P.E. "Mechanical System Strategies for Energy Efficiency." Cleanroom Technology Forum Proceedings, 1991.

Laboratory Control and Safety Solutions Application Guide - Rev. 2. Buffalo Grove, IL: Landis and Gyr Powers, Inc., 1994.

Lacey, Randall D., P.E. "Selecting mechanical systems for laboratory buildings." ASHRAE Journal, November 1993.

Lentz, M.S., P.E and A.K. Smith, P.E. "A Procedure for Modeling Diversity in Laboratory VAV Systems." ASHRAE Transactions, V. 95, Part 1, Laboratory HVAC, 1989.

Lyons, D.K., B.H. Atkinson, and J. Kasica. "Mechanical Systems," Handbook of Facilities Planning, Vol. One Laboratory Facilities. ISBN 0-442-31852-9. Ruys, Theodorus, AIA, ed. New York: Van Nostrand Reinhold, 1990.Matson, S. "Life Cycle Costs," Handbook of Facilities Planning, Vol. One, Laboratory Facilities. ISBN 0-442-31852-9. Ruys, Theodorus, AIA, ed. New York: Van Nostrand Reinhold, 1990.

McDiamid, M.D., P.E. "A Quantitative Evaluation of Air Distribution in Full-Scale Mock-Ups of Animal Holding Rooms." ASHRAE Transactions, V. 95, Part 1, Laboratory HVAC, 1988.

"Minimizing Life-Cycle Costs-and First Costs-of New Building Systems." Ideas Reader Service Card, 1994.

Nelson, N. "Chapter 6 - Energy Conservation," Handbook of Facilities Planning, Vol. One, Laboratory Facilities. ISBN 0-442-31852-9. Ruys, Theodorus, AIA, ed. New York: Van Nostrand Reinhold, 1990.Parker, J. A., O. Ahmed, and K.A. Barker. "Application of Building Automation System (BAS) in Evaluating Diversity and Other Characteristics of a VAV Laboratory." ASHRAE Transactions, V. 99, Pt. 2, July 1993. 
Patel, Bill, Jerry Greiner, and Tom R. Huffman. "Constructing a High-Performance, Energy-Efficient Cleanroom." Microcontamination, February 1991.

Patel, Bill, Jerry Greiner, Tom Huffman, and Les Grant. "Designing a High Performance, Low Energy Cost Cleanroom A Case Study." Cleanrooms '91 Proceedings, 1991.

Patel, Bill, Jerry Greiner, Tom R. Huffman. "High Performance, Low Energy Cost Cleanroom: A Case Study." Microcontamination Conference Proceedings, 1991.

Pike, R. M., "Laboratory-associated infections: Summary and analysis of 3,291 cases." Health Laboratory Science, No. 13, 1976.

Rabiah, Talal M. and James W. Welkenbach. "Determining Fume Hood Diversity Factors." ASHRAE Transactions, Laboratory HVAC, 1993.

Saunders, G. Thomas. Laboratory Fume Hoods - A User's Manual. ISBN 0-471-56935. New York, NY: John Wiley \& Sons, Inc., 1993.

Schicht, H.H. "Chapter 6 - Cost-Efficiency and Energy-saving Concepts for Cleanrooms." Cleanroom Design. Whyte, W., ed., Chichester, England: John Wiley \& Sons, Ltd., 1991.

Steere, Norman V. "Managing Laboratory Hazards by Design," Handbook of Facilities Planning, Vol. One, Laboratory Facilities. ISBN 0-442-31852-9. Ruys, Theodorus, AIA, ed. New York: Van Nostrand Reinhold, 1990.

Varley, John O., PE. "Measuring Fume Hood Diversity in an Industrial Laboratory." ASHRAE Transactions, V. 99, Part 2, Laboratory HVAC, 1993.

Zhang, Y., Ph.D., L.L. Christianson, Ph.D., P.E., G.L. Riskowski, Ph.D., B. Zhang, G. Taylor, Ph.D., D.V.M., H.W. Gonyou, Ph.D., P.C. Harrison, Ph.D. "A Survey of Laboratory Rat Environments." ASHRAE Transactions: Symposia, 1992. 


\title{
4. DIRECT DIGITAL CONTROL (DDC)
}

\author{
Abstract: Energy Efficiency and Direct Digital Control
}

The overall impact of a DDC system upon the energy efficiency of a research laboratory is considerable and includes a broad range of positive benefits. Some impacts have a direct energy influence, e.g., precise temperature control, while others have indirect energy consequences, e.g., consumption reporting. While the structure/architecture of the DDC system is very important, the operator interface, called the Person/Machine Interface (PMI), should be given much greater consideration by the energy engineer. There are particular advantages that the distributed DDC system has over a pneumatic system and individual controllers. The building of a comprehensive sequence of operations is the first step in the implementation of the laboratory Energy Monitoring and Control System (EMCS). Depending upon budget and scope constraints, a DDC system can provide the core of a growing, flexible system that can provide Total Laboratory Energy Management (TLEM) which is further described in Section 4.4, below. A highlighting of DDC advantages and benefits follows:

- Centralized User Interface

- Dynamic, Precise Facility Control

- Coordination of Facility Systems Operation

- Speed and Reliability from Computational Power

- Optimizing Facility Diversity

- Durability and Flexibility

- Troubleshooting/Easing of maintenance

- Trending and History Data Logging

- Customized Energy Reporting

\subsection{DDC Implementation}

\section{Energy Efficiency and DDC Implementation}

When a DDC system is used to control a building at a facility site, it is typically referred to as a "Building Automation System" (BAS). When used to control a group of buildings at a site, it may be more accurately called an "Energy Monitoring and Control System" (EMCS) or an "Energy Management System" (EMS). BAS, EMCS, and EMS are terms used interchangeably but each refers to DDC systems that incorporate integrated hardware and software designed to: perform data acquisition, monitor alarms, provide exception reporting, automate controls, and produce historical records of the buildings or the site.

Once an EMCS is in place, multiple tasks can be accomplished with a degree of accuracy and speed that makes operations optimally cost effective. Aside from maintaining zone comfort in the laboratory, the EMCS can access the system locally (for each building) and centrally (for the entire site) at the same time, to monitor local and remote alarm systems, and provide graphical system displays, graphical analyses, and energy-use summary reports customized to the facility's operations. In addition, the EMCS helps insure the operation of the laboratory's HVAC system, which must safeguard the health and well-being of laboratory personnel as well as sensitive and costly equipment and experiments housed in the laboratory. Assuring that there is no leakage of contaminants into adjacent areas, for example, is a key concern in any working laboratory. The EMCS can evaluate the energy characteristics of the HVAC system and validate that cost reductions are, in fact, being achieved. [Barker et al., 1993] 
One of the underutilized benefits of an EMCS is the ability to evaluate the energy characteristics of a laboratory's HVAC system. Energy cost reduction is an important factor in the selection of VAV system for research laboratories. Simulations performed by Neuman and Rosseau (1990) demonstrated the energy savings benefits of the VAV labs. An evaluation and verification method is necessary to ensure that a VAV system is actually providing operational cost savings. [Barker et al., 1993]

\subsubsection{EMCS acceptance}

Despite the advantages listed in Section 4.0 above, the laboratory industry has been slow to recognize the power and utility of EMCSs. Design engineers do not always specify what variables need to be monitored and how to extract and analyze the data in a sequence of operation. Frequently the EMCS is underutilized since the facilities personnel often do not understand the implementation of the control and usefulness of the monitoring. Unfortunately some control companies do not adequately demonstrate the performance benefits of their EMCS. [Barker et al., 1993]

\subsubsection{Control industry}

The dramatic developments in computer power have brought a revolution to the control industry. The microprocessor and communication technologies developed during the past 20 years have enabled DDC systems to become a reality. Earlier, conventional pneumatic and electrical signals performed the control process with a complex network of hardware that was cumbersome in its application. Most importantly, it could not support the sophisticated control sequences required for safe, efficient research laboratories. As discussed below in Section 4.2.1, DDC technology has many advantages for laboratory environments over conventional control systems. [Ruys, 1990]

\subsubsection{An EMCS alternative}

An alternative to an EMCS in a laboratory is a stand-alone programmable logic controller (PLC). Like the EMCS the $P L C$ is a microprocessor-based device that does not depend on a central computer processor. Some VAV terminal box and fume hood control manufacturers offer an integrated package of sensors, controller, and operator. These systems can communicate with a central EMCS. With proper installation, operation and maintenance costs and complexities associated with redundant monitoring systems can be eliminated. [Ruys, 1990]

\subsubsection{EMCS Pyramid structure}

The levels of control offered by an EMCS can be viewed in a pyramid fashion with a "user" at the top of the pyramid and the "device" at the bottom of the pyramid. A presentation and description of this structure follows.

\subsubsection{User}

The User is the person in the conditioned space who actually benefits from or uses the systems in a facility. The User has the particular requirements for the facility in mind, e.g., zone air temperature required, when ventilation must occur, etc.

\subsubsection{Analyst}

The Analyst is concerned with the performance and safety of EMCS operation. Typically Analysts use the EMCS in a responsive mode, asking, for example, how much did the electricity for the animal laboratory cost? The Analyst's 
interest is larger than the User's; typically the Analyst monitors a whole building or a research division. Comparative analyses can identify inefficiencies in system operation.

\subsubsection{Operator}

System operators are concerned with an even larger scale than Analysts. Their interest is site-wide, and they use the EMCS in a proactive mode, including adjusting set point temperatures, responding to alarms and trouble calls, and performing preventative maintenance. The efficient function of the Operators is extremely important to the successful daily operation of the entire facility.

\subsubsection{Manager}

System Managers are involved with the fundamental organization and structuring of EMCS elements that feed information to higher levels of the pyramid and that perform lower level routines and logic. Managers' tasks to support higher level needs include, creating point groups and schematics that are important to the Operators, building the routines that will produce reports for the Analyst, and entering initial set points that satisfy the Users. Lower level tasks in the pyramid include translating the sequence of operation into DDC blocks, verifying the function of the devices during system commissioning, and insuring the stability of the EMCS software and hardware. The impacts of the Managers ripple throughout the EMCS.

\subsubsection{Control logic}

The control logic, once in place, dictates the efficacy of the EMCS. The impact of this control is obvious and readily lends itself to optimization. Optimizing opportunities include but are not limited to: device/system start/stops, temperature resets, temperature setbacks, operation schedules, and control loop tuning.

\subsubsection{Devices}

The physical interface with every system starts with the input/output $(I / O)$ device. This is the fundamental control level; optimization of devices begins with the comprehensive design and specification of the EMCS. Simplified installation, ease of calibration/adjustment, streamlining of commissioning, uncomplicated verification of operation, steadfast reliability, and unswerving repeatability will all contribute to the optimization of the EMCS.

\subsubsection{Person/Machine Interface}

In this computer age, the term "user friendly" has been coined with a particular set of connotations, including streamlined program access and a forgiving, helpful computer environment. "User friendliness" is critical to an EMCS's efficient, optimized application. The energy engineer should be aware of the long term, consequential impact the EMCS will have upon the facility and aware that the representation displayed on the computer screen will be THE EMCS for all personnel. Therefore, this Person-Machine Interface (PMI) ${ }^{1}$ is the most critical element of the day-to-day long-term use of the EMCS. The energy engineer needs to carefully consider the presentation, features, and "user friendliness" of the PMI software.

${ }^{1}$ The expression Person-Machine Interface is more commonly referred to in the controls industry as a Man-Machine Interface (MMI). 


\subsubsection{PMI software}

The EMCS person-machine interface (PMI) software is the major influence in complex situations such as the handling of trouble calls and alarms reported by the EMCS. These calls are a complicated mix of: the type of callalarm, its criticality, the individual required to respond, the time of day, and the trouble-shooting ability of the respondent. The comfort level that the respondent to the call feels toward the EMCS's PMI is the major variable in the response to alarms and trouble calls. The "User friendly" features to consider for the PMI include:

- Graphical User Interface,

- Schematic and "Picture" representations,

- Help Features,

- Screen Function and Prioritization,

- Software Main Menu Structure,

- Multiple Levels of EMCS Jurisdictions and Clearances,

- Method to Standardize Point Descriptions and Formats, and

- Scheduling/Programming and Report Features.

\subsubsection{EMCS coordinator}

Although the energy engineer may not have a great deal of influence over the staffing of a facility, the staffing of a dedicated EMCS Coordinator is recommended. This person would be responsible for:

- Training all personnel using the EMCS software,

- Providing Information and Help Screen Development,

- Conducting "User Group" meetings on a regular basis for operators and managers,

- Serving as liaison to the User, Analyst, and Operator for information and report creation,

- Providing Point Group Organization,

- Plotting Trend,

- Using and Archiving Historical Data,

- Generating Report,

- Reviewing, testing, evaluating, and optimizing all control logic,

- Providing Supervisory Control Strategies,

- Providing Control Loop Tuning,

- Providing Optimal Start/Stop Routines,

- Providing Boiler/Chiller Temperature Reset Schedules,

- Providing Economizer Operational Routines,

- Creating all building system schematics with real-time information,

- Creating Quick Sketches and Diagrams vs. Detailed Graphics, and

- Maintaining the LAN, host, and client workstations. 


\subsubsection{Monitoring considerations}

Among the major factors that should be monitored by the EMCS, temperature and ventilation are the most important. Temperature inputs are usually an analog signal from platinum RTD elements or precision thermistors, depending upon cost and the accuracy required by the application. Laboratory ventilation is monitored either directly with flow sensors or indirectly, with pressure differential sensors in ductwork or between adjacent spaces, as well as current monitors on fan motors, to indicate motor failure. Humidity control can be important in a research laboratory environment. Humidification monitoring can be provided within the duct system or in various areas of the laboratory where the humidity ratio is critical. Monitoring of the differential pressure between the laboratory and the adjacent space is also important to provide laboratory isolation. Additionally, monitoring of particles and the external air sodium concentration is particularly important in research cleanrooms, as are sulfur oxide and nitrous oxide. The many details of sensor type and location must be decided with the mechanical engineer, operations and maintenance personnel, and the researcher. [Mcllvaine, 1992]

\subsubsection{Particle counters}

In research cleanrooms, multiple particle sensors should continuously monitor every critical location to provide an understanding of what is happening throughout the space. Laser particle counters and condensation nuclei counters are now being integrated into continuous monitoring systems. Sensor designers are being asked to improve the technology for measurement of ultrafine submicron particles, so periodic or infrequent bursts of contamination can be detected and this information supplied to the EMCS. There also may be the need to monitor air impurities other than particulates. Consideration should be given to monitoring sodium and other alkali metals, total hydrocarbons, and heavy metals. [Mcllvaine, 1992]

\subsubsection{Sensors}

Temperature sensors using RTDs should use platinum. Precision thermistors can obtain 0.1 degree $F$ accuracy. [Morris and Payne, 1989]

Humidity sensors using lithium chloride or fiber sensors to measure relative humidity are obsolete. Newer, ultrafast, polymer capacitance sensors using film technology are a better choice. These sensors read relative humidity with a $\pm 2 \%$ accuracy. They are highly accurate, repeatable, and stable with a negligible hysteresis. For accuracy of $\pm 1 \%$, a chilled mirror sensor is available. [Morris and Payne, 1989]

\subsubsection{Sensor location}

Proper location of sensors for local temperature, humidity, air pressure, and particulate counting is critical in a laboratory environment. Sensors' nature and placement should be considered in the laboratory design and construction, to avoid performance loss and damage. Temperature sensors can usually be installed in exposed locations. Humidity sensors, however, can be very sensitive to chemicals and should be protected from nomal sanitizing procedures. These sensors can be protected in the return air ductwork outside the room while still detecting room conditions accurately. [Mcllvaine, 1992]

Install sensors as close to the specific area of concern as possible. Several sensors per laboratory may be necessary so that "hot spots" can be identified and conditioned. Sensors should not be so isolated that they cannot be reached for maintenance. Pressure differential and particle sampling tubing should be routed to minimize lengths and bends and eliminate kinks. Tubing that projects into the room requires protection from damage. Particle tubing that is located on a continual purge manifold must be kept free of water and chemicals. [Mcllvaine, 1992; Morris and Payne, 1989] 


\title{
4.2 Direct Digital Control (DDC) Advantages
}

\author{
Energy Efficiency and DDC Advantages
}

DDC EMCSs replace conventional pneumatic or electromechanical HVAC control systems with equipment capable of performing not only control but energy management and system diagnostic functions in the environment of a centralized computer network. An EMCS accepts analog, discrete, and digital input from remote sensors and devices, processes the data, and then controls remote mechanical equipment. An EMCS inherently has more accurate control because it reduces the drift, maintenance and recalibration problems common with pneumatic control systems. Additionally, an EMCS can make all facilities function more efficiently when the gathered data are compiled into useful, pertinent reports. Quality control, production, research, and maintenance will all benefit from the increased information flow when it is properly managed. [Ruys, 1990]

Compared to conventional control systems, DDC offers the following advantages:

- Control Precision,

- Systems Coordination,

- Optimum Start,

- Diversity Analyses,

- Retrofit Identification,

- System Load Tracking,

- Monitoring and Maintenance Information,

- Trend Information and History data, and

- Energy Reporting.

\subsubsection{DDC vs. conventional pneumatic controls}

Sold-state sensors and controllers used in DDC systems have considerable energy-efficiency advantages over conventional pneumatic systems. Substantial advantages are realized in calibration and maintenance, but the critical value lies in the accuracy and reliability of the DDC systems. These features can yield operational energy savings of $15 \%$ and greater when compared to the conventional pneumatic system. The inherently precise positioning of valves and dampers with EMCS control loops and blocks are responsible for these energy savings. For instance, to realize the energy-savings opportunity offered by VAV fumehoods, an 8:1 turndown ratio of the exhaust air flow is required. Pneumatic airflow systems typically lose accuracy at $25 \%$ of their span, resulting in the capability of only a 4:1 turndown ratio. Solidstate DDC systems provide the degree of precise air-flow measurement and control that enables the operation of these VAV systems. [Ruys, 1990]

\subsubsection{Dynamic system response}

The use of programmable, computer-based, $D D C$ systems offers the potential for self tuning of controllers with optimized feedback loops that can provide a dynamic system response. The computational requirement of these analysis techniques precludes the use of pneumatic controllers. [Curtiss et al., 1993] 


\subsubsection{DDC system startup}

Conventional pneumatic control systems require that their settings be tuned manually during system startup. Expensive manpower is required to retune these pneumatic controllers and potential errors can occur in manual tuning, causing unsatisfactory system operation and energy waste. Retuning is often necessary when there are system modifications or changes in process conditions. DDC initial adjustments and tuning are performed remotely, and most return calls can be eliminated. [Ho, 1993]

\subsubsection{DDC and pneumatics combined}

$D D C$ systems can accurately modulate VAV boxes, control dampers, valves and other mechanical equipment with electronic operators. However, pneumatic operators are still used for certain components in air-handling systems. When a large amount of torque is required to position large air-handling unit dampers and control valves, costeffective, reliable electronic operators may not be available. Control air systems give the system designer the option of using the combined powerful control capabilities of a DDC system with inexpensive, reliably operating conventional pneumatic valve and damper control systems. [Ruys, 1990]

\subsubsection{DDC control integration}

Conventional pneumatic and electric control employs subsystems and components that traditionally operate without the coordination and sharing of information available with DDC systems. DDC systems integrate subsystems and components to work together, to share information, and to maximize energy efficiency of the environmental conditioning system. This integration of subsystems maximizes energy efficiency by reducing energy-wasting operating times and conflicting zone conditioning requirements. An integrated laboratory system also allows fume hood use and laboratory conditions to be monitored remotely or historically with the data compiled by the DDC system. Monitoring fume hood use helps indicate where and when energy is being wasted. [Mayhew, 1993; Barker et al., 1993]

\subsubsection{Optimum start}

A DDC system can provide daily building warm-up using temperature sensors in all building zones. $A$ calculation program (see Mayhew, 1993) is used to determine the optimum time to start warm-up, with significant differences from the pneumatic control method. The DDC software allows the operator/manager to gain instant, system-wide access and control from a single computer. [Mayhew, 1993; "Building Management System's Goal," 1992]

\subsubsection{Diversity analyses}

$D D C$ system integration provides a major opportunity to modify systemwide control sequences to take advantage of the part-load, diversity performance of the laboratory facility. Data collection and analyses in an integrated laboratory facility can result in both on-line and statistical diversity information. On-line diversity information can be used for identifying fume hood and laboratory characteristics on a continuous basis for real-time control sequence modifications. The statistical diversity data can be applied to future system designs. The potential impacts of system diversity performance are enormous. The DDC system architecture for a specific laboratory facility should be carefully investigated to meet data acquisition objectives. [Mayhew, 1993; Parker et al., date]

\subsubsection{Monitoring and maintenance}

To provide the desired environmental conditions, laboratories, cleanrooms, and environmental rooms require constant control of the following air-quality factors: temperature, humidity, ventilation and particle contamination. Specialized research and experiments impose tight restrictions on these factors. A DDC system is needed to determine an undesirable condition quickly and report with an alarm to the 
central operator/manager. Along with control functions, the DDC provides monitoring, alarm, and extensive data logging functions of the environmental conditioning system's supply, return, and mixed air temperatures; clogged filter alarms; fan "on" status, laboratory; and cleanroom isolation pressures; distributed hot- and chilled-water supply, return, and mixed temperatures. [Ruys, 1990; "Building Management System's Goal," 1992]

\section{- Energy Profiling}

The ability to monitor and collect data on laboratory HVAC operations provides a wealth of information for the facility operator concerned with energy management. A complete energy profile of a laboratory building can be a useful tool for facility personnel to understand building energy patterns and take necessary steps to further reduce energy use. For example, if fume hood operation accounts for $30 \%$ to $40 \%$ of the facility's total energy consumption profile, the retrofit of an energy recovery system could be investigated. Determination of energy consumption is a prerequisite for developing comprehensive energy efficiency retrofit strategies. [Barker et al., 1993]

\section{- Load Tracking}

Since it is not uncommon for lab space to undergo renovation in 15 percent of the space on average each year, the facilities management group would like such renovations to take place with minimum interruptions. Space renovations will either increase or decrease system load. The tracking of energy utilization will provide two pieces of important information: identifying the current trend of increased or decreased use of the environmental conditioning system and projecting the profile-of-use of the system into the future. [Parker et al., 1993]

\subsubsection{Graphical User Interface (GUI)}

Graphical video displays by PMI software provide information to facilitate monitoring and control functions with Graphical User Interface (GUI). The GUI can be customized and consists of a variety of depictions: flow diagrams of mechanical systems, room layouts, equipment location floor plans, and dynamic graphs showing the current relationship of various operating systems. These graphics are an excellent means of seeing up-to-date, on-line information. GUI displays also are helpful in viewing alarms, analyzing operational systems, training and, in some cases, verifying regulatory agency compliance. [Landis and Gyr, 1994]

\subsubsection{Combined monitoring application}

Animal room environmental conditions such as temperature, humidity, and air flow must be monitored for regulatory compliance. Additionally, environmental monitoring systems can be combined with automatic watering, trough flush systems, and access control system packages. Animal room systems have traditionally been stand-alone, microprocessor-based systems connected to a computer for historical log storage and central monitoring. These systems should be connected with the facility's EMCS because the EMCS typically monitors similar conditions, resulting in a redundant use of equipment. [Ruys, 1990]

\subsubsection{Reporting}

With EMCSs, monitoring of the facility's environmental conditions, and printed summary reports of alarm conditions will be available on demand and can be formatted to group these conditions according to facility management preferences, e.g., by time, area, or system(s). Additional presentations include dynamic graphs showing the relationships of various operating parameters over a period of time. These reports can be used to: fine-tune HVAC systems, troubleshoot system problems, determine preventative maintenance needs, train operators, and provide information relating to energy-efficiency needs. Laboratory energy reports can be developed to quantify the facility's energy use. The reports can also be 
used for charging the appropriate department or projects for their energy use, making them directly accountable. [Barker et al., 1993; Landis and Gyr, 1994]

\subsection{Sequence of Operation}

\section{Energy Efficiency and the Sequence of Operation}

The Sequence of Operation is the organizing narration of the facility's integrated EMCS functions that will determine the ability of the laboratory to perform in an energy-efficient manner. The importance of describing the function of the laboratory facility's environmental systems with detailed, comprehensive control strategies cannot be overemphasized. Topics that affect energy efficiency and should be addressed by the sequence of operation control strategies include:

- systems and equipment controlled;

- system initiation;

- modes of operation, cooling heating, ventilation;

- occupied periods;

- unoccupied periods;

- set points for temperature, pressure, humidity;

- set-back routines;

- optimal starts;

- time limited control of equipment;

- override sequences;

- alarm point ranges; and

- control vs. monitoring point descriptions.

\subsubsection{Facility control sequences}

Typically, DDC system control sequences are structured as if conventional pneumatic controls were operating the systems. In these cases, DDC technology is not being used to its greatest advantage. Standard control functions that use open-loop logic, i.e., without feedback to related systems, and indirect control logic, are inappropriate in DDC system control sequences, which require closed-loop control logic to assure feedback to related systems. Comprehensive sequencing of controls provides the facility with the greatest comfort possible at the lowest possible energy consumption by taking advantage of diversity and precisely coordinated system interactions. Closing open and indirect control loops also manages any potential energy waste resulting from overdesign. [Mayhew, 1993]

\subsubsection{Sequence implementation}

The facility's sequence of operation is implemented through PMI software program. The EMCS programmer's task is to translate the sequence of operations stipulated by the energy engineer into the control logic language of the PMI software program using control blocks. These DDC blocks are tested to verify functionality and should be revisited to ensure optimization, especially in the case of proportional-integral-derivative (PID) control blocks which operate VFDs, valves, and dampers. Tuning the control blocks to attain their optimized function is an art. Time, perseverance, and a full understanding of each building system are mandatory to optimize control blocks. 


\subsubsection{Control block algorithms}

Algorithms used in control blocks combine three types of control calculations: proportional, integral, and derivative. Error signals are based on the difference between the controlled medium and a desired set point; the error signal integrated (or summed) with time (yielding an "amount of error") is the driving force in integral control systems, and the derivative of the error signal by time (yielding a "rate of control") is the driving force in derivative control systems. Ruys (1990) describes these control calculations:

\section{- Proportional control}

Proportional control signals vary linearly with the error signals. Proportional, or $P$, control is a simple and effective control technique. Valve or damper position, the output of the controller, is proportional to the error signal. In order for the operator to maintain a required position, a nonzero error signal may be necessary. Unfortunately, $P$ controls are unable to maintain an exact setpoint. $P$ Systems are designed to maintain a control point within a given range. The location of the range is specified by the setpoint; the width of the range is called the "throttling range." Another term used by some vendors is "offset"-the difference between the control point and the setpoint.

Throttling range is a form of proportional gain. If a selected throttling range is too small, the gain is too large and the controller overreacts, resulting in a form of instability known as "hunting." The valve or damper continuously overshoots between open and closed when the controller responds faster than the medium.

- Proportional Integral

Proportional integral, or Pl, control is becoming more popular [due to DDC technology] because of the ability to maintain an exact setpoint. Cost and complexity, the major disadvantages of pneumatically performed integration, have been eliminated with DDC technology. Computational methods simplify integration, using an approximation based on repetitive calculation. The more frequent the calculation, the more precise the approximation. The amount of precision is determined by the sampling time between calculations, which is selected to be as small as possible.

The integral signal is simply a total of $P$ calculations multiplied by sampling time. The valve or damper continues to change position unless offset and successive $P$ calculations equal zero. $P I$ control calculates an initial position based on the error signal. Successive calculations are based on previous offsets. These combined calculations continue to refine the operator's position until the offset equals zero.

\section{- Proportional Integral Derivative (PID) control}

PID control combines a PI control signal with derivative (D) control, $D$ control is also referred to as "rate control"; the controller responds to reduce the rate of change. Most thermal systems have a small rate of change. Space temperature, return air temperature and mixed air temperatures change very slowly and require nothing to reduce their rates. Discharge air temperature should change quickly when needed and does not benefit from $D$ control.

On the other hand, a static pressure system changes very quickly. A cleanroom begins to depressurize immediately if a door is opened or a fumehood is started. A D controller monitoring this static pressure will respond immediately, while the $P$ control signal changes slowly after a noticeable change in the static pressure is detected; I control is the slowest of all The $D$ constituent is most significant in the initial seconds after a disturbance in order to speed up the controller's response. 
When safety depends on the control systems of a laboratory environment, PID control will eliminate the dangers caused by a slow response. In these critical applications, the control system must be designed carefully. Because PID utilizes three dimensions of control, these systems have three times the potential to become unstable. A control loop consists of many components, and each of the following must be carefully selected for response, accuracy and reliability: sensors, sensor locations, transmitters, controllers, transducers, transmission media (particularly pneumatic tubing) and orators. Additionally, the precision of the controller, as measured by the sampling time, must be evaluated to ensure a fast, stable system.

\subsubsection{Tuning aids}

The derivative term has little effect upon thermal system control sequences but can increase the system's effective damping, and, consequently, the stability of thermal control systems. Self-tuning software has been developed to provide "adaptive" control algorithms. These algorithms automatically vary the PI and $D$ gains as required to control a system or process. [Ho, 1993]

\subsubsection{Pressure isolation}

Systems designed to control laboratory static pressure differential to maintain isolation gradients between clean and "dirty" or safe and hazardous areas, require sophisticated, automatic DDC systems. As noted above, laboratory static differential pressure is highly volatile. These pressure control systems must respond quickly to even small disturbances such as those caused by an opened door. PID control is particularly well suited to this application (see above). [Ho, 1993]

\subsubsection{Control strategy overview}

Energy and mechanical engineers must understand the EMCS at its most fundamental level to develop adequate control strategies for energy-efficient operation of the facility. They must appreciate the limits of the microprocessors, sensors, transducers, controllers, and, most importantly, the PMI control logic software. Without a working knowledge of the EMCS, the energy engineer cannot develop an optimal control system responsive to specific laboratory uses. [Morris and Payne, 1989]

Control strategies that focus on environmental conditioning features aimed at assuring energy-efficient operation of a laboratory involve:

- Global zone control,

- Air-handling unit control,

- Economizer operational routines,

- Occupancy-based controls,

- Historical data use and achiving,

- Peak electrical demand control,

- Optimal start/stop routines,

- Boiler/chiller temperature reset schedules, and

- Supervisory control strategies 


\subsubsection{Global zone control}

Zone temperature set points can be shifted up in warm days and down on cold days with global control of the zones to reduce laboratory energy use. Setpoints can be returned to their original states at the site or even through a telephone or internet interface. Set-back temperatures at the end of every occupied period will allow reduced chiller or fan energy. The EMCS can provide occupants with control over their zone set points, but the range of set point adjustment can be limited to reduce the impact on feedback systems. [Mayhew, 1993]

\subsubsection{Air-handling unit control}

The air-handling equipment must be controlled as a system and not as a series of conventional open-loop controllers tuned to individual set points. The preheat, pre-cool, and main heating and cooling coils must work in conjunction with humidifiers and zone heating/cooling coils to provide energy-efficient results. [Morris and Payne, 1989]

\subsubsection{Economizer operational routines}

DDC can provide more accurate control of economizers and can verify operation conveniently with temperature and damper position checks. The application of a remote economizer override, using a comparison between return air dry bulb or enthalpy, can then be employed if necessary. [Mayhew, 1993]

\subsubsection{Occupancy-based controls}

One of the most effective energy savings opportunities not typically employed by conventional, discrete component control systems is some form of occupancy control strategy. Energy-efficient lighting control of buildings includes infrared/ultrasonic occupancy devices. The potential savings in a VAV system includes both fan energy and chiller energy. With DDC at the zone level, two opportunities to implement occupancy-based control systems become apparent: [Mayhew, 1993]

The first opportunity is when a laboratory is sensed to be unoccupied during a normally occupied period, typically during the day between the hours of 7:00 am and 6:00 p.m. Estimates are that there is a 10\% to $20 \%$ vacancy factor in most occupancies during the work day. An interface between the lighting occupancy sensors and the zone temperature set point can make a significant contribution to energy efficiency. In this temporarily unoccupied zone, the temperature set point range can be broadened slightly to allow the zone temperature to "float," subject to the nature of the work performed in the laboratory. The set point range would then be returned to the normal tolerance range where the zone becomes occupied. [Mayhew, 1993]

The second opportunity for energy savings using occupancy control is when a facility is unoccupied outside the normal work day - during the evenings, weekends, and holidays. Subject to safety and researcher review, these unoccupied periods present interesting, and sometimes controversial, energysavings opportunities. Control strategies include set-back schedules to reduce fume hood face velocity, room air change rate, and temperature set point. Push-button overrides that give a predetermined number of hours or minutes of override allow occupants to restore normal air flows and temperatures. Access by a telephone override system provides an additional degree of flexibility, because this enables occupants to initiate an override in advance before they arrive at the building. The facility manager can receive printouts of override activity to analyze after-hours activities and see if there is a need to adjust control strategies. 


\subsubsection{Peak electrical demand control}

A control strategy to reduce peak electrical demand in laboratory buildings should be evaluated and tested. The local utility rate structure requires evaluation to identify cost incentives that a peak reduction control strategy can capitalize upon. The testing of the control strategy can be complicated because of to the numerous variables of space use, climate fluctuations, and system efficiencies. The following test simulation, described by Andrews et al. (1993), is presented as an example of the energy saving potential:

A test chamber designed to simulate the thermal response of a house was used in the experiment. The control strategy involved pre-cooling the house before the onset of the peak and then controlling on humidity rather than temperature during the peak. A variant of the strategy substituted low setpoint temperature and a limit on fractional ontime during the peak. Using this variant, the maximum on-peak demand was reduced by $35 \%$ while maintaining acceptable thermal comfort. Overall energy consumption was increased by $12 \%$; means for eliminating this excess consumption are suggested for further evaluation.

An alternative control strategy was found to provide a more reliable reduction of the maximum on-peak demand. This strategy was termed time-limited control, or TLC.

In this variant, an upper limit is imposed on the fractional on-time of the air conditioner during any 15 -minute period during the peak. The setpoint is left at $72^{\circ} \mathrm{F}\left(22.2^{\circ} \mathrm{C}\right)$. Early in the peak period, the air conditioner will do its best to maintain the temperature at this value, as long as its on-time does not exceed the present limit. As the peak progresses and the cooling load increases, there will come a time when it is no longer able to maintain the setpoint temperature, and the room will begin to get warmer. The effect of the pre-cooling in this case will be to give the room a "head start" so that the maximum temperature will not be as high as it would have been had the process been started with the room at a higher temperature." [Andrews et al., 1993]

\subsection{Total Laboratory Energy Management (TLEM)}

\section{Energy Efficiency and TLEM}

An approach to laboratory energy monitoring and control is suggested which is called "Total Laboratory Energy Management" (TLEM). TLEM incorporates advanced features and enhancements to control systems with the long-range objective of managing energy use for the life of the laboratory facility. A TLEM approach includes maximizing the power of computers to evaluate all interacting variables that affect the laboratory's energy consumption. A variety of enhancements and evaluation tools have become available to expand and extend the EMCS's power to improve the facility's function and energy efficiency. An energy engineer will need to consider the ability of the PMI software program to take advantage of the latest tools and techniques. Some of the analyses and enhancements evaluation tools make possible with available "desk top" computers include:

- PID loop tuners,

- DDC program simulation,

- Feed-forward peak load management,

- External maintenance program interfacing,

- Touch screen interface,

- Real-time energy evaluations, 
- Enthalpy stabilization,

- Multivariable control strategies,

- Dynamic interfacing with energy calculation programs,

- Fuzzy logic, and

- Artificial neural networks.

\subsubsection{EMCS enhancements}

- PID loop tuners, available from third-party vendors, can be added to an existing EMCS. Their energy efficiency benefit is readily apparent because a control strategy that is not optimized wastes energy by over- and under-shooting space and process set points.

- DDC program simulation is a more difficult evaluation to perform, largely because a computational model of the laboratory's space or process is often required to complete the control block simulation. Logic conflicts and initiation sequences are more easily simulated. The PMI software program vendor will provide these capabilities rather than a third-party vendor.

- Feed-forward peak load management can be performed with most existing EMCSs as long as adequate sensors are installed. The local utility rate structure directly determines whether the extra cost involved in installing the appropriate sensors for this energy-efficiency measure is worth it.

- The ability of the EMCS to reference and provide information to external maintenance programs saves energy that can result from deteriorating system performance; the EMCS can initiate a request to perform maintenance to restore a particular system's efficiency. Preventative maintenance scheduling is an area of information to be shared with the EMCS; values and alarms can be tracked and trended to validate these schedules. Evaluations based on run-times can also be performed and can easily add up hours of equipment operation.

- The incorporation of a Touch Screen Interface may, at first, seem to have no impact upon energy efficiency. It has been shown, however, that a user's comfort with an EMCS leads to competence and speed, and allows system operators to maintain the EMCS's peak efficiency. A touchsensitive screen has been shown to increase the user-friendliness of the PMI.

\subsubsection{Real-time energy evaluations}

As facility operators become comfortable with the EMCS, interest in real-time energy evaluations increases. The availability and arrangement of information provided with real-time energy evaluations should be considered during the design process when budget constraints are being discussed. Tracking and trending energy usage of chillers and boilers is typically the first real-time energy evaluation performed. These evaluations provide useful input to feed-forward peak demand control strategies.

\subsubsection{Enthalpy stabilization}

A TLEM temperature control strategy that responds to rapid changes in the supply air volume and temperature rather than waiting for a response from the room temperature sensor is an example of a real-time energy evaluation. Enthalpy Stabilization is a control strategy that considers supply volumetric flow as well as supply air temperature.

Consider a laboratory with changing exhaust volume because of fume hood operation. To compensate for increased exhaust volume, the supply air volume will change, but the supply air enthalpy must not change. The supply air 
temperature must be adjusted to stabilize the enthalpy of the increased supply air flow and not overheat (or overcool) the laboratory unnecessarily because the room temperature sensor and its assigned PI control strategy are inherently slow to react (see above).

Under normal, stable laboratory operating conditions, the EMCS enthalpy stabilization control strategy determines the enthalpy of the supply and exhaust air flows. The EMCS then calculates the heat gain (or loss) of the laboratory by using the difference between the enthalpy of these two air flows. When a large change (i.e. 20 percent or more) in the supply air flow occurs, an enthalpy stabilization control strategy adjusts the heating (or cooling) coil's temperature control valve to provide the laboratory with the required enthalpy calculated during normal, stable laboratory operating conditions. [DeLuga, 1995; Landis and Gyr, 1994]

\subsubsection{Multivariable control strategies}

Multivariable control strategies consider the energy implications of air-flow enthalpy in a larger context than the real-time, stabilization context noted above. The question is posed in a cooling mode for equivalent enthalpies: Is it more energy-efficient to provide more air-flow volume at a higher temperature or less air-flow volume at a lower temperature? Multivariable control strategies optimize energy usage by the chiller system versus energy usage by the air handler/fan system.

\subsubsection{Multivariable control-case study}

An excerpt from a research paper is presented to demonstrate the degree of sophistication required in the control programming, sensor installation, and cost optimization routines [MacArthur and Foslien, 1993]:

\section{- Variable Identification and Function}

In the optimized [Multivariable Control] strategy, [fan] cfm is the primary manipulated variable and [chiller VFD] rpm is the free variable. The setpoint change is handled primarily by increasing [fan] $\mathrm{cfm}$. During this time the free variable is constrained to its lower limit [with the chiller VFD], 500 $\mathrm{rpm}$. At approximately 7 o'clock [am], the [chiller] rpm is no longer constrained and begins to increase to maintain optimal COP as the load increases. [Eventually] With the rapid increase in load [at about 12 noon], the [fan] crm is driven to its upper constraint. When this occurs, the [chiller] rpm can no longer be maintained at its optimal level. To do so would compromise regulatory performance [i.e., not provide adequate cooling]. At this point [the chiller] rpm becomes a manipulated variable. The full unconstrained optimization is still solved at each control interval... This is necessary to ensure that constrained variables can become unconstrained if appropriate.

\section{- Load Changes}

As the load increases and decreases, there is a rapid change in [chiller] rpm to ensure minimum deviation from setpoint. Eventually the load decreases and the [fan] cfm becomes unconstrained. At this point (approximately 7 o'clock) [p.m.], [fan] cfm become the manipulated variable and [chiller] $\mathrm{rpm}$ becomes the free variable, taking on its optimal value.

\section{- Energy Savings}

In addition to providing robust servo-regulatory performance, it is the objective of the algorithm to maximize COP. In the non-optimized case, the average COP for the day is 2.98. In the optimized case, the daily average COP is 3.54 , an $18 \%$ increase in COP. As would be expected, a direct result of the increase in efficiency is a decrease in energy consumption. Without optimization, the total daily energy consumption is $57.53 \mathrm{kWh}$. With optimization, the total daily energy consumption is $45.41 \mathrm{kWh}$. Thus the non-optimized control consumes $26 \%$ more energy than the 
optimized case. Clearly the energy reduction with optimized control is attributable to more than COP improvements alone. The synergistic effect is due to the fact that the PMV [VFD] controller replaces energy-intensive comfort provided by the cooling coil with less energy-intensive comfort provided by air movement.

\section{- Concluding Remarks}

A new multivariable control strategy with the capability of nonlinear cost minimization has been presented. The basic controller is a receding-horizon policy with end-time constraints. Cost minimization is accomplished by solving an auxiliary optimization problem on-line and invoking the natural feed-forward capabilities of the controller. A specific residential cooling application was used as an example to illustrate the salient features of the algorithm. While the example chosen was relatively basic, it showed that the approach can be used to significant advantage. It is believed that the concept can be applied/extended to numerous other environmental applications.

\subsubsection{Fuzzy logic}

The term "fuzzy logic" created by Zadeh is used generally to describe decision indices using qualitative values that do not rely upon precise measurement. With regard to control strategies, a range of set point values can indicate to the control logic when a space needs to be "cooler" rather than "cold." An exhaustive review of the topic is beyond the scope of this design guide; however, fuzzy logic is a topic of much discussion in the DDC industry. Further work is needed to design optimal control systems capable of making energy-efficient decisions with fuzzy logic. Thus far, the following decision strategies have been proposed: [Mayhew, 1993]

"Fuzzy logic" could be applied to provide a more energy efficient chilled water system. There will be instances when resetting chilled-water temperatures "up" may be more energy efficient than "increasing" pump flow to handle an increased load.

It may be more energy efficient to allow the supply air temperature to "coast" higher instead of turning "on" the mechanical cooling depending upon the degree which the laboratory facility and its mission can tolerate "drift" off of a setpoint.

With "fuzzy logic," energy savings can result from to turning off the boiler and associated pumps "earlier." When a laboratory is warmed up and the outside temperature is above the "thermal balance point" of the facility, the boiler should be shut off. In most conventional control systems, the heating system is not turned off until the outside air temperature is greater than $65^{\circ} \mathrm{F}$. When the climate zone has a large number of hours between $50^{\circ} \mathrm{F}$ and $65^{\circ} \mathrm{F}$, this extra run-time will result in a large amount energy waste. [Mayhew, 1993]

\subsubsection{Artificial neural networks}

Studies of artificial neural networks (ANNs) for EMCSs have indicated that they can provide good predictive control in environmental conditioning systems and have the potential to outperform standard PID algorithms. Not only do they minimize process errors better than PID controllers, but ANNs have the unique capability of being both adaptive and predictive. In other words, from their efforts to control a process by reflecting changes in the operating environment, they can learn enough to examine the future effect of the current controller action. The application of neural network controllers in the future also has promise for use in feedback loop processes such as HVAC zone control. [Curtiss et al., 1993] 


\section{References}

"Building Management System's Goal: Reduce Energy Use 20\%." Air Conditioning, Heating \& Refrigeration News, October 1992.

Andrews, J.W., Ph.D., M. Piraino, and J. Strasser. "Laboratory Testing of Control Strategies to Reduce Peak Air-Conditioning Loads." ASHRAE Technical Data Bulletin, Vol. 9, No. 1, Optimal Control Strategies,1993.

Barker, K.A., O. Ahmed, and J.A. Parker. "A Methodology to Determine Laboratory Energy Consumption and Conservation Characteristics Using an Integrated Building Automation System." ASHRAE Transactions, V. 99, Pt. 2, July 1993.

Curtiss, P.S., Ph.D., Kreider, J.K., Ph.D., P.E., and Brandemuehi, M.J., Ph.D., P.E.; "Adaptive Control of HVAC Processes Using Predictive Neural Networks." ASHRAE Technical Data Bulletin, Vol. 9, No. $1,1993$.

DeLuga, Greg, PE. "Special Testing: Controlling VAV Laboratory Ventilation Systems (Part I)." Landis and Gyr Powers, Inc., Month 1995.

Handbook of Facilities Planning, Vol. One, Laboratory Facilities. ISBN 0-442-31852-9. Ruys, Theodorus, AIA, ed. New York: Van Nostrand Reinhold, 1990.

Ho, W.F. "Development and Evaluation of a Software Package for Self-Tuning of Three-Term DDC Controllers." ASHRAE Technical Data Bulletin, Vol. 9, No. 1, Optimal Control Strategies, 1993.

Laboratory Control and Safety Solutions Application Guide - Rev. 2. Buffalo Grove, IL: Landis and Gyr Powers, Inc., 1994.

MacArthur, J.W., Ph.D., PE and W.K. Foslien. "A Novel Predictive Strategy for Cost-Optimal Control in Buildings." ASHRAE Technical Data Bulletin, Vol. 9, No. 1, Optimal Control Strategies, 1993.

Mayhew, F.W. "Application of Direct Digital Temperature Control Systems for Maximum System Efficiency." ASHRAE Technical Data Bulletin Vol. 9, No. 1, Optimal Control Strategies, 1993.

Mcllvaine, Robert W. "Chapter 1, Rooms; Chapter 4, Engineering \& Design." Cleanrooms - 1992-2000, Rooms and Components Vol. Three. McIlvaine, Robert W., Sally Halderman, Alpa Bagga, and Joseph Schwartz, eds. Northbrook, IL: The McIlvaine Co., 1992.

Morris, R.J. and Payne. Retrofit Opportunities for Energy Management and Cogeneration, Ch. 44, "The Billion-Dollar Clean Room Humidity Control Race." Lilburn, GA: Fairmont Press, 1989.

Neuman, V.A. and W.H. Rousseau. "VAV for laboratory hood - Design and costs." ASHRAE Transactions 92(1A), 1986.

Parker, J.A., O. Ahmed, and K.A. Barker. "Application of Building Automation System (BAS) in Evaluating Diversity and Other Characteristics of a VAV Laboratory." ASHRAE Transactions: Symposia, Month, Year. 


\section{SUPPLY SYSTEMS}

\section{Abstract: Energy Efficiency and Laboratory Supply Systems}

Energy engineers designing laboratory supply systems now have numerous opportunities for better contamination control and energy efficiency than in the past. More than 60 percent of the energy consumed by a conventional lab or cleanroom is used to circulate air and to supply heating, cooling, humidity, and clean air, so energy-efficient designs can result in substantial savings. Generally, annual supply system energy costs are ranked from highest to lowest as follows:

- Cooling/Chillers,

- Fan energy,

- Humidification, and

- Heating.

In the case of cleanrooms, the energy consumed by humidification and heating varies depending on climatic conditions and can shift from season to season. In large, specialized cleanrooms (Class 1000 and cleaner), the largest amount of energy, aside from that used for manufacturing equipment, is to supply vertical unidirectional air flow.

This chapter looks at four areas of supply systems that should be considered for energy efficiency:

- Plant Devices,

- Air Systems,

- Air-Handling Units, and

- Energy Recovery.

We analyze these categories separately; however, design decisions for one category affect the energy use of the others, so the cumulative effects of interactions among them must be considered. [Takenami et al., 1989; Brown, 1990; Naughton, 1990a; Naughton, 1990b]

\subsection{Plant Devices}

\section{Energy Efficiency and Plant Devices}

In the past, mechanical plants have been sized for 100 percent of peak load at 99 percent climatic tolerance with an additional 20 to 50 percent "start-up factor" and another 20 to 30 percent "safety factor." These days are over. "Right-sizing" a laboratory facility's mechanical plant reduces first costs and operational energy costs, reducing energy waste by 40 to 50 percent compared to conventional design practices. Two key choices help optimize the energy-efficient operation of supply systems:

- modularizing the boiler/chiller plants,

- matching the plant operation to load as it varies annually.

Selecting boilers/chillers with the best efficiencies will nearly always prove cost effective; dualtemperature cooling systems should also be considered to optimize chiller operation. Free Cooling can supplant chiller operation by using installed cooling tower capacity to its fullest extent. A plate-andframe heat exchanger acts like a "substitute chiller" to provide cooling water when the system is designed to take advantage of cool ambient temperatures. 


\subsubsection{Chillers}

Chillers consume 25 to 50 percent of a laboratory's annual energy budget. Chillers come in several different mechanical arrangements: reciprocating, rotary-screw, and centrifugal and with practically unlimited combinations of features, capacities, and efficiencies. The chiller's energy savings potential depends on operating conditions, space constraints, and willingness of the building owner to pay for energy saving features. [Kruse, 1991]

Understanding the annual load distribution of a laboratory facility is crucial to efficient sizing of the chiller system. Chiller compressor loads range from 100 percent during the summer to as low as 10 percent in the winter, depending on energy-efficiency features of the air-handling system. As stated above, optimizing the energy-efficient operation of the chiller system requires that the chiller plant be modularized and the plant operation be matched to the cooling load as it varies annually. ["Screw Compressors Provide Energy and Cost Savings." 1989]

\section{- Modularize}

Chiller plants are not often modularized. An understanding of the relative merits of different chiller types-reciprocating, rotary-screw, and centrifugal-is a prerequisite to designing a modular chiller plant. In general, reciprocating chillers can serve the smallest loads efficiently, rotary-screw chillers are the most flexible, and centrifugal chillers are most efficient when fully loaded. Typical $\mathrm{kW} /$ ton profiles must be identified for the loads identified and temperatures required; consideration can then be given to using two chillers of unequal size instead of two chillers of equal size, which allows more flexibility in matching load. The energy-efficient modularizing approach can help designers match loads effectively by a rotary-screw compressor and a centrifugal compressor instead of two centrifugal compressors; a reciprocating chiller could also be part of the energy-efficient module, combined with a screw compressor or a centrifugal compressor. [Beyene and Asfaw, 1994]

\section{- Match load}

A laboratory-type facility's chiller operation will vary widely during the year because of the changing load profile. To satisfy this load profile, sensible heat removal and dehumidification requirements can be defined as two distinct thermal cooling levels. An energy-savings opportunity is presented when these cooling levels are evaluated and matched separately. [Brown, 1990]

To meet dehumidification requirements, a low-temperature fluid is required, typically $38^{\circ} \mathrm{F}\left(3.3^{\circ} \mathrm{C}\right)$ to $45^{\circ}$ $\mathrm{F}\left(7.2^{\circ} \mathrm{C}\right)$. If a chiller efficiency, with auxiliaries, is $0.80 \mathrm{~kW} /$ ton $(0.227 \mathrm{~kW} / \mathrm{kW})$ to produce water at $40^{\circ} \mathrm{F}$ $\left(4.4^{\circ} \mathrm{C}\right)$, the efficiency to produce water at $60^{\circ} \mathrm{F}\left(15.6^{\circ} \mathrm{C}\right)$ could increase to about $0.65 \mathrm{~kW} /$ ton $(0.185 \mathrm{~kW} / \mathrm{kW})$, saving nearly 20 percent. When cooling is required all year for the facility support spaces, water at $60^{\circ} \mathrm{F}\left(15.6^{\circ} \mathrm{C}\right)$ can be produced using a free-cooling heat exchanger system. [Brown, 1990]

\section{- Cleanrooms}

Approximately one-half of the HVAC energy consumed in cleanrooms is for chiller and associated pump operation. Therefore, incorporating two temperatures of chilled water works very well in cleanroom designs, yielding major energy savings. [Kruse, 1991]

\section{- Rotary-screw chillers}

Rotary-screw chillers provide significant operational energy savings because they can match full load or part load as small as 10 percent of the chiller's capacity. Rotary-screw compressors can vary their capacity infinitely. This continuous capacity modulation results in 25 percent energy savings in contrast to standard unloading techniques. ["Screw Compressors Provide Energy and Cost Savings," 1989] 


\section{- Variable flow}

In particular instances, chiller compressor or auxiliaries can be operated with VFDs to produce energyefficient matching of the cooling load. The energy engineer who is considering adding variable flow through the compressor, evaporators, or condensers needs to be sure that a VFD is compatible with the particular chiller.

\section{- Oversizing evaporators/condensers/cooling towers}

Installing oversized evaporators and condensers saves energy by reducing internal pressure losses and altering the temperature lift in the chiller. For instance, lowering condenser water entering temperature to 75 by using an oversized cooling tower can be cost effective within five years.

\subsubsection{Two-temperature systems}

Kruse (1991) discusses the use of two-temperature chiller systems for energy-efficient cleanroom design.

Two temperatures are usually needed for two reasons. First, to dehumidity, you cannot beat low temperature chilled water (approx. $35^{\circ} \mathrm{F}$ ) for good control. However, at that temperature, unwanted de-humidification can also occur. With a second chilled water system operating at or above the space design dew point, this problem and the expense of re-humidifying are avoided. Second, as shown by the following data, it costs more to make colder chilled water. The $k W$ per Ton for 40 _ water is $7 \%$ more than that for 45 water. Dropping down to 35 is usually at least another $7 \%$.

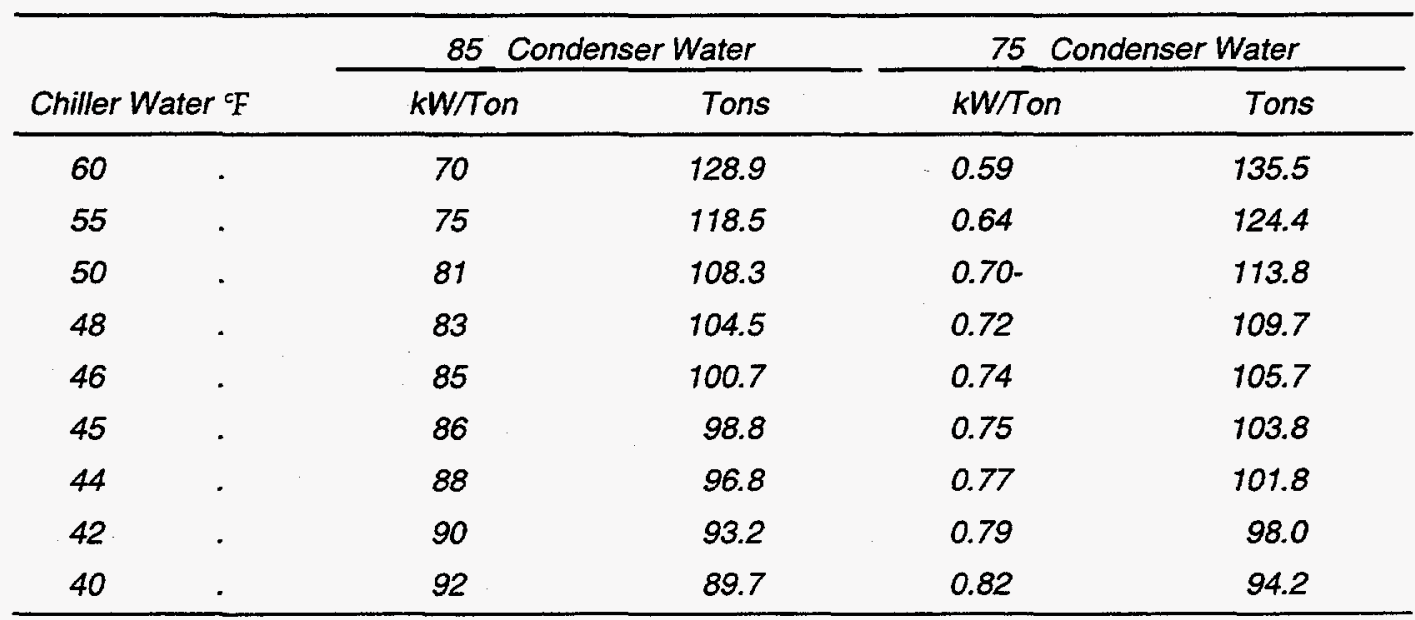

Brown (1990) similarly points out that energy efficiency is increased when "a dual-temperature $40^{\circ} \mathrm{F}\left(4.4^{\circ} \mathrm{C}\right)$ and $60^{\circ} \mathrm{F}$ $\left(15.6^{\circ} \mathrm{C}\right)$ mechanical cooling system is included. First-cost penalties are limited primarily to the low-temperature piping loop and not additional chillers, since most system designs require multiple refrigeration units."

\subsubsection{Centrifugal refrigeration}

Naughton ("HVAC Systems... Part 1," 1990) discusses components for cleanroom cooling.

Chiller Polytropic Head: 
When designing the chiller and chilled-water systems, understanding the factors that affect system operating costs will help in maximizing overall system efficiency. The total brake horsepower required by a centrifugal refrigeration machine is directly related to the polytropic head and refrigerant weight flow and inversely related to compressor efficiency. The polytropic head is determined by the suction and condensing temperatures where the difference between the suction pressure and the refrigerant condensing pressure roughly equals the polytropic head or lift of the compressor. Changes in polytropic head have the greatest effect on brake horsepower (Aloi 1976) ${ }^{2}$ Increasing cooler water temperature differentials or increasing the log mean temperature difference (LMTD) will result in higher suction temperature and a lower polytropic head. High system temperature differentials also benefit lower pumping costs.

The condenser water LMTD should be reduced to a minimum to reduce the condensing temperature and thus reduce the polytropic head. The refrigerant condensing temperature will decrease as the condenser water temperature is decreased; therefore, operating cooling towers and chillers at the lowest possible temperature will afford a more efficient chiller.

\subsubsection{Compressor motors}

Kruse's 1991 article "Mechanical System Strategies for Energy Efficiency" discusses chiller motor choices.

One major decision to make when selecting a chiller is the type of motor it uses. Some use hermetically sealed motors which are cooled by the Freon in the chiller. Others use open drives which means that they are cooled by the air in the room. Open drive chillers use less energy since they don't have to cool the motors. The savings is usually at least $10 \%$ but can be as much as $25 \%$ depending upon make and model. However, the motor must be cooled somehow. In most climates and circumstances, the chiller room can be inexpensively ventilated so as to remove the heat from the motors. In cold climates, the motor heat will offset the need to heat the room thus offering additional savings. In warmer climates more of the savings are traded for the cost of cooling the room, but the savings are still worth investigating.

\subsubsection{Internal pressure drop}

Kruse (1991) also points out the need to consider chiller pressure drop.

One final item to remember when analyzing chiller efficiencies is to account for the related pumping costs due to the pressure drop through the chiller. Chillers have pressure drops the same as the water side of coils, and they can vary significantly from model to model. It would be short-sighted to purchase the chiller with the lowest $\mathrm{kW}$ per Ton only to discover that the savings were lost to higher pumping costs due to increased internal water pressure drop.

\subsubsection{Cold condenser water}

Kruse (1991) recommends cold condensed water for energy-efficient chiller operation.

This [sic] same data also points out that the capacity of a chiller is increased if the condenser water is colder. At the same time, the $\mathrm{kW}$ per ton is lower, thus increasing the efficiency and reducing the energy consumption. A 42, chilled water system runs at $0.79 \mathrm{~kW}$ per Ton at 75 condenser water versus $0.90 \mathrm{~kW}$ per Ton at 85 . This is a $12 \%$ savings. Clearly a strategy of

\footnotetext{
${ }^{2}$ See referenced document for full citation.
} 
running the cooling towers so as to make condenser water as cold as possible will save chiller energy. Be careful, however, not to exceed the manufacturer's recommendations.

\subsubsection{Cooling tower capacity}

The energy-efficiency impacts of cooling towers are analyzed in Kruse (1991):

Cooling towers play a relatively minor role in the direct energy consumption of a project, but their relationship with chillers allows them to have a significant indirect effect. As previously mentioned, the efficiency of a chiller improves with colder condenser (cooling tower) water. For this reason, don't be afraid to buy plenty of cooling tower. Towers are relatively inexpensive pieces of equipment, and they can lose efficiency if not sufficiently maintained. Also, don't be in a hurry to cycle down or cycle off the tower fans. Compare the fan energy savings with the chiller performance first. It is likely that running the fans to create colder tower water will reap overall savings due to improved chiller efficiency.

\subsubsection{Cooling tower fans}

Kruse (1991) comments on the choice of cooling tower fans.

Even with an aggressive tower fan strategy, the fans will need to be slowed down or turned off eventually due to winter weather conditions. A two-speed fan motor is a popular method of accomplishing this. However, with VFD's becoming increasingly affordable, it is possible for the savings to offset the cost of the VFD. Caution must be used in the control circuit design to prevent the fan speed from ramping up and down excessively [especially when a gear train is involved in the cooling tower fan drive].

\subsubsection{VFD cooling tower operation}

Ciborowski and Pluemer (1991) present a case study of energy-efficient cooling in a semiconductor cleanroom in Sunnyvale, California.

...the power requirements ( $k W / T o n)$ for chillers drops the cooler the condenser water that is used. Temperature approach for condenser water to outside wet bulb is on the order of 5-7 ${ }^{\circ} \mathrm{F}$ at $75-80^{\circ}$ $F$ wet bulb temperatures. At an outside wet bulb temperature of $50^{\circ} \mathrm{F}$, a typical cooling tower temperature approach is on the order of $15^{\circ} \mathrm{F}$. Even with this approach divergence, it is possible to get $65^{\circ} \mathrm{F}$ condenser water with a $50^{\circ} \mathrm{F}$ outside wet bulb. ...the cooling tower fans are equipped with variable frequency drives. As part of the general building information, ... the dew point and dry bulb temperature of the outside air [are measured]. From this information the wet bulb temperature is calculated. The tower sump water temperature is also monitored. Based on approach information provided by the cooling tower manufacturer, an algorithm was written to reset the condenser water temperature based on outside wet bulb, by varying the speed of the cooling tower fans.

\subsubsection{Optimum operating point}

The Micro-Electronics Facility Efficiency Workshop (1995) covered the topic of an optimum operating point for chillers.

... high efficiency [Cooling] towers [can be used] with variable speed drives ganged together and controlled to take advantage of favorable ambient air conditions to lower the condenser water temperature. However the cost-effectiveness of this strategy depends greatly on the specific 
climate and in particular the wet-bulb temperature. Since cooling towers get more efficient with higher leaving condenser water temperatures while chillers get less efficient, ...the concept of an optimum operating point that maximizes the combined performance of the chiller and cooling tower [must be implemented]. With more efficient cooling towers, this optimum point can be dropped to a lower condenser water temperature which will further improve the overall system efficiency.

\subsubsection{Part-load conditions}

The Micro-Electronics Facility Efficiency Workshop (1995) report on efficiency in micro-electronics facilities suggests there are "benefits of operating chillers using variable speed drives," including "the ability to take full advantage of part-load conditions."

This could be especially important in a mild climate such as the Pacific Northwest [and Northern California] where the chillers may be operating at well below full capacity all but a few hours out of the year. ...it is important to know your chiller manufacturer and to test the chiller performance in the field. ...plots of data [can be] supplied by the manufacturer that a part load[ed chiller] actually .... [will get] less efficient as condensing water temperature [is] decreased. ...plots [were displayed] of actual installed chiller performance measurements for [a] project where the chiller never even came close to the rated efficiency at full or part load. ...detailed monitoring of chiller performance with written performance guarantees with cash penalties for non-performance from the manufacturer [is recommended].

\subsubsection{Boilers}

Energy savings can be realized in the production of heating hot water by modularizing the boiler plant. The use of multiple, high-efficiency ( 88 to 95 percent) boilers allows staged operation of the plant to match the laboratory's heating load. Multiple-boiler plants incorporate relatively small boilers in the range of 500,000 to 1 million BTUH; these are cold-start boilers that do not require continuous operation when there is no load. Each boiler is manifolded in a primary circulation loop with isolation valves to prevent circulation during inoperative periods. The laboratory load is on the secondary loop and, in special instances, a tertiary loop. The energy savings from efficient operation, matched loading, and elimination of standby energy losses range from 40 to 60 percent compared to conventional boiler plants. The modular boiler plant has the added benefits of back-up redundancy in its multiple units and simplified maintenance because any one boiler can be easily taken out of service without disrupting the hot water heating supply.

\subsubsection{Free cooling}

During cool weather, the outside ambient temperature can help save energy in chilled-water systems. The low temperature of the cooling tower water supply enables free cooling of research laboratories, computer rooms, and office buildings. This free cooling is possible if the central plant incorporates a plate-and-frame heat exchanger to provide chilled water production, which means the chiller's compressor can be shut down. Free cooling can be used to save energy whenever the outside wet-bulb temperature drops below the required chilled water setpoint. This energy-efficiency measure can save enough compressor electric power to pay for plate-and-frame heat exchanger installation costs in less than two years. [White, 1994]

\section{- Chilled water temperature reset}

If mechanically generated chilled water is used only to maintain a specified maximum laboratory humidity condition that cannot be achieved with indirect cooling, free-cooling system energy savings will be maximized. The chilled-water supply temperature can be set as a function of outdoor dew point to the 
highest value that will satisfy the laboratory conditions. The plate-and-frame free-cooling system is operated whenever the chilled-water return temperature is greater than the cooling tower's supply water temperature. This operating strategy maximizes indirect evaporative cooling opportunities and can reduce chiller operation by one-third to one-half. [Brown, 1993; Kruse, 1991]

\section{- Fan energy tradeoff}

When chilled-water supply temperatures are raised to save compressor energy and to enable free cooling to operate longer, the laboratory's air handling units (AHUs) will also operate longer or at higher speeds to maintain the required space temperatures. This can lower the energy savings from free cooling or cause an increase in energy use. Therefore, monitoring the energy use of the entire chilled water/air handling system with an EMCS can prevent negative energy impact. [White, 1994]

\subsubsection{Stabilized temperature control}

White (1994) presents a case study that describes the cooling of a large office and research laboratory complex.

To maximize the hours of free-cooling operation, the chilled-water supply temperature ...[is] allowed to vary, but this ... [can cause] problems in controlling temperature and humidity for the various building systems. Starting and stopping free-cooling operation produce[s] a quantity of higher temperature fluid in the distribution piping, which upset[s] the building temperature control systems. The transition time for stabilizing temperatures during free-cooling start or stopping is about 30 minutes [for this example], which is not acceptable for some critical research and computer loads. For example, in the [example] central computer facility, when the chilled-water temperature [was] increased to $48^{\circ} \mathrm{F}\left(8.9^{\circ} \mathrm{C}\right)$, a $65-\mathrm{hp}(48.5-\mathrm{kW})$ booster chiller would be started to lower the temperature.

\subsubsection{Blended tower water}

Kruse (1991) highlights the advantage of using blended cold tower water and warm undersea water to achieve optimum chiller water temperature.

The details of optimum economizer design have been covered well in other articles and are beyond the scope here. However, a few points are worth bringing up. First, remember that the clean room needs cold water all year 'round. This means that little opportunity exists for chilled water reset, unlike offices and libraries. This, in turn, means that tower water in the 40's [ $\left.{ }^{\circ} \mathrm{F}\right]$ is required to serve as chilled water. The problem occurs just prior to switch-over. If you run tower water in the 40's [ $\left.{ }^{\circ} \mathrm{F}\right]$ through the condenser of the chiller, you won't like the result and you can kiss your warranty good-bye. Instead, use a three-way valve or similar strategy to blend the cold tower water with warm condenser water so as to keep the mix where the chiller is happiest. Definitely consult the chiller manufacturer to find our how cold the condenser water can be, and don't cut it too close.

\subsubsection{Tower water isolation}

Kruse (1991) recommends,

...select an economizer system which doesn't compromise the chiller efficiency by running dirty tower water through the chilled water side of the system. As other articles have pointed out, strainer cycles have not solved this problem and shell-and-tube heat exchangers are not effective enough due to large approach temperature requirements. A plate-[and-]frame heat exchanger design will usually offer the best choice. 


\subsubsection{Additional refrigerant}

White (1994) points out that, "In order to achieve design free-cooling capacity, additional refrigerant must be added so that all evaporator tubes are covered. This is [may] not [be] practical and ... therefore, maximum free-cooling capacity [may] not [be] achieved."

\subsection{Air Systems}

\section{Energy Efficiency and Air Systems}

The HVAC Air System can be considered the "lungs" of the facility. Many major energy-using components are necessary to provide the desired environment. We examine energy efficiency by reviewing major system requirements for laboratory and cleanroom environments.

\section{- VAV systems}

Laboratory-type facilities benefit especially from VAV systems. VAV systems reduce both operating energy costs and capital costs. By continuously adjusting to match the environmental conditioning required by the facility, VAV systems save operating energy. When diversity or varying loads are taken into account, the additional first cost of VAV systems can have life-cycle paybacks, including operational energy savings, in less than six months. [Atwell and McGeddy, 1989; Neuman and Guven, 1994; Parker et al., 1993]

When air-handling equipment is operated at low air-flow rates, the reduction of the pressure loss and the higher degree of efficiency of the heat exchangers can more than compensate for the higher purchase costs of the VAV system. Outside working hours, the air-flow rate can be reduced to 50 percent of the design value. The resulting energy consumption of the VAV system for conveying the air decreases to less than 25 percent of peak load. [Schicht, 1991]

\section{- Make-up air systems}

One of the largest subsystem energy users in a laboratory's space conditioning system is the make-up airhandling system. Make-up air units can use tremendous amounts of energy unnecessarily in part because of basic design decisions regarding the temperature and humidity tolerance allowed in the laboratory or cleanroom. The energy requirements to heat, cool, dehumidify, or humidify the make-up air are considerable and can represent 30 percent to 65 percent of the total energy required to maintain the laboratory or cleanroom environment. [Kruse, 1991; Naughton, 1990a; Brown, 1990]

\section{- Cleanroom recirculation air systems}

Cleanrooms of class 1000 and cleaner have air change rates of 600 to 900 per hour. Large amounts of energy are necessary to transport these huge quantities of cleanroom air and remove fan heat. Recirculation air systems for cleanroom designs can maximize energy savings by reducing both the unidirectional air-flow rate and the pressure drop in the air recirculation loop. Significant energy savings are also possible when high-efficiency components are used for circulating these large quantities of air. [Naughton, "HVAC Systems ... Part 1, 1990]

In cleanrooms, air flow is a generally fixed parameter based on the air velocity desired. Required fan horsepower can be reduced by one-third if the clean room is provided with a mixed HEPA filter air velocity and only the product and the production equipment are covered with $90 \mathrm{fpm}(0.457 \mathrm{~m} / \mathrm{s})$ air flow while the remainder of the cleanroom operates at a lower velocity of $60 \mathrm{fpm}(0.305 \mathrm{~m} / \mathrm{s})$. [Naughton, "HVAC Systems ... Part 1, 1990] 
Major energy savings can be achieved by lowering system static pressure and improving fan efficiency. The energy required to overcome the system static pressure rises at a cubed rate, thus increasing energy requirements exponentially. [Ciborowski and Pluemer, 1991]

\subsubsection{VAV systems}

A laboratory-type facility has stringent air-flow requirements to create a safe, constant, controlled environment. Additionally, laboratories have areas where air volume and temperature must be adjusted according to occupancy. In either new designs or retrofits, VAV systems can make HVAC systems operate more efficiently to meet these needs. [Atwell and McGeddy, 1989]

When a facility is only partially used or occupied during the day, the VAV system has a high, part-load operating efficiency. In order to achieve additional energy savings, the VAV system reduces the average ventilation rate in laboratories when they are unoccupied. [Neuman and Guven, 1994]

A VAV system also has other advantages: it monitors and controls pressurization in laboratories for increased safety, it readily adapts to adding or moving fume hoods around during remodeling, and it improves fume hood safety monitoring. The advantages of the VAV system make up for the fact that the system may not have the lowest first cost. [Neuman and Guven, 1994]

\subsubsection{VAV terminal devices}

Lyons et al. (1990) describes the use of VAV systems.

Most laboratories today consider VAV with reheat. This has been made possible by the development of economical and reliable hood controls and the ability to accurately track the quantity of supply and exhaust air locally in order to main constant pressure relationships.

Many terminal devices are available today. Essentially, each hood or group of hoods controls its respective VAV box. A matching supply box or boxes, depending on air quantities, is provided, with controls to permit tracking.

Operating diversities of 70 to $85 \%$ are possible.

\subsubsection{VAV relative humidity}

In their discussion of the use of VAV systems, Lyons et al. (1990) point out that, "In all systems which employ VAV, the relative humidity in the space...[may be] difficult to control. Calculations must be made to ensure that design limits are not exceeded. Also, even though the exhaust requirements of the hoods within the lab are satisfied, the load within the space may require additional air."

\subsubsection{VAV comparison case study}

Neuman and Guven (1994) describe a simulation that compared HVAC systems for a proposed laboratory facility in Southern California.

The [laboratory] research and development building is an important type with high demands for energy effectiveness and safety to be provided by the air-conditioning system. A simulation of different mechanical systems was made for a proposed 200,000 square foot research building located in San Diego. The systems compared are variable volume with reheat, constant volume with reheat, auxiliary air hoods, two-fan variable air volume dual-duct, and constant-volume reheat 
with individual fume hood fans. The variable-volume system with reheat was the best overall. This alternative is safe, reliable, and adaptable. The life-cycle cost of this system was $\$ 11$ million compared to the worst alternative life-cycle cost for constant-volume reheat with individual fume hood fans of $\$ 18$ million. The additional first cost of the variable-volume reheat system is paid back in energy savings in less than six months.

\subsubsection{Constant-volume reheat comparison}

Neuman and Guven (1994) point out that:

The constant-volume reheat system...has both benefits and drawbacks. This system has been proved to have low maintenance costs. Ventilation levels are maintained at all times, and the reheat system also provides good temperature control. The constant-volume system does not readily lend itself to changes. No active pressurization control or monitoring is usually included, and the local hood safety monitors are minimal with this system. Partial occupancy of the building for part of the day is very inefficient.

\subsubsection{Double-duct VAV}

Neuman and Guven (1994) discuss pros and cons of double-duct VAV systems:

The two-fan double-duct variable-volume system...shares many of the advantages of the variablevolume reheat system. Pressurization is actively controlled and hoods have adequate safety monitors. Temperature control is adequate, and average ventilation rates are higher than for other variable-volume altematives. This system has the disadvantage of requiring more room for ductwork above the ceiling, and controlling a double-duct system is more difficult.

\subsubsection{VAV retrofit example}

Atwell and McGeddy in their paper "Variable Air Volume Retrofits for Hospitals and Laboratories" (1989) describe a $\checkmark A V$ retrofit in an office and research complex.

The original HVAC system serving this building consisted of four central air handlers that provided constant volume conditioned air to all areas except the core laboratories and two additional central air handlers that provided makeup air to the core laboratories. The remaining system still in the original configuration was retrofitted to provide variable volume flow to all areas. $A$ variable air volume terminal was installed for each space and was controlled by a space thermostat. The plenum return air system was eliminated and retum air ductwork was installed to provide better air circulation in each space. In the penthouse, the four central air handlers were retrofitted with standard chilled water cooling coils, steam preheat coils, steam humidifiers and variable frequency drives and motors; inlet vortex vanes were removed. Return fans were also provided with variable frequency drives and motors. Supply fan variable frequency drives were controlied via a common static pressure sensor.

\subsubsection{Make-up air systems}

Make-up air systems condition outdoor air and distribute it to laboratories or cleanroom air recirculation loops. A good make-up air system:

- Provides humidity control,

- Ensures make-up air is balanced with exhaust air, 
- Maintains and controls building pressurization,

- Effectively treats outdoor contaminants, and

- Provides cost-effective energy-savings opportunities. [Brown, 1990]

Make-up air for laboratories should be limited to $1 \mathrm{cfm} / \mathrm{ft}^{2}\left(5.08 \mathrm{~L} / \mathrm{s}-\mathrm{m}^{2}\right)$, per the right-sizing techniques described in Chapter 3. Make-up air for cleanrooms can be from $1 \mathrm{~cm} / \mathrm{ft}^{2}\left(5.08 \mathrm{~L} / \mathrm{s}-\mathrm{m}^{2}\right)$ to $10 \mathrm{cfm} / \mathrm{ft}^{2}$ $\left(50.81 \mathrm{~L} / \mathrm{s}-\mathrm{m}^{2}\right)$, typically averaging $5 \mathrm{cfm} / \mathrm{ft}^{2}\left(25.4 \mathrm{~L} / \mathrm{s}-\mathrm{m}^{2}\right)$. Conditioning such large amounts of outside air is very energy intensive. Therefore, the greatest opportunity for energy savings is to reduce or displace mechanical cooling or fuel-generated heating requirements. Significant portions of the cooling load can be satisfied with "warmer" cooling water. The sensible heat load produced by a cleanroom and the air recirculation loop can usually be removed with water no colder than 60 degrees $F\left(15.6^{\circ} \mathrm{C}\right)$. [Brown, 1990]

\subsubsection{Make-up air components}

Kruse (1991) discusses make-up air system components.

Make-Up air handlers have all the same components as recirculation units, and then some. The most noticeable difference is the addition of some form of humidification. All of the other components (fans, coils, filters, sound attenuators) follow the...laws of Mother Nature... There will likely be, however, more of each component. Filters may include $30 \%, 90 \%$ and $99.99 \%$ efficiencies. Coils may include pre-heat, chilled water, brine and re-heat styles. Cooling coils will have more rows. The good news is that this offers more opportunity to create an energy efficient design. The bad news is that a make-up air handier contradicts the meaning of energy efficiency.

Brown ("HVAC Systems... Part 1," 1990) comments on reasons to use make-up air systems.

Fundamentally, a makeup unit would appear... [with] the fan...located upstream of the cooling coil and final filter for the following reasons:

- It removes makeup unit fan heat that is equivalent to $\pm^{\circ} \mathrm{F}\left( \pm 2.22^{\circ} \mathrm{C}\right)$, thereby maximizing the cooling effect to the conditioned space.

- Any casing leakage is outward, which ensures the required dew point and the cleanest air to the cleanroom.

- Most important, it improves the ability to maximize energy savings with the introduction of energy conservation components.

\subsubsection{Cleanroom make-up air}

Naughton ("HVAC Systems...Part 1," 1990) points out the importance of make-up air systems in semiconductor cleanrooms.

The quantity and quality of makeup air supplied to the cleanroom are two of the most important elements in the design of semiconductor facilities. Makeup air is used to provide fresh air to offset the large quantities of process exhaust. It also is used to provide cleanroom pressurization. (Semiconductor cleanrooms are normally positively pressurized to prevent infiltration of external contamination.) The trend to reduce exhaust levels, and thus makeup air quantities, must be balanced against life safety concerns. Reducing process exhaust quantities may not be possible due to the nature of the many chemical processes used during manufacturing. Attempts to reduce 
system energy costs by decreasing process exhaust flows must be carefully evaluated by the facility's industrial hygienist, safety personnel, and manufacturing personnel.

\subsubsection{Make-up system acoustics and vibration}

Ciborowski and Pluemer (1991) describe the relationship between fans and acoustical effects for a make-up air system in a Califomia semiconductor facility.

While the plug fan worked very well to provide low energy use in the recirculation system, the high system pressures encountered in make-up air systems shift the ideal selection to vane axial fans. This is due to the fact that both types of fans now require [noise] attenuation to meet the building acoustical requirements and the energy use is only dependent on fan efficiency.

\subsubsection{Air recirculation systems}

Vertical, laminar flow, air recirculation systems are typically used in laboratory cleanrooms to achieve the required cleanliness. This air flow may bathe only the product and manufacturing equipment or be provided throughout the cleanroom. Energy savings are realized when the rate of air flow is reduced throughout the cleanroom and maintained over the product and manufacturing equipment only. [Naughton, "HVAC Systems... Part 1," 1990]

Three air recirculation configurations should be evaluated for the clean room: the fan can be mounted locally over the cleanroom in an AHU; the fan can be installed remotely in a fan "tower" configuration; or a group of small, local fans with filter units (FFUs) attached can be mounted directly in the ceiling grid. [Hunt et al., 1990]

AHUs with vane-axial fans have high individual efficiencies but do not necessarily yield the highest system efficiency. Pressure losses from dynamic system effects must be considered. These include airflow velocity conversions at the fan entrance and exit as well as duct work sound attenuation and vibration isolation pressure drops. [Hunt et al., 1990]

The fan tower configuration operational cost is higher because of system pressure drops associated with the longer duct distribution system. This configuration is used when separation is required between rotating equipment and the area directly over the cleanroom. Vane-axial fans or centrifugal fans can be used in a fan tower configuration. [Hunt et al., 1990]

Small, local fan filter units (FFUs) for cleanroom recirculation should be evaluated in contrast to the use of larger, more efficient fans, mentioned above. When localized FFUs are used to reduce a system's static pressure, there is a tradeoff between decreasing efficiency and decreasing static pressure. [Naughton, "HVAC Systems... Part 1," 1990]

\subsubsection{Filter fan units (FFU)}

Naughton ("HVAC Systems... Part 1," 1990) discusses the choice of filter fans.

For many small FFUs with motor sizes less than $1 \mathrm{hp}(0.75 \mathrm{~kW})$ and in-line centrifugal forwardcurved fans, the total efficiency drops to $50 \%$ or less. An $85 \%$ mechanically efficient, direct-drive vane-axial fan has a motor efficiency of $94 \%$ and total efficiency of $(0.85 \times 0.94) \times 100 \%=79.9 \%$.

Compare this with an FFU operating at 1.5 in. WC [W.G.] (373.5 Pa) of static pressure, 55\% mechanical efficiency, $70 \%$ motor efficiency, and total efficiency of $(0.55 \times 0.70) \times 100 \%=38.5 \%$. The total efficiency ratio of $79.9 \%$ over $38.5 \%$, or 2.07 , means the large fan system must have 
2.07 times higher static pressure, or $2.07 \times 1.5$ inc. -3.11 inc. WC [W.G.] (775.1 Pa), in order to use the same amount of energy as the FFU system. Therefore, when one considers the higher maintenance costs and shorter equipment life of the FFU, the lower static pressure FFU may not be as attractive a choice as the large centralized vane-axial fan system. The energy trade-off in reduced efficiency can also be seen when comparing other fan choices.

\subsubsection{Recirculation and make-up air combined}

Kruse (1991) discusses the combination of recirculation and make-up air units.

Some projects may require an air handler to be able to function as a recirculation unit while treating a certain portion of outside air, essentially combining a recirculation unit with a make-up air unit. The common way to do this is to add a return air opening next to the outside air inlet of a make-up air unit. Add some dampers for air balancing and you are in business. The problem with this from an energy standpoint stems from two sources. First, this arrangement forces all of the recirculation air through all of those coils and filters which caused the fan horsepower to be so high. It would be more energy efficient to direct this air through only those components necessary for its proper conditioning. Second, during humid weather the outside air is being dehumidified by cooling and re-heated to the required design condition. The recirculation air doesn't need all of that. An arrangement of a relatively energy efficient dual purpose air handler...for a specific project will depend, of course, on the ratio of outside air to return air as well as all of the usual design requirements.

[The energy consumption of each component should follow the rules described elsewhere is this guide.]

\subsubsection{Recirculation system acoustics and vibration}

Ciborowski and Pluemer (1991) discuss noise considerations in an efficient air recirculation system in a semiconductor facility.

During the design phase... in addition to energy efficiency, [a] high priority was given to minimizing acoustic and vibrational contamination of the cleanroom. To achieve these ends, a low pressure ducted HEPA system was designed. In addition, air handler components (cooling coils, filter banks, etc.) were sized for low pressure drop. Vane axial fans and plug fans were the most promising air movers for low energy use. While the vane axial fan was much more efficient [than the plug fan] (88\% vs. 53\%) for the air flow and initial system pressure, its sound characteristics were such that an external sound attenuation was required to meet the specified sound power levels for the clean space. The increased pressure drop of the attenuators resulted in a system pressure increase that more than negated the benefit of the increased fan efficiency. The plug fans selected required no attenuation because with a low system pressure a large fan wheel (54 in.) revolving at a low speed (450 RPM) would meet the design requirements.

\subsection{Air Handling Units}

\section{Energy Efficiency and Air Handling Units}

The air handling unit (AHU) is a complicated device involving many interrelated design selections that affect its energy efficiency. The overall efficiency of an AHU is determined by the energy it takes to move a given quantity of air against the system. Three major energy choices for the AHU design must be considered: [Hunt et al., 1990] 
- Reducing AHU pressure drop,

- Incorporating the most efficient fan "system," and

- Displacing conventional cooling and heating energy. [Hunt et al., 1990]

\section{Reducing AHU pressure drop}

The AHU pressure drop can be reduced by:

\section{- Lowering face velocity}

Lowering face velocities necessitates larger area coils and filter elements and bigger AHU housings than conventionally used. These larger items increase the AHU's cost, but a resulting decrease in face velocity from $500 \mathrm{fpm}$ to $400 \mathrm{fpm}$ usually makes up for the increased cost over the life of the AHU. Face velocity reductions from $500 \mathrm{fpm}$ to $400 \mathrm{fpm}$ can have a simple payback of about three years. A comparable decrease in face velocity at filters can have a simple payback of one year or less. [Brown, 1990]

\section{- Considering filter loading and VFDs}

Variable system resistance, primarily resulting from filter loading, can be efficiently corrected for with a VFD on the fan. AHU prefilter pressure drop will typically vary from $0.5 \mathrm{in}$. $\mathrm{H} 2 \mathrm{O}(125 \mathrm{~Pa})$ when "clean" to 1.7 in $\mathrm{H} 2 \mathrm{O}(423 \mathrm{~Pa})$ when "dirty." The system design point is usually sized for the "dirty" condition. However, on average, about 90 percent of the design head and energy is actually required. The energy saved by a VFD will pay for the drive in two to five years, depending upon system capacity. [Brown, 1990]

\section{- Adding bypass dampers}

Some AHU components are only utilized during a portion of the year; therefore, bypass dampers should be used to reduce parasitic energy losses when these components are not needed. [Brown, 1990]

\section{- Evaluating System effects}

Energy engineers must carefully evaluate inlet and outlet configurations of the AHU because physical restrictions imposed by architectural considerations often limit the space allocated to air-handling equipment. [Hunt et al., 1990]

\section{Incorporating the most efficient fan "system"}

The fan "system" includes the following:

\section{- Fan type}

Centrifugal fan efficiencies range from 50 percent to about 70 percent depending upon blade configuration and vane-axial fan efficiencies range from 80 percent to over 90 percent. However, the energy engineer must keep in mind that all fans add heat to the air stream. The air stream temperature typically rises between three degrees $F$ and six degrees $F$ for inefficient fan types. Also, actual installed efficiency is typically worse than the manufacturer's rating data indicates, dropping the fan's efficiency by 10 to 30 percent in some cases. [Shepard, M. et al., 1995; Micro-Electronics Facility Efficiency Workshop 1995] 
- Drive mechanism

Direct drive fan/motor combinations are the most efficient at 100 percent. Standard V-belt drives are about 93 percent efficient when first installed but drop over time. Synchronous belt systems offer an energy-efficiency increase to about 96 percent for the life of the belt.

\section{- Motor efficiency}

Premium efficiency motors that have full-load efficiencies of greater than 94 percent depending upon horsepower are preferable. It is also important to consider the part-load motor efficiency and its operation with a VFD in VAV systems.

\section{- Sound Power Requirements}

Acoustical attenuators, used to reduce a fan's sound, increase the pressure drop of the AHU. Therefore, engineers should consider the disadvantages of high-efficiency but noisy fan that will require acoustical attenuation devices. These devices can negate the energy savings from face velocity reductions.

\section{Displacing conventional cooling and heating energy}

The following methods to displace conventional cooling and heating energy pertain only to the components and features of the AHU. Energy recovery is discussed separately in Section 5.4.

\section{- Evaporative cooling}

Evaporative cooling is an alternative to conventional compressor-type cooling systems. Direct and indirect evaporation systems or a combination can supplant or displace conventional cooling systems.

\section{- Economizers}

When mixing of the facility's exhaust air with make-up fresh air is permitted, economizers can save energy in both cooling and heating modes.

\section{- Coil placement}

Brown (1993) points out that placement of the fan upstream from the cooling coil and evaporative cooler has two energy advantages. In cooling mode, fan heat enhances operation of the cooling coil, and, in heating mode, the same fan heat is used to provide humidification energy and to displace preheat energy input. [Brown, 1993]

\subsubsection{Fans}

Good fan selection influences system energy efficiency. The fan itself can be seen as a "system" with the efficiency of each component-the fan, the drive, and the motor-affecting the total fan "system" efficiency.

Engineers should evaluate fan types, drive mechanisms, and motor options for efficiency.

- Centrifugal vs. vane-axial fans

The choice of forward-curved centrifugal or backward-inclined centrifugal or airfoil centrifugal fans versus vane-axial fans will affect the energy efficiency. Standard centrifugal fan systems are typically very inefficient ( 50 percent to 60 percent), and their actual installed efficiency is usually much worse than 
the manufacturer's ratings. Efficiencies as low as 30 to 40 percent have been measured in the field. It is recommended that high-efficiency ( 80 percent to 90 percent) axial air-foil fans be considered with direct drive and static regain devices. However, flexibility of adjustments will be compromised. [Naughton, "HVAC Systems... Part 1," 1990; Micro-Electronics Facility Efficiency Workshop 1995]

\section{- Fan size vs. speed}

Fan size influences horsepower requirements, with larger fans tending to have higher efficiencies than smaller fans. Larger, low-speed fans also have reduced drive losses and lower maintenance costs. [Micro-Electronics Facility Efficiency Workshop, 1995]

\section{- Sound power levels}

If a vane-axial fan is selected, louder fan sound may require attenuation, resulting in system pressure drops. Even though some centrifugal fans have lower efficiencies, they can operate at lower sound levels, eliminating energy-wasting pressure drops. [Naughton, "HVAC Systems... Part 1," 1990]

\section{- System dynamics}

The design engineer should investigate various options for the prescribed laboratory configuration and examine the total system dynamics, not just one component such as system static pressure. When the entire system is evaluated, unexpected results may occur. Kruse (1991) points out that, "Until all other components of the air-side system, including ductwork and filters, have been designed, the fan(s) cannot be selected."

This is contrary to typical design practice. Engineers should consider the brake horsepower required for not only the design condition, but all other conditions that the fan may experience, such as part-load, start-up load and full RPM load. Also, the number of fans used in a pressurized plenum design influence system redundancy and flexibility as well as total energy use. [Kruse, 1991; Naughton, "HVAC Systems... Part 1," 1990; Micro-Electronics Facility Efficiency Workshop 1995]

\subsubsection{Selection and optimum BHP}

Kruse (1991) presents and analyzes "published fan performance data for single-width, single-iniet, air-foil style plug fans at 20,000 CFM and 2.5 inches static pressure":

\begin{tabular}{rrr}
\hline Size & BHP & RPM \\
\hline 33 & 15.6 & 1,200 \\
36 & 13.8 & 960 \\
40 & 12.3 & 767 \\
44 & 12.1 & 653 \\
49 & 12.6 & 586 \\
54 & 13.8 & 524 \\
\hline
\end{tabular}

These data indicate two common trends. First, as fans get larger, they perform the same work at lower RPM's. Second, there is an optimum BHP selection with poorer selections for larger and smaller fans. Based purely on the above data, a size 44 fan would be the optimum selection. The worst fan would consume $29 \%$ more energy. Two factors, however, might lead to the selection of the size 40 fan, even though it consumes $1.6 \%$ more energy. First, the size 44 might simply not fit in the available space. Second, if both are driven by 900 RPM direct drive motors with variablefrequency drives (VFD's), the size 40 fan would draw 20 horsepower at 900 RPM while the size 44 
fan would draw 30 horsepower at 900 RPM. This condition could easily occur if the VFD went into a bypass mode. Providing a $20 \mathrm{HP}$ motor for the size 40 fan makes more sense than buying a 30 HP motor for the slightly more efficient size 44 fan, considering the costs of the fan, the motor, the wiring, the VFD and the lower efficiency of a 30 HP motor operating at 12.1 horsepower.

\subsubsection{Fan selection evaluation}

Hunt et al. (1990) describe the process of evaluating air-handling system fans.

In evaluating any fan system and the corresponding system effects, there are two basic areas of consideration: those elements that are constant from one selection to the next and those that are variable based upon which fan is utilized.

\section{Constant Elements}

- Filter Pressure Drops-Based on constant flow rates, filter pressure drops remain the same between alternate fans.

- Coil Pressure Drops-Based on constant flow rates, coil pressure drops remain the same between alternate fans.

- Airflow-Airflow rates are maintained as a constant between alternate fans.

- External Static Pressure-The resistance to aiflow external to the unit discharge and prior to the return air inlet is considered a constant.

- Inlet/Outlet Sound Power Specification-Inlet and outlet sound powers are a constant, given for compatibility to room sound level specifications. Although levels might vary from selection to selection, the specification will remain constant.

\section{Variable Elements}

- Total Pressure - In all systems where air is moved, a fan must develop pressure to overcome all friction and dynamic losses within that system. The pressure that the fan generates is total pressure, which is the sum of two components, static pressure and velocity pressure. Static pressure is that portion of the air pressure which exists by virtue of the degree of compression only. If expressed as gauge pressure, it may be negative or positive. Velocity pressure is that portion of air pressure which exists by virtue of the rate of motion only. It is always positive. Total pressure is the air pressure which exists by virtue of the degree of compression and the rate of motion. It is the algebraic sum of the velocity pressure and the static pressure at a point.

- Noise Control - Inlet and outlet sound power specifications are constant system criteria. However, to meet stringent clean room sound level specifications dependent upon the fan selected, based upon physical constraints, varying amounts of noise control will be required within the system. Noise control elements often add static load to the fan, which results in increased fan noise. This increased fan noise must be considered in the choice of the control element.

- Fan Efficiency - The efficiency of a fan is an important element in the selection process and an element that will vary from one fan selection to another and from manufacturer to manufacturer. With many clean room applications where large airflow rates are involved, optimizing system efficiency can result in substantial operating cost savings. Equally 
significant, an improper selection can yield large penalties in operational costs. Concentrating solely on one aspect of the system will often result in a fan system's failure to achieve its highest overall efficiency. Often the critical error is concentrating solely on fan efficiency. The important thing to recognize is that catalog data and efficiency ratings are developed under "ideal" test conditions, which are rarely duplicated in clean room configurations. As a result, the actual field conditions must be carefully evaluated and an analysis made of their effect on fan performance with corrections being made both from factory-supplied data and other sources, such as AMCA publications, personal field experience, and private lab testing.

- System Effect - The term "system effect" is a subjective term, intended to ask how the fan's performance is affected by external conditions. Critical examination of the inlet and discharge conditions relating to the fan is appropriate whether utilizing an axial or centrifugal device. The application of correction factors relating to fan performance is necessary where field conditions vary from test conditions. Application of these factors will essentially ensure that full air delivery to the system will be accomplished.

\subsubsection{System effect}

The report of the Micro-Electronics Facility Efficiency Workshop (1995) points out that:

Specifying a high efficiency fan out of a catalog is not enough. Careful design requires looking at all aspects of the fan-motor-housing system. ...[In] an example...an otherwise efficient direct-drive axial fan...had a motor mounting scheme that covered up nearly a third of the fan opening. Likewise, it is not enough to just specify fan efficiency at a single point, it is also important to specify a fan with a large "bulls-eye"; i.e., where the peak efficiency can be maintained over a wide range of static pressure and fan flow rate. ...efficiency plots from one manufacturer of virtually identical models [can be quite different], one with a very small efficiency "bulls-eye" and one with a very large "bulls-eye" for an othenwise identical " $80 \%$ efficient" fan.

\subsubsection{Variable frequency drive (VFD) application}

Kruse (1991) discusses fan volume control.

Volume control can affect the efficiency of the air system. Belt drives are common and work well for non-clean purposes such as offices, but the particles they shed preclude their use in clean rooms. Dampers and inlet vanes can throttle a fan to the desired operating point with some energy savings. One plug fan manufacturer has a patented device which goes one step better by effectively reducing the fan width. With vane-axial fans, the blade pitch can be changed, either while the fan is running (low RPM fans only) or while the fan is off. The RPM has to do with the mechanism involved and not the skill of the mechanic. VFD's can be used on any style of fan and are very efficient. Depending on the style of fan being used and the flexibility desired, blade pitch adjustment or VFD control will be the most efficient.

Brown (1993) describes the use of VFD control in a laboratory in Colorado.

Fan speed is controlled by the lowest reading of multiple-duct static pressure sensors. Each fan receives the same control signal, thereby providing nearly equal loading. This loading is dependent upon manifold design; however, there is an equalizing effect when any imbalance occurs. The system operates at a constant volume, as determined by the flow setting of each constant-volume terminal unit. Even though the system is constant volume, VFD control is provided to account for variable filter loading, future capacity changes, and three- or four-unit operation without affecting system balance. It should be noted that the constant-volume design was predicated on the fact that the majority of laboratory exhaust is through process equipment, 
customer-fabricated hood/enclosures, laminar flow fume hoods and gas cabinets, etc., all of which are not adaptable to current VAV control technology.

\subsubsection{Drive and motor efficiency}

Naughton (("HVAC Systems... Part 1, 1990) discusses energy savings from drive and motor choices.

The choice of drive mechanism and motor type will also yield considerable energy-savings potential. Additional energy savings of 2 to $5 \mathrm{~W} / \mathrm{ft}^{2}\left(21.6\right.$ to $\left.54 \mathrm{~W} / \mathrm{m}^{2}\right)$ may be achieved with the substitution of high-efficiency motors for standard-efficiency motors. The choice to use fans with motors outside the primary air stream will save 1.0 to $1.5 \mathrm{~W} / \mathrm{ft}^{2}$. (10.7 to $\left.16.15 \mathrm{~W} / \mathrm{m}^{2}\right)$ due to motor inefficiency, but removal of the motor from the air stream by using belt-driven fans with lower mechanical efficiencies will reduce the energy savings. High-efficiency motors have an inefficiency of $6 \%$ to $8 \%$, whereas belt-drive systems have inefficiencies of $4 \%$ to $6 \%$. The use of special direct-drive fans with motors outside the air stream (bifurcated fan housings) may result in higher system effects and lower total efficiency.

\subsubsection{Synchronous belts}

De Almeida and Greenberg (1995) point out that,

Synchronous belts are stretch-free and can achieve higher efficiency than V-belts due to lower hysteresis, lower friction losses, and truly synchronous operation (no slip; no creep). The lower flexing losses result from the small thickness of the belt between the teeth. The absence of speed losses (slip and creep) is due to the positive mating of the teeth of the belt with the teeth of the sprockets. Because of these lower losses the synchronous belts have not only higher peak efficiency than V-belts, but also the efficiency curve is flatter.

Synchronous belts require toothed pulleys (sprockets), which are more expensive than $V$-belt pulleys. In a retrofit application, the additional investment required is the cost of the sprockets, plus the extra cost of the belts and of the installation. In the cost-effectiveness calculations it is assumed that those extra costs fall in the range $\$ 8-16 / \mathrm{hp}$. This price variation is strongly dependent on the rating of the belt drive, with the large drives requiring a smaller price premium per horsepower. The sprockets typically cost 1.5-2 times the cost of belts (the second and third purchased at future times and thus discounted) and one set of sprockets. Additionally, it is assumed that there is an average 5\% efficiency improvement and that the belt will last 24,000 operating hours. Synchronous belts provide slip-free synchronous operation, have a long lifetime, and can operate in wet and oily environments. Their operation can be noisy at high speed and their main weakness is the lack of capability to absorb shock loads.

\subsubsection{Scroll housing effects}

Eidam (1988) recommends against fans with scrolls. "One would prefer to have a fan without a scroll which could just be bolted into the housing of the cleanroom equipment without any additional connections on the inlet and/or pressure side. The scroll housing is not desirable because the proportion of dynamic pressure maintained in the discharge of our fan is of little use to the cleanroom equipment."

\subsubsection{Manufacturers' data}

Kruse (1991) recommends, 
When comparing fans, remember that fans are mass produced and that fan performance data (curves) has [sic] evolved over time without the benefit of a factory test on each and every fan ever produced. This means that one manufacturer may publish different data than another manufacturer for the theoretically same fan. Although some of the difference could possibly be due to minor design differences between the two fans, it could also be due to a series of statistical interpolations over a period of time.

\subsubsection{Coils}

The selection of hot and chilled water coils will have a substantial impact on the fan energy use.

\section{- Thin coil design}

Traditional AHU design specifies coil sizes assuming a face velocity of between 400 and 500 feet per minute. A new design technique called low face velocity, high coolant velocity or LFV/HCV has been researched at the University of Adelaide, Australia. This technique uses a "thin" coil design that is roughly half the number of tubes in depth as in conventional designs but double the coil face area. The net result is a face velocity in the range of 150 to 200 feet per minute, with much higher heat transfer efficiency and lower pressure drop than in conventional designs. Because the coil's pressure loss is proportional to the velocity at a square rate, face velocity reduction can result in pressure drops of onefourth or less compared to the equivalent, traditionally designed coil. [Micro-Electronics Facility Efficiency Workshop 1995]

\section{- Preheat coils}

A preheat coil is commonly used to control condensation inside the HVAC system for laboratories that use 100 percent outside air or when the outside air temperature falls below freezing. If a heating coil is used downstream, the preheat coil should become inactive to save energy when outdoor temperatures reach 45 degrees F. Preheat coils are also used to warm the outside air stream, assuring better air stream mixing and providing free humidification. [Suhail, 1989]

\subsubsection{Evaporative cooling}

Evaporative cooling systems have been used to condition facilities since before refrigerated cooling was invented. There are two types of evaporative cooling techniques: indirect and direct. The indirect approach removes sensible energy only from the air stream with an exchanger that has the air stream flow on one side of a plate and water on the other. The direct approach removes energy from the air stream adiabatically by adding moisture to the air stream. These approaches can be combined to provide cooling and humidification that displaces energy from a conventional compressor-type HVAC system. Annual energy savings of more than 15 percent for a one-stage, direct system and over 38 percent for a two-stage indirect/direct system can be realized when compared to a conventional HVAC system. Brown (1993) says that "The use of direct evaporative cooling to humidify increases the opportunity to recover heat by 36 percent and reduce energy consumption during the heating season." One- to two-year paybacks are possible. The justification of evaporative cooling should not be based solely on the ability to replace mechanical cooling but should be considered as an opportunity to displace mechanical cooling/humidification energy. [Brown, 1992; Brown, 1993]

Evaporative cooling should always be considered for all make-up air systems, regardless of geographic region, as noted in the descriptions of the approaches below: 
- Indirect

Indirect evaporative cooling is applicable when there is a large process equipment cooling load, the HVAC system operates on a continuous basis, and a direct evaporative cooling opportunity exists. [Brown, 1993]

\section{- Direct}

Direct evaporative cooling can be justified on the basis of eliminating the need for a steam humidification system, enhancing economizer operation, reducing humidification energy used in conjunction with heat recovery, and controlling the temperature of a space independent of controlling its humidity. Direct evaporative cooling for both make-up air and recirculation-type systems should always be considered when the outdoor wet-bulb temperature is $53^{\circ} \mathrm{F}\left(11.7^{\circ} \mathrm{C}\right)$ or less for 3,500 or more hours per year. [Brown, 1990; Brown, 1993]

\section{- Two-stage}

Typically, a two-stage evaporative cooling system comprises a direct evaporative cooler downstream of an indirect evaporative cooler. The two coolers can be combined in a myriad of arrangements to increase energy efficiency. [Brown, 1992; Brown, 1993; Brown, 1990]

\subsubsection{Evaporative cooler configuration}

Brown (1992) describes the use of evaporative cooling in a university life sciences laboratory in Arizona.

The indirect precooler is comprised of a standard finned-tube heat exchanger connected with piping to a cooling tower. Water cooled in the tower is circulated through the coil to precool outdoor air. Accordingly, mechanical cooling is displaced by indirect atmospheric thermodynamic exchange. (All evaporative cooling components are commercially available and can be competitively bid.)

\section{Basis of analysis}

The baseline analysis is predicated on a conventional two-fan dual-duct HVAC system with steam humidifier (hereafter referred to as the conventional system). The actual system is identical to the conventional system except that a direct evaporative cooler is located downstream of the cooling coil in the cold deck, replacing the steam humidifier. In addition, the preheat coil is replaced with a preheat/precooling coil, which is connected via piping to cooling tower. A plate-and-frame heat exchanger in the piping loop provides a means to heat water during the winter.

Brown (1990) analyzes the effectiveness of indirect evaporative cooling and concludes that

Indirect evaporative precooling will only be effective where the difference between outdoor dinbulb and wet-bulb remains high $\left(13^{\circ} \mathrm{F}\left(7.2^{\circ} \mathrm{C}\right)\right.$ or more) for the majority of the cooling hours. The concept is not applicable when the difference between dry-bulb and wet-bulb is small $\left(12^{\circ} \mathrm{F}\left(6.7^{\mathrm{C}} \mathrm{C}\right)\right.$ or less) for the majority of the cooling hours. Thus, this energy consenvation measure will be limited to dry climates.

\subsubsection{Humidity control}

Kruse (1991) analyzes methods of providing humidification. 
Humidification can be provided in one of several forms. The need for clean air which is free from particles and ions usually eliminates humidifiers which use untreated water, treated water or steam from treated boiler systems. This leaves steam and evaporative styles which use deionized water or reverse-osmosis reject water. The analysis actually hinges around two issues; the cost of the water and the cost of the energy to convert it into a usable form. Regarding the cost of the water, if the building has a [Deionized Water] D.I. production system which uses a Reverse Osmosis [R.O.] unit, use the R.O. rejected water because it is essentially free. Otherwise, use the same source of $D . I$. water as the rest of the project, and pay the price. Regarding the energy required to use the water, the most expensive is usually electric energy. Each analysis must be site specific, of course. Packaged humidifiers can use electricity to convert D.I. water into steam. These may be your only choice for small projects, but they will consume lots of energy on large designs. Packaged humidifiers can also use steam as an energy source to convert D.I. water into steam. This is usually more cost effective since the plant steam will have usually been made by using a lower-cost fossil fuel instead of electricity. Steam generators can produce D.I. steam in a similar fashion, but on a larger scale. Evaporative humidifiers are the best economic choice... . This is especially true with tight humidity tolerances and in dry climates where an adiabatic "free cooling" effect can be obtained. Altogether, the best combination is evaporative humidification fed by $R$. 0 . rejected water.

Brown (1993) identifies typical humidity ranges for laboratories.

For energy conservation reasons, the laboratory humidity ... [is typically] allowed to vary from a maximum of $50 \% \mathrm{RH}$ when outdoor wet-bulb is greater than $54^{\circ} \mathrm{F}\left(12.2^{\circ} \mathrm{C}\right)$ to a minimum $40 \% \mathrm{RH}$ when outdoor air wet-bulb is $50^{\circ} \mathrm{F}\left(10^{\circ} \mathrm{C}\right)$ or less. Supply air dew-point control ... [is] reset down accordingly. Face and bypass dampers ...[are] controlled to bypass air around the evaporative cooler to maintain supply air dew point.

Brown (1990) discusses humidification choices.

It is not possible to fully evaluate heat recovery potential and benefits without considering humidification. When humidity is added by steam, fuel-generated energy is always required. When humidity is provided with a direct evaporative cooler, all or a portion of the energy required to evaporate water can be supplied by recovered heat. While any supplemental energy required is fuel-generated, the source is not restricted to steam and the use of hot water is generally the preferred choice. As expected...the greatest requirement for humidification energy occurs in the colder/drier climates. Therefore, it is the author's opinion that a direct evaporative cooler be given highest consideration for humidification an energy conservation measure. ... In some climates, direct evaporative cooling has an added benefit by providing simultaneous cooling and humidification.

\subsubsection{Economizers}

Suhail (1989) points out that, "Laboratories, research facilities, clean rooms, and hospitals require large amounts of outside make-up air. These facilities can only benefit from economizers when the facility does not require 100 percent outside make-up air. Exhaust air from the facility may be added into this outside make-up air stream with an economizer to save energy. Inadequate mixing of the make-up air stream and the exhaust (return) air will defeat the function of economizer." Consequently, errors made by the mixed-air temperature sensor "can increase annual energy consumption by as much as 30 to 50 percent." In the same report, Suhail (1989) describes a study by Kao et $\mathrm{al}^{3}$ of economizer operation which found

${ }^{3}$ See referenced document for full citation. 
that "a sensor error of only $1^{\circ} \mathrm{F}$ wasted 10 percent of the cooling energy and 6 percent of the heating energy in the HVAC systems studied." To maximize the savings from economizer system, proper blending and sensing of the air streams must occur. Stratified, unblended joining of the return and outside air streams in HVAC economizer systems can result in varied building temperatures, uneven filter distribution, and, in the right climate, frozen coils. [Suhail, 1989]

\subsubsection{Mixing box efficiency}

Suhail (1989) discusses mixing box efficiencies.

In the typical mixing box, outside air and return air pass through galvanized steel damper blades before entering the mixing chamber. Once in the chamber, the two air streams are expected to blend and then continue through the rest of the air handling system at a consistent temperature. However, standard mixing boxes can be limited in their ability to mix effectively due to poorly placed inlets, chamber leakage and dampers that freeze shut, allowing excessive amounts of outside air into a building. Properly proportioned parallel blade dampers are more effective in mixing air streams of different temperatures within the mixing box, but they are less effective than opposed blade dampers in controlling the air stream velocities.

The distance specified to mix air before it reaches the mixed-air temperature sensor may be inadequate in a typical box sized by the design engineer. In such cases the sensor will not detect the true average temperature of the mixed air; variances of more than 10 degrees $F$ are not uncommon in the stratified air streams.

\subsubsection{Air blenders}

Suhail (1989) describes air blenders and their use.

The air blender is a static device that can be used to blend outside air and return air within a predictable standard deviation. Aerodynamically designed for manageable pressure drops, the standard blender is fabricated of 0.08 in.-thick aluminum. Blenders have also been used as a diffusion device on the outlet of a centrifugal fan to provide uniform velocity across cooling coils downstream. One aspect about air blenders ...[to consider] is the length required to get mixing, which can add 5 to 8 feet to the unit....the length of ductwork that the blender requires for proper mixing ... is a minimum distance equal to the diameter of the blender face.

\subsubsection{Economizer case study}

Atwell and McGeddy (1989) present a case study of a VAV retrofit project in a New York hospital.

A second method of reducing the energy consumption of the operating rooms to incorporate variable air flow and the use of outside air according to occupancy and weather conditions was developed. The hospital requested and received permission from the New York State Department of Health to use the federal standard of 15 air changes per hour with 100\% outside air when outside conditions made that selection more economical than the current state standard of 25 air changes per hour with $20 \%$ outside air. To enable the system to easily change back and forth from 25 to 15 air changes per hour, variable speed drives were installed on the supply and return fans. An energy management system was installed to control the heating and cooling coils, humidifiers, and variable speed drives. The system also monitors space conditions.

This system helps the HVAC systems run as efficiently as possible. The air flow rate is now determined by outside conditions; as a result, the system uses outside air with more frequency. 
The energy management system monitors outside air conditions during occupied hours and then determines whether the HVAC system should operate at 15 air changes per hour with $100 \%$ outside air or 25 air changes per hour with $20 \%$ outside air. When the outside temperature is between $3^{\circ} \mathrm{F}$ and $70^{\circ} \mathrm{F}$, the system will operate according to the federal standard. When the outside temperature is below $35^{\circ} \mathrm{F}$ or above $70^{\circ} \mathrm{F}$, the system will operate according to the New York State standard. During unoccupied hours, the systems operate at 15 air changes per hour with full return air.

\subsection{Energy Recovery}

\section{Energy Efficiency and Energy Recovery}

Energy recovery systems typically incorporate heat exchange equipment to reduce energy costs by extracting heat from the facility's exhaust air stream before it is vented outside. Energy recovery from the laboratory's exhaust should be considered when a significant portion of operating hours are at ambient temperature of $50^{\circ} \mathrm{F}\left(10^{\circ} \mathrm{C}\right)$ and below. When properly designed, these energy recovery systems can reduce installed HVAC system capacity by one-half; reduce operating energy from one-third to twothirds, depending upon mode of operation; and have life-cycle cost paybacks from immediate to three years. The four major energy recovery systems include run-around coil systems, regenerative heat wheels, heat pipes, and fixed-plate exchangers. [Brown, 1993; Industrial Ventilation: A Manual of Recommended Practice - 22nd Edition, 1995]

\section{- Run-around coil systems}

These systems can recover energy in other ways besides recapturing the heat in the exhaust air. For example, waste heat in the process cooling water from the laboratory equipment can be recovered. Water chiller waste heat can provide domestic hot water and space heating for laboratories and offices with a run-around coil system. [Schicht, 1991]

The following types of energy recovery systems require side-by-side exhaust and supply ducting.

\section{- Regenerative heat wheels}

A regenerative heat wheel is a revolving disc filled with an air-permeable medium. When the exhaust air passes through the medium, heat energy is transferred to the medium. As the medium rotates into the make-up air stream, the warmed medium transfers the heat to the cooler make-up air. There has been a renewed interest in heat wheels since molecular sieve coatings have been used that ensure minimal contaminant transfer. [Industrial Ventilation: A Manual of Recommended Practice - 22nd Edition, 1995; Besant and Johnson, 1995]

\section{- Heat pipes}

Heat pipes offer a unique, compactly sized method of energy recovery that requires no external energy; however, they are not often used because of the restrictions they place on location of supply and exhaust air streams.

\section{- Fixed-plate exchangers}

Typically, fixed-plate energy recovery systems are coated, air-to-air aluminum heat exchangers; they may have to be quite large to perform effectively. 


\subsubsection{Laboratory energy recovery selection factors}

Brown (1990) recommends that a

Heat recovery coil should be incorporated for geographic regions with high preheating/humidification requirements.

a. Locate coil upstream of preheating coil in cold climates.

b. Coil can be located downstream of fan in non-severe climates to maximize benefits of precooling where applicable.

The American Conference of Governmental Industrial Hygienists Industrial Ventilation: A Manual of Recommended Practice (1995) discusses issues in selecting heat exchangers.

Several factors are important in the selection of the appropriate heat exchanger. A partial list is as follows:

- The nature of the exhaust stream. A corrosive or dust laden stream may need to be precleaned.

- The need to isolate the contaminated exhaust stream from the clean replacement air stream.

- The temperature of the exhaust stream. Unless the box air stream is well above the desired delivery temperature of the replacement air stream and the exhaust air stream is at elevated temperatures whenever heat is demanded by the replacement air stream, additional heating capacity will be required.

- Space Requirements. Space requirements for some heat exchangers can be very extensive, especially when the additional duct runs are considered.

- The nature of the air stream. Many exhaust air streams are corrosive or dirty and special construction materials may be required.

- The need for a by-pass. During failure mode or summer conditions, a by-pass will be required.

\subsubsection{Run-around systems}

The run-around heat recovery system is a simple piping loop, containing a circulator; the loop connects a finned-tube coil in the exhaust plenum with a finned-tube coil in the make-up air plenum or AHU. The circulating fluid is heated by the warm exhaust air; this fluid then warms the cool make-up air. The heat recovery system typically operates to preheat outdoor make-up air but also to pre-cool the make-up air when the exhaust air stream is cooler than the outdoor makeup air. [Brown, 1993; Industrial Ventilation: A Manual of Recommended Practice - 22nd Edition, 1995]

\section{- Energy savings and benefits}

A high-performance, run-around energy exchanger can provide a large increase in overall HVAC system effectiveness from 50 percent to nearly 70 percent, large returns on investment, typically 33 percent, and short payback periods of three years. In new building designs and retrofits, a run-around system can reduce peak heating and cooling loads as well as total heating and cooling loads. The run-around system 
can have a significant impact upon the boiler and chiller capacity in new HVAC designs. [Besant and Johnson, 1995]

\section{- System effectiveness}

Depending upon its arrangement and features and a thorough sizing analysis by an energy engineer, a system's overall effectiveness can be much higher than in the past (50 percent or less) using run-aroundcoil-tube heat exchanger systems that are accurately designed for maximum cost-effective performance. Because of the relatively small temperature differences between the energy exchange coils, very accurate simulation and cost models are needed. [Besant and Johnson, 1995]

\section{- Separation advantage}

A main advantage of the run-around coil is that exhaust and supply duct systems can be separated by a significant distance. This feature reduces the potential for contamination of fresh intake air by exhaust air. [Industrial Ventilation: A Manual of Recommended Practice - 22nd Edition, 1995; Besant and Johnson, 1995]

\section{- General application}

Depending upon utility rates, situations with ventilation air-flow rates greater than $10,000 \mathrm{cfm}(5000 \mathrm{~L} / \mathrm{s})$ are usually good opportunities to use run-around systems. [Besant and Johnson, 1995]

\subsubsection{Manifolded exhaust and energy recovery}

Neuman and Sandru (1990) emphasize the advantage of a manifolded exhaust system.

.... manifolded exhaust system offers the opportunity for energy recovery. Since all effluents are brought to a single exhaust system only one large recovery unit would be required and would operate at a higher efficiency than small individual recovery units. The recovery system or equipment should be chosen on the basis of temperature level. Practically all exhaust air recovery systems could be implemented such as run-around coils ... pipe heat exchangers etc. Care must be taken to prevent contaminant carryover between exhaust air and supply air streams.

\subsubsection{Run-around vs. indirect evaporative precooling}

Brown (1990) discusses run-around and indirect evaporative pre-cooling.

Two basic concepts are applicable-run-around heat recovery and indirect evaporative precooling. These concepts have been limited to schemes that rely on piping the cooling fluid to a finned-tube heat exchanger within the makeup air unit. While there are other variable heat recovery or indirect evaporative cooling concepts, they are predicated on a close-coupled arrangement of makeup air and exhaust air. This results in a physical arrangement not considered practical for most cleanroom system designs. For the run-around heat recovery arrangement, the recovery coil in the exhaust duct can be placed upstream or downstream of the scrubber. When placed downstream, the entering coil temperature is less (due to adiabatic cooling in the scrubber), thereby resulting in greater cooling potential. However, while enhancing cooling opportunities, preheating opportunities are reduced. With the coil placed upstream, cooling heat recovery is decreased, while preheating opportunities are enhanced. To select the best location, it is necessary to evaluate how the exhaust stream is partitioned. Generally, only the acid exhaust is scrubbed and could amount to $50 \%$ or less of the total exhaust. Further, as the semiconductor industry moves toward more dry processing vs. wet, the opportunities to benefit from better cooling potential associated with scrubbed exhaust diminish. 


\subsubsection{Condenser water heat recovery}

Kruse (1991) discusses the use of condenser water for reheating.

A[nother heat recovery] ... system is a low-temperature chilled water (brine) system which uses its condenser water for re-heat purposes. A make-up air unit will normally have brine coils and reheat coils. This can also be true for dual purpose units. Normally the brine is supplied by a chiller whose condenser water is cooled by a cooling tower. At the same time, the re-heat coil is fed from a boiler. Frequently, the boiler and tower can be eliminated from this portion of the building system. (Don't throw them away. Simply make them smaller.) By using a local, water cooled chiller somewhere at the project site, the condenser water can be piped to the re-heat coil instead of to a cooling tower. Again, depending on the design requirements of the air handler, there may be a need for simultaneous cooling and re-heating for de-humidification purposes. A psychometric analysis will easily verify the feasibility and predict the savings. Knowing the energy consuming nature of make-up air units, the savings can be considerable.

\subsubsection{Coupling fluid glycol concentration}

Besant and Johnson (1995) discuss details of fluid glycol the use in a run-around system in Saskatchewan, Canada.

...the temperature difference between the air and coupling fluid is only a few degrees in a runaround system. This implies that the designer must not only specify the glycol concentration and flow rate for the coupling fluid but also the coil height, coil width, number of coil tube passes, coil tube size, thickness and spatial configuration and fin wavy pattern, spacing and thickness for each heat exchanger coil in the design. [In this example] the system operators, over the years, increased the ethylene glycol content of the coupling fluid to nearly $60 \%$ just to be sure there would be no freezing problems, a measure that would reduce the system effectiveness.

\subsubsection{Simulation model}

Besant and Johnson (1995) point out that

... a simulation model must include all of the many design and operating variables. With such a large number of design variables and wide range of operating temperatures under which these systems perform, it is not surprising that, in the past, run-around systems have not been designed for least life cycle cost nor for high performance. The designer needs an accurate, validated numerical model of the thermal behavior of the run-around system, along with the detailed manufacturing costs associated with each coil design variable and the utility rate structure for fuel and electricity.

\subsubsection{Cooling load reduction}

Besant and Johnson (1995) explain the use of run-around systems during the cooling season.

During the cooling season with ambient air above $18^{\circ} \mathrm{C}\left(64^{\mathrm{C}} \mathrm{F}\right)$, the run-around system can be used to reduce cooling loads. To take full advantage of the run-around system under warm ambient temperatures it is necessary to cool the exhaust air from about $27^{\circ} \mathrm{C}\left(81^{\circ} \mathrm{F}\right)$ just before it passes through the run-around exhaust coil using an evaporative water spray cooler... . In most dry or moderately dry climates evaporative coolers can reduce the exhaust air temperatures by 5 to $11^{\mathrm{c}}$ $C\left(9\right.$. to $\left.20^{\circ} \mathrm{F}\right)$ depending on the initial relative humidity of the exhaust air. For buildings in warm, moist climates with high indoor values of relative humidity the temperature reduction of the exhaust air may be only a few degrees and the cooling load savings will be smaller. 


\title{
5.4.1.7 Run-around system commissioning
}

Besant and Johnson (1995) describe commissioning run-around systems.

In addition to starting and controlling run-around systems, run -around systems for ventilation air energy exchange should be commissioned for performance over a range of ambient temperatures from cold to hot. That is commissioning a run-around system should take place over a duration of at least six months and perhaps one year. Similar evaluations should be done periodically after the initial commissioning to ensure that the performance has not declined.

\subsubsection{Run-around system limitations}

Doyle et al. (1993) explain the disadvantages of run-around systems for a laboratory project in the midwest of the U.S.

\begin{abstract}
A run-around heat recovery system was also considered and rejected for several reasons in this example]. First, acids are commonly used in several of the laboratories, and there were concerns that a conventional copperlaluminum water coil would soon be corroded. Special coatings or stainless steel were found to be expensive and to reduce heat recovery efficiency. Therefore, the exhaust air stream would require filters installed upstream of any heat recovery coils, adding additional first cost to the project as well as a long-term maintenance expense and hazard. In addition, the physical layout of the existing exhaust plenums and fans was restrictive and would have required extensive modification to incorporate heat recovery coils. Finally, there was insufficient space to install new heat recovery coils in the existing supply systems, and the potential for mixing of glycol for heat recovery and central plant chilled water precluded the use of the existing cooling coils.
\end{abstract}

\subsubsection{Desiccant heat wheels}

In a typical laboratory facility, more than half the total HVAC load can be latent. To optimize energy recovery, energy engineers should recover both sensible and latent energy from the exhaust air stream. In the past, use of the rotating energy recovery wheels has not been recommended because of the potential carryover of contaminants from the exhaust air stream to the supply air stream. Recently, a molecular sieve, desiccant-based heat wheel technology has been developed that actually improves indoor air quality. The molecular sieve heat wheel provides sensible and latent energy recovery with a very low level of cross contamination between the incoming outdoor air and the exhaust system discharge. [Wier, 1983; Carroll, 1995; Diblasio, 1995]

\section{- Energy savings}

Molecular sieve heat wheels have been installed in many laboratory facilities from a multiple-story medical research facility to an animal virology laboratory to hospitals. Cooling requirements have been reduced by half and heating and humidification requirements by more than two-thirds. Installed chiller and heating plant capacities have been reduced by as much as 50 percent, saving both money and space. These new heat wheels have provided enough first-cost savings to pay for themselves before they were put into operation. [Diblasio, 1995]

\section{- Energy transfer}

The mass of the molecular sieve heat wheel is a coated desiccant matrix. The wheel rotates slowly, typically at about $20 \mathrm{rpm}$, between the building exhaust and supply air streams. The desiccant medium transfers heat with an efficiency of 75 percent to 90 percent by adsorbing and transferring vapor from one 
air stream to the other. Because moisture is transferred in vapor form, there are no wet surfaces to support microbial growth or chemical byproducts associated with boiler steam humidification. [Diblasio, 1995]

\section{- Molecular sieve}

Overcoming the major obstacle of exhaust contaminant cross-contamination into the supply air stream is accomplished with a three-angstrom $(\AA)$ molecular sieve. The wheel incorporates a sieve, which prevents the transfer of materials larger than $3 \AA$. All molecules larger than $3 \AA$ are too large to enter the sieve and pass by the wheel without being absorbed into the underlying desiccant medium. Water vapor at $2.8 \AA$ passes through the sieve so that latent energy is recovered. With a heat recovery wheel and this selective adsorption feature, cross-contamination has been virtually eliminated. The molecular sieve heat wheel recovers latent energy and limits cross-contamination to less than 0.04 percent by particulate count. [Carroll, 1995]

\subsubsection{Heat wheel operation}

Diblasio (1995) describes the use of a heat wheel in a research facility in Maryland.

In hot weather, the bottom of each desiccant-coated wheel adsorbs humidity and heat from the outdoor air. Cooler, drier air leaves the other side of the wheel, and passes through chilled-water coils before being circulated throughout the building. Exhaust air is drawn from the many laboratory areas, lab hoods, and biocontainment cabinets throughout the facility. Before leaving the building, this air picks up heat and humidity from the top part of the rotating wheel. In colder weather, the process is reversed. Cold, dry air enters the building and passes through the wheels, picking up heat and moisture recovered from the exhaust air. Then the pre-heated, pre-humidified air passes through hot water coils, and-if necessary-is further humidified. The heated and humidified air is circulated to occupied areas of the building.

\subsubsection{Cross-contamination}

Diblasio (1995) explains that the use of an energy recovery system in a Maryland medical research facility has not caused cross-contamination problems. The heat wheel used in this project

... has been applied to numerous similar installations, with a successful track record. Independent test data were available to confirm the performance claims, as well as the ability of the product to limit cross-contamination. This pilot installation was completed in a new animal virology laboratory, which was housed in a renovated bookstore. The project was tested for crosscontamination by ...[the] Health and Safety Department; the system was found not to transfer contaminants from one airstream to the other. Since providing for the safety of the researchers was the primary directive to the mechanical design team, ... Ithe director of the safety and environmental health department] also needed to be satisfied with the resultant indoor air quality. When recently asked about his perception of the system's performance, [he] reported that he was very pleased. His original concern was that an energy-recovery system would cause crosscontamination-contaminants from the exhaust air coming back into the building. This doesn't appear to have happened at all. ... [The director] said that "There hasn't been a single indoor air quality complaint." Proof of the equipment's effectiveness came through an unscheduled "test" late one night, when a researcher accidentally spilled a container of mercaptoethanol, the chemical added in minuscule concentrations to provide the odor in natural gas. Mercaptoethanol can be smelled in concentrations of three parts per trillion. .... The director] reported that "The odor cleared out of the building within about 20 minutes, and not a trace of it returned." 


\subsubsection{3 $A H U$ installation}

Carroll (1995) describes the installation of an air handling unit in an Ohio biosciences laboratory.

The heat wheels were incorporated into a large custom air handling unit. The unit was manufactured in 20 separate sections...and reconstructed "erector set" fashion. One hundred percent outdoor air enters the unit through louvers that face west ....Air that passes through the unit is conditioned as follows: roll filters; 30 percent particulate filters; heat wheels; heating coils; cooling coils; 99.9 percent final filters; "ultra sorb" grid stainless steel humidifiers, then into the supply air duct. Steam for the humidifiers is provided by boiling deionized water in special stainless steel humidifiers ... . Exhaust air returns through sealed stainless steel ductwork to the air unit. The exhaust air passes through 30 percent particulate filters, the heat wheels, the exhaust fans and then is discharged through exhaust louvers that face east. The prevailing winds dilute the exhaust air and carry it beyond the recirculation range of the intake louvers.

\subsubsection{Heat pipes}

The heat pipe is a unique device, invented early in the days of satellite space exploration. A heat source boils a heat transfer fluid, and a heat sink condenses the fluid back to its liquid state, liberating the energy transferred from the fluid's change of phase. The transfer fluid is contained inside a pipe; it provides both vapor transport and return of the condensate to boil again in a closed loop evaporation condensation cycle. Heat pipes have been successfully installed in laboratory heat recovery systems when the proximity of the supply and exhaust air streams can be closely arranged, and corrosion resistance of the heat pipe is assured. A benefit of a heat pipe system is that it recovers both heating and cooling energy passively without requiring energy use for pumps or motors. [Industrial Ventilation: A Manual of Recommended Practice - 22nd Edition, 1995]

\subsubsection{Fixed-plate systems}

Fixed plate heat exchangers, commonly known as air-to-air heat exchangers, can reduce laboratory energy consumption. The transfer of waste energy from exhaust to laboratory make-up air depends on the location and characteristics of the air streams. These air streams are separated by plates that are usually augmented with fins. The heat exchange principle is simple: warm exhaust air heats a fixed plate, which, in turn, heats the cool make-up air on the other side of the plate. This exchanger uses no transfer media other than the plate-forming wall of the exchanger. [Industrial Ventilation: A Manual of Recommended Practice - 22nd Edition, 1995]

\section{REFERENCES}

Atwell, Cindra M. and Donald McGeddy, P.E., P.C. "Variable Air Volume Retrofits for Hospitals and Laboratories." Energy Technology Conference, Proceedings, November 1989.

Besant, R.W., P.E., and Allan B. Johnson. "Reducing Energy Costs Using Run-Around Systems." ASHRAE Journal, 1995.

Beyene, Ph.D., and Lowrey Asfaw, Ph.D. "A Preliminary Assessment of Strategies to Raise the OffDesign Energy Efficiency of Chiller Machines." San Diego State University Mechanical Engineering Department, San Diego, CA, 1994.

Brown, W. K., P.E. "Evaporative Cooling for a Laboratory Facility." ASHRAE Journal September 1992. 
Brown, W.K., P.E. "An Integrated Approach to Laboratory Energy Efficiency." ASHRAE Transactions, V. 99, Part 2, Laboratory HVAC, 1993.

Brown, W.K., P.E. "Makeup Air Systems Energy-Saving Opportunities." ASHRAE Transactions V. 96, 1990.

Carroll, John, Jr. P.E., C.P.E. "Designing Safe and Efficient Fume Hoods at Research Lab." AIPE Facilities, March, April 1995.

Ciborowski, Thomas J., P.E., and Herb Pluemer. "Actual Results of Energy Efficient Designs." Cleanroom Technology Forum Proceedings, 1991.

De Almeida, Anibal and Steve Greenberg. "Technology assessment: energy-efficient belt transmissions." Energy and Buildings, 1995.

Diblasio, Robert. "Desiccants in Hospitals: Conditioning a Research Facility." Engineered Systems, September 1995.

Doyle, D.L., P.E., R.D. Benzuly, P.E., and J. M. O'Brien, PE. "Variable-Air-Volume Retrofit of an Industrial Research Laboratory." ASHRAE Transactions: Symposia, 1993.

Eidam, H. "Low-Energy Consumption Clean Room Equipment with Laminar Flow." 9th ICCCS Proceedings, Institute of Environmental Sciences, 1988.

Hunt, E., P.E., D.E. Benson, and L.G. Hopkins, P.E. "Fan Efficiency vs. Unit Efficiency for Cleanroom Application." ASHRAE Transactions V. 96, 1990.

Industrial Ventilation: A Manual of Recommended Practice -22nd Edition; ISBN: 1-882417-09-7 (ACGIH). The American Conference of Governmental Industrial Hygienists, Inc., eds. City, State: Publisher, 1995.

Kruse, Robert K., P.E. "Mechanical System Strategies for Energy Efficiency." Cleanroom Technology Forum Proceedings, 1991.

Lyons, D.K., and B.H. Atkinson, J. Kasica. "Mechanical Systems," Handbook of Facilities Planning, Vol. One, ISB Laboratory Facilities; N 0-442-31852-9. Ruys, Theodorus, AIA, ed. New York: Van Nostrand Reinhold, 1990. Micro-Electronics Facility Efficiency Workshop: Meeting Report, Northwest Power Planning Council, Portland, Oregon, 1995.

Naughton, P., P.E. "HVAC Systems for Semiconductor Cleanrooms-Part 1: System Components." ASHRAE Transactions V. 96, 1990.

Naughton, P., P.E. "HVAC Systems for Semiconductor Cleanrooms-Part 2: Total System Components." ASHRAE Transactions V. 96, 1990.

Neuman, V.A., P.E and H.M. Guven, Ph.D. "Laboratory Building HVAC Systems." ASHRAE Transactions, V. 94, Part 2, Laboratory HVAC, 1994.

Neuman, Victor A., P.E. and Emil Sandru, Ph.D. "The Advantages of Manifolding Fume Hood Exhausts." ASHRAE Transactions, V. 96, November, 1990.

Parker, J.A., O. Ahmed, and K.A. Barker. "Application of Building Automation System (BAS) in Evaluating Diversity and Other Characteristics of a VAV Laboratory." ASHRAE Transactions: Symposia, 1993. 
Schicht, H.H. "Chapter 6 - Cost-Efficiency and Energy-saving Concepts for Cleanrooms." Cleanroom Design. Whyte, W., ed., Chichester, England: John Wiley \& Sons, Ltd., 1991.

"Screw Compressors Provide Energy and Cost Savings." Business News Publishing Co., January 1989.

Shepard, M., J. Gregerson, D.J. Houghton P.E., L. Fryer, J. Elleson, B. Pattinson, W. Hawthorne, L. Wester, J. Stein, D. Davia, and S. Parson. Commercial Space Cooling and Air Handling Technology Atlas. E Source, Inc., Boulder, CO, June 1995.

Suhail, Khalid. "Maximizing the Savings from Economizer Systems (Air Stratification in Buildings)." Building Design and Construction, V. 30, N. 6. Reed Publishing Co., May 1989.

Takenami, Toshihito, Tadahiro Ohmi, and Souji Fukuda. "Air Conditioning and Particle Filtration Systems for Energy Saving." Solid State Technology April 1989.

Industrial Ventilation: A Manual of Recommended Practice - 22nd Edition. ISBN: 1-882417-09-7. The American Conference of Governmental Industrial Hygienists, Inc. (ACGIH), eds. Cincinnati, OH: Publisher, 1995.

White, T.L., P.E. "A Winter Cooling Tower Operation for a Central Chilled-Water System." ASHRAE Transactions: Symposia, 1994.

Wier, Robert C., P.E. "Toxicology and Animal Facilities for Research and Development." ASHRAE Transactions, V. 89, Part 2B, Laboratory HVAC, 1983. 


\title{
6. EXHAUST SYSTEMS
}

\begin{abstract}
Energy Efficiency and Exhaust Systems
In laboratory-type facilities, a fundamental goal of energy engineers is to reduce the amount of exhaust air to the lowest safe level for any particular design because conditioned exhaust air is very energy intensive. Code and certification requirements that determine the amount of exhaust need to be verified with the authority that has jurisdiction over the facility design and operation; however, there are surprisingly few codes that stipulate the actual amount of exhaust for laboratory-type facilities. Certification standards must be carefully understood to insure that they are appropriate for the actual activities for which laboratory equipment and space are being used. Devices that exhaust air from a laboratory have evolved in response to concerns about safety and energy consumption. For fume hoods, the most important energy-efficiency measure is to incorporate variable volume exhaust air flow that changes with the position of the protective sash. Energy consumption of the exhaust system is reduced by manifolding fume hoods, when appropriate; manifolding can also reduce first costs and increase system flexibility. The energy required to disperse the effluent from the exhaust stack can be minimized by optimizing stack heights and air stream exit velocities. Finally, even the most sophisticated, energyefficient exhaust system can be rendered ineffective if operators are not trained and motivated to use the system to its maximum potential.
\end{abstract}

\subsection{Overview of Exhaust Systems}

As presented in the Laboratory Control and Safety Solutions Application Guide - Rev. 2, 1994 all exhaust systems for laboratory-type facilities must meet the following four fundamental requirements:

- The system capacity and air velocity must transport all hazardous airborne substances away from their origin and discharge them sufficiently high above the facility. These substances include one or a combination of chemical fumes, vapors, airborne biological substances and various particulate and radioactive elements.

- The system must not leak or allow the exhaust air stream to re-enter the facility.

- The system's components such as ducts, fans, and dampers must be able to withstand the corrosive or other adverse effects of the transported substances.

- The system operation must not generate an unacceptable sound level or excessive vibration.

In selecting an exhaust system, one must also consider: first costs, life-cycle costs, maintainability, space requirements, expansion possibilities, and component reliability (see Chapters 2 and 3 ).

\subsubsection{Configuration}

Laboratories generally use either individual or centralized exhaust system configurations. In an individual exhaust system, each fume hood has its own exhaust fan and ducts. In a centralized system, multiple fume hoods are connected to shared exhaust ductwork. [Laboratory Control and Safety..., 1994]

\subsubsection{Exhaust air cleaning systems}

Exhaust from fume hoods cannot be recirculated; however, some localities and regulatory agencies permit laboratories to recirculate room air if health or fire hazards are small and adequate filtration or air 
cleaning is maintained. The energy savings from recirculating room air may not be sufficient to warrant this design approach in view of the entire system's energy requirements and the need for future flexibility. Extreme caution is advised (see Chapters. 2, 3, and 5). [Laboratory Control and Safety..., 1994]

\subsubsection{Specialized exhaust systems}

Some specialized laboratory fume hoods require filtration or air cleaning before hood exhaust is discharged into the atmosphere. HEPA filters and air scrubber systems are available to remove most undesirable exhaust effluents; however, these added components significantly increase the pressure drop of the exhaust system and thus greatly increase the system's energy consumption. [Laboratory Control and Safety..., 1994]

Perchloric acid fume hoods present a special hazard because of the extremely corrosive vapor and explosive potential of perchlorate salts. Perchlorates typically condense in exhaust ducts downstream from the fume hood. For these reasons, a perchloric acid fume hood is normally operated as a constant air volume fume hood with an individual exhaust system. [Laboratory Control and Safety..., 1994]

Radioisotope fume hoods must also be specially constructed; charcoal and HEPA filters must be installed between the fan(s) and the fume hood. [Laboratory Control and Safety..., 1994]

\subsection{Exhaust Devices}

\section{Energy Efficiency and Exhaust Devices}

Devices that exhaust air from laboratories have evolved in response to increasing concerns that they function as "primary safety barriers." These design changes have also resulted improved their energy consumption. Some basic principles of energy-efficient laboratory exhaust include:

- Safety features, such as entrance air foils, must be included in specified fume hoods to insure energy efficient operation.

- A laboratory's exhaust volume is directly proportional to the fume hood face velocity. The higher the stipulated face velocity, the greater the amount of laboratory exhaust volume and energy use.

- In choosing face velocity, energy engineers must consider the "room air challenge," that is, the disruptions presented to the fume hood face velocity caused by, for example, the operator's movements in the laboratory.

- Biological safety cabinets (BSCs) are constant volume exhaust devices; energy savings result when the intake velocity and the cabinet's opening area are minimized by using the appropriate "Class" and "Type." Using an energy-saving VAV system compensates for dynamic HEPA filter loading over time and different cabinet operational modes.

- Glove boxes, which can be used instead of BSCs, have substantially reduced exhaust than BSCs. Therefore, they offer an interesting energy-saving alternative to BSCs.

\subsubsection{Fume hoods}

There are many types of open and enclosed exhaust hoods including canopy hoods, equipment hoods, biological safety cabinets, and chemical fume hoods. Laboratory-type facilities primarily utilize chemical fume hoods and biological safety cabinets. Fume hoods currently being manufactured incorporate 
entrance air foils, beveled side-wall entrances, internal baffles, and sash options to provide both safety and energy efficiency. Fume hoods typically have either a vertical sash or a horizontal sash arrangement. The horizontal sash can reduce exhaust air volume by 50 percent over the vertical sash system. Because these features are important to insure safe and energy-efficient operation, old fume hoods without them should not be reused. [Neuman and Guven, 1994; Ruys, 1990; Suhail, 1989]

\subsubsection{Fume hood types}

Fume hoods are used to contain various levels of airborne toxic or hazardous materials. Fume hoods are available in numerous types and sizes, depending on the required function. Specific examples include; standard, "constantvolume" bypass air hoods, radioisotope hoods, walk-in hoods, distillation hoods, and perchloric acid hoods. Fume hoods are generally available in four-, five-, six-, eight-, ten-, and twelve-foot widths. [Ruys, 1990]

Saunders (1993) emphasizes, that "Constant-volume bypass hoods are NOT constant face velocity hoods... [When the vertical] sash is raised from the closed to the open position, the velocity increases by a factor of from three to four depending on the clear open size of the bypass."

Hoods incorporating variable air volume (VAV) control systems have nearly constant face velocity. [Saunders, 1993]

According to Monsen (1989), "Auxiliary-air fume hoods [can be] less expensive to operate than conventional or bypass hoods. [However, their use has] significant trade-offs and potential problems." Air flow at the hood face may not be uniform. Temperature or humidity control can be influenced by drafts caused by the auxiliary-air fume hood. The auxiliary air can create a potential venturi effect, drawing contaminated air from inside the hood into the laboratory. Consequently, laboratory balancing and pressurization control can be difficult. [Monsen, 1989]

\subsubsection{Vertical sash}

Vertical sashes offer greater safety than a full open-faced hood. The lowered sash offers the operator "a quick place to hide" in the event of a mishap. Typically, the sash is framed and moves in tracks in the hood's wall. It is counterbalanced to facilitate raising and lowering. The glazing material is normally safety glass; however, rigid plastics compatible with laboratory procedures are acceptable. Sash stops that limit the travel of the sash can aid in solving pressure balance problems sometimes encountered when hoods are retrofitted during renovations. [Saunders, 1993]

\subsubsection{Horizontal sash}

Laboratory operating costs and capital first-costs for HVAC equipment can all be reduced by incorporating fume hoods with horizontal sashes. Horizontal sashes move from side to side only. This design approach allows the sashes to act as a series of movable safety shields which always limit the size of the fume hood opening to some degree. Therefore, the fume hood is never in a fully open position unless the operator removes a sash permanently. Energy savings are from reducing the conditioned air supplied to the room, which is exhausted through the fume hood. [Saunders, 1993]

The sashes are typically provided in a series of panels usually 14 or 15 inches wide. Saunders (1993) observes that a sash "over 15 inches wide is not [considered] comfortable for most people to reach around with both arms simultaneously... [A fume hood narrower] than 6 feet wide should not be considered for a horizontal sash design." [Saunders, 1993] 


\subsubsection{Horizontal/vertical sash}

Combining a vertical sash and a horizontal sash can save significant energy and give flexibility to the hood operator. A horizontal panel system is built into a vertical sash. The increased cost of this arrangement can be justified by the energy savings potential and increased flexibility for the laboratory work. [Saunders, 1993]

\subsubsection{Hood testing}

When a project can afford to test the fume hood performance "AS INSTALLED," the face velocity chosen can be checked for effectiveness and possibly reduced even further to save energy. The testing of the fume hood can be performed under three sets of criteria with a flow rate stipulated and the resulting control level attained as presented in Saunders (1993):

$$
\begin{aligned}
& x x A M y y y \text { or } \\
& x x A \text { Uyyy or } \\
& x x \text { Alyyy }
\end{aligned}
$$

where:

- $x x$ is the flow rate in liters per minute $(1 p m)$. [This value directly relates to the face velocity.]

- AM is "AS MANUFACTURED" and is usually performed by a manufacturer in a test room with no apparatus located inside the hood.

- $A U$ is "AS USED" and is done in the resident laboratory with the equipment inside the hood as it [will be] used.

A third category is "AS INSTALLED," which is the safest way to test a hood because it reflects actual operating conditions.

- Al, "AS INSTALLED," involves testing after construction but before occupancy. The laboratory ventilation system strongly influences the outcome of this test procedure.

- $\quad y y y$ [is] the sampled test gas concentration, in ppm, as determined by the test protocol.

Saunders explains:

To understand whether a hood performs well, the following ratings are reviewed to give the energy engineer a point of reference.

The American Conference of Governmental Industrial Hygienists has suggested that a hood tested at $4 \mathrm{lpm}$ under $A M$ conditions should have a control level not to exceed $0.05 \mathrm{ppm}$. New fume hoods should also be able to achieve this performance rating of $4.0 \mathrm{AM} 0.05$ when measured by ASHRAE 110-1985. For hoods tested under AU conditions the control level of $0.10 \mathrm{ppm}$ is desired. [Saunders, 1993]

According to Knutson (1987),

When an adequately designed and manufactured fume hood is installed in a laboratory where most of the variables that affect the hood performance have been controlled, the [as-installed] hood should be able to perform at a 4.0 AlO 10 level. In order to achieve this level, the hood 
[installation] must be well designed and properly balanced. ...supply air systems, location of the laboratory hood, pedestrian traffic, and operations within and around the hood, must be considered in the design. [Knutson, 1987]

\subsubsection{Fume hood face velocity}

The purpose of a fume hood is to contain contaminants. Ideally, fume hoods provide maximum protection using the least amount of air possible to capture and remove contaminants. In the past, air velocity at the hood face was stipulated according to the worst hazard anticipated in the hood. However, face velocities higher than $125 \mathrm{fpm}$ have been shown to create significant turbulence inside the hood, causing fumes to spill into the laboratory. [Saunders, 1993; Monsen, 1989]

Turbulence induced from the operator standing in the air-flow path is another consideration in the selection of face velocity. The recommended face velocity for most fume hoods is 80 to $100 \mathrm{fpm}$ during occupied hours of laboratory operation. The face velocity has been successfully lowered to $60 \mathrm{fpm}$ when the hood sashes are lowered during unoccupied hours in the laboratory. Leaks in the fume hood system drastically increase the quantity of exhaust air required to produce a stipulated face velocity and thus increase energy consumption. [Ruys, 1990]

\subsubsection{Room air challenge}

Reduced fume hood face velocities provide increased worker protection but must be considered in the context of factors such as: the hood's location in the laboratory, the location of work inside of the hood, and throw velocity of the supply air diffusers.

According to the Handbook of Facilities Planning, Vol. One the "...delicate nature of fume hood performance can be demonstrated easily. A person can make a candle flame flicker from a considerable distance by blowing at it, but cannot do so by inhaling the same amount of air at the same velocity even from a very short distance." In other words, it is more difficult to capture and pull contaminants into a fume hood than to disrupt the air flow into the hood face and draw contaminants out of the fume hood. A worker walking at three miles per hour generates an air velocity of $264 \mathrm{fpm}$. A $100 \mathrm{fpm}$ face velocity only generates a $1.13 \mathrm{mph}$ velocity into the hood. Therefore, a worker walking by the fume hood can easily create enough back draft suction to temporarily reverse the air-flow into the fume hood. [Ruys, 1990]

Supply grills, opening doors, and traffic paths within the laboratory present a "Room Air Challenge" that must be considered by the energy engineer who wishes to apply recommended, relatively gentle, face velocity values of $100 \mathrm{fpm}$ or less. Normally, the HVAC engineer specifically selects supply air diffusers to cause mixing in the room that will establish adequate temperature distribution. However, in laboratories this mixing action interferes with the fume hood exhaust air flow, negatively affecting the hood performance. Supply diffusers must not blow directly at the fume hood face unless they have a throw velocity of only one-half to two-thirds of the hood's face velocity (Caplan \& Knutson, 1978a, 1978b; ACGIH 22nd ed.). Even lower throw velocities are advisable to maximize fume hood performance. [Knutson, 1987; Ruys, 1990]

\subsubsection{Room airflow recommendations}

ASHRAE's recommendations for laboratory design conditions (Caplan and Knutson, 1978a, 1978b) are as follows:

1. Terminal velocity of supply air jet at the face of the hood is at least as important as hood face velocity in controlling spillage of contaminant, in the range of 0.25 to $0.75 \mathrm{~m} / \mathrm{s}$ [50 to 150 FPM] face velocity. 
2. Unless there is significant air velocity challenge parallel to the hood face, the "center position" experiences a higher control level than does a side position. This would indicate that, for an equal hood face area, a number of smaller hoods would provide greater protection than would a single large hood.

3. The terminal velocity of supply air jets should be less than the hood face velocity, preferably no more than one-half to two-thirds the face velocity. Such terminal velocities are far less than conventional practice for room air supply. This consideration makes "crowding" of hoods inadvisable since there would then be insufficient wall or ceiling space for supply air fixtures that would meet this criterion.

4. Increased hood face velocity does not necessarily result in a lower control level. This is observed with both the perforated ceiling panels and wall grilles adjacent to the hood.

5. Increased hood face velocity has a more beneficial effect for a "poor" supply system than for a "good" supply system. Consequently, for equal hood working space and equal protection, a well designed supply system permits lower hood face velocities and hence lower energy consumption.

6. Perforated ceiling panels provide better supply system than grilles or ceiling diffusers in that the system design criteria are simpler and easier to apply and precise adjustment of fixtures is not required. Ceiling panels also permit a greater concentration of hoods than do wall grilles or ceiling diffusers.

\subsubsection{Fume hood location}

The location of the fume hood in a laboratory is critical to its safe and efficient operation. Fume hoods should not face each other within short distances because air may be drawn from one to provide make-up air for the other.

Laboratory entrance doors, according to Knutson (1987), "can have a detrimental effect on [a hood's] performance... for two reasons. First, the [stream] of air entering the room through the doorway can affect hood performance in the same way as ... from a supply air fixture... Secondly, the door [operation] can cause a pumping action. [Knutson, 1987]

\subsubsection{Biological safety cabinets}

Biological safety cabinets (BSCs) require different considerations than fume hoods. BSCs are constantvolume devices, depending on operational mode, and must be set and operated within close tolerances (NSF, 1992). For some cabinets this may represent an air flow tolerance of as little as $15 \mathrm{cfm}$. Typical airbalancing specifications usually call for an accuracy of $\pm 10 \%$ (AABC, 1989). Certifications of the BSC must be carefully understood to insure that they are appropriate for the facility. For these reasons, energy-efficiency opportunities are limited when a laboratory has BSCs required, as follows:

- BSC energy consumption is proportional to the required intake velocity of the "Class" and "Type" of the cabinet and the area of its opening. Therefore, the greatest energy efficiency can be achieved when the appropriate intake velocity and cabinet opening area are minimized with the choice of a BSC. Researchers and engineers should not choose BSCs that are more sophisticated than needed. [Crane, 1994]

- Not all BSCs are exhausted outside of the facility. Some BSCs can recirculate the air back into the laboratory in which they are located, saving energy by reducing heating and cooling energy rejected by the exhaust system. 
- BSCs that are exhausted outside require constant air flow during their normal operational mode because they do not have a moveable sash. However, using a VAV system, which compensates for dynamic HEPA filter loading over time, will save energy In contrast to typical arrangements where the air flow is simply set to accommodate the HEPA filter's clogged state. The VAV system must carefully track and provide the flow level for BSCs, which have a narrower flow tolerance $( \pm 5 \%$ for BSCs) than fume hoods. The typical VAV has a $\pm 10 \%$ flow tolerance, according to many manufacturers' specifications, so the necessary control can be difficult to achieve. [Carroll, 1995]

- Depending on class and type, a BSC has different modes of operation: a zero-flow mode during decontamination, an idle mode where only an internal fan is on, normal mode with internal and external fans on, and emergency mode for full speed exhaust fan operation. A laboratory that accommodates these different air flows with a VAV system will save energy.

\subsubsection{Types of biological safety cabinets}

Biological safety cabinets reduce hazards by three methods: isolation of the biohazard to an identifiable area, containment of the bichazard, and removal of the biohazard from the exhaust air stream.

Class I biological safety cabinets utilize airflow to protect the user and environment from hazards in the cabinets... [C]lass I/ biological safety cabinets use tightly balanced aiflow to protect the user and environment from hazards present in the cabinet and to prevent contamination of the product inside the cabinet... [C]lass III BSCs [a.k.a. glove boxes] protect the user, environment, and product by means of a physical barrier, i.e., an enclosed box where the product inside is manipulated with attached "rubber" gloves. Class /l biological safety cabinets are most frequently utilized in biomedical laboratories. [Crane, 1994]

\subsubsection{BSC type selection}

Crane (1994) points out that

Inadequate attention is often given to proper selection of biological safety cabinets in biomedical laboratories. Many "type $B^{\prime}$ cabinets are selected because the user feels that an exhausted cabinet is inherently safer than a recirculating model. If they are properly installed and maintained, class II, type B cabinets may provide some degree of flexibility for chemical vapor use (Stuart et al. 1985). However, many (if not most) BSL1, BSL2 and BSL3 laboratories can be adequately served by Class II, Type A cabinets that exhaust air through a HEPA filter back into the room. This eliminates the need for direct connection to the HVAC system and the more difficult installation that ensues.

Simons (1991) points out that

[T] Class II, Type A cabinet does not require a separate exhaust system for proper operation. Since the exhaust air from an internal fan in the cabinet is HEPA filtered, the air can be exhausted directly to the laboratory if the facility operator and local codes permit that practice after an adequate risk assessment is performed.

Eagleson (1990) explains that

Class II, Type A minimally impact the building's HVAC system, affecting it only as an additional heat load and in determining the location of supply air diffusers. However, it should be noted that this heat load can be substantial since researchers often group several BSCs into a single laboratory. 
Simons adds that the "failure of the building exhaust system does not affect the biohazard protection of the Class II, Type A cabinets since protection is independent of the building exhaust system." [Simons, 1991]

\subsubsection{BSC Jocation}

Crane (1994) emphasizes that

BSCs require the same considerations as fume hoods as far as room aifflow patterns and location of the hood in relation to room traffic pattems. The location of the cabinet within a room is critical to safe operation. Cabinets should be located away from walking paths. Studies have shown that even walking at moderate speeds up to 42 inches away from the face of a cabinet can cause the cabinet to fail personnel protection tests. [Simons, 1991; Crane, 1994]

\subsubsection{Exhaust air requirements}

The design of the BSC exhaust system must consider the static pressure of the cabinet with dynamic filter loading over time. This static pressure value, generally assumed to be twice the initial pressure drop for the new (unloaded) HEPA filters, provides for a reasonable life of the HEPA filter(s). Therefore, the initial balance point for the exhaust is set at twice the initial pressure drop that is actually required. A VAV exhaust system can reduce energy consumption in contrast to exhaust systems that are balanced for the eventual loading of these filters, because a VAV system adjusts flow slowly over time to match actual filter loading.

The same exhaust air system can be used for laboratories, chemical fume hoods, and BSCs, according to the National Institutes of Health (NIH). This provides an energy-efficient, cost-effective installation of back-up exhaust fans. Exhaust for these cabinets may be singly vented or manifolded with other biological safety cabinets. However, when biological safety cabinets are ducted into manifolded constant-volume or VAV systems, the cabinets must isolated from system air flow fluctuations and static pressure changes. [Simons, 1991; Crane, 1994],

\subsubsection{Glove boxes}

Glove boxes, which are Class III BSCs, have traditionally been used for difficult or dangerous operations, but they can be the most cost-effective technology for a wider range of applications. Glove boxes have significantly lower air flow than exhausted biosafety cabinets and improve control of laboratory space conditioning. [Lacey, 1994; McIlvaine et al., 1992]

\subsubsection{Glove box flow control}

The exhaust air volume of a glove box can be reduced with manual balancing valves in the duct work. The glove box will approach the negative pressure of its exhaust system. With the lower pressure inside the glove box, the air consumption can be 500 percent greater than is necessary. [Laurin, 1995]

An alternative to a manual balancing valve is a mechanical, closed-loop, high-speed pressure regulator that can be used to maintain a constant pressure differential between the glove box and the exhaust system. A mechanical closed-loop pressure regulator in the exhaust duct will prevent fluctuations in the central exhaust system from reaching the glove box. During normal operation of the glove box, the mechanical closed-loop system can maintain process pressure within five percent of set point, even with central exhaust fluctuations of 30 percent. [Laurin, 1995]

When the glove box is opened, exhaust air through the box immediately increases. Some mechanical closed-loop pressure regulators can respond to a change within a tenth of a second, for a 5-to-1 turn-down ratio. During this response time, the pressure is maintained within five percent of set point. [Laurin, 1995] 
With either a manual valve or an automatic valve, the amount of air flow required to maintain a constant pressure differential will be reduced. Either approach has the potential for significant (five- to tenfold exhaust volume reduction) savings to the facility.

\subsection{Variable Volume Hoods}

\section{Energy Efficiency and Variable Volume Hoods}

A primary design feature of an energy-efficient laboratory is a variable volume fume hood and its control system, which maintains a constant, average fume hood face velocity during the hood's dynamic operation. According to Ahmed and Bradley (1990) energy savings will result from:

- the decrease in the exhaust flow rate from the laboratory, which results in a decrease in the amount of conditioned supply air needed; this reduces heating and cooling costs, and

- the decrease, as a function of exhaust flow rate, in the supply and exhaust fan horsepower requirements.

McDiamid (1990) adds another source of energy savings:

- the reduction in airflow when fume hoods are not in use (care must exercised to maintain proper room pressurization).

Energy savings from reduction in the loss of conditioned air can be dramatic: 60 to $70 \%$, with two- to three-year paybacks possible. Initial HVAC capital costs will be lower because the installed chiller, boiler, and air-handling unit capacities can be smaller. There is also an opportunity, through right-sizing, diversity, and load management techniques, to operate equipment at higher efficiency levels. [Wendes, 1990]

\subsubsection{Features and benefits}

Variable volume HVAC systems can offer large energy savings for laboratory applications, but they present special design and operational problems. Although the design considerations are similar to those for a conventional VAV air-conditioning system, more careful analysis of safety issues is required for VAV systems. VAV fume hood control systems have received considerable review and analysis due to their proven energy savings.

VAV control maintains a constant face velocity to ensure safety and save energy by varying exhaust and make-up air volume. SAMA Standard LF-10-1980 (SAMA 1980) ${ }^{4}$ suggests that for most commonly used Class B fume hoods, $100 \mathrm{fpm}(0.508 \mathrm{~m} / \mathrm{s})$ is a reasonable average face velocity for safe operation. Generally, a modulating damper in the fume hood exhaust duct is used to maintain the precise air flow necessary for a given sash position, providing continuous on-line control of the flow through the fume hood. The supply and make-up air are controlled to provide a negative balance of air flow into the room. [Wendes, 1990; Laboratory Control and Safety..., 1994]

According to Wendes (1990), additional desired features and benefits of VAV systems include:

${ }^{4}$ See referenced citation for complete information. 
- Remote monitoring of sash position, which allows user compliance and energy waste to be monitored,

- Remote monitoring of face velocity and laboratory pressurization, which provides the facility operator with valuable energy and safety information,

- Integrated control of total exhaust and supply volumes to maintain both laboratory room temperature and negative pressurization,

- Ability to solve chronic negative building pressure problems by reducing average exhaust volume, and

- Emergency exhaust mode actuation with a push button that overrides normal system operation for maximum exhaust in case of a lab spill or fire.

\subsubsection{Face velocity control}

Fume hood face velocity control is provided as follows: When a hood's sash position changes, the face velocity deviates from the set point, e.g., $100 \mathrm{fpm}(0.508 \mathrm{~m} / \mathrm{s})$. A sash position sensor "notices" this change in velocity and "sends" this information to a velocity controller, which adjusts the face velocity back to the setpoint by adjusting the exhaust air flow rate either up or down. [Ahmed and Bradley, 1990]

There are two types of sash position sensors, an Electronic Velocity Sensor and a Sash Position Sensor. [Neuman, 1994]

\subsubsection{Electronic velocity sensing}

An electronic velocity sensor is a mass flow device installed in the side wall of the hood. It uses a hot-wire anemometer arrangement to detect the velocity and direction of the air passing through it.

\subsubsection{Sash position sensor}

A sash position sensor physically measures sash position either through a cable and pulley to a rheostat or a sensing strip on the hood and a magnet on the sash. Position sensors rely upon a direct proportional relationship to the changing area of the hood opening, as determined by sash height, and to the face velocity. Rapid response time and a linear response are benefits from this approach. [Wendes, 1990] I

\subsubsection{Velocity controller}

Each sensing method has a dedicated electronic velocity controller that varies the position of an exhaust damper/valve or the speed of the dedicated exhaust fan to maintain proper fume hood face velocity.

An added feature of some face velocity control systems is exhaust-flow sensing. This feature can insure that exhaust air is flowing and that the volume is correct for the particular laboratory. This device can also provide energy monitoring information for advanced control techniques (see Chapter 4).

\subsubsection{Response time}

Ahmed and Bradley (1990) stress that "[The movement of a vertical sash... [has a] profound effect on [reducing] pressure in front of the sash." A dynamic change in sash position can cause fumes to spill from the fume hood. 
Consequently, the issue of response time of the face velocity control system is strongly debated for competing system approaches.

The time required for a system to reach set point face velocity and remain steady after a disturbance is one way of defining fume hood control system response time. However, recent research has evaluated the time needed for controllers to respond in order to prevent increases in tracer gas concentration outside the fume hood. This measurement of tracer gas spillage and response recognizes a more critical parameter for safe operation of a fume hood than time needed to reach set point velocity. This research indicated that tracer gas did not escape the fume hood when the damper control took only two to three seconds to return to a constant face velocity after the sash position was changed from minimum to full open. [Ahmed and Bradley, 1990] .

\subsubsection{Face velocity control - A case history}

Monsen (1989) describes a retrofit project at a pharmaceuticals research and manufacturing facility in New Jersey.

A small laboratory was in the process of being renovated with three new $5 \mathrm{ft}(1.524 \mathrm{~m})$ bench hoods. These hoods were installed side by side so that performance of the sash hood controls could readily be compared. Separate variable-speed fans were installed on each of the three hoods with separate ducts to the roof. The laboratory already had several constant-volume hoods and a makeup air system, which also served the rest of the building. A new makeup air system with variable-speed drive was installed to match the air removed by the three new hoods and provide lab pressure control. The makeup air system was controlled by means of an electronic differential pressure control with the adjacent corridor as a reference.

One fume hood was controlled through a mass flow sensor installed in the side wall of the hood. A dedicated electronic controller varies the speed of the dedicated exhaust fan to maintain proper mass flow at the sensor and also at the face of the fume hood. A second hood is controlled by a sash position sensor and a dedicated controller that varies the speed of the dedicated exhaust fan motor proportionally as the sash position changes. The third hood uses both the sash position sensor and the side wall mass flow sensor coupled with a computer-based control system. Here, the sash sensor provides a "feed forward" signal, while the mass flow sensor provides monitoring and refinement of the setpoint. The controller modulates the exhaust fan speed to maintain mass flow setpoints. In addition, the computer-based controller monitors the other two hoods and controls lab pressure and temperature.

All three systems have operated satisfactorily for more than a year and a half with face velocity measurements repeatable within $\pm 10 \%$ of original values. Several minor changes, such as adding a duct velocity sensor to the system with the sash position sensor, have been made to gain more information.

What was learned?

1. All three systems properly control face velocity over the normal range of sash position. The results were repeatable over an extended period of time (more than one year) with no recalibration.

2. Door openings (i.e., lab pressure changes) can seriously affect face velocity, and we have learned to pay close attention to the location of sensors in the course of these installations. In this case, the hood was too close to the corridor door, and door openings were affecting the sensor. The solution was to seal the door and use alternate access to the lab.

3. Although all three systems functioned properly, we have made the following observations: 
a. The mass flow sensor system most accurately controlled face velocity.

b. The sash position sensing system responded much faster to changes in sash position than either of the other systems.

c. The hybrid system was not as responsive and tended to overshoot (which was probably due to the scan time of the microprocessor).

\subsubsection{Retrofits}

In most cases, variable volume fume hood systems are the best choice in new laboratories because they are adjustable and flexible. However, they are not always the appropriate choice in retrofit situations because of the extensive modifications required to accommodate them. To incorporate state-of-the-art control systems including constant face velocity hoods, room pressurization control, and properly located supply and exhaust registers, it is beneficial to study the experiences of completed retrofit projects. The following case studies are offered for consideration of the value and limitations of incorporating state-ofthe-art variable volume fume hood control systems.

\subsubsection{VAV necessity}

A driving force in favor of using variable volume hoods is noted by Monsen (1989).

Managers of existing laboratories will face serious problems in the near future. More than 1,000,000 existing laboratory fume hoods along with their companion makeup air systems may have to be retrofitted to comply with pending Occupational Safety and Health Administration (OSHA) regulations and various state "Right to Know" laws. Even if many present-day hoods maintain adequate capture velocity at the maximum sash position, they most likely have excessive face velocity at lower sash positions. Existing bypass and auxiliary air type hoods do not adequately compensate for varying sash positions, and managers will have to insist on improvement in order to protect employers from future litigation.

\subsubsection{VAV organic chemistry research laboratory}

McDiamid (1990) describes a renovation project at an organic chemistry laboratory.

A new organic chemistry research laboratory was designed with 18 fume hoods. There are typically 18 people working in the laboratory during the day and fewer at night. A minimum ventilation rate of 15 air changes per hour (ach) of $100 \%$ outside air was required by a university design standard to cautiously maintain air quality. The ventilation rate was 18 ach with the 18 fume hood sashes at wide-open position.

The renovation of the organic chemistry research laboratory included the installation of 18 variable-volume fume hoods in a single space. Each fume hood was equipped with a local face velocity controller. All exhausts were gauged to one variable-speed exhaust fan. The fan speed was modulated to control static pressure in the exhaust duct.

Problems were encountered with the fan speed controls components. Good control was finally achieved by connecting them to the central energy management and control system (EMCS).

The large volume of exhaust air required in the space created room pressurization problems: rapid fluctuations in flow rate and extreme room pressure transients [sic]. 
Aiflow reduction and energy savings depend upon user cooperation in closing the fume hood sashes. Fan speed was monitored continuously by the EMCS, which indicated nightly decreases [in fan speed].

Energy savings were apparent even with open bypass grilles on the hoods. Tests were conducted that demonstrated the greater energy savings available with the bypass blocked.

A variable-volume fume hood exhaust system was chosen to reduce aifliow during unoccupied hours or when hoods were not in use and also to achieve good control of fume hood face velocity.

Health and safety were primary concerns with the exhaust system. During testing, there were fluctuations in the exhaust aiflow. The fluctuations appeared to be caused by fan surging due to failure of the fan control system to maintain static pressure at setpoint. This problem was solved by utilizing the central energy management and control system (EMCS) to better control exhaust fan speed. There were also problems with maintaining a steady negative air pressure in the laboratory relative to the corridor. These problems were solved by tuning the supply air tracking controls and installing barometric relief dampers to prevent under pressurization of the laboratory. Adequate dilution of combustible fumes was ensured by keeping the hoods' bypass grilles open, although this fimited the energy-savings potential.

Monitoring the system with the EMCS showed that the variable-speed exhaust fan maintained steady static pressure in the duct while fan speed was reduced at night and on weekends.

The results demonstrated that user cooperation can be obtained in a university laboratory to achieve moderate energy savings without compromising safety.

The supply air control system required careful calibration. Fluctuations in room air pressure caused by opening the doors resulted in erratic hunting by the differential pressure controller. The controller was then adjusted to respond more slowly to brief pressure fluctuations. After this adjustment was made, another problem became apparent. If a laboratory door was left open for a few minutes, the supply air damper would gradually close to the minimum position, attempting to maintain negative room air pressure. Then, when the door was suddenly closed, the room air pressure immediately became extremely negative, so negative that a small person was unable to open the door to exit. This condition could persist for half a minute while the supply air damper gradually responded. Obviously, this constituted a potential safety hazard. This problem was solved by installing barometric relief dampers that were adjusted to open if the air pressure dropped below an allowable minimum.

The data collected show a distinct reduction of fan speed at night and on weekends... Fan speed increases steadily after 7 a.m. as people come to work and open sashes. Fan speed modulates near the maximum in the afternoon until 4 p.m., then decreases steadily until 5 p.m. Then it decreases very slowly, reaching the minimum speed at about midnight. ...fan response is very regular through the weekdays. Then on Saturday, the fan speed does not increase as much, indicating that fewer people come to work and open sashes on the weekend.

\subsubsection{Analytical chemical laboratory}

The retrofit design of an Analytical Chemical Laboratory in New Jersey incorporated the following features, as described by Monsen (1989).

1. All hoods were retrofitted to achieve constant face velocity. Bypass openings were sealed. 
2. VAV reheat boxes were installed for each laboratory space to balance the variable exhaust volume. Each lab had its own electronic pressure sensor connected to a common reference point. Laboratory pressure was maintained at 0.025 in (6.23 pa) WG less than reference pressure. Electric reheat coils were also installed, as no steam was available during the summer.

3. Three analytical labs had research equipment loads of $200 \mathrm{Btu} / \mathrm{ft}^{2}\left(2280 \mathrm{~kJ} / \mathrm{m}^{2}\right)$. Total aiflow to these labs was some $4,195 \mathrm{cfm}(1980 \mathrm{~L} / \mathrm{S})$ and any supply incursion on the fume hood face was very critical due to the compounds being used in the fume hoods.

4. After investigating several types of ceiling diffusers and arrangements, it was decided to use a pressure plenum to properly distribute the air. Metal perforated ceiling panels were installed in the lab area with $1 / 16$ in. $(1.58 \mathrm{~mm})$ diameter holes on staggered centers. With this design, extreme care was exercised not to have any openings in the walls or ceiling in the environmental supply plenum above the perforated ceiling.

5. To provide the supplemental conditioned makeup, a separate self-contained makeup air unit with variable-volume controls was installed. This unit was capable of supplying $8,000 \mathrm{ctm}$ $(3716 \mathrm{~L} / \mathrm{s})$ and was located with its inlet well away from the exhaust of the analytical wing.

6. To provide sufficient airflow for the condition in which the required dehumidification airflow to cool the room would exceed the exhaust flow through the fume hoods, a supplemental variable-volume exhaust box was installed. This box is under control of the room temperature sensor and opens when the required supply exceeds the exhaust.

What was learned?

1. The combination of the existing exhaust fans and the variable-frequency drives resulted in too slow a response if the sashes were opened quickly. Personnel were instructed to move sashes slowly and observe the monitor closely before starting experiments.

2. The fume hoods had openings that communicated with the ceiling plenum, which affected the readings of the side wall mass velocity sensor. The openings to the ceiling were sealed, and separate openings with grilles were made to the laboratory itself.

3. The older hoods were not tightly sealed. Openings around the sash itself were considerable and seriously impacted on fume hood face velocity. These sash clearances had to be reduced in order to get the specified face velocity with the existing fans.

\subsubsection{VAV technology research center}

Reed (1994) describes the conversion of a research center from constant volume to variable air volume hood exaust.

In December 1992, several major changes were completed on the exhaust systems at ithe research center]. The desired result of these changes was to redesign the system to reduce the exhaust volume and ultimately reduce the overall energy consumption. The most significant of the changes was the modification of 1,120 laboratory fume hoods from constant volume type hoods to variable air volume (VAV) types. This was accomplished by installing velocity controllers. The second most significant change involved eliminating the general exhaust and installing a return air duct to several electronic labs.

The conversion to VAV hood exhaust cut fan horsepower [by] 32 percent. 
An additional eight-percent reduction in fan horsepower was accomplished by electronically rebalancing the system. This rebalancing was performed using the advanced feature of the velocity controller's connection to the building automation system. [The] site was one of the very first for this type of computer connection. The original projections of savings did not include this benefit as an energy reduction feature. From the actual measurements taken during the verification period, [it was] found that [the system] not only met original projections, but exceeded them by eight-percent. This was an unexpected plus to the project.

Each lab was set at approximately -0.02 in. WG static pressure relative to the exit corridor. Room static pressure was dynamically controlled by varying the general exhaust to maintain the room at -0.02 in. WG static pressure.

An evaluation of the center's hood control systems was performed which resulted in the selection of a thermal anemometer velocity sensor type system. Technically the system consists of three basic parts. The main component is the controller itself, which is a microprocessor and is mounted on the face of the hood where the hood user can see the display. The second component is a thermal anemometer sensor that is mounted in the side of the hood to detect velocity changes. A blade damper is the final component and is mounted in the exhaust duct above the hood.

It takes approximately four seconds to open the sash at a normal comfortable rate from fully closed to fully open. To maintain a safe and functional system, we concluded that the hood should not vary greater than $\pm 15 \mathrm{fpm}$ for more than four seconds at any time, especially during sash movement.

Before the installation of the velocity controllers, [the research center] was verifying quarterly that each of the 120 hoods met our required $105 \mathrm{fpm}$ face velocity. With a system that now actively controls the hood velocity and provides good indication of exhaust flow, [the industrial hygiene department] is extending this verification procedure to once every six months. A six-month observation period to validate the ability of the velocity controller to hold calibration is underway. This reduction in verification of hood performance was estimated to provide $\$ 30,000$ in labor savings. Therefore, the total annual saving of the exhaust reduction project was estimated at $\$ 197,000$ per year. The [cost of the] reduction project was $\$ 450,000$. [Therefore, a simple payback of 2.5 years was realized.]

Installation of the hood velocity controllers was the main accomplishment of the exhaust reduction project. Velocity controllers were installed on four-, six-, and eight-foot chemical fume hoods. This changed their operation from constant volume hood to VAV.

With the change to the variable volume hood design, the bypass could be blocked on the nonemergency hoods. Bypass blocks were installed on over half of the total number of hoods. Installation of the velocity controllers on the emergency hoods provided some savings and was necessary to account for the now variable upstream conditions that could be created by surrounding hood sash fluctuations. Most of our savings resulted from the bypass blocked nonemergency hoods.

Now that all labs are variable volume, most labs have less air supply to meet the cooling needs. Therefore, the supply coil that was previously set at $62^{\circ} \mathrm{F}$ is now designed to float up or down to meet the needs of the lab. Each lab is equipped with an electronic temperature sensor that the existing control system uses to control the reheat coil. All the lab temperatures are collected in the computer and evaluated to optimize the set point temperature of the main coil. This project was also completed in 1991 to optimize the coil set points and reduce the reheat to a minimum. Energy savings were realized in 1991, and the system design supports the new exhaust changes... . 
An off-shift evening spot check of the amount of user participation was made over a period of a month. The average weekend hood sash closure across the site averaged 74 percent, which was slightly lower than the 80 percent used in the original calculations. Because of lab employee participation, we were able to go back to the minimum fans each weekend. However all is not as ideal as it could be. We are finding that because of the small number of fans now required to support the systems, we experience a significant jump in negative static pressure when a fan is activated. The fan start causes the pressure to jump through the dead-band we desire and the fan immediately shuts off. To fix this temporarily, we have widened our dead-band, but fan cycling is now restricted. Our future plan is to install one variable frequency drive fan on each of the wings. A design change is also planned when the drives are installed that will make the system a continuously balanced system. The variable frequency drive will be designed to control the greatest flow riser damper to 95 percent open. This will require programming the computer to select the most loaded riser and control it to 95 percent open. Depending on loads, this could be a different riser each day or even change during the day. Our projection is that this will provide us a continuously smooth running balanced system controlled by the computer--a much welcomed change from the old, costly, manual balance schemes of the past.

\subsubsection{VAV chemistry building}

Bard (1995) describes the integration of variable air volume fume hood controls with the building automation system in a college chemistry laboratory building.

During the design phase, several alternate systems were analyzed to determine the most efficient and reliable system for this facility. Many of the energy efficient design solutions implemented in this project were initiated using the ASHRAE standard 90.1.

Because this building has 133 fume hoods, the control of supply and exhaust air was a very critical design criteria [sic] for potential energy savings. The final analysis compared variable air volume control to constant volume hoods equipped with a heat recovery system.

Due to savings realized from heating and cooling $100 \%$ outside air, a VAV fume hood system was designed. Based on actual observations in the Chemistry Building, it is estimated that an average of $40 \%$ air flow $(40,000$ to $45,000 \mathrm{cfm} ; 18,876$ to $21,236 \mathrm{~L} / \mathrm{s})$ is saved by using VAV fume hood system.

The major design task of this facility was to integrate the VAV fume hood control system with the central building automation system. During the design period, this was a new technology; it was a risk for system reliability. The result of combining these systems provides detailed system information of each laboratory with reliability and safety.

A flow measuring station, located upstream of the exhaust fan, sends its signal to the building automation system and is utilized to reset corresponding variable supply air terminal boxes as the exhaust valves open/close. This tracks the supply air and maintains negative pressure in the laboratories... .

The fume hoods are individually ducted to variable speed exhaust fans because of the variety of chemicals used there. Each has a variable frequency drive controlled by a sash-mounted potentiometer that controls fan speed and resets the corresponding variable position supply air germinal boxes to maintain negative laboratory pressure. All information (including individual hood exhaust flow, supply air flow, temperature and other data) is fully accessible through the building automation system. 
The first-cost premium for all of the implemented energy saving features was approximately $\$ 850,000$. At average rates of 8 cents $/ \mathrm{kWh}$ and $\$ 15.70 \mathrm{MIb}$ [for steam], annual energy savings are estimated to be approximately $\$ 355,000$. With a rebate of $\$ 479,166$, the effective payback for [the] college is one year.

\subsubsection{VAV alternative}

In certain situations, variable volume fume hood control systems will not be life-cycle cost effective. However, control of air flow can be achieved by altemative means. For example, in a small laboratory with only one or two fume hoods individually ducted with dedicated exhaust fans and without a centralized control system, a dual-speed exhaust fan could reduce exhaust air flow of a bypass fume hood if the sash is normally left in the closed position. This modification could, depending on circumstances, bring actual running time costs down by as much as one-half for heating load and by up to eight-fold for electrical costs when compared to an uncontrolled bypass fume hood. [Dodd, 1992]

\subsection{Manifolded Exhaust}

\section{Energy Efficiency and Manifolded Exhaust}

A manifolded exhaust system saves energy because:

- It requires less installed fan power, less duct work, and less electrical wiring than for individual systems,

- It can use multiple fans sized for partial volume so the air flow can be stepped up or down by starting or stopping additional fans,

- Exhaust fans can use Variable Frequency Drives (VFDs) to save fan power and energy depending on how many fume hoods are operating (see "fume hood diversity," Chapter 3),

- Energy recovery opportunities are simplified (refer to Chapter 5), and

- BSCs that are not in use can be isolated from the exhaust manifold.

\subsubsection{Overview of manifold exhaust systems}

Manifolded fume hood exhaust in complex laboratory buildings can provide substantial energy and firstcost savings. A manifolded system also offers opportunities for energy recovery, flexibility, redundancy, and better air quality. Neuman (1987) compares manifold and individual systems: "Proponents (of individual exhaust systems) feel that the isolation provided by the individual ducts and dedicated fume hood fans is worth the expenditure of cost and sacrifice of floor space," but "the individual fume hood scheme results in lower energy efficiency, more maintenance, and more roof penetrations." However Nelson (1986) points out that "The primary reason for using the individual system is that there is something unusually hazardous in the exhaust from the fume hood." Experience has shown that central exhaust systems are appropriate in large laboratories and in buildings with large numbers of fume hoods as well as in multifloor, multisection buildings. [Neuman, 1987]

\section{- Fan Energy Savings}

Wendes (1990) stresses the point that, "...manifolded exhaust systems are characterized by lower energy consumption than individual fume hood systems." A single exhaust fan, with a back-up unit, in an 
optimized duct system has higher energy efficiency than numerous lower power fans working independently. The addition of any new fume hood would result in only a slight increase in the required energy of the manifolded system versus the energy required to operate a new independent exhaust system. [Neuman, 1987]

\section{- Energy Recovery}

The central manifold presents an opportunity to recover the energy value contained in the conditioned air that is being exhausted from the laboratories. There are numerous design and operational challenges and problems with recovering this energy including: corrosion of the devices, added pressure drops for the air moving systems, increased maintenance costs, operational durability in the form of continued beneficial use, and control complexity, to name a few. See Chapter 5, for expanded review of heat recovery systems.

Secondary benefits of the manifolded fume hood exhaust systems can help in the decision to incorporate this design approach. They include:

\subsubsection{First-cost}

Manifolded exhaust systems can be less costly than individual systems. Fewer fans ducts, ceiling and roof penetrations, and exhaust terminals represent smaller capital and maintenance cost. [Neuman, year]

\subsubsection{Fume dilution}

The internal dilution with respect to the building's duct work system and external dilution with respect to the building's envelope are regarded as advantages of manifolded fume hood systems. External dilution has an energy cost that is covered in the sections below. [Neuman, 1990]

\subsubsection{Flexibility}

Manifolded fume hood exhaust systems are very flexible. Many possibilities exist for adjusting and expanding the systems without affecting the building structure. Hoods can usually be moved or added with only minor changes in the HVAC system. In potential laboratory spaces without isolation, hoods could be added by tapping into the exhaust duct in an interstitial space. This renovation requires combining general room exhaust and fume exhaust into the system remodel. [Neuman, 1990]

\subsubsection{Manifold limitations}

Generally, individual exhaust systems are applicable in single-story buildings that have a small number of widely separated standard fume hoods. In these situations an extended duct that runs to a central exhaust system is not economically justifiable. Otherwise, the use of individual fume hood exhaust systems should be limited to special processes and hoods with pertinent, restrictive codes and regulations. Perchloric acid fume hoods and radioisotope fume hoods are examples of such special cases with particular handling requirements for their exhaust. [Neuman, 1990; Laboratory Control and Safety..., 1994]

\subsubsection{Manifold arrangements}

Manifolded exhaust systems use a limited number of large fans that require less total duct work and less internal space for their duct work than a large number of individual exhaust systems. Building Performance - Fume Hood Retrofits (1994) describes three basic configurations for the manifolded exhaust system; each uses duct work, fans, and dampers differently: 


\section{- Bypass Inlet Damper}

This configuration uses an inlet damper at the central exhaust fan to provide a constant exhaust velocity while insuring a constant duct static pressure. This constant volume control approach does not save exhaust fan energy but does reduce the amount of exhausted conditioned air from the facility. Control precision is good.

- Multiple Fans

This configuration controls the duct static pressure by operating multiple fans off a common plenum. Each fan's capacity insures that the stack exit velocity is maintained at a minimum value. Control precision is fair.

\section{- Discharge Dampers}

This configuration employs a dedicated variable speed exhaust fan, usually with back up, and multiple exit stack dampers that modulate with fan speed in a common plenum. The damper position insures that the stack exit velocity is maintained at a minimum value. Control precision is fair to good.

\subsubsection{Manifold duct work}

The duct work can be arranged to serve all or specific groupings of laboratories and fume hoods, typically on a particular floor or in a wing of the building. Manifolded exhaust systems may use horizontal or vertical exhaust headers or a combination. One large centralized exhaust backbone plenum serving the total exhaust needs of a laboratory building helps maximize the benefit of a manifolded exhaust system. Dilution of the exhaust is enhanced when the general laboratory room exhaust air is included in the overall exhaust air. [Laboratory Control and Safety..., 1994]

\subsubsection{Manifold fans}

The energy engineer must consider the benefits and drawbacks of various configurations of centralized exhaust systems, as summarized above; it is strongly recommended that at least two exhaust fans be incorporated in the system to provide a modular, stepped application of the energy needed to move the exhaust air and to provide redundancy in the system, for safety. The energy engineer must also design the fan arrangement to insure that:

- Exhaust stack discharge air velocity is maintained above the required minimum,

- Fan failure is backed up by automatic start of a standby exhaust fan,

- The system provides positive proof of the fan operation, and

- The system includes static pressure control.

Specialized axial-type exhaust fans are available for constant air volume and variable air volume manifolded exhaust systems. These fans are designed to move large amounts of ambient air into the exhaust plume as it is discharged from the stack at a high upward velocity. See Chapter 5 for further energy impacts of fans. [Laboratory Control and Safety...., 1994]

\subsubsection{Manifold dampers}

Manifolded exhaust systems must incorporate high-quality, leakage-rated isolation dampers between both the inlet and outlet of each exhaust fan depending upon the design configuration. The system must not allow stack exhaust air to retum from an operating fan through a nonoperating fan. Motorized isolation dampers that interface with the facility's EMCS are recommended. [Laboratory Control and Safety..., 1994] 


\subsubsection{Manifolded biological safety cabinets}

The manifolded BSC exhaust can be arranged to provide energy-efficienct operation so as long as the cabinet's certification is not compromised. The following general guidelines should be followed, according to Eagleson (1990):

1. Connect only biological safety cabinets of the same "Class" and "Type" together. For instance, do not connect a Type B1 or B2 cabinet on the same system as a Type A or B3 cabinet. Connects with a chemical fume hoods must be carefully reviewed with the pertinent, restrictive codes and regulations.

2. Install balancing dampers near cabinets, with one damper for each. The issue of the quality of the damper is very important. It must operate very accurately with repeatability and a bubble-tight seal.

3. Provide highly accurate, automatic volume control and sensing. If one cabinet is turned off and shut down while others continue to operate, the exhaust system must maintain the proper, constant volume from the operational cabinets.

\subsubsection{Duct static pressure control}

Duct static pressure control in a manifolded exhaust system insures energy-efficient operation by automatically compensating for static pressure fluctuations. This precise control of pressure provides stable air flow through connected fume hoods and from the laboratory's general exhausts. Integral components of the system are the static pressure sensor(s) and static pressure controller. The static pressure sensor is typically located either in the exhaust system branch farthest from the main exhaust riser or in the main plenum because adequate static pressure must be maintained in the duct work farthest from the exhaust fan plenum. In very large or complex exhaust systems, multiple static pressure sensors should be used and possibly averaged for control purposes. The static pressure controller can either be a dedicated unit with PID capabilities or can be part of the EMCS. [Laboratory Control and Safety..., 1994]

\subsubsection{Suggested sequence of operation}

The preferred configuration for a large system controls static pressure within the exhaust system using a bypass damper and individual VFD fan speed modulation for each fan installed. The total installed fan capacity is equal to the total exhaust requirements of the facility, with all equipment in use. A minimum of at least two fans should provide this capacity. The fans' minimum speed will provide the minimum stack exit velocity.

When the open sash area of the fume hood(s) increases, the need for more laboratory ventilation capacity also increases, but the duct static pressure becomes less negative. To compensate, the bypass damper is modulated toward the closed position, making duct static pressure more negative. As even more exhaust capacity is required, the bypass damper is eventually modulated to the closed position by the control system. When greater exhaust capacity is required, the fan(s) that are running are speeded up with the VFDs. Depending upon the capacity of the exhaust system, additional fans are started, with all fans controlled to maintain identical speed. Finally, in an extreme case with maximum demand on the system, all fans operate at maximum speed. This basic static pressure control arrangement can be applied to any centralized exhaust system, regardless of size and overall configuration. [Laboratory Control and Safety..., 1994]

\subsubsection{Example sequence specification}

The following sequence of operation from the Laboratory Control and Safety Solutions Applications Guide (1994), is provided as an example that could be included in the construction bid set:

Exhaust stack discharge velocity 
Each exhaust stack outlet shall be sized to produce an upward aiflow velocity of approximately 3,000 feet per minute while exhausting 50\% of the minimum facility exhaust airflow rate and with the outside air bypass damper at $50 \%$ open. As the facility exhaust aiflow rate increases beyond the minimum, the outside air bypass damper shall be modulated toward the closed position as necessary to maintain the required exhaust system static pressure. This shall decrease the amount of outside bypass air and partially compensate for the increased facility exhaust airflow thus limiting the increase in stack discharge velocity.

\section{Two Exhaust Fan Option}

The two primary (and an optional standby) exhaust fans shall all be identical, and each shall be sized to provide $60 \%$ of the required maximum facility exhaust airflow at the exhaust system design static pressure and with the outside air bypass damper at $50 \%$ open.

\section{Three Exhaust Fan Option}

The three primary (and an optional standby) Exhaust Fans shall be identical, and each shall be sized to provide $40 \%$ of the required maximum facility exhaust airflow at the exhaust system design static pressure and with the outside air bypass damper at $50 \%$ open.

\section{Fan Speed}

Each exhaust fan's minimum operating speed shall be sufficient to maintain a minimum of 3,000 feet per minute exhaust stack exit velocity at the required static pressure and with theOutside Air Bypass Damper 50\% open.

Exhaust system static pressure control

Static pressure shall be sensed at two locations. One static pressure sensor shall be in the exhaust plenum just after the entry of the main exhaust inlet duct. The other sensor shall be in one of the exhaust system duct branches at the location where the static pressure is anticipated to be at the lowest value (least negative value). Typically, this will be in the longest exhaust system branch duct, at the farthest end from the exhaust plenum.

\subsection{Effluent Dispersion}

\section{Energy Efficiency and Effluent Dispersion}

Dispersive effluent at the laboratory's exhaust vent consumes energy in two ways: dilution of effluent and creation of the necessary effluent exit velocity. Engineers must consider the height of the exhaust stack to optimize its combined effect with the exit velocity. Wind modeling, as outlined below, provides the best tool for analyzing the exit velocity and the stack height interaction.

\subsubsection{Overview of effluent dispersion}

The energy engineer should be involved in the design considerations that develop the necessary effluent dispersion from the exhaust vent. The necessary effluent dispersion is assured when the exhaust vent produces a specified level of dilution at any building air intake from the "available dilution." This "available dilution" is the combination of three effects:

- internal system dilution, 
- wind dilution, and

- stack dilution (resulting from stack height and vertical plume rise).

Of particular interest to the energy engineer is stack dilution, specifically, the exhaust exit velocity that produces the vertical plume rise. The height of the exhaust stack has a direct influence on the minimum exit velocity. Wind modeling can help to calculate full-scale dilution at "critical" wind speed and helps design the most energy-efficient stack. [Wilson, 1983]

\subsubsection{Available dilution concept}

Wilson (1983) explains that diluting laboratory exhaust gas between the points of exit and intake "depends critically" upon the combined effect of the "wind speed and direction [and] relative elevation of the exhaust vent and intake." The absolute minimum dilution will occur between the points of exit and intake at a critical wind direction and at particular wind speed. Under these conditions, according to Wilson, there are three separate effects that multiply to produce the available dilution:

1. The internal system dilution, $D_{\text {system, }}$ obtained by combining exhaust streams to produce in stack dilution. The internal system dilution must be evaluated by the ventilation designer.

2. Dilution from entrainment of ambient air, $D_{\text {wind, }}$ as the wind blows the plume from a flush roof level vent with no plume rise to the air intake.

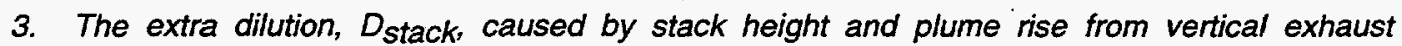
velocity.

The total available dilution, $D_{\text {total, }}$ is the product of these three dilution factors:

$$
D_{\text {total }}=D_{\text {system }}{ }^{*} D_{\text {wind }}{ }^{*} D_{\text {stack }}
$$

\subsubsection{Exit velocity}

Energy is required to provide the effluent's stack exit velocity. In the absence of a thorough wind model for the facility, accepted design practice recommends that exhaust air be ejected upward at 3,000 fpm $(15.24 \mathrm{~m} / \mathrm{s}$ or $34 \mathrm{mph})$. This will compensate for shadowing effects from the stack itself resulting from a horizontal wind velocity of approximately $22 \mathrm{mph}$. The accepted design practice further assumes that 22 mph is an "average" wind velocity for all facilities and that higher wind velocities will not have a stack shadow effect because the effluent will be diluted by the higher windspeed itself. However, the literature also points out that: "higher exit velocities may be necessary due to the proximity of adjacent structures, topographical features, or other unique situations." [Laboratory Control and Safety..., 1994]

Accepted design practice gives little guidance to the energy engineer who wishes to insure that effluent is discharged upward at a high enough velocity but at the same time to use the smallest amount of possible fan power and energy.

\subsubsection{Exit velocity enhancement}

The Laboratory Control and Safety Solution Application Guide (1994) points out that, as an energy-efficiency measure, a conical top can be added to an exhaust stack to increase the final "velocity at the point of stack discharge." The conical top's diameter determines the actual exit velocity. Engineers should not incorporate "a weather hood or rain cap on a stack that would impede" exit velocity of the exhaust from the stack. "Rain or condensation will not run down into a stack if the exhaust air exit velocity as at least $2,500 \mathrm{fpm}(12.7 \mathrm{~m} / \mathrm{s})$." 


\subsubsection{VAV exit velocity}

In large, manifolded exhaust systems of 20 or more fume hoods, the range of exhaust air flows that must be handled by the system can be wide, with five to one turn-down ratios possible. Therefore, when a variable volume exhaust system is used to compensate for turn-down ratios, fan speed or volume reductions must be limited to insure that a minimum stack exit velocity is maintained under all operating conditions. Laboratory Control and Safety..., 1994; Neuman, 1990]

\subsubsection{Stack heights}

Ventilation designers should provide the tallest possible exhaust stacks so that effluent exit velocity can be minimized in order to save energy. The concept of "available dilution" helps determine the amount of contamination one can expect from an exhaust stack configuration of a given exit velocity and height. The minimum stack height above the roof should be at least $10 \mathrm{ft}(3.0 \mathrm{~m})$ as per ANSI Z9.5. However, the stack height, after correction for downwash, must also protrude above any flow recirculation cavity or obstructions, such as those typically caused by variation of roof levels, architectural fences, penthouses, and roof-mounted equipment. [Wilson, 1983; Industrial Ventilation..., 1995]

\subsubsection{Stack downwash}

Stacks that have a low vertical discharge velocity relative to wind speed at the stack exit suffer from "downwash," which occurs when the plume is sucked downward into the wake behind the stack. High vertical exit velocity will reduce this downwash when it is greater than 1.5 times the wind speed at stack exit. However, there is an energy cost associated with the increase in the exit velocity. An increase in stack height validated with wind modeling could result in energy savings. [Wilson, 1983]

\subsubsection{Manifolded vs. individual exhausts}

A single stack from a manifolded exhaust system provides a higher plume rise. Individual exhaust stacks should be grouped together in a tight cluster to create the effect of a manifolded exhaust system. The process of diluting exhaust fumes can be more difficult when one stack is used for each fume hood. A single, higher stack for a manifolded system can be more economical. [Neuman, year]

\subsubsection{Wind modeling}

The relatively new approach of wind modeling to determine the effectiveness of an exhaust stack configuration offers energy engineers a useful tool to optimize effluent dispersion from a laboratory-type facility. The technique is generally recognized as accurate for modeling dispersion of exhaust gases; however, wind modeling is a complex science, and the modeling tools that have been developed from wind-tunnel simulations are beyond the scope of this design guide. It is strongly recommended that this modeling be completed because of the energy savings that can be realized from exit velocity reductions.

\subsubsection{Wind model input criteria}

To classify an exhaust stack configuration as acceptable or unacceptable using wind tunnel simulation, the following essential information must be gathered:

- type of source emission,

- quantity of source emission,

- frequency of source emission, 
- toxicity/health effects of source emission,

- local wind and climate data, including meteorological and terrain information,

- physical geometry of stack,

- flow rates of stack,

- threshold limit value, and

- acceptability criteria that address odor potential and health effects of stack emissions. [Laboratory Control and Safety..., 1994]

As with any simulation technique, the results of the model are only as good as the scope, depth and accuracy of the input criteria. Therefore, the following summary is offered for consideration:

- To classify an exhaust stack configuration as acceptable or unacceptable, an accurate estimate of the source emissions must be made and an acceptability criterion must be established that accounts for odor potential and health effects of the exhaust stack at the location of concern.

- The acceptability of a stack design hinges not only on the wind-tunnel test results but also on the type of source, the anticipated frequency of operation, the local wind climate, the quantity emitted, and the toxicity or annoyance of the chemicals being released.

- The other essential pieces of information...include physical geometry, stack flow rates, emission rates, meteorological wind statistics, frequencies of emission events, threshold limit values, and a set of acceptability criteria. [Smeaton et al., 1991]

- Complicated terrain and numerous structures may require the construction and study of scale models of the facility in a wind tunnel to determine the optimum placement of the exhaust stacks necessary heights and required exit velocity. [Laboratory Control and Safety.... 1994]

\subsection{User Interface}

\section{Energy Efficiency and User Interface}

The user interface is very important in achieving exhaust system energy efficiency. A sophisticated, welldesigned, and expensive variable volume laboratory exhaust system is useless if the operators do not use a fume hood as it is designed. Periodic training "refreshers" should be offered in addition to initial, comprehensive training for fume hood users. Operators should use an EMCS that monitors the sash positions of the facility's fume hoods as well as their face velocity and alarm status. The energy-efficient operation of each fume hood should be insured either by observation, e.g., night watchmen checking positions, or remotely with the EMCS. The "airvest" is a new device currently being researched that should improve both operator safety and the energy efficiency of the fume hood.

The airvest eliminates the eddy that develops in front of a worker standing in the open face of a fume hood. Normally this eddy draws some of the pollutant, commonly generated near and in front of the worker, towards the worker's breathing zone. Experiments at LBNL have demonstrated that worker exposure to pollutants in the breathing zone can be reduced by about a factor of 50 while direct energy consumption of the fume hood is also reduced. Large savings in indirect energy (used in the building to condition make-up air) are also estimated to result from the use of an airvest along with a reduced fume hood face velocity. Annual savings are estimated to be about $\$ 1,000$ per hood, per shift in Chicago weather; actual savings would vary according to local climate and number of shifts. [Gadgil et al., 1992] 


\subsubsection{Training}

Many work practices and modifications influence the performance of a laboratory fume hood. Significant energy reductions can be achieved by reducing exhaust air volume and not disturbing a hood's face velocity. Good energy-efficiency and safety practices include:

- Closing the fume hood sash when the hood is not being used. This is especially important when the laboratory is unoccupied.

- Reducing the opening of the hood using either a fixed sash operation position of the sash or a revised sash arrangement, e.g., vertical to horizontal. This will be especially important when face velocity is relatively low. [Knutson, 1987]

- Keeping the exhaust slot free; do not block the slot with apparatus or bottles. [Knutson, 1987]

- Placing objects inside the fume hood at least 6 inches back from the sash; if they are less than six inches from the sash, air can bounce off these objects and overcome the face velocity entering the hood, injecting contaminants into the laboratory. [Ruys, 1990]

- Providing legs on hot plates or other apparatus to allow air to sweep under equipment, so the equipment does not block air flow. [Knutson, 1987]

- Minimizing traffic in the laboratory. Special care is required where hoods are close to doors that, when opened, could cause fan action at the hood. [Knutson, 1987]

- Removing any portable cooling fans from the laboratory. [Knutson, 1987]

- Working as far as possible into the hood. Increasing the distance between the source of contamination and the chemist or technician improves the hood's effectiveness. [Knutson, 1987]

- Moving slowly while at the hood. [Knutson, 1987]

\subsubsection{Sash function}

Saunders (1993) points out that, in many instances, the energy-efficient use of a fume hood by an operator is thwarted by the sash. "The two most annoying problems" the operator has with a sash are "(1) it is hard to move up and down and (2) it binds in the sash track. The sash should be easy to move [when the counterbalance] weights are of the proper size and the pulley system is uncomplicated and well-lubricated." The energy engineer should insure that each fume hood is a high-quality device and that an operational installation check is made after the unit is set in place and leveled. [Suhail, 1989]

\subsubsection{Monitoring/Enforcement}

The EMCS should be used to ensure safety and to meet the goals of the lab's energy-efficiency program and design diversity analysis. The EMCS should generate reports for supervisors if excessive air is consumed, particularly during unoccupied periods, in each laboratory. [Monsen, 1989] 


\subsubsection{New devices}

\section{- Airvest research results}

The following was excerpted from a research paper produced at the Lawrence Berkeley National Laboratory (LBNL), Energy and Environment Division, University of California, and presented at the 1992 Indoor Air Quality Conference:

Substantial reduction in the fume hood airflow without compromising the performance of the exhaust hood can be envisaged if a device can be designed that makes the worker essentially transparent to the flow of air into the exhaust hood. The proposed device, called an "airvest," could be worn by the worker. It would draw air from the back of the worker, and expel it in the front. Under ideally matched flow conditions, the resulting airflow pattern behind and in front of the worker would be identical to that obtained without a worker blocking the flow. No back eddy would develop, and pollutant removal and transport would be as effective as that with an unobstructed exhaust hood. Under conditions of imperfect matching, the hood performance can be still expected to be improved because the airvest ventilates the region of the eddy.

Reduction in the breathing zone concentration of an experimentally simulated pollutant, by factors ranging from 100 to 800, was observed with the device (called an airvest). With use of the airvest by the worker, the hood face velocity can be reduced, leading to substantial energy savings in conditioning of make up air in the building.

Experiments using a heated full-size mannequin were conducted with a full-scale walk-in fume hood. Sulfur hexafluoride was used to simulate pollutant generation and exposure during a work situation. Flow visualization with smoke was also undertaken to evaluate the airvest qualitatively.

The airvests tested in this project were very rough prototypes. However, they have demonstrated the proof of the concept, as intended in the project objective. Reduction by factors ranging from 100 to 800 in the breathing zone concentration of a simulated pollutant was observed with the use of an airvest on a heated mannequin in a full sized fume hood. Airvests could therefore be useful in meeting the declining limits on acceptable worker exposure to various industrial pollutants.

Reduction in the bulkiness and power consumption of the airvest designs described here appears possible with additional work. Further investigation should address issues such as the shape of the front manifold (to make it less bulky), the position of air-intakes, the method of supplying air to the airvest, and airvest performance in field settings with real workers. For this purpose, collaboration with industry would be desirable. The future research effort should also address the possibility of failure modes of the airvest (e.g. pollutant exposure at different orientations of the airvest to the hood air flow, and for different release points and release velocities of the pollutants than those investigated here). [Gadgil, 1992] 


\section{REFERENCES}

AABC - Associated Air Balance Council, "National Standards for Testing and Balancing Heating, Ventilating, and Air Conditioning Systems." Washington, DC: Associated Air Balance Council, 1989.

Ahmed, Osman and Steven Bradley. "An Approach to Determining the Required Response Time for a VAV Fume Hood Control System." ASHRAE Transactions V. 96, Part 2 HVAC, 1990.

Bard, Eugene M. P.E. "Laboratory Integrates VAV Fume Hood Controls with Central Building Automation System." ASHRAE Journal, March 1995.

Building Performance - Fume Hood Retrofits, Pacific Gas and Electricity Energy Center, eds. San Francisco, CA: Pacific Gas and Electricity, 1994.

Caplan, K.J., and Knutson, G.W., "Laboratory fume hoods: A performance test." ASHRAE Transactions, Vol. 84, Part1. Atlanta, GA: AHRAE, 1978a.

Caplan, K.J., and Knutson, G.W., "Laboratory fume hoods 1978b: Influence of Room Air Supply." ASHRAE Transactions, Vol. 84, Part2. Atlanta, GA: AHRAE, 1978b.

Carroll, John, Jr. P.E., C.P.E. "Designing Safe and Efficient Fume Hoods at Research Lab." AIPE Facilities, March, April 1995.

Crane, J.T. "Biological Laboratory Ventilation and Architectural and Mechanical Implications of Biological Safety Cabinet Selection, Location, and Venting." ASHRAE Technical Data Bulletin, Vol. 10, No. 1, 1994.

Dodd, D.J. and P.J. Padley. "Energy-Efficient Use of Fume Cupboards." Applied Energy, No. 41, 1992.

Eagleson, D. "Biological Safety Cabinets." Handbook of Facilities Planning, Vol. One, Laboratory Facilities. ISBN 0-442-31852-9. Ruys, Theodorus, AIA, ed. New York: Van Nostrand Reinhold, 1990.

Gadgil, A.J., D. Faulkner, and W.J. Fisk. "Reduced Worker Exposure and Improved Energy Efficiency in Industrial Fume-Hoods Using an Airvest." Lawrence Berkeley National Laboratory Report. May 1992.

Handbook of Facilities Planning, Vol. One, Laboratory Facilities; ISBN 0-442-31852-9. Ruys, Theodorus, AIA, ed. New York: Van Nostrand Reinhold, 1990.

Industrial Ventilation: A Manual of Recommended Practice - 22nd Edition. ISBN: 1-882417-09-7. The American Conference of Governmental Industrial Hygienists, Inc. (ACGIH), eds. Cincinnati, $\mathrm{OH}$ : ACGIH, 1995.

Knutson, Gerhard W., Ph.D. "Testing Containment of Laboratory Hoods: A Field Study." ASHRAE Transactions, V. 93, Part 2, Laboratory HVAC, 1987.

Lacey, D.R., P.E. "HVAC for a Low-Temperature Biohazard Facility." ASHRAE Technical Data Bulletin Vol. 10, No. 1, 1994.

Laboratory Control and Safety Solutions Application Guide - Rev. 2. Landis and Gyr, eds. Buffalo Grove, IL: Landis and Gyr Powers, Inc., 1994. 
Laurin, Lise. "Clean Air Usage in Automated Wet Benches." Cleanrooms For Information Circle No. 22, June 1995.

McDiamid, Michael D., P.E. "Variable-Volume Fume Hoods: Use Experience in a Chemistry Research Laboratory." ASHRAE Transactions, V. 96, Part 2, Laboratory HVAC, 1990.

Mcllvaine, Robert W. Cleanrooms - 1992-2000, Rooms and Components Vol. Three. Mcllvaine, Robert W., Sally Halderman, Alpa Bagga, and Joseph Schwartz, eds. City, State: The Mcllvaine Co., 1992. Chapter 1, Rooms; Chapter 4, Engineering \& Design.

Monsen, R.R., PE. "Practical Solutions to Retrofitting Existing Fume Hoods and Laboratories." ASHRAE Transactions V. 95, Part 2, Laboratory HVAC, 1989.

Neuman, V.A., PE and H.M. Guven, Ph.D. "Laboratory Building HVAC Systems." ASHRAE Transactions, V. 94, Part 2, Laboratory HVAC, 1994.

Neuman, Victor A., P.E. and Emil Sandru, Ph.D. "The Advantages of Manifolding Fume Hood Exhausts." ASHRAE Transactions, V. 96, November, 1990.

Neuman, Victor A., P.E. Laboratory, Fume Hood and Hospital Isolation Rooms - Applications and Systems Manual. Scranton, PA: The Anemostat Systems Group, 1994.

NSF - National Sanitation Foundation, "Standard 49, class II (laminar flow) biohazard cabinetry." Ann Arbor, MI: National Sanitation Foundation, 1992. ref177

Reed, Michael A. "Conversion to VAV Hood Exhaust Slashes Fan Horsepower." Heating/Piping/Air Conditioning, January 1994.

Saunders, G. Thomas. Laboratory Fume Hoods - A User's Manual; ISBN 0-471-56935. New York, NY: John Wiley \& Sons, Inc., 1993.

Simons, C.G. "Specifying the Correct Biological Safety Cabinet." ASHRAE Journal, August 1991.

Smeaton, William H., Michael F. Lepage, and Glenn D. Schuyler. "Using Wind Tunnel Data and Other Criteria to Judge Acceptability of Exhaust Stacks." ASHRAE Transactions, V. 97, Part 2, 1991.

Stuart, D.G., D. Eagleson, and J.M. eagleson, Jr. "Primary containment principles and practices." Proceedings of the Institute on Critical Issues in Health Laboratory Practice. Wilmington DE: The Du Pont Company, 1985.

Suhail, Khalid. "Maximizing the Savings from Economizer Systems (Air Stratification in Buildings)." Building Design and Construction, V. 30, N. 6. Reed Publishing Co., May 1989.

Wendes, H. C. "Variable Volume Fume Hood Exhaust Systems." Lilburn, GA: Fairmont Press, 1990.

Wilson, D.J. "A Design Procedure for Estimating Air Intake Contamination from Nearby Exhaust Vents." ASHRAE Transactions V. 89, Part 2A Laboratory HVAC, 1983. 


\title{
7. DISTRIBUTION SYSTEMS
}

\begin{abstract}
Energy Efficiency and Distribution Systems
This chapter considers methods and designs to optimize delivery of air and water to condition laboratory spaces. The method used to size the air distribution system is critical. Most computerized duct sizing programs available are simply automated versions of methods that do not consider life-cycle cost and energy-efficiency optimization. The engineer wishing to save energy should design an air distribution system with low-velocity, large-diameter, round duct work including efficient fitting transitions, largearea coils and filters, and active noise attenuation. The laboratory pressure control system contributes to overall safety and energy efficiency by correctly isolating the laboratory from adjacent spaces without wasting conditioned air. Energy-efficient fume hood systems in the modern laboratory must take into account the discharge velocity of supply diffusers near hoods. When noise attenuation devices are necessary, the air distribution system will have a higher pressure drop, which increases fan energy size and power consumption. Using quiet fans to minimize noise is the first step in the design process. Even though hot and chilled water pumps are not large consumers of energy, their impact is significant, as much as 5 to 15 percent of HVAC system energy use.
\end{abstract}

\subsection{Air Distribution}

\section{Energy Efficiency and Air Distribution}

Air distribution through a laboratory is critical to the facility's safety and energy efficiency; nonetheless, air distribution systems are typically treated as an afterthought in the design process. Small duct work is often routed circuitously, resulting in significant energy waste. In addition, the system air velocity is usually selected by rule-of-thumb and its noise impact is addressed afterward. However, the design of an energy-efficient air distribution system should be an iterative process, facilitated with the "T-Method," which incorporates life-cycle cost. A key to saving energy is to reduce the friction loss of the air distribution system by using large-diameter, round duct work, efficient fittings, lower coil and filter face velocities, and energy-efficient noise attenuators.

Air distribution components typically used in the research laboratory include:

- Air handler with fan,

- Cooling/heating coils,

- Air filters,

- Sound attenuators,

- Duct work or plenums,

- Variable air volume (VAV) terminals or air balancing devices,

- Duct work fittings,

- Fire and smoke protection devices (supply side only), and

- Fume hoods, biological safety cabinets, or other exhaust devices. [Naughton, "HVAC Systems... Part 1," 1990]

Laboratory cleanrooms require special consideration because of the need to move large, laminar volumes of air for contaminant removal. For cleanrooms, energy efficiency is increased with efficient duct work 
design and lower face velocities for coils, dampers, and filters. Naughton, in "HVAC Systems for Semiconductor Cleanrooms - Part 1" (1990) notes that, ,

When hundreds of thousands of $\mathrm{cfm}$ are involved, the reduction in fan static pressure of just $0.1 \mathrm{in}$. WC (24.9 Pa) can result in $\$ 7,200$ per year of savings for a $10,000 \mathrm{ft}^{2}\left(929 \mathrm{~m}^{2}\right)$ clean room. In addition to fan horsepower savings, each 0.1 in WC (24.9 Pa) will also produce 3.9 tons $(13.7 \mathrm{~kW})$ of air-conditioning savings due to the reduced fan heat load.

\subsubsection{Duct work design methods}

The preferred approach to duct work design is the "T-method," presented in a series of American Society of Heating, Refrigeration and Air-Conditioning Engineers (ASHRAE) papers in 1988. This design technique was incorporated into the 1989 ASHRAE Fundamentals Handbook. The T-method integrates the life-cycle cost of the air distribution system-first-cost, energy cost, hours of operation-into the analysis of duct work and fan selection. The system total pressure is optimally derived while costs are minimized. According to Shepard et al. (1995), "the size and the energy use of the fan can be about 45 to 75 percent smaller with [the] T-method" than with the conventional "equal friction" sizing method. However, acceptance of the T-method has not been widespread because hand calculation of the results is time-consuming. According to Tsal (1995), a computerized version of the method is being developed, which will link to computer aided drafting (CAD) programs. [Shepard et al., 1995; Tsal, 1995]

The "static regain" duct work design method has been the choice of engineers for many years even though it is more difficult and time-consuming than the equal friction technique. Static regain designs yield more balanced systems that have better flow characteristics than equal friction systems. The equal friction method is the least energy efficient because it relies on energy-wasting balancing dampers to provide each space with the desired air flow.

\subsubsection{Low-velocity duct design}

Low-velocity duct work design is very important for energy efficiency in air distribution systems. Designers should be aware that, for a particular air-flow rate, doubling of duct diameter will reduce friction loss by a factor of 32 times. However, low-velocity systems occupy more space and have higher first costs; facility owners are often reluctant to provide the space for more expensive duct work, but significant energy savings can be realized even when the duct work is only increased by one standard size. The use of pressurized plenums also reduces friction losses in supply duct work. [Shepard et al., 1995; Naughton, "HVAC Systems... Part 1," 1990]

\subsubsection{Duct work}

The duct work material influences the energy use of the air distribution system. Attention should be paid to the roughness of the duct material; because of code requirements, most duct work in the laboratory facility will be metal with smooth interior surfaces. However, flexible duct will usually be installed at the branch level to connect to diffusers. These lengths should be minimized because they increase pressure drop. Turning vanes with airfoil shapes should always be included in the duct work turns. Extra consideration should be given to standard procedures for preventing duct leakage and to determining type and amount of insulation used. [Industrial Ventilation: A Manual of Recommended Practice -22nd Edition, 1995]

\section{- Round duct work}

Round duct work provides maximum air-carrying capacity for the pressure loss incurred. Round duct work is also stiffer than rectangular and therefore much quieter during operation. Round ducts usually 
have lower installation costs, are easier to insulate, and can be sealed more easily than rectangular ducts. Drawbacks to incorporating round duct work include expensive fittings and takeoffs and larger heights for a given cross-sectional area than needed for rectangular duct work. A combination of a rectangular plenum and round branches can offer the designer a good compromise when round duct work is not possible everywhere. [Shepard et al., 1995]

\subsubsection{Animal room distribution system: case study}

Wier (1983) describes distribution system design for research facilities that house animals.

\section{Air-Handling System}

Proper distribution of air in the animal rooms is very important. The velocity of air hitting the animals must not be excessive; drafts can cause undesirable effects such as snuffles and pilar erecta (hair movement) on animals. The proper velocity varies with the animals and the types of cages, i.e., whether they are wire or solid "shoe boxes." Other factors -- temperature, humidity, noise, objectionable ammonia vapors -- may vary greatly between rooms and cage types (Yamauch, Takahaski and Audo, 1965; Bernstein and Drew, 1980)5.

One style consists of a cage support system that includes an exhaust-air connection to each individual cage, allowing the removal of dander, hair, odors, particulate matter and pathogens without exposing other animals or personnel. This arrangement uses room air for makeup air and keeps cages drier by increasing urine evaporation rates. Rack and cage systems that include both a supply and an exhaust plenum in the rack are also available from laboratory equipment manufacturers. This unit uses room air or a supply air duct for supply air. Exhaust from ventilated cages may require treatment depending on the substances in the airstream.

Supply diffusers and grilles are still widely used as an economical trade-off, but their high induction rate requires that caution be exercised in preventing drafts and cross-contamination in a given room. Such cross-contamination can result in dosed animals contaminating non-dosed (control) animals in the same room. A design in which two supply registers and return grilles are placed high at the end of the room has been found to provide an acceptable solution to the crosscontamination problem at a reasonable cost (Neil, 1982) ${ }^{6}$. However, low-level returns do a better job of removing particulates because the density of such materials causes them to settle to the floor... .

The clean/dirty (supply/retum) corridor concept is a combination of the containment and barrier designs. In this design, a clean-corridor pressure is maintained sufficiently above the animal-room pressure to cause ainfow into the animal-room that may contain pathogenic or toxic test substances. The dirty-corridor pressure is maintained at approximately 0.1 inch of water [gauge] below that in the test rooms. Animals, contaminated material, and personnel exit the animal rooms into the dirty corridor. These pressure differentials can be established and maintained with various levels of sophistication in instrumentation, or, if, the facility has a properly designed air-handling system, by using manual balancing dampers and reading differential-pressure gauges. Manually operated systems must be checked regularly because conditions change, with variables such as supply and exhaust filters becoming loaded with hair.

\footnotetext{
${ }^{5}$ See referenced citation for full information.

${ }^{6}$ Ibid.
} 


\subsubsection{Displacement flow}

An interesting alternative to the conventional placement of both supply and return (exhaust) registers in the ceiling is a displacement flow configuration. In this configuration, cooling air, which weighs more than the room air, is supplied at floor level, flowing into the room from, or near, the floor upwards. Displacement ventilation uses low-velocity air flows at small temperature differences compared to the room air. Buoyant, rising warmed room air is drawn off from lighting, process, and occupants at the ceiling level. According to Shepard et al. (1995) and Ruys (1990), the following energy saving benefits are realized from displacement flow:

- fan power is reduced,

- room heat rejection is optimized,

- warmer temperature cooling air is required,

- high-ceilinged rooms can be easily conditioned, and

- during room heating, under-floor plenum supply acts as a radiant heating panel.

In addition, displacement flow removes pollutants more effectively than traditional air-flow design. Caution is advised because spills in laboratory environments can be problematic with a floor that has an air-flow system below.

\subsubsection{Cleanroom air distribution}

Although many laboratory cleanroom air distribution systems have unique arrangements, some features are common. In general, medium pressure duct designs are not applicable to cleanrooms. Typically, the area above the cleanroom ceiling is an equalizing plenum, supplying clean air from high-performance filters. Process and personnel heat and contaminants are removed as the air flows through the room and exits through a grated floor. An air passageway under the floor brings the air back to the fan(s), which return it to the plenum to complete the cycle. Heat is removed from this air stream by an air conditioner positioned in the return duct. Before being mixed into the clean room supply air, make-up air is also conditioned by this air conditioner or a second one. [Kruse, 1991; Takenami et al., 1994]

Large ducts and plenums reduce power consumption but require large spaces. High-velocity duct systems are not the most energy efficient because even slight increases in pressure drops translate into large energy costs. The configuration of air recirculation, heat removal, and make-up air conditioning is highly sensitive to climate, local energy costs, and the class of the cleanroom. Extensive analyses are recommended to optimize these system interactions for each installation. [Kruse, 1991; Takenami et al., 1994]

\subsubsection{Laminar flow cleanroom}

The National Air Filtration Association (NAFA) Guide to Air Filtration (1993) describes laminar flow cleanrooms in general.

In the unidirectional air flow type of cleanroom, more commonly known as laminar flow clean rooms, the design intent is that air should make a single pass through the room with a piston-like effect. In one configuration sometimes referred to as vertical laminar flow rooms, cleaned air enters the room through the ceiling and exits through floor grilles or through continuous outlets in the walls at floor level. When returns are in the walls, there are restrictions as to how wide the room can be and still maintain unidirectional flow. Air can also enter through one wall and exit through the opposite wall. This is sometimes referred to as horizontal laminar flow. 
In a conventional cleanroom, HEPA filters are usually located in the mechanical room and are the last items in the mechanical equipment sequence. They are downstream of the blower, so that only HEPA-filtered air enters the ductwork connecting the mechanical equipment to the cleanroom. The ductwork is frequently stainless steel, although other non-shedding materials are also used.

In a laminar flow cleanroom, the HEPA filters are located in the wall or ceiling of the room, so that once the air passes through the filter it is in the cleanroom. Intermediate sources of contamination are eliminated. HEPA filters must be sealed into the framing system so that there can be no bypass of dirty air around them and into the cleanroom. The filters themselves must also be leakfree. Different filter manufacturers have developed framing systems which provide such support.

\subsubsection{Vertical laminar flow cleanroom}

Mcllvaine (1992) describes the use of ceiling-to-floor air flow.

This vertical down flow design usually has the capability of providing the greatest control for the entire clean working environment, because airborne contamination generated by personnel or specific operations is immediately carried down and out of the room. This design may be varied such that the blowers and HEPA filters are remotely located and the filtered air is ducted to the top of the room and enters the room through a diffusion ceiling arrangement. This variation may reduce cost, the area of filter bank required greater motor/blower capacity and greater attention to leak proof duct joints.

\subsubsection{Horizontal laminar flow cleanroom}

Mcllvaine (1992) describes a horizontal laminar flow cleanroom distribution system in a particular cleanroom.

HEPA filters are placed on entire wall surfaces and supply the air at constant velocity across the entire room and the air exits through the ceiling or wall at the opposite end of room and is recirculated. A major limitation is that downstream contamination in the direction of air flow will occur, but this clean room has Class 100 cleanliness with a practical design and is used extensively throughout the electronics industry as well as for bio-clean operating rooms or patient isolators. Since these rooms are normally longer than they are wide and the filter bank occupies only one end of the room, a substantial cost savings can be realized over vertical flow rooms due to the reduction in HEPA filters, supporting structure, and air handling equipment.

\section{- Tunnel cleanroom}

Mcllvaine (1992), explains the details of a tunnel cleanroom with wall-to-open-end air flow.

This type of room is rectangular in shape, usually 12 to 16 feet wide and 30 feet or more in length. Generally, these are Class 100 or better. This design combines features of both the horizontal room and the down flow curtain unit. The filter bank is normally composed of prefabricated modules, each containing a motor/blower unit, prefilter, and HEPA filters. The rigid or flexible plastic ceiling and side walls are supported by a simple exterior wood, pipe or angle iron framework, while the end opposite the filter bank is open. Plastic material used in this application should be the self-extinguishing type. The tunnel room is the least costly type of room, can be disassembled and moved, and its effectiveness is comparable to the normal horizontal room.

Patel et al. (1991) describe the design of a high-performance tunnel cleanroom for a semiconductor manufacturer.

The key to reducing the overall system pressure drops was in opening up the air returns. ...the service bays and interstitial spaces...are one continuous open area. The side wall returns...were 
continuous openings, twenty to thinty inches high. Proper aifflow direction and pressurization were controlled by utilizing portable panels of two types, solid and louvered. Return air required by the makeup air handler for temperature and humidity control... was retumed directly though a grill in the roof to the mixing chamber. Return air for the local tunnel modules... was retumed directly through the service bays. The tunnel modules were designed to use low-pressure drop, single row, sensible heating cooling coils,...energy efficient motors,...and low pressure drop HEPA filters...Makeup air was supplied to the local tunnels...through solid ducts...(versus flex ducts). They were not connected to the units but were terminated in close proximity to the prefilters. It should be noted that in the Class 1000 areas, the air was also delivered in the same manner to self-powered 2' $\times 4^{\prime}$ drop-in ceiling units. No solid connection was used between the makeup air handler and final units at any point. This was planned to reduce the pressure drop in the delivery duct system, but, even more importantly, to allow the delivery system to remain balanced when small changes are made throughout the fab area. Temperature and humidity were controlled by the makeup air handler.

\subsubsection{Modular laminar flow systems}

The Handbook of Facilities Planning (1990) describes cleanroom workstations and benches using modular laminar air flow.

Cleanroom devices are mostly thought of as modular laminar flow systems, also called benches. However, the definition can be extended to cover everything from glove boxes through minienvironment cleanrooms. In fact, the growing emphasis on mini-environments for the semiconductor industry is blurring the distinction between devices and rooms. There is a tremendous opportunity to marry the modular laminar flow station technology with the ballroom cleanroom technology to provide zones with various degrees of cleanliness throughout the room.

\section{- Cleanroom work stations}

Cleanroom working areas of work stations are used in many places where air-transported particles, germs and other contaminating material are expected to affect products, working processes and analysis results. The pharmaceutical, microbiology and virology, electronics, space and aircraft, optical and precision mechanical industries all have a need for work stations in their cleanrooms.

\section{- Laminar flow clean bench}

Benches are referred to as devices in the trade and are used separately as well as inside cleanrooms. The laminar flow clean bench is generally described as a work bench or similar enclosure characterized by its own filtered air supply. In recent years, the use of clean benches has spread from research and manufacturing to other fields such as aerospace, bioscience, pharmaceutical, and food processing. The main air flow clean bench has been utilized in a variety of facilities, including medical research laboratories, manufacturing, hospitals, and other clinical and research settings. Applications have included syringe filling, sterile preparation, plant tissue culturing, and media preparation. In addition, the clean bench has been used extensively in the electronics industry for testing, assembly, and inspection of products. The clean bench was developed as an adjunct to cleanroom technology -- the need to protect the product or experiment from contamination. The clean bench provides product protection by ensuring that the product is exposed only to HEPA-filtered air. It does not provide protection to either personnel or the ambient environment. Since the clean bench is not designed to contain any aerosols generated by the procedure, the operator is constantly exposed to such aerosols. Thus, the clean bench is recommended for work with non-hazardous materials where clean, particle-free air conditions are required. 


\subsubsection{Fan filter units}

Takenami et al. (1994) discuss the clean-air distribution system for a super cleanroom is the semiconductor industry.

The major characteristic of this type of system is that large ducts and fans are not used to circulate the air. Instead, clean air is blown out from fan-equipped filters installed on the ceiling. The air then passes through floor grates into the air return space behind the cleanroom walls where it is returned to the chamber behind the ceiling and recirculated by the filter units. The advantage is that since ducts are not used, duct-induced pressure loss is eliminated, making it possible to reduce blowing power costs to less than one-third of conventional levels.

\subsubsection{Nonlaminar flow cleanroom}

Nonlaminar flow cleanrooms are analyzed in the Handbook of Facilities Planning (1990).

The air flow system is the same as the common air-conditioning system except it uses a HEPA filter and more air changes to reduce the contamination level. This type of clean room is generally employed to maintain Class 1,000 to 10,000, but when it is supplemented by local laminar flow work stations, it can provide a high degree of contamination control for critical operations. The construction cost is economical.

\subsubsection{Cleanrooms-Pressurized plenum vs. ducted designs}

Naughton, (“HVAC Systems... Part 1," 1990) quotes Gerbig (1984), who points out, "Pressurized plenum designs may reduce system static requirements up to $1.0 \mathrm{in}$. WG (249 Pa) when compared to ducted HEPA filter systems. The primary benefit of ducted HEPA filters is the precise balance of the clean room unidirectional velocity profile or parallelism. Precise balance also provides the flexibility to have mixed clean room velocities."

Energy savings result when a cleanroom uses mixed velocities. The average velocity is reduced when production equipment air-flow velocity is $90 \mathrm{fpm}(0.457 \mathrm{~m} / \mathrm{s})$ and the balance of the cleanroom area air flow is $60 \mathrm{fpm}(0.305 \mathrm{~m} / \mathrm{s})$. The amount by which the velocity is reduced is simply proportional to the areas of mixed velocity. Even though mixed velocities can be provided with a pressurized plenum design, a ducted design is flexible for future changes. The designer is cautioned that ducted systems require "... a more tedious and iterative balancing procedure with higher maintenance operating costs." [Naughton, "HVAC Systems... Part 1," 1990] 7.1.6.1 High- and low-velocity cleanrooms

The Handbook of Facilities Planning (1990) points out some issues in high-velocity cleanroom design.

A high velocity system can create turbulence, which will influence the air flow and the conservation of energy. The condition of the filters, the lights in the ceiling, and the fans and motors must all be considered in the selection of a high velocity air system. Because the filters determine the pattem of the air flow, the lights can create a void in the air-flow pattern and the use of high-volume fans and motors increases installation, operating and maintenance costs. A low velocity system with proper lighting, filters and plenum is suitable for some manufacturers. However, any manufacturer needing a cleanroom with a Class 10 or even Class 100 may not be able to utilize a low velocity system.

\subsubsection{Cleanroom Jaminar flow velocity}

Mc/lvaine et al. (1992) outline air-flow considerations for cleanrooms. 
When maximum particle reduction is sought, air velocity through the cross-section of the room normally is maintained at 90 feet (approximately 27.5 meters) per minute with a uniformity within plus or minus 20 percent throughout the undisturbed room. In certain applications where user requirements permit, air velocity in vertical laminar flow rooms may be reduced below the 90 fpm level. Any significant reduction in velocity can increase both the clean down time and the possibility of cross-contamination between work locations. The elimination of particles from the work area is essential to ensure cleanliness, sterility and functional requirements.

The following general outline can be used to determine the velocity throughout a room and is based upon desired cleanliness level:

(High Velocity)

Class 1

$100 \mathrm{fpm}$

Class 10

72 to $100 \mathrm{fpm}$

Class 100

72 to $100 \mathrm{fpm}$

Class 1,000

25 to $30 \mathrm{fpm}$

Class 10,000

7 to $15 \mathrm{fpm}$

Class 100,000

2 to $7 \mathrm{fpm}$

Change rate is calculated on the basis of average uniform velocity expressed as fpm times 60 divided by ceiling height equals exchange rate.

\subsection{Room Pressure Control}

\section{Energy Efficiency and Laboratory Pressure Control}

By insuring that the laboratory is safely and correctly isolated from adjacent spaces, the air pressure control system contributes to the overall energy efficiency of the laboratory facility. An energy-efficient VAV supply and exhaust can be used to control this pressure. The techniques to provide laboratory pressure control include differential pressure sensing, air-flow tracking, and combination pressure sensing/tracking.

The advantages and drawbacks of these techniques make clear that the best choice for safe and energyefficient laboratory operation is a combination of pressure sensing and air-flow tracking. The pressure control system's efficient maintenance of laboratory conditions has a large effect on heating, cooling, and air moving expenses. According to Grossman (1995), "Depending on the technology used, each laboratory air-flow control system may require a different maximum volume of air measured in cfm, to do the job properly. At an average cost of $\$ 3 / \mathrm{cfm}$ each year, the differences between the energy costs associated with systems can often be quite dramatic."

\subsubsection{Laboratory pressure control objectives}

The objectives of the laboratory pressure control system are to:

- maintain laboratory isolation during heating and cooling fluctuations, 
- respond to changes in fume hood sash position,

- respond to opening of doors to the laboratory,

- respond to pressure changes in adjacent space(s),

- inform the operators of problems with the system's operation, and

- report to the EMCS the pressure status of the laboratory at all times. [Building Performance Fume Hood Retrofits, 1994]

The air-flow control system must be highly accurate, stable, and responsive to changes in the laboratory. A VAV system is more energy efficient because it can accommodate a wide range of air-flow changes; the pressure control system is responsible for adjusting to these changes. [Grossman, 1995]

\subsubsection{Static pressure relationships and pressurization}

The Laboratory Control and Safety Solutions Application Guide (1994) discusses static pressure relationships for laboratory exhaust systems and laboratory room pressurization.

The static pressure relationship for the individual fume hood exhaust system...applies to both individual and centralized laboratory exhaust systems. The outside of the building is shown as the point of static pressure $\left(0.00\right.$ in $\left.\mathrm{H}_{2} \mathrm{O}\right)$. The laboratory room is kept at a slight negative static pressure to prevent migration of laboratory room air to adjacent non-laboratory spaces. Nonlaboratory spaces are kept at a slightly positive static pressure with respect to both the outside and to laboratory rooms to prevent infiltration of unconditioned outside air and laboratory room air. To understand the concept of negative static pressure, it will be helpful to think of a negative static pressure as a slight vacuum with respect to a neutral or positive static pressure point. Air will always flow towards the location of the lower or most negative value of static pressure

A properly designed laboratory ventilation system will maintain the laboratories, chemical storage areas and other chemical handling rooms at a "negative pressure" with respect to all nonlaboratory areas. Maintaining a room at a negative pressure means that the room will be at a slight vacuum with respect to an adjacent area. Air from adjacent non-laboratory areas will flow into a laboratory rather than allowing air to flow out from the laboratory. This condition will be most evident when a door to a laboratory is opened. A slight air movement into the laboratory should be sensed. However, since even fully closed doors always have some opening, particularly along the bottom, some air will always be flowing into a laboratory. This constant aiflow helps prevent any. fumes or hazardous airborne substances from migrating beyond a laboratory or other chemical handling room and allows the laboratory exhaust system to remove these unwanted substances from the building.

\subsubsection{Temperature control considerations}

DeLuga (1995) presents temperature control considerations for VAV ventilation systems in laboratories. In relatively larger laboratories or in laboratories with few fume hoods, [a] basic VAV temperature control application...is usually adequate. However, if a laboratory is relatively small in size (i.e. 300 square feet or less) or has a high density of fume hoods, the basic VAV temperature control application may not adequately handle the large variations in the room air change rate, which can occur due to the impact of the fume hoods. Temperature control in the laboratory must be more responsive and precise than in most other applications. The first requirement of the temperature control arrangement is to provide comfort for the occupants. Sometimes it is necessary to maintain ambient conditions necessary for experimental processes taking place. Individual preferences on temperature vary from person to person and through the calendar year. Since a laboratory's function and the types of chemicals used will change over time, the temperature 
control system must be capable of responding to and accommodating changes in the room temperature setpoint. As the total exhaust cfm of the room varies due to opening and closing of the fume hood sashes, the room controller modulates the supply air damper to maintain the flow tracking differential. The room controller also modulates the supply air reheat coil valve in response to the temperature control needs of the room. The room controller must ensure that the minimum room ventilation rate is always maintained and that the flow tracking differential between the room exhaust and the room supply air is also maintained. With these conditions fulfilled, the room controller will modulate the reheat coil valve to maintain a supply air temperature which will satisfy the room temperature needs.

Because of the high ventilation rates typically applied to laboratories (i.e. 10 to $12 \mathrm{ACH}$ ), the heat loss of the room through external walls during the heating season has little impact on the ambient temperature of the room. As a result, a moderate tempering effect by the reheat coil on the supply air normally maintains the room temperature as desired. During the cooling season, a laboratory's heat gain (due to equipment present) will often require an increase in the minimum amount of supply air even with the reheat valve fully closed. Under these conditions, the room controller can increase the amount of supply air as needed, but must also make a corresponding increase in the room general exhaust to maintain the flow tracking differential.

\subsubsection{Static pressure force}

There is a limit to the pressure differential that should be maintained between a laboratory and adjacent spaces because of the need to enter and leave the laboratory through doorway(s). Typically, safety concerns are satisfied with a negative differential, i.e., air flow towards the laboratory, in the range of 0.01 to 0.02 inches W.G. A small, discernible air flow is noticed through an open doorway with a pressure differential of 0.01 inches W.G. However, a pressure differential of 0.35 inches W.G. requires a force of about 20 pounds to open the door, which is too much in the view of many laboratory operators. [Laboratory Control and Safety Solutions Application Guide, 1994]

\subsubsection{Air lock entry}

The Laboratory Control and Safety Solutions Application Guide (1994) points out that: If laboratory pressurization is extremely critical (as when highly toxic agents may be present in the laboratory), it may be necessary to use an air lock entry arrangement to ensure against aiflow out of the laboratory room. In such designs, entry or exit requires passing through a set of double doors (one door and then another) with a negatively controlled passageway between the two doors.

\subsubsection{VAV and laboratory pressure control}

The combined laboratory pressure sensing and air-flow tracking control system continuously measures both total room exhaust and absolute pressure differential. A general laboratory exhaust damper and a supply damper modulate to maintain the required minimum air flow and pressure differential. The supply damper begins in a minimum position that provides cooling and heating. Variations in the fume hood sash location affect total laboratory exhaust. When all fume hoods are in their minimum position, the general exhaust is in its maximum open position. When the exhaust volume increases because a fume hood sash is raised, the general exhaust damper begins to close to maintain the required negative pressure differential. At some point, depending on the size of the laboratory and the number of hoods, the general exhaust will reach a fully closed position, and the supply damper will begin to open to maintain the required negative pressure differential. Temperature control comes from the operation of the heating/cooling coil's control valve. 
During the cooling season, the laboratory heat gain may require more supply air to be provided than is needed just to make up the exhaust air. Accordingly, the pressure control system will open the supply damper to change the amount of supply air for cooling purposes. The pressure differential is maintained by opening the general exhaust air damper. There is a corresponding increase in total laboratory exhaust and, consequently, energy use. [Laboratory Control and Safety Solutions Application Guide ,1994]

\subsubsection{Application of pressure sensing}

The application of a pressure sensing system provides precise closed-loop control and a continuous monitoring of the laboratory differential pressure. The closed-loop feature compensates for a laboratory door being left open, and the monitoring capability notifies operators of the open door. However, the pressure sensing system may have a slower overall response time than other methods of laboratory pressure control. In addition, the quantity of actual supply and exhaust air is not known with this system; knowing this information could provide increased laboratory safety. [DeLuga, 1995; Laboratory Contro] and Safety Solutions Application Guide, 1994]

\subsubsection{Pressure sensing control}

Deluga (1995) explains that: The most direct method of room static pressure control is to sense the static pressure between the laboratory and the adjacent area, and control the ventilation airflow of the two areas to create the desired static pressure difference. The laboratory room controller measures the static pressure of the laboratory with respect to the adjacent area by means of the differential pressure sensor located in the wall between the laboratory and the adjacent area. The room controller modulates the supply air damper to maintain the static pressure at setpoint. Aside from maintaining control the static pressure of the room, the room controller must also ensure that the laboratory is always being ventilated at a minimum number of air changes per hour (ACH). This requires that the room controller always maintain control over the total room exhaust cfm. If the laboratory has variable air volume (VAV), the individual fume hood controllers continue to vary the total amount of air leaving their respective fume hood to maintain required fume hood face velocity. These variations in the fume hood exhausts will affect the total room exhaust cfm. As a result, the room controller must constantly monitor the total room exhaust cfm and modulate the room general exhaust damper to ensure that the required minimum air change per hour rate is maintained.

Each individual fume hood controller provides the room controller with its respective fumehood exhaust cfm value. The room controller adds all of the fume hood exhaust cfm values together and also adds the room general exhaust aifflow rate to calculate the total room exhaust cfm. As fume hoods begin exhausting more air, thus increasing the total room exhaust, the room controller must close off the room general exhaust air damper to reduce the amount of air taken from the room by the general exhaust. As the fume hoods exhaust less air, the room controller must modulate the room general exhaust air damper open to increase the amount of air taken from the room by the general exhaust.

A specific amount of supply air in relation to the total room exhaust cfm is simultaneously required to makeup for the total room exhaust and also provide control over the room's static pressure. As the fume hood sashes are opened, increasing the total room exhaust cfm beyond the amount of air needed to maintain the minimum $A C H$, the room controller must increase the amount of supply air to makeup for the increased total room exhaust cfm. There may be times, particularly during the cooling season, when the heat gain of the laboratory will require more conditioned supply air than that needed to just provide the makeup air. In these instances, the room controller will increase the amount of supply air and maintain control over the room static pressure by also opening the room general exhaust damper as necessary. 
Note that at any time someone in the room may reposition a fume hood sash and thus cause a change in the total room exhaust cfm. As this happens, the room controller will modulate the room general exhaust damper and the supply air damper to compensate for the increase or decrease in the fume hood exhaust. This action is intended to maintain the minimum required room ventilation rate and the room's static pressure level.

\subsubsection{Application of air-flow tracking}

Air-flow tracking provides quick response to changes in exhaust air-flow rate resulting from fume hood sash movement. Air-flow tracking can provide more stable operations under certain conditions such as momentary door opening or transient readings by the pressure sensor, as described above. However, airflow tracking control does not maintain specific differential pressure and therefore cannot guarantee that a laboratory's air pressure is always negative with respect to adjacent areas. The differential flow is determined using a rule of thumb and is established during the testing and balancing procedure because it cannot be determined beforehand. Consequently, the construction integrity of the laboratory directly affects the chances of attaining the specified differential flow. In addition, because the actual air-flow velocity desired (usually 50 to $100 \mathrm{fpm}$ ) is not known, the rule-of-thumb differential flow value (typically $200 \mathrm{cfm}$ ) may be excessive and waste energy. [DeLuga, 1995]

\subsubsection{Air-flow tracking control}

DeLuga (1995) describes the use of air-flow tracking to maintain negative air pressure in a laboratory. Another means to maintain a laboratory room at a negative pressure with respect to an adjoining nonlaboratory area is by aiflow tracking, commonly called flow tracking. ... aifflow tracking is based upon always removing more air from a space than is supplied to the space. This will tend to create a slight vacuum condition within the space and make the space at a negative static pressure with reference to an adjacent area. Airflow tracking is applied to maintain the negative pressurization level of a space by ensuring that the amount of air being exhausted form the space exceeds the amount being supplied by a specific amount. Although at any given time the quantity of total room supply air and total room exhaust air will vary as the needs of the laboratory vary, the cfm difference between the total room supply air and the total room exhaust air will be controlled to remain at a constant value.

The essential difference [between the aiffow tracking method and pressure sensing control] is that there is no differential pressure sensor in the aiflow tracking method. However, an air flow sensor has been added to measure the total room supply air...the laboratory has a modulating damper in the supply air and room general exhaust which is controlled by the room controller. The laboratory room controller measures total room supply air cfm and also determines the total room exhaust air cfm. While maintaining the flow tracking differential airflow between the room supply air and the total room exhaust air, the room controller must also ensure that the laboratory is always being ventilated at the required minimum number of air changes per hour.

If the laboratory has VAV fume hoods, the individual fume hood controllers continue to vary the total amount of air leaving their respective fume hood face velocity. These variations in the fume hood exhausts will affect the total room exhaust cfm. As a result, the room controller must constantly monitor the total room exhaust cfm and modulate the room general exhaust damper to ensure that the minimum air change per hour rate is maintained. Each individual fume hood controller provides the room controller with its respective fume hood exhaust cfm value. The room controller adds all of the fume hood exhaust cfm values together and also adds the room general exhaust aiflow rate to calculate the total room exhaust cfm. As the fume hoods begin to exhaust more air and thus begin to increase the total room exhaust, the room controller must close off the room general exhaust air damper to reduce the total amount of air being exhausted from the room. 
As the fume hoods exhaust less air, the room controller must modulate the room general exhaust air damper open to increase the amount of air taken form the room by the general exhaust. As the total room exhaust cfm changes, a specific amount of supply air is simultaneously required to maintain the flow tracking differential. As the fume hood sashes are opened, increasing the total room exhaust cfm beyond the amount of air needed to maintain the minimum $\mathrm{ACH}$, the room controller must increase the amount of supply air to track with the increased total room exhaust cfm.

There may be times, particularly during the cooling season, when the laboratory's heat gain will require more conditioned supply air than the amount needed to provide the makeup air. In these instances, the room controller will increase the amount of supply air and maintain the tracking differential by opening the room general exhaust damper as necessary. Note that at anytime someone in the laboratory may reposition a fume hood sash and thus cause a change in the total room exhaust cfm. As this happens, the room controller will modulate the room general exhaust damper and the supply air damper to compensate for the increase or decrease in the fume hood exhaust, so that the minimum required room ventilation rate and flow tracking differential is maintained at the setpoint.

The specific difference between the total room supply and total room exhaust air is generally established at 100 to $200 \mathrm{cfm}$ per laboratory door. The actual tracking value should be established when the ventilation system is in the process of being commissioned by adjusting the tracking value setpoint until the desired specific static pressure differential is obtained by an actual measurement. The actual tracking value will vary between laboratory rooms and is highly dependent upon construction and architectural factors such as the clearance around doors, "tightness" of the laboratory, wall construction and other unpredictable factors.

\subsubsection{Combined pressure sensing and air-flow tracking}

Vendors may recommend one type of laboratory pressure control as superior to the other. However, many experiences with the application of both technologies show that the most energy-efficient arrangement capitalizes on the best features of the two systems together.

The combined arrangement uses the differential pressure measurement from the pressure sensor to fine tune the air-flow tracking value, which is normally fixed. The air-flow tracking value is varied as required during laboratory operation to maintain precise, energy-efficient pressure control. If the required differential pressure modulates because of wind forces, outside temperature variations, or adjacent air conditioning system effects, the combined system responds accordingly. An additional energy-efficiency benefit of the combined system is the ability to remotely monitor the laboratory and adjacent areas and make air flow and temperature adjustments, for example, because of laboratory occupancy. [DeLuga, 1995; Laboratory Control and Safety Solutions Application Guide, 1994]

\subsubsection{Air-flow tracking and pressure sensing - case study}

Monsen (1989) compares air-flow tracking and pressure sensing for laboratory distribution systems. In a ... test in a ... laboratory, flow tracking was compared to direct pressure measurement for control of laboratory pressure. A small lab with one hood, one fan, and a separate makeup air system was identified, and a system utilizing a side wall mass sensor to control hood face velocity was installed. Flowtracking sensors, as well as differential pressure sensors, were installed in the supply and exhaust systems with the corridor (which was previously tested for stability at various outdoor wind and barometric conditions) as a reference. Control of the makeup air fan speed and monitoring of all pressure and flow sensors was accomplished through a computer-based controller. 
This lab has run satisfactorily since May 1987 and has operated altemately with differential pressure sensing and with the airflows being tracked and vice versa. The response time of the system was checked periodically under both control schemes, and the fume hood face velocity checked at various sash positions.

What was learned?

- Both pressure differential and flow-tracking systems, if properly installed and adjusted, can prevent laboratories from becoming positive in pressure while limiting excessive negative pressure.

- Although both systems were satisfactory, further testing on this and other labs indicated that flow tracking is more desirable when substantial infiltration is designed into the project, when the lab cannot be tightly sealed, or when openings (i.e., doors) cannot be controlled. A greater number of control points and proprietary supply and exhaust boxes may be required for a larger installation, which could increase costs, and differential pressure is beneficial as one is measuring the controlled variable (room pressure). A proper reference datum, void of disturbances, is essential, as is a "tighter" laboratory structure.

\subsubsection{Enthalpy stabilization}

Enthalpy stabilization increases the energy efficiency of a laboratory facility by insuring that the conditioning system does not overshoot space temperatures. Overshooting can occur when the conditioning system is asked to respond to rapid changes in supply air volume in small laboratories with high relative fume hood densities. Enthalpy stabilization uses the air-flow tracking sensor in conjunction with a supply air temperature sensor to close the coil's temperature control valve when the pressure control system demands sudden increases in supply air. [DeLuga, 1995]

\subsubsection{Combined control with enthalpy stabilization}

The Laboratory Control and Safety Solutions Application Guide (1994) specifies the following for "cascaded room pressurization control":

The DDC PANEL shall utilize a DIFFERENTIAL PRESSURE SENSOR in the wall between the room and the nearest adjacent non-laboratory area to continuously measure the actual differential pressure between the laboratory room and adjacent area. The DDC PANEL shall utilize the differential pressure measurement to establish the FLOW TRACKING DIFFERENTIAL required to maintain the room differential pressure setpoint. The DDC PANEL shall also utilize an AIRFLOW SENSOR in the ROOM SUPPLY AIR to continuously measure the actual ROOM SUPPLY AIRFLOW. The DDC PANEL shall continuously calculate the ROOM SUPPLY AIRFLOW necessary to maintain the required FLOW TRACKING DIFFERENTIAL setpoint by subtracting the required FLOW TRACKING DIFFERENTIAL from the TOTAL ROOM EXHAUST. The DDC PANEL shall modulate the ROOM SUPPLY AIRFLOW to ensure that the required FLOW TRACKING DIFFERENTIAL is always maintained by a proportional, integral and derivative loop control algorithm.

\section{Room Temperature Control}

The DDC PANEL shall maintain the room temperature at the room temperature setpoint (adjustable). The DDC PANEL shall continuously measure the ROOM TEMPERATURE SENSOR and continuously measure the ROOM SUPPLY AIR discharge temperature by means of an averaging DISCHARGE AIR TEMPERATURE SENSOR. Whenever a heat loss or heat gain exists 
for the room, the DDC PANEL shall calculate the room's BTU/hour heating or cooling load by utilizing inputs from the ROOM TEMPERATURE SENSOR, the DISCHARGE AIR TEMPERATURE SENSOR and the required pressurization ROOM SUPPLY AIRFLOW.

The DDC PANEL shall maintain the room temperature at the setpoint by positioning the THREEWAY NORMALLY OPEN (N.O.) HEATING VALVE to attain a ROOM SUPPLY AIR discharge temperature which, in combination with the ROOM SUPPLY AIR required for pressurization, will offset the room's BTU/hour heating or cooling load using a proportional, integral and derivative (PID) closed loop control algorithm. This [Enthalpy Stabilization] ... control action shall minimize the potential for room temperature swings due to sudden changes in the ROOM SUPPLY AIRFLOW which are necessary to maintain room pressurization.

\subsection{Diffusers}

\section{Energy Efficiency and Diffusers}

The discharge velocity of the supply diffuser is one of the most important parameters that must be considered in energy-efficient fume hood systems. Air diffusers also must be located properly to minimize air turbulence in the laboratory space. [Saunders, 1993; Laboratory Control and Safety Solutions Application Guide 1994]

\subsubsection{Discharge velocity}

The discharge velocity from air diffusers at the fume hood should not exceed 60 percent of the face velocity stipulated for the laboratory's fume hoods. In addition, the supply air velocity that arrives at the fume hood should be no more than 50 percent of its face velocity. [Laboratory Control and Safety Solutions Application Guide, 1994; Saunders, 1993]

High-velocity blade diffusers with average directed velocities of 200 to $800 \mathrm{fpm}$ are not acceptable for laboratories, because supply air discharged through a perforated ceiling panel will have a lower velocity than that discharged from standard blade diffusers. A non-aspirating supply diffuser provides a lowvelocity, evenly distributed, downward-moving column of conditioned air without creating disruptive turbulence. [Watts, 1995; Laboratory Control and Safety Solutions Application Guide, 1994; Saunders, 1993]

\subsubsection{Diffuser placement}

Air supply diffuser placement influences laboratory air patterns and fume hood performance. Diffusers should be located to avoid creating drafts at the face of fume hoods. Supply and exhaust air diffusers should be located so that the exhaust does not draw a significant portion of supply air out before the supply air has had a chance to properly diffuse into room air. [Saunders, 1993; Laboratory Control and Safety Solutions Application Guide 1994]

Supply air should be introduced near the laboratory entry doorway and flow towards the fume hoods. The general exhaust should be located near the fume hoods where the greatest hazardous releases are likely to occur. The ideal arrangement is to locate the fume hoods at the opposite end of a laboratory space from the supply air. The supply air needs to diffuse and gently sweep into the laboratory, moving away from the primary entry doorway. An alternative is to locate the diffusers along the center of the room with the hoods on opposite walls. [Saunders, 1993; Laboratory Control and Safety Solutions Application Guide, 1994] 


\subsubsection{Animal room diffuser systems - case study}

McDiamid (1988) in "A Qualitative Evaluation of Air Distribution is Full-Scale Mock-Ups of Animal Holding Rooms," describes direct ventilation of animal cages in a research facility.

Effectiveness was defined as uniformity of airspeed among the 16 cages, airspeed being measured at the front face of each cage. This measurement plane was chosen since it represents the interface between the cage and the environment at which air exchange is free to occur through the cage grille. In so defining the design objective, the design scope was limited to providing a high quality environment around the cages. Determination of air quality inside occupied cages would be a complex undertaking beyond the scope of this design problem.

A high velocity airstream flows from the supply diffuser across the top of the room to the far wall. Near the far wall the air turns and flows downward in a 2- to 3 foot wide stream. Some air flows out the exhaust register and the rest of the stream flows back along the aisle floor and rises uniformly to be entrained in the high velocity stream. Another advantage of [the] scheme... is that it does not blow air out the doorway when the door is opened and thus helps to maintain room isolation.

\subsection{Noise Attenuation}

\section{Energy Efficiency and Noise Attenuation}

Noise attenuation devices typically increase the pressure drop of the air distribution system, increasing its energy consumption. Numerous strategies exist for eliminating noise; however, it is preferable not to design a noisy system in the first place. Noise is caused by air movement and transmitted by vibrations to the duct work from fans, dampers, and other components, especially fume hoods. An engineer can make a system quieter by selecting low-noise fans, incorporating round duct work, and reducing air-flow velocity by oversizing the duct work. Active noise cancellation technology can reproduce low-frequency fan noise electronically and reintroduce the noise $180^{\circ}$ out of phase, canceling it without restricting air flow within the duct work. [Wise and Dineen, 1995; Micro-Electronics Facility Efficiency Workshop, 1995; Handbook of Facilities Planning, 1990]

\subsubsection{Fans and noise}

Most noise generated in the air distribution system is caused by fan operation. Noise attenuation devices are usually designed to reduce transmission of fan noise through duct work. Generally, noise attenuation devices increase the fan power required to move air in the distribution system because they create an added pressure drop. Therefore, the first step in noise control is to select a fan that creates less noise. Low-noise fans, such as "sickle blade" fans, are slightly less efficient than the best axial fans but eliminate the need for noise attenuation devices. The energy engineer has to balance decreased efficiency from noise attenuation devices against less efficient but quieter fans. Designing the duct work to absorb noise can also influence fan selection. [Kruse, 1991; Micro-Electronics Facility Efficiency Workshop, 1995]

\subsubsection{Fume hoods and exhaust duct work noise}

Fume hoods do not generate noise but amplify noises generated in the exhaust system. The potential noise level from a fume hood increases as the hood gets wider. According to Saunders (1993), "These system noises come from a variety of causes: air going in excess of 2,000 fpm through the ducting; turbulence caused by the improper treatment of ducting turns or transitions to smaller or larger ducting; unbalanced blower impeller wheels or frayed and cracked blower/motor belts; assorted junk left in the 
ducting during construction. In-line dampers cause noise when they are partially closed." [Saunders, 1993]

The Handbook of Facilities Planning (1990) suggests the following to minimize fume hood noise:

- Fume hood plenum velocity should be approximately half the fume hood slot velocity, and the slot velocity should not exceed $1,200 \mathrm{fpm}$.

- The fume hood collar must have a one-inch radius between the chamber and the duct, and the air velocity must not exceed 1,400 fpm at this point. Provide a 12-inch diameter sleeve for a six-foot hood, and two 10.5-inch sleeves for an eight-foot hood or larger.

- Air velocity in the duct must not exceed 1,600 fpm unless dust and other solid particles must be exhausted.

- Exhaust fans should be located as far from supply air as practical to reduce noise transmission.

- Fan speed should not exceed 1,800 rpm to reduce noise generation.

- Radial-blade, centrifugal fans should be used; they produce less air noise than backward-inclined airfoil fans. Forward-curved fan blades move more air with less fan wheel blade velocity, i.e., "tip speed" and may even be less noisy.

- A vibration isolator, such as a flexible, neoprene-coated glass fiber cloth, must be installed between the fan and the duct.

\subsubsection{Noise criteria}

The Handbook of Facilities Planning (1990) explains:

The noise criteria (sic) (NC) is a single numerical index commonly used to define design goals for the maximum allowable noise in a given space. They primarily apply to the noise produced by a ventilation system, but they may be applied to other noise sources. The NC criteria consist of a family of curves that define the maximum allowable octave-band sound pressure level corresponding to a chosen NC design goal. Although alternate contours have been proposed (most notably the room criterion or RC curves), the NC criteria remain the most widely accepted.

... Acceptable Limits of Noise

Space Noise Criterion

$(N C)^{*}$

$\begin{array}{ll}\text { Lab office } & 35 \\ \text { Laboratory } & 45 \\ \text { Instrument room } 40 & \\ \text { Contr.-temp. room } & 45 \\ \text { Darkroom } & 35 \\ \text { Glasswash } & 45\end{array}$




\section{Noise Criteria Levels for Rooms}

Type of Space (and acoustical requirements) $\quad$ NC level

Conference rooms, churches, lecture halls, classrooms $\quad$ NC 30-35

Open-offices, schools, lobbies, public areas $\quad$ NC 35-40

$\begin{array}{ll}\text { Large public offices } & \text { NC } 40-45\end{array}$

Shops, garages, etc. (for just acceptable speech and telephone communication) $\quad$ NC 50-60

For work spaces where speech or telephone communication is not required, but $\quad$ NC 55-70

where there must be no risk of hearing damage*

* Most cleanrooms are at this NC level

\subsubsection{General laboratory noise minimization}

The Handbook of Facilities Planning (1990) points out that::

Many laboratory operations generate noise, some of which can be minimized by:

- Moving noise-producing equipment (e.g., freezers, refrigerators, incubators and centrifuges) from the laboratory to an equipment room.

- Locating compressors for controlled-temperature rooms remotely

- Providing acoustical treatment on ceilings and walls.

\subsubsection{Noise attenuation - case study}

Hitchings and Shull (1993), present a case study of noise reduction techniques used in a large laboratory building addition. Great care was taken to reduce noise levels in the laboratory by proper fan selection and efficient ductwork design and sound traps. During start-up, the system operated very quietly and no problems were discovered. Startup occurred in early spring. A few months later, after ambient temperatures had increased and additional sensible heat-producing equipment had been added to the laboratories, a noise problem did occur. When all the fume hoods were closed and there was not enough aiflow through the system to keep the internal temperatures at or below setpoint, the general exhaust valves would open, as they were supposed to, to stimulate more supply flow. When this occurred, a great deal of noise was produced by the general exhaust valve, which propagated backward through the duct and out the exhaust grille in the ceiling. This was objectionable enough to the researchers that they would leave a fume hood open to prevent it from occurring. When this was discovered, a sound trap was inserted in the ductwork between the exhaust grille and the general exhaust valve. This solved the problem completely and the researchers no longer leave a fume hood open to compensate. 


\subsubsection{Active noise attenuation}

Conventional noise attenuators (e.g., silencers and sound traps) cancel random, low-frequency noise that is typically generated by HVAC fans. This low-frequency noise in the $63-$ and $125-\mathrm{Hz}$ octave bands is attenuated with devices that have internal baffles. These devices restrict air flow, thereby increasing the pressure drop of these systems by about one inch W.G. for each device in the duct work. However, active noise attenuation devices cancel low-frequency noise without restricting air flow. These electronic systems use a microphone to sense noise, a processor to determine the cancellation sound, and a speaker to produce cancellation sound in the wall of the duct work. [Wise and Dineen, 1995]

\subsubsection{Adaptive signal processing}

Wise and Dineen (1995) describe approaches to active noise control for energy-efficient HVAC systems. One approach uses an...adaptive filter to compensate for the acoustic feedback from the canceling loudspeaker to the input microphone. With the...adaptive filter, the controller is not used to generate wave forms from the input frequency; rather, it creates an electronic representation, or model, of the duct acoustics. Any noise detected by the input microphone is processed by the controller which responds by playing the exactly appropriate canceling sound just as the noise reaches the speaker downstream.

\subsubsection{Active noise attenuation in cleanrooms - case study}

Wise and Dineen (1995) present the following case study of active noise control in a cleanroom. Active noise control was recently applied to the supply air ducts of a 350 sq. ft. cleanroom. Measurements taken in the room showed an initial rating of NC68. Approximately 10 feet of the discharge duct on each of the four air handlers serving the area was treated with a 1-inch thick encapsulated fiberglass sheet along the internal perimeter. The fiberglass encapsulation prevents erosion and moisture absorption. This provided sound absorption of the mid and high frequencies, but would not interfere with the air flow. Active noise control systems were added to cancel the low-frequency noise that remained. The overall result was a drop to NC58, a $10 \mathrm{~dB}(\mathrm{~A})$ reduction, and appreciable reduction of the low-frequency background noise that affects workers who spend several hours per day in the room. The system can be applied to the supply or return air duct. Broad band reduction of 10-20 dB was achieved between 50 and $200 \mathrm{~Hz}$. Data shows the lowfrequency attenuation provided by the active system. The higher frequencies are attenuated with 1" of internal duct lining. Although widely used because of the ability to state design goals as a single number, an A-weighted Sound Level $(d B)$ does not provide any information on special content. A-weighted sound levels are not recommended for use in the design of HVAC systems. Noise criterion curves provide more information about the spectral content and are used to evaluate noise conditions in enclosed spaces and to aid in the writing of specifications of noise control in such spaces. Noise criteria (NC) levels specified for cleanrooms are often as high as NC60 to NC70. These levels are at the upper end of the range for noise levels in a room.

\subsection{Pumping Systems}

Energy Efficiency and Pumping Systems

As Kruse (1991) points out,

Pumps are not the biggest consumers of energy, but they're not the smallest either. A little extra effort in the system design and equipment selection can make a worthwhile difference. The main three points to remember are that slower flows mean lower pump horsepower, slower flows mean 
improved chiller efficiency via greater temperature differentials, and that not all pumps have the same efficiency. Since pump horsepower is directly proportional to flow at a cube rate, the cost of chilled water pumping can be reduced by 33 percent by increasing the coil temperature differential from $10^{\circ}$ to $15^{\circ}$ and reducing the flow accordingly. Further savings are sometimes possible depending on the chilled water supply temperature being used.

Pump energy savings can be further enhanced by incorporating variable frequency drives (VFDs) which can vary pump speed to match load. VFDs provide power savings at a cubed rate. Incorporating primary/secondary and even tertiary piping loops facilitates load matching, increasing energy savings. Incorporating two-way control valves on heating/cooling coil(s) allows reduced pump horsepower at part-load conditions. Conditioning coils consume energy on both the air and water-sides. According to Kruse (1991), "An air-side increase of 0.5 inches at 20,000 CFM can cost an additional 2.4 horsepower. For a recirculation air handler which runs continuously, this is equal to 1300 kilowatt-hours of electricity per month for each air handler. The water-side effects are usually less alarming, but worth paying attention to as well."

\subsubsection{Variable speed pumping}

The principal advantage of a variable frequency drive (VFD) with a pump is the significant energy savings realized from reduced pump horsepower required as flow rate is decreased to match decreased load. The VFD saves pumping energy at a cubed rate; therefore, even a small (20 percent) reduction in the pump's speed translates into large energy savings (50 percent). The energy engineer should keep in mind that, "the greater the average annual load variation from maximum design conditions, the greater the energy savings potential with variable speed pumping." [Carroll, 1995]

\section{- Riding the pump curve}

Conventional pumping arrangements have incorporated two-way valves at the conditioning coils and allow constant-speed pumps to "ramp back" on their pump curve to save some energy. This configuration jeopardizes the pump's operation in a number of ways, including overheating and cavitation. Incorporating a VFD eliminates these problems and maximizes the pump's efficiency. [Kruse, 1991]

\section{- Sensor location}

A pressure sensor located in the piping loop provides the signal for varying the pump's speed with the VFD. The sensor identifies differential pressure in the loop; as pressure increases, because a coil's control valve closes, the VFD slows down the pump to maintain a stipulated set point. Conversely, as the differential would decrease, the VFD would speed up the pump to maintain the set point. However, Mayhew (1993) points out that,

"Too often much of the energy savings from a secondary chilled-water pumping system is wasted by using differential control of the variable-speed drive but selecting the wrong location for the control sensor. Control sensors are found a few feet away from the secondary chilled-water pumps set at 30 psig. The more efficient installations put the differential pressure sensor between the supply and return, toward the end of the chilled-water loop set about 10 psig."

Sensor location is also a consideration in primary pumping loops and heating systems.

\section{- Control set point}

Mayhew clearly notes that, "The setpoint is selected to ensure that there is enough differential pressure at full flow to provide design flow through the control valve, the coil, and associated piping." However, 
energy can be saved if this set point is varied based on the energy-use profiles of the facility, which can be understood through an EMCS. A lower differential pressure set point will require lower pumping power. [Mayhew, 1993]

\subsubsection{Pump selection}

Kruse (1991) gives advice on energy-efficient pump selection.

Select pumps with an eye toward efficiency. The following data illustrates the various horsepower and efficiencies for different pumps at 800 GPM and 80 feet of head.

\begin{tabular}{rrrc} 
Size & RPM & H.P. & Efficiency \\
\hline 4006 & 3450 & 21.3 & $76 \%$ \\
$4 \infty 8$ & 3450 & 34.0 & $40 \%$ \\
$5 \infty 12$ & 1750 & 23.3 & $70 \%$ \\
$6 \infty 10$ & 1750 & 23.0 & $71 \%$ \\
$6 \infty 12$ & 1750 & 23.0 & $71 \%$
\end{tabular}

Although several of the pumps in this example would make equally good selections based on energy consumption, the worst pick uses $59 \%$ more horsepower than the best.

\subsubsection{Variable speed pumping-case study}

Carroll (1995) describes the design process for a large energy-efficient biosciences laboratory and the advantages of variable speed pumping. Engineers viewed two methods of supplying chilled and heating water to their respective loads in the research building. The first was the "constant volume" system that employs pumps that are sized for the maximum required flow and pump this flow during all hours of operations (in this case 24 hours per day, 365 days per year). The other was the "variable speed pumping" system that is sized for the maximum load less diversity and pumps only that amount of fluid required to meet the actual load. The research building is large enough to realize a net lower first cost when the higher cost variable speed drives and controls are offset by decreased piping sizes, replacing three-way valves and coil by passing piping with two-way valves, reduced motor horsepower and electrical service size.

\subsubsection{Primary/secondary/tertiary loops}

A primary/secondary hot-water and chilled-water loop increases energy efficiency in a number of ways. One way is to design the primary loop to accommodate the modular boiler/chiller arrangement that is recommended in the "right-sizing" approach in Chapter Three. In such a multiple-plant configuration, staging the boiler and chillers on and off allows flexibility in meeting load. This design includes a variable volume circulator, electric isolation valves, and DDC. Care must exercised so that flow rate within the boilers and chillers does not go below minimum during their operation. [Mayhew, 1993; Ciborowski and Pluemer, 1991] 
The second way to increase energy efficiency is to replace with a variable volume pump any bypass valve that controls differential pressure in the secondary loop. The goal is to have a true primary/secondary piping loop arrangement that is hydraulically pressure independent, which allows different flow rates in each loop in order to minimize pump energy. Each secondary loop utilizes a variable frequency drive and two-way valves at each coil except the end coil, which uses a modulating three-way valve. "Thermal inertia problems" are eliminated when there is low demand for hot/chilled water because of the differential pressure control of this arrangement. [Mayhew, 1993; Ciborowski and Pluemer, 1991]

A third way that primary/secondary and tertiary loops save energy is that they can be operated at different temperature drops. Designing an increased temperature drop means that the pumping horsepower can decrease for a given amount of cooling/heating, saving energy. For instance, a primary loop may be sized for a $10^{\circ} \mathrm{F}$ temperature drop to allow production of low-temperature chilled water. However, secondary loops could be designed for a range of temperature drops from $12^{\circ} \mathrm{F}$ to $15^{\circ} \mathrm{F}$ or more, creating a medium-temperature chilled water loop. The secondary and tertiary loops operating at different temperatures can match their respective connected loads with optimized pumping power. [Mayhew, 1993; Ciborowski and Pluemer, 1991]

\subsubsection{Piping pressure drop}

The first step to lower energy consumption in the pumping system is reduce the pressure drop of the piping loop. However, good piping design and sizing may not be enough to accomplish this goal. Optimizing piping loop design is an iterative process of balancing cost with efficiency gains for larger diameter piping and simplified configurations. Having the best possible understanding of the actual pressure drop required helps enormously in determining optimum pipe size. A side benefit of larger piping and a lower pressure drop is flexibility for future renovations. In addition, selection of lowpressure-drop coils and control valves with optimum $C_{v}$ flow factors contributes to reduction of the entire piping pressure drop.

\subsubsection{Coil pressure drops}

Though it is clear that coil selection has energy use impacts on both air-side and the water-side flows, we review only the water-side issue. The design approach promoted by the Micro-Electronics Facility Efficiency Workshop (1995), uses Low Face Velocity/High Coolant Velocity, or LFV/HCV that, "lowers the typical pressure drop across the coil because it uses typically half the rows of coils of a conventional design. It also allows for greater heat transfer efficiency and may allow the chilled water supply temperature to be raised slightly." In addition, careful analysis and selection of a preheating/cooling coil can optimize energy savings for the climate in which the laboratory is located. If variable speed pumping is used as well, flow-rate reductions of more than 50 percent can be realized when the outdoor dry-bulb temperature drops from $100^{\circ} \mathrm{F}$ to $75^{\circ} \mathrm{F}$.

\section{REFERENCES}

Building Performance - Fume Hood Retrofits, Pacific Gas and Electricity Energy Center, eds. San Francisco, CA: PG\&E, 1994.

Carroll, John, Jr. P.E., C.P.E. "Designing Safe and Efficient Fume Hoods at Research Lab." AIPE Facilities, March-April 1995.

Ciborowski, Thomas J., P.E., and Herb Pluemer. "Actual Results of Energy Efficient Designs." Cleanroom Technology Forum Proceedings, 1991. 
DeLuga, Greg, P.E. "Special Testing: Controlling VAV Laboratory Ventilation Systems (Part I)." Buffalo Grove, IL: Landis and Gyr Powers, Inc., 1995.

Grossman, Irwin. "Troubleshooting Lab Systems: Comparing Laboratory Airflow Control Systems: A practical guide to a complex subject." Engineered Systems. Troy, MI. September 1995.

Handbook of Facilities Planning, Vol. One, Laboratory Facilities. ISBN 0-442-31852-9. Ruys, Theodorus, AIA, ed. New York: Van Nostrand Reinhold, 1990.

Hitchings, Dale T., P.E., Richard S. Shull, P.E. "Measuring and Calculating Laboratory Exhaust Diversity-Three Case Studies." ASHRAE Transactions, Laboratory HVAC, 1993.

Industrial Ventilation: A Manual of Recommended Practice - 22nd Edition. ISBN: 1-882417-09-7. The American Conference of Governmental Industrial Hygienists, Inc. (ACGIH), eds. Cincinnati, OH: ACGIH, 1995.

Kruse, Robert K., P.E. "Mechanical System Strategies for Energy Efficiency." Cleanroom Technology Forum Proceedings, 1991.

Laboratory Control and Safety Solutions Application Guide - Rev. 2. Buffalo Grove, IL: Landis and Gyr Powers, Inc., 1994.

Mayhew, F.W. "Application of Direct Digital Temperature Control Systems for Maximum System Efficiency." ASHRAE Technical Data Bulletin, Vol. 9, No. 1, Optimal Control Strategies, 1993.

McDiamid, M.D., P.E. "A Quantitative Evaluation of Air Distribution in Full-Scale Mock-Ups of Animal Holding Rooms." ASHRAE Transactions, V. 95, Part 1, Laboratory HVAC, 1988.

McIlvaine, Robert W. "Chapter 1, Rooms; Chapter 4, Engineering \& Design." Cleanrooms - 1992-2000, Rooms and Components Vol. Three. Mcllvaine, Robert W., Sally Halderman, Alpa Bagga, and Joseph Schwartz, eds. Northbrook, IL: The Mcllvaine Co., 1992.

Micro-Electronics Facility Efficiency Workshop: Meeting Report, Northwest Power Planning Council, Portland, Oregon, 1995.

Monse, R.R., P.E. "Practical Solutions to Retrofitting Existing Fume Hoods and Laboratories." ASHRAE Transactions, V. 95, Part 2, Laboratory HVAC, 1989.

NAFA Guide to Air Filtration. NAFA Certification Committee, eds. Washington, DC: NAFA, 1993.

Naughton, P., P.E. "HVAC Systems for Semiconductor Cleanrooms-Part 1: System Components." ASHRAE Transactions V. 96, 1990.

Patel, Bill, Jerry Greiner, Tom Huffman, and Les Grant. "Designing a High Performance, Low Energy Cost Cleanroom A Case Study." Cleanrooms '91 Proceedings, 1991.

Saunders, G. Thomas; Laboratory Fume Hoods - A User's Manual; ISBN 0-471-56935. New York, NY: John Wiley \& Sons, Inc. , 1993.

Shepard, M., J. Gregerson, D.J. Houghton P.E., L. Fryer, J. Elleson, B. Pattinson, W. Hawthorne, L. Wester, J. Stein, D. Davia, and S. Parson. Commercial Space Cooling and Air Handling Technology Atlas. E Source, Inc., Boulder, CO, June 1995. 
Takenami, Toshihito, Hitoshi, Inaba and Tadahiro, Ohmi. "Total System Cost Effectiveness Must Keep Pace with Submicron Manufacturing." Microcontamination, August 1994.

Takenami, Toshihito, Tadahiro Ohmi, and Souji Fukuda. "Air Conditioning and Particle Filtration Systems for Energy Saving." Solid State Technology April 1989.

Tsal, Robert. Personal communication, March 1995.

Watts, Wayne, P E. "Meeting Lab Requirements: An Engineer's Point of View." Engineered Systems, Troy, MI. September, 1995.

Wier, Robert C., P E. "Toxicology and Animal Facilities for Research and Development." ASHRAE Transactions, V. 89, Part 2B, Laboratory HVAC, 1983.

Wise, Steve and Susan Dineen. "Using Active Noise Control to Design Quiet, Energy-Efficient HVAC Systems." Clean Rooms '95 East Proceedings, 1995. 


\section{AIR FILTRATION}

\section{Abstract: Energy Efficiency and Air Filtration}

The first step in energy-efficient air filtration design is to determine accurately rather than estimate the filtration required for the laboratory's process needs and for safety. Close attention to filtration efficiency will result in significant energy use reductions over the life of the facility, especially when the optimization of the filter's final pressure drop is calculated.

The next step in designing energy-efficient filtration is reducing pressure loss in filter systems by selecting filters with the lowest pressure drop available, usually those with deep, extended surfaces; underrating filter bank(s) by sizing for reduced volume compared to the rated filter volume; and designing the filter bank for a low face velocity of no more than 300 feet per minute (100 feet per minute is best for energyefficient design). The Micro-Electronics Facility Efficiency Workshop (1995) points out that, "...since filter life is inversely proportional to the square of velocity, cutting velocity in half can extend filter life by a factor of four." Some High-Efficiency Particulate Air (HEPA) filters cause less pressure drop than the filters typically included in conventional supply systems; HEPA filtration does not necessitate large pressure drops.

The features described above will cost more than conventional designs partly because of their requirements for increased duct size and filter area. However, these recommendations are usually shown to be cost effective when life-cycle cost analysis is done.

\subsection{Degree of Filtration}

\section{Energy Efficiency and Degree of Filtration}

The degree of air filtration needed is determined primarily by the process that the air stream serves and is typically stipulated by codes or researcher requirements. In a typical laboratory, high-efficiency filtration is not normally required. Filters with 30 percent ASHRAE efficiency (atmospheric dust spot test method) provide adequate filtration for a reasonable first cost if maintenance is provided at appropriate intervals. The type of laboratory isolation required, e.g., hazardous or protective (see Chapter 3), will also determine the degree of filtration necessary. In a laboratory isolated for hazardous research, the exhaust air steam may need to be filtered with High Efficiency Particulate Air (HEPA) and activated-carbon filters. A research laboratory that is protectively isolated may also require HEPA filtration of the supply air, as in the case of a cleanroom. For energy efficiency, the filter system should be "underrated." [Mcllvaine, 1992; NAFA Guide..., 1993]

\section{- Underrating filters}

Underrating a filter system means passing less air through it than its rated capacity allows, that is, less volume of air per unit time than the clean filter can manage at a specified pressure drop. Because underrating means a lower pressure drop and increased dust holding capacity compared to operation at rated capacity, the filter will have a longer life and a lower energy consumption during its life. The NAFA Guide to Air Filtration (1993) points out that underrating means, "The time required for a pressure drop increase due to captured dust will be extended." 


\subsubsection{Filtration overview}

As noted by the NAFA Guide to Air Filtration (1993), there are two types of air filters: mechanical air filters and electronic air cleaners.

- Mechanical air filters remove dust by capturing it on the filter media, the material that makes up the filter element. This capture involves two different considerations. The first is the probability that a dust particle will collide with one of the "fibers" which make up the filter media. (The word "fibers" is used in the broadest sense to cover any component of filter media). The second is the probability that the particle, once contacting the filter fiber, will continue to adhere to it.

- Electronic air cleaners are devices that, while the dust-laden air is passing through them, impose a charge on dust particles and then set up an electrostatic field to attract the charged particles to oppositely-charged collectors. These collectors are usually parallel plates between which the air passes. They can also be filter media actively electrostatically charged by a continuous external power source.

\subsubsection{Filter processes}

The NAFA Guide to Air Filtration (1993) gives an overview of mechanical air filters.

\section{Mechanical Air Filters}

There are three different processes responsible for the capture of dust in a mechanical filter. Usually one prevails in a specific filter, but rarely is it the exclusive mechanism. These functions are:

- Impingement (Impaction),

- Interception (including Diffusional Effect), and

- Straining.

\section{Factors Affecting Interception}

Particle capture by interception is affected by the following factors:

- Size of dust particle: Larger dust particles are more likely to be captured by direct interception. Smaller particles, on the other hand, have an enhanced opportunity of coming in contact with a fiber because of their wider effective path created by the diffusional effect.

- Fiber diameter: The strongest force occurs between particles and fibers that are approximately the same diameter. Consequently, the smaller a filter fiber, the greater its retention of smaller particles.

- Distance between fibers: The closer that fibers are spaced, the greater the chance that a dust particle will come in contact with one.

- Depth of media: The greater the depth of media, the greater the opportunities for collision between a dust particle and fiber.

- Velocity through the media: Low velocity reduces the drag force of the air. The longer it takes for a small dust particle to pass through a series of fitter fibers, the greater the chance that it will come in contact with one of them and will adhere because the drag forces are weaker. 


\section{Factors Affecting Mechanical Filter Selection}

The following considerations are involved in the selection of a mechanical air filter:

- Efficiency: The most important consideration is the ability of a filter to remove from an air stream the greatest number of dust particles whose size is of most concem. This ability is described as efficacy....

- While liquid filters are often classified according to their absolute ability to remove particles larger than a given size, this is not done for air filters. The only absolute air filter is one which depends on straining. In this instance, the smallest dimension of the particle must be greater than the largest distance between filter fibers. While air filter efficiency increases as particle size increases, it never becomes $100 \%$ until straining is the only mechanism. It may come so close that the difference between the actual efficiency and $100 \%$ is not measurable.

- Pressure drop: The resistance to air flow created by an air fitter is an important consideration. The higher the resistance, the greater the energy required to overcome it. Consequently, all other considerations being equal, the filter with the lowest resistance is preferred.

- Atmospheric dust holding capacity: The term "dust holding capacity" is used in a variety of ways. As defined here, it means the amount of atmospheric dust which a filter will capture during its service life. If the amount of dust in the air that is being filtered is constant, the filter with the highest atmospheric dust holding capacity will have the longest life and must be senviced less frequently. There are long-standing disagreements as to whether "dust holding capacity" as defined in the ASHRAE test method using a synthetic dust can be correlated with atmospheric dust holding capacity....

- Capacity: This is the amount of air that a filter can handle. Usually capacity is defined as the volume of air per unit time that a clean filter can handle at a specified pressure drop. This volume is expressed in cfm (cubic feet of air per minute) or in SI metric as L/s (liters of air per second). Changing the amount of air being handled by a filter will affect other performance values such as pressure drop and dust holding capacity. It may also affect efficiency.

\subsubsection{Filter performance}

The NAFA Guide to Air Filtration (1993) describes a method for evaluating HEPA filter performance.

The DOP [dioctyl phthalate] test does not measure efficiency, rather it measures penetration, i.e., the fraction of DOP which passes through the filter. Efficiency is determined by subtracting the penetration (percent) from 100\%. The original maximum [HEPA] penetration was $0.5 \%$ so that the efficiency was $99.95 \%$ (100-0.05). Later improvements in media manufacture and materials allowed efficiency to be extended to $99.97 \%$ without any increase in pressure drop.

For every filter operating at a specific cfm rating, there is a most-penetrating particle size (mpps). This is the size particle on which the filter efficiency is the lowest. Efficiency will be higher on particles both larger and smaller than this mpps. This is not a significant concern for typical ventilation filters, but is important wherever high collection efficiency on small particles is required, such as in the case of HEPA filters. Particles 0.3 micron in size were originally chosen as the test challenge because it had been calculated that this would be the most-penetrating particle size for HEPA filters. Filter media used in HEPA filters actually have a higher efficiency (lower penetration) than that guaranteed for the filter. This difference allows for the pinhole leaks which can occur in the media or the leaks where the pack is sealed to the filter frame. As a result, the guaranteed efficiency makes no claim as to where the penetration is coming form. 
When laminar flow equipment was introduced for cleanrooms, the penetration location in HEPA filters became a matter of concern. Wherever there was leakage, a stream of unfiltered air could pass through these leakage openings. Because the flow was "laminar" (non-turbulent) the stream of dirty air remained intact, potentially contaminating a product in the "clean" air stream. This resulted in the requirement that a HEPA fitter for use in a laminar flow application had to be leakfree. When leak-free filters were made, their minimum efficiency was $99.99 \%$ Leakage came either from "pinhole" leaks too small to detect or from the limited capability of the filter media.

\subsubsection{Filter power calculation}

Avery (1973), as cited in the NAFA Guide to Air Filtration (1993), discusses calculation of the power requirement for a filter bank:

The energy used to overcome the resistance of a filter bank is provided by the blower which is part of the HVAC system. The blower, in turn, gets its energy from a motor. It is rare that this motor is not an electric motor so that the energy it uses is in the form of kilowatts.

The formula for air horsepower is:

$$
h p a=(C F M \times T P) / 6358
$$

Where:

$$
\begin{aligned}
& \text { hpa }=\text { Air horsepower required to overcome filter system resistance } \\
& C F M=\text { Quantity of air being filtered expressed in cubic feet per minute. } \\
& T P=\text { Total pressure of filter system (in. w.g.) }
\end{aligned}
$$

Total pressure is the sum of static pressure and velocity pressure. Since the filter media velocity is low, the velocity pressure can be ignored. For this reason, the equation can be written as:

$$
h p a=(C F M \times S P) / 6358
$$

Where:

$$
S P=\text { Static pressure of the filter system (in. w.g.) }
$$

To be useful, air horsepower must converted into kilowatts. Using appropriate conversion factors the formula for theoretical kilowatts becomes:

$$
k W t=1.173(C F M)(S P) / 1000
$$

Where:

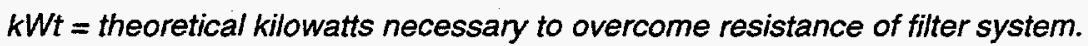

The theoretical kilowatts thus calculated assume that there is no power loss in the transfer of energy through the $v$-belt drive between the motor and the fan and that the motor and fan are $100 \%$ efficient. This is not the case. One commercial publication suggests that:

$$
\begin{aligned}
& \text { Fan Efficiency }=68 \% \\
& \text { Drive Efficiency }=99 \% \\
& \text { Motor Efficiency }=86 \%
\end{aligned}
$$

If these are the correct values for the system under consideration, the actual power requirement would be: 
$k W A=k W t \times 1 /(.68 \times .99 \times .86)$

Where:

$$
k W A=\text { actual kilowatts required }
$$

\subsubsection{Filter construction}

The NAFA Guide to Air Filtration (1993) describes the construction of various filters:

The formulation of filter media by different paper manufacturers is proprietary. However, all media is made by beating fibers (usually all glass) under controlled conditions in a properly buffered water base until the fibers are all separated and suspended. Proprietary binders are added, usually modacrylic suspensions of different types. Antifungal inhibitors may also be used. The suspension of glass fibers is allowed to flow onto a continuous screen (Fourdrinier screen) where it is dewatered as it moves along. At the end of the screen line, it is moved onto drying rolls where the balance of the water is removed. Before rolling, the media may be waterproofed, usually by treatment with a silicone-based material.

- Separators: Originally corrugated separators were made of Kraft paper. It was replaced by aluminum foil which is the most popular material for this application today.

- Separatorless HEPA Filters: One filter manufacturer has developed a process where the media is formed with built-in embassed grooves. When the media is pleated, the grooves then butt against one another creating channels through which the air can flow. The elimination of corrugated separators reduces the resistance of the filter pack. However, it also makes the pack more flexible. To compensate for this, reinforcing struts are inserted inside the pack as needed.

\subsubsection{Impingement filters}

The NAFA Guide to Air Filtration (1993) describes panel fitters.

Panel filters are fixed-media air filters in which the face velocity and media velocity are essentially the same. The fact that both velocities are essentially the same requires that the media be in a flat panel form. Some pleated media filters are described as "pleated panel" filters. By our definition, these filters are "extended surface" filters. Panel filters can be categorized by the material used as the filter media, and by their method of servicing.

\subsubsection{Extended surface filters}

The NAFA Guide to Air Filtration (1993) defines extended surface filters and describes their advantages.

Extended surface filters consist of that category in which the filter media area is greater than the filter face area, or to phrase it another way, units in which the media velocity is less than the face velocity. Media velocity is the speed of the air as it moves through the filter media. Face velocity is the speed of the air as it approaches the filter face. 
Filters designed with extended media surface are desirable for the following reasons:

1. Media may perform more efficiently at lower media velocities. This is especially true of filters which depend on interception and diffusion effect for their performance. Both interception and diffusion require lower velocities of air through filter media in order to be effective.

2. Media resistance may be too high when the material is used in a flat sheet. This is especially true of high efficiency media. The resistance of a filter media is, as a general rule for cell-type filters, directly proportional to the velocity of air through it. If the amount of media is doubled, the velocity of air through it, and consequently the resistance of the media, is halved.

3. Filter life will be extended. The more filter media available to hold dust, the longer the filter life will be.

\subsubsection{HEPA filters}

According to the NAFA Guide to Air Filtration (1993), the Institute of Environmental Sciences (IES) defines a HEPA filter as "a throw-away extended-media dry-type filter in a rigid frame, having minimum particle-collection efficiency of 99.97\% for 0.3 micrometer (micron) thermally-generated dioctyl phthalate (DOP) particles or specified alternative aerosol, and a maximum clean-filter.pressure drop of ... 1.0 in w.g. when tested at rated air flow capacity." The NAFA Guide offers the following general description of HEPA filters,

- Media is the filtering material. It is a paper which can be pleated back and forth to form a compact filter element. Close-pleating is necessary to fit all the required media into the desired space because the paper has a high resistance to air flow and the media velocity is usually in the range of $6 \mathrm{fpm}(.03 \mathrm{~m} / \mathrm{s})$.

- Separators are devices which support the media and provide channels through which the air can flow to reach the media and then, after passing through the media, flow out of the filter.

- Filter Pack is the combination of media and separators.

- Filter Frame (Cell Side) is the rigid box into which the pack fits.

- Sealant is the adhesive or other material intended to create a leak-proof seal between the filter pack and the filter frame.

- Edge sealant is intended to prevent any bypass of unfittered air around the filter. In many instances, it is a gasket attached to the filter frame.

\subsubsection{Bacteria removal}

The NAFA Guide to Air Filtration (1993) points out that, "The use of HEPA filters to remove bacteria from the air stream has been well documented. One report gave the result of tests on four different HEPA filters which had been purchased on the open market. In this series of tests... bacillus subtilis spores ... were used as a challenge."

Average penetration was found to be $0.00069 \%$ and average efficiency of $99.9993 \%$ resulted.

\subsubsection{Mounting and location}

Mcllvaine et al. (1992), in their study of cleanrooms, discuss HEPA filter location: 
One of the most important factors affecting fitter performance is the location of the HEPA filters. HEPA filters should always be located so that they are the last item of the mechanical equipment. This insures that all the air entering the clean room is filtered and that there is no possibility of contamination with unfiltered air. It is also very important that the HEPA filters be installed in such a way as to prevent any possibility of leakage around them. Since there is a pressure differential of approximately one inch w.g. (water gauge) across these filters, it is also very important that the fitter holder be designed and installed to withstand the loading caused by the force produced.

\subsubsection{Filtration application-chicken house case study}

Mazzola (1995) describes a filtered-air positive pressure (FAPP) system that. "... was developed for a facility that houses chickens and fertile eggs for research on Newcastle disease, avian influenza and infectious bronchitis, which cause heavy losses in infected flocks."

The system has been widely adopted by companies that produce eggs for use in growing vaccine viruses in germ-free embryonating eggs or cell cultures. "The most important components of the FAPP system are clean air and positive pressure," says Bailey Mitchell, the agricultural engineer who designed and built the computer control system that runs the Athens FAPP facility. "Air entering the chicken house is filtered twice-first by a 35-percent-efficient filter and than by a 95percent-efficient one. This ensures that no germ-bearing dust particles get in."

"The filtered air blown into the house raises the inside pressure. This positive pressure inside the FAPP house helps keep out unfiltered-and possibly germ-laden air-when the door is opened. Air blows outward, preventing unfiltered air from entering the facility," says Mitchell.

\subsubsection{Filtration arrangement-case study}

Wier (1983)points out that the following filter arrangements provide the best efficiency:

The supply air-system should include a proper filtration system. The final filters should be on the discharge side of the fan (under positive pressure). For some acute toxicology studies, these filters can be of a medium efficiency ( $40 \%$ to $50 \%$ ); however, to ensure the elimination of variables in the test rooms, high-efficiency particulate air (HEPA) filters are recommended. HEPA filters provide $99.9 \%$ efficiency on particles of 0.3 micron and larger. Bacteria range from 500 microns in diameter to 0.3 micron and are, therefore, removed as the air passes through the HEPA filter. Viruses range from 4 microns in diameter to 0.003 micron and therefore, would not necessarily be filtered out by the HEPA filters; however, viruses are obligate parasites and are not usually found in the air. Experience has shown that HEPA filters, when properly installed in supply-air systems, provide satisfactory bacteria and virus control. Although these supply-air systems operate continuously, with positive pressure, the duct between the final filter and the supply outlet should be of welded construction to ensure clean air conditions. Air exhausted from animal rooms contains hair and dander. These tend to agglomerate on grilles, turning vanes, fans, etc. If the exhaust system is to include filters, prefilters should be provided to protect the more expensive high-efficiency filters. It is good practice to mount the prefilter in the animal room in an accessible location (U.S. Department of Health, Education, and Welfare 1978) ${ }^{7}$.

\footnotetext{
${ }^{7}$ See referenced citation for full source information.
} 


\subsubsection{Cleanroom filtration}

Cleanrooms commonly use HEPA filters in air recirculation. These filters are the main causes of filter system energy consumption in this kind of laboratory. However, filtration of the make-up outside air for a cleanroom also consumes some energy. The air flow usually requires filtration with a 20-25 percent efficient prefilter and a 90-95 percent efficient final filter. [NAFA Guide..., 1993]

All classes of cleanrooms do not require the same recirculation rate or degree of air filtration. Down-flow cleanroom classes can be related to the percentage of the ceiling area that contains HEPA filters. According to the NAFA Guide to Air Filtration (1993), several sources suggest the following relationships between cleanroom class and percent of the ceiling that should incorporate HEPA filters:

$\begin{array}{cc}\begin{array}{c}\text { Class } \\ \text { (Fed. Std. 209) }\end{array} & \begin{array}{c}\text { Percent } \\ \text { (Ceiling Area) }\end{array} \\ 100 & 90 \\ 1,000 & 75 \\ 10,000 & 60 \\ 100,000 & 40\end{array}$

Air cleanliness of less than Class 100 requires the use of ULPA or SULPA filters in the ceiling. The filters should make up at least 90 percent of the ceiling.

\subsubsection{Cleanroom prefilter}

Naughton ("HVAC Systems... Part 1," 1990) discusses prefiltration in cleanrooms.

Lowering the air-side pressure drop associated with heat transfer coils and filters is a readily available energy-saving option available to the designer. While the use of air filters is the primary means to achieve the desired air cleanliness level, the quantity and quality of prefiltration are normally established by the cleanroom owner's contamination control specialist. Many semiconductor cleanrooms use only minor amounts of prefiltration, typically one set of $30 \%$ efficient prefilters. Other semiconductor firms use two stages of prefiltration, a $30 \%$ and a $90 \%$ efficient filter in series. The primary advantage of two stages of prefilters is to reduce the load on the expensive cleanroom HEPAULPA filters. The choice of one-stage filtration, two-stage filtration, or no prefiltration is normally made by the owner. Therefore, the extra operating costs associated with the $0.75 \mathrm{in}$. WC (186.8 Pa) to $1.0 \mathrm{in}$. WC [W.G.] (249 Pa) pressure drop required for prefiltration must outweigh the shorter HEPA filter life expectancy. (Prefilter operating costs will vary from $\$ 5.00$ to $\$ 8.00$ per year per square foot vs. the HEPA filter cost of $\$ 12.00$ to $\$ 15.00$ per square foot.) The expected life of the HEPAULPA filters is not the only issue. The potential downtime required to replace the HEPA filters is typically an overriding factor in the decision.

\subsubsection{Cleanroom laminar flow}

Mclivaine et al. (1992) points out that:

Most HEPA filters are constructed so that the filter paper is arranged in a large number of parallel pleats. The pleats are very narrow and very deep. A typical 2 ft by 4 ft by 6 in. HEPA filter contains 140 to 190 such pleats. These pleats act to straighten the direction of gas as it flows 
through the filter. In addition, the resistance of HEPA filter paper to gas flow is reasonably uniform, which means that approximately equal volumes of gas move simultaneously through each pleat of the filter. These two factors, the uniform resistance of the filter paper and the large number of parallel pleats, cause the air to flow uniformly 12 in. downstream of the HEPA filter face. It is this uniformity of flow that initiates the phenomenon of laminar flow, causing small particles to be dragged along in the path of the flow. The use of a HEPA filter does not guarantee laminar flow. Some HEPA filters are constructed with $V$-banks of pleated media, and filters of this type are not intended for laminar flow applications. Incorporation of adsorption capabilities into HEPA filters is also accomplished during the pleating process. The media impregnated with carbon is pleated along with the microfiberglass media.

\subsubsection{ULPA and SULPA filters}

The NAFA Guide to Air Filtration (1993) describes ULPA and SULPA filters.

As early as 1961, a filter with a higher efficiency than a HEPA filter was offered. It had a DOP efficiency of $99.999 \%$ and the $12 \mathrm{in}$. (304.8 mm.) deep version had a clean pressure drop of 1.1 in. w.g. (273.6 Pa) when operating at a face velocity of $250 \mathrm{fpm}(1.27 \mathrm{~m} / \mathrm{s})$. This filter has helped meet the requirement for cleaner air in facilities needed for the manufacture of microelectronics. It is identified by the generic name ULPA (Uitra Low Penetration Air) filter.

It was previously noted that the most-penetrating size particle for a HEPA filter was calculated to be 0.3 microns. The development of the laser photometer dust particle counter has provided evidence that the cost-penetrating size is less than this and depends not only on the filter media but also on the velocity of air through it. For this reason, the new IES Recommended Practice for ULPA filter media does not reference a specific particle size. Instead, by inference from the definition of the media, an ULPA filter is one which has a minimum efficiency 0 f $99.999 \%$ for particles in the most penetrating particle size at the specified media velocity. The most penetrating particle size is defined as that particle diameter for which penetration through the medium is a maximum.

SULPA (Super ULPA) filters are available where maximum cleanliness is required. These filters have an efficiency of $99.9999 \%$ on the same basis as ULPA filters. The low penetration expected from ULPA and SULPA filters is such that they must be totally free of even the smallest leak. The standardization of testing methods in both the United States and Europe for ULPA and SULPA filters is now in the process of being finalized. Until it is, the individual user requiring filters at this efficiency level must be certain that the tests performed on filters demonstrate their ability to meet the user-defined needs.

\subsubsection{Impurity ion removal}

Matsumoto and Tanaka (1994) describe a method for removing "impurity ions that may affect integrated circuit (IC) processing speed." Their study "confirmed that not only dust but also impurity ions could be removed by filtering as a result of measuring the concentration rate of impurity ions in the air conditioning system of clean rooms. The effect of removing impurity ions by a washer was also confirmed." Their procedure and its background are described as follows:

External air processing systems are to take in air for pressurization from outside to control temperatures and humidity in a clean room and to remove dust. It is therefore necessary to take appropriate actions for adverse effects on $1 \mathrm{Cs}$ brought by contamination materials in the external air. If the plant location is close to sea, removal of salt is important and if the location is in a freeze area in winter, removal of anti-freezers and snow-removers is important. In addition, if the degree of air contamination by SOx and NOx is very severe, strong acid needs to be removed. 
Consequently, a method to remove contamination materials tailored for each case must be devised in external air processing systems. Filtering is a preferred method to remove contamination materials of floating particles and chemical filtering combined with a washer is the best for those materials that cannot be cleaned by absorption through regular filters. Most of the chemical filters use synthetic zeolite soaked in chemical solution and contamination materials are removed by chemical reaction and chemical absorption. It is necessary to select the optimum combination of chemical filter depending on the type and concentration of contamination materials. Potassium permanganate, potassium carbonate and phosphoric acid are used as chemicals. As it is difficult to predict the life of chemical filters, periodic exchange is necessary.

A removal method by combining a filter and a washer that does not cause re-contamination is desirable to remove impurity ions in external air processing systems. The following have been examined and used ...:

\section{Using pure water as washer water}

... it was found that impurities in water for humidification were introduced in the air during the washer operation to increase humidity in the winter season. For this reason, pure water can be used as washer water for humidification to reduce the concentration rate of impurity ions.

\section{Two-stage operation of humidifier and washer}

... impurity ions can be removed by the washer operation ... when humidity is high ... when humidity is low, a two-stage operation can be carried out in which humidity is increased by a humidifier in the first stage and impurity ions can be removed by a washer operation in the second stage.

The above methods of (1) and (2) were verified by using pure water for humidification. When outside humidity is low on sunny days, pure water is added frequently so that the purity rate of pure water is maintained. When humidification is not needed such as on rainy days, impurities in the air are absorbed in pure water and the impurity removal effect is even more efficient.

\section{Using HEPA filter at the last stage of filtering}

In this method, a three-stage filtering is adopted that consists of a pre-filter (for crude dust), a middle filter (middle capability) and a final fitter (high efficiency particulate air filter, abbreviated as an HEPA filter thereafter). By using an HEPA filter at the last stage, introduction of impurity ions in the external air can be minimized. It was confirmed that the concentration rate of impurity ions at downstream of the HEPA filter was reduced to less than a few $\mathrm{mg} / \mathrm{m}^{3}$.

\subsubsection{Sodium elimination}

Takenami et al. (1989), in their study "Air Conditioning and Particle Filtration Systems for Energy Saving," conclude that:

TThe most effective means for reducing the energy required to deliver clean air is to employ high performance filters which are designed to minimize pressure loss.... The concept behind the sodium elimination unit is to remove impurities at the point furthest upstream from the cleanroom by installing high efficiency filters behind the prefilters located at the external air intake port. Based on the premise that sodium may permeate the filters due to deliquescence if the humidity of the external air exceeds 60 percent, the external air is heated immediately before the filter to regulate humidity to less than 60 percent in order to eliminate sodium. 


\subsection{Filter Pressure Drop}

\section{Energy Efficiency and Pressure Drop}

Air filters are basic components of air handling systems, and their life-cycle pressure drop significantly impacts a laboratory's energy consumption. Air filtration consumes energy in the way that conditioning coils do; however, the filters' energy consumption is greater because their resistance to air flow increases over time by definition. Specifying air filters with the lowest possible pressure drop nearly always pays for itself. Generally, the pressure drop is a direct function of the filtration efficiency; in other words, highefficiency filtration results in a high pressure drop. When HEPA or ULPA filters are specified with only small reductions in pressure drop, significant energy savings can result from their long-term use. Filter media manufacturers have made great progress in developing low-pressure-drop media. Typically, specifying deeper filters reduces pressure drop and increases energy savings. For example, the average pressure drop at a face velocity of 100 feet per minute is between 0.35 and 0.40 inches w.g. for two-inch HEPA filters. A four-inch HEPA filter, which increases active media surface by 50 percent over a twoinch filter, lowers the pressure drop to between 0.25 and 0.35 in. w.g. A six-inch HEPA filter reduces the pressure drop to between 0.15 and 0.20 in. w.g. [Mcllvaine et al., 1992; Lippold et al., 1990; NAFA Guide..., 1993; Kruse, 1991]

According to Lippold et al. (1990), the energy engineer should be aware of the following basic design requirements for pressure drop reductions:

- High ratio of pleating

This means that a large ratio is desirable between the air stream and the filter-media area exposed to the face area of the filter element. This ratio also requires reducing the media area that is covered by separators and therefore is not exposed to the air stream.

- Pleat-geometry

The total pressure drop is the result of pleat in- and outlet-losses, air friction within the pleats against the separators and against the filter-media and the pressure drop of the media itself. A proper choice of the pleating configuration can reduce in- and outletlosses as well as friction losses.

- Pleat precision and uniformity

The only way to guarantee the pressure drop predetermined by the geometry of the single pleat is a constant pleat distance all over the filter package.

- Thermal molding technology

All comparisons show the distinct technical advantage of the thermal molding technology. Thermally molded filters are uniquely designed to reduce pressure drop and thus save considerable energy. They can also be used for higher air velocities without an increase in pressure drop, which fits the new requirements for velocities above $0.5 \mathrm{~m} / \mathrm{s}$ in the microelectronics industry.

\section{- Balancing life-cycle cost and energy-efficient operation}

In operating the laboratory, a balance must be achieved between the life-cycle cost benefit of a filter's life and the energy use of the filter's extended life. The longer the filter is in service, the more likely that any increased cost will be recaptured. However, operating the filter to a high final pressure drop requires increased energy use that may nullify the gains in life-cycle payback. The optimum final pressure drop 
should be analyzed for any particular laboratory installation. [McIlvaine et al., 1992; Lippold et al., 1990; NAFA Guide..., 1993; Kruse, 1991]

\subsubsection{Optimizing final pressure drop: analysis method}

The NAFA Guide to Air Filtration (1993) quotes Avery (1978): "A method has been suggested to find the static pressure which optimizes the owning and operating cost of an extended surface filter." Avery plots filter cost per hour and energy cost per hour against time; this is what the energy engineer can do to determine optimum final pressure drop. Avery stresses that

Energy costs are low when the filter is clean but the filter cost per hour is high. The longer the filter is used, the lower its cost per hour becomes. At the same time as the filter resistance increases, the energy costs go up. At any point, the total cost per hour of operation is the sum of both the filter cost and the energy cost.... The optimum pressure drop at which to change a filter is when the total cost is the lowest. Changing the filter before [it reaches its time] is uneconomical because filter life is not optimized. Changing the filter after [it reaches its time] is uneconomical because the cost of power is greater than the saving in extending the filter life.

\subsubsection{HEPA filter pressure drop}

The pressure drop for HEPA filtration is dependent on the types and amounts of media used in the filter, per unit area of the filter face. Pressure drops can be as low as 0.1 inches w.g. (24.9 Pa) and as high as 1.0 inches w.g. (249 Pa), with significant energy use impacts resulting from the nonlinear power use requirements of higher pressure drop filters. Lower pressure drop filters usually have higher first cost but offer the benefit of lower operating cost, in part because of their higher dust-holding capacity. [Naughton, "HVAC Systems... Part 1," 1990; Micro-Electronics Facility Efficiency Workshop, 1995]

\subsubsection{Arc-shaped filter- case study}

Mounteer and Scholler (1987) describe a cleanroom design at a pressure-transducer manufacturer that uses an arcshaped filter, which helps cut operating costs.

Even though the cleanroom facility was originally designed for Class 1000 operation (less than 1,000 particles of 0.5 or larger $/ \mathrm{ft}^{3}$ of air), testing by Federal Standard $209 \mathrm{~b}$ shows the operation approaching the Class 100 standard. Class 10 operation is obtainable by changing the highefficiency particulate air (HEPA) filter.

The heart of the cleanroom facility is the arc-shaped HEPA filters and the resulting air-flow control. Because the filter sits where the wall and ceiling meet, the air falls diagonally across the room to a low-exhaust, return-air prefilter on the opposite wall at floor level. The exhaust vent draws heavy and light particles alike. Air flow is uni-directional with little turbulence, but it is not perfectly laminar. In any laminar or unidirectional flow, the stream is disrupted by many factors, such as equipment, convected heat, and people. These flow-disrupting factors create turbulence, which causes particulate matter to re-enter the air stream.

Turbulence is also a function of air velocity. In so-called laminar-flow cleanrooms, where the HEPA filter occupies an entire wall or ceiling, air velocity must be high to meet the federal standard for air velocity through the filter $(90 \pm 20 \mathrm{fpm})$. ...the arc-shaped HEPA filter occupies only $1 / 3$ the space of a full-wall filter. Hence, the required air-flow volume is cut by a factor of three. The exit air velocity is from 90 to $100 \mathrm{fpm}$, but the overall air velocity in the room is less, drastically reducing turbulence. 
Operating costs are directly related to air flow. Fans and air conditioning equipment in ... [the] cleanroom facility are much smaller, which accounts for the $67 \%$ reduction in operating costs.

Design for the future. The cleanrooms are expandable for future growth and are portable in case they need to be moved. The structure is of white, melamine hardboard-and-insulated-core prefabricated panels assembled into extruded, anodized aluminum frames. The entire structure is sealed with silicone-rubber to control air loss and particle intrusion. In fact, these cleanrooms, which have been in operation for 9 years, have required only one filter change. With the filters being near the ceiling instead of occupying an entire wall,...the whole room [can be used] and is not bound by an "unusable" wall. And the filter's arc shape does not limit location of lights, doors, and windows.

\subsubsection{Mini-pleat filter}

The mini-pleat filter design configuration increases a HEPA filter's energy efficiency. The aluminum separators that give the filter media support are eliminated, thus reducing pressure drop. The mini-pleat filter works best with an air velocity of $250-300 \mathrm{fpm}$, which is desirable for energy-efficient design but is low compared to conventional rules of thumb. [McIlvaine, 1992]

\subsubsection{Membrane filtration}

Membrane filtration, which replaces standard microfiber glass filtration, can reduce energy consumption. Membrane filters remove particles more efficiently than microfiber filters and at a lower pressure drop; however, membrane filters can cost more per unit area. Life-cycle cost analysis and determination of optimum pressure drop, as described above, may justify the additional expense. According to Mcllvaine (1995) , "The [energy-efficiency] impact of membrane filters could be substantial. It could reduce air movement energy cost by as much as 15 percent." [Mcllvaine, 1995]

\subsection{Electronic vs. Media Filtration}

\section{Energy Efficiency and Electronic Filtration}

Electronic filtration, also commonly known as Electrostatic Precipitation, can save energy because of its inherently low pressure drop. However, many considerations must be addressed during the design process to insure that this method cleans the air flow effectively over the long term. Electronic filtration seems to work better when a low-efficiency prefilter is installed upstream of the unit. Maintenance and cleaning must be considered along with the impact of power outages and the re-entrainment of collected dust. The power consumed for electrostatic filter operation is scanty. Electronic filtration in cleanrooms may be best used to prefilter HEPA or Ultra Low Penetration Air (ULPA) filter banks. In this situation, HEPA filters would consume less energy because much of the usual filter loading would be handled by the electronic filter; the HEPA filters would provide both a final cleaning and a guard against re-entrained dust, etc.

\subsubsection{Efficiency of electronic air cleaners}

Many manufacturers claim that their electronic air cleaners are effective on particles down to 0.01 micron or smaller. However, as the NAFA Guide to Air Filtration (1993) points out, "Usually no information is given about the fractional efficiency of the device, that is, its efficiency on particles of a certain size." Studies on this appear in technical literature; the energy engineer is referred to the NAFA Guide to Air Filtration as a comprehensive resource on the subject of electronic filtration. 
The NAFA Guide to Air Filtration (1993), notes that,

The ability of an electronic air cleaner to remove dust from an air stream depends on a variety of factors. Some of these are:

- Particle size of the dust

Very large particles in an air stream have relatively high inertia and so may not be in the collecting field (between the parallel charged plates) long enough to be attracted to the plates. On the other end of the spectrum, very small particles may be so buffeted by gas molecules that attraction to an oppositely charged plate is impeded or blocked.

\section{- Velocity through the filter}

Electronic air cleaners are velocity-sensitive. The slower the movement of air through the collector section, the better the chance that collection will be accomplished. Because of velocity sensitivity, electronic air cleaners require uniform air flow across the face of the filter to insure maximum efficiency.

- Voltage on ionizer and collector

The usual values for ionizer section voltage is [sic] $12 \mathrm{kV}$ and for the collector section 6.0 $\mathrm{kV}$. Upward variations are likely to result in ozone formation and downward variations will result in lower efficiency. Lower voltages are used in self-contained commercial and residential electronic air cleaners.

\section{- Collector plate spacing}

The space between the collector plates must be optimized. If it is made smaller, the collection efficiency will improve because the distance a particle must be deflected to a collector plate is reduced. However, closer plate spacing makes maintenance cleaning of the collector section more difficult and leads to the possibility of a bridging short-circuit between oppositely-charged plates. Increased plate spacing will reduce collector efficiency.

\section{- Ionizer spacing}

It is important to make sure that particles passing through the ionizing fields are given an adequate charge. The ionizing field strength depends on the space between the ionizing wire and the oppositely-charged strut. If the ionizing field is too strong, ozone formation may take place. If it is too weak, particle charging may be incomplete.

\subsubsection{Electronic air cleaner design}

The NAFA Guide to Air Filtration (1993) identifies factors affecting the use of electronic air filters:

- Ozone: One of the major considerations in electronic air cleaner design is the prevention of ozone formation. An oxygen molecule contains two oxygen atoms. Ozone consists of three oxygen atoms and is a relatively unstable molecule that is a toxic gas. The EPA has set guidelines that establish maximum exposure levels of this gas for human health and safety. Ozone formation is minimized or eliminated by proper ionizer design and by proper maintenance of an electronic air cleaner. 
- Capacity: The amount of air handled by an electronic air cleaner relates to the velocity sensitivity of the device. It can be underrated with improved efficiency. Conversely, the efficiency may fall off significantly when the device is overrated.

- Uniform air flow: As mentioned previously, electronic air cleaners are velocity-sensitive. It is important that they be installed in a location and with suitable baffles, if necessary, so that the flow of air to be filtered passes through the entire unit at a uniform velocity.

Different arrangements for cleaning electronic air cleaners ... [have] design considerations [that] must be ...[included] which will make it easy to clean the units whenever this becomes necessary. Time for cleaning may be dictated by amount and type of airborne contaminants accumulating on plates.

\subsubsection{Electronic air cleaner prefiltration}

According to the NAFA Guide to Air Filtration (1993), low-efficiency prefilters placed upstream of an electronic air cleaner are recommended because:

1. The filters will act as air distribution panels to equalize the air flow through the electronic air cleaner.

2. They will capture large particles which could bridge the electrically charged plates causing a short circuit to deactivate the power supply. If shorting does not occur, arcing caused by large particles can result in excessive power consumption.

3. By preventing arcing, the disturbing "snapping" noise made by the discharges is eliminated.

4. Elimination of arcing helps control ozone generation.

\subsubsection{Airborne microorganisms}

The NAFA Guide to Air Filtration (1993) quotes Public Health Service Publication No. 953, "Air Filtration of Microbial Particles" $(1963)^{8}$ as follows on the subject of airborne microorganisms:

Although electrostatic precipitators can remove a high percentage of bacteria and dust from the air, they may not be satisfactory as fitters where a constant supply of clean air is required. Electrostatic precipitators that receive maximum maintenance have been shown in laboratory tests to remove or destroy approximately 90 percent of the microorganisms in the air. However, tests of some units under normal operating conditions have shown much lower efficiencies. Under optimum physical conditions and with satisfactory maintenance, electrostatic precipitators can be used in place of medium efficiency filters. They should be equipped with high-or ultra-highefficiency filters downstream if the air is to be supplied to critical areas. Without maximum maintenance, electrostatic precipitators can give a false sense of security.

\subsubsection{Dust disposal}

The NAFA Guide to Air Filtration (1993) explains that, "[the removal of dust which an electronic air cleaner has captured can be accomplished in two general ways":

\footnotetext{
${ }^{8}$ See referenced citation for full source information.
} 
1. It can be washed off the collector plates. The typical process uses detergent and hot water.

2. If it has aggiomerated on the plates, it can be allowed to blow off the plates. The blowout can then be captured by a mechanical filter placed downstream of the electronic air filter. This two-step process is known as agglomeration.

\subsubsection{Historical background}

Historical background on electronic air cleaner is given in the NAFA Guide to Air Filtration (1993).

\section{Electrostatic Precipitation}

The principle of electrostatic precipitation as a means of stack gas cleaning goes back to the earliest part of the 20th century. The process consisted of applying a high voltage (50-100 kV) to electrodes installed between grounded plates. The electrostatic field established by this difference imposed a charge on all the dust particles passing through the field. The particles were then attracted to the oppositely-charged plates where they were captured. This type of equipment could not be used in air conditioning systems because the concentration of ozone formed by the electrostatic field was irritating to the human respiratory system.

Dr. Gaylord Penny of Carnegie institute of Technology determined that the generation of ozone could be nearly eliminated if electrostatic precipitation was done in a two-stage operation.

In the first stage (ionizing section), the particles in the air stream were given an electrostatic charge. In the second stage (collecting sections), these particles were removed from the air stream by electrostatic attraction to oppositely charged plates. In the original design, a $12 \mathrm{kV}$ charge was placed on the ionizer section to electrostatically charge the particles. This section was made small and was designed with ionizing wire and grounded struts so that ozone generation was minimized. In the collection section, the alternately-charged plates were sized and spaced so that a $6 \mathrm{kV}$ charge was enough to collect the particles but not enough to create ozone.

Devices used in air-conditioning and ventilating systems are now called electronic air cleaners to distinguish them from the earlier high-voltage, stack-gas cleaning electrostatic precipitators.

\subsubsection{Cleanroom electronic air cleaner}

Electronic air cleaners used in a HEPA filtration system offer a higher degree of removal efficiency at lower average lifetime pressure drop than in the traditional arrangement. Electrostatic prefilters for cleanrooms reduce energy consumption by removing the dust and particles from the air stream before they can load the HEPA filters. This increases HEPA filter life and can increase the HEPA filter's efficiency rating to an ULPA filter level. [McIlvaine, 1992]

Mcllvaine et al. (1992), says that when used with cleanroom HEPA filters, "Electrostatic systems of various types have been shown to significantly enhance the efficiency of the usual fiber filter media. Not only does efficiency increase, pressure drop decreases and filter life is extended by about a factor of $3 . "$

\subsubsection{Two-stage filtration}

Mcllvaine et al. (1992) explain 
The patent [for the two-stage filtration device] covers the combination of a HEPA filter and an ionizer. The ionizer has alternate wire and plate electrodes connected to a dc high voltage low current source and is located upstream of the HEPA filter remote from the air inlet base.

It consists of two filter stages, an ionizer stage, and a special absolute filter collector stage. This combination enables the following: (1) Increase of the efficiency of absolute filters to ratings which heretofore were unobtainable; and (2) reduction of initial pressure drop by up to 50 percent for efficiency ratings in comparable ranges featured by conventional absolute filters operating on a mechanical basis. A further advantage is considerably slower increase in the pressure drop, as dust collects over the course of operation.

In addition to the separation phenomena featured in a purely mechanical absolute filter, forces of attraction are created in the electrostatic HEPAULPA filter which act between the charged or polarized particles, and the polarized fibers of the filter medium. By virtue of these electrostatic forces, a filter medium with a lower intrinsic mechanical efficiency rating-with the important low specific pressure drop associated therewith-can be stimulated to perform with a higher efficiency rating.

In the case of purely mechanically operating absolute filters, the accumulation of particles in and on the filter medium and its microfine fibers results in formation of a filter cake. With the electrostatic HEPAULPA filter, however, the separated particles form dendrites on the filter medium in the form of treelike structures. These particular particle structures-as well as the fact that a portion of the particles deposited will remain on the separation plates of the ionizer and the collector-having the significant advantage of a prolonged initial penetration of the filter medium and resulting in a considerable reduction of the pressure drop.

\section{REFERENCES}

Avery, R.H. "Air Filtration: Resistances, Energy and Service Life." Heating, Piping, Air-Conditioning, December 1973.

Avery, R.H., "Energy Effective Air Filtration." Plant Engineering, Sept. 28, 1978.

Kruse, Robert K. P.E. "Mechanical System Strategies for Energy Efficiency." Cleanroom Technology Forum Proceedings, 1991.

Lippold, J.J., F. Reichert, and A. Ohde. "Reducing Energy Costs with High Precision Optimized Air Filter Elements." Swiss Contamination Control, March 1990.

Matsumoto, Mikio and Norio Tanaka. "Impurity Ions in the Clean Room and Their Removal System." OKI Technical Review 151, V. 60, December 1994.

Mazzola, Vince. "The Cleanest Little Chicken House in America." Agricultural Research, September 1995.

Mcllvaine, Robert W. "Chapter 1, Rooms; Chapter 4, Engineering \& Design." Cleanrooms - 1992-2000, Rooms and Components Vol. Three. Mcllvaine, Robert W., Sally Halderman, Alpa Bagga, and Joseph Schwartz, eds. Northbrook, IL: The Mcllvaine Co., 1992.

Mcllvaine, Robert W. Northbrook, Illinois, Correspondence, September 1995.

Micro-Electronics Facility Efficiency Workshop: Meeting Report, Northwest Power Planning Council, Portland, Oregon, 1995. 
Mounteer, Carl and Robert W. Scholler. "Cleanroom Design Cuts Operating Costs 67\%." Production Engineering, April 1987.

NAFA Guide to Air Filtration. NAFA Certification Committee, eds. Washington, DC: NAFA, 1993.

Naughton, P., P.E. "HVAC Systems for Semiconductor Cleanrooms-Part 1: System Components." ASHRAE Transactions V. 96, 1990.

Takenami, Toshihito, Tadahiro Ohmi, and Souji Fukuda. "Air Conditioning and Particle Filtration Systems for Energy Saving." Solid State Technology April 1989.

Wier, Robert C., P.E. "Toxicology and Animal Facilities for Research and Development." ASHRAE Transactions, V. 89, Part 2B, Laboratory HVAC, 1983. 


\section{LIGHTING}

By Doug Avery, Michael Siminovitch, Ph.D., and Geoffrey C. Bell. P.E.

\section{Abstract: Energy Efficiency and Lighting}

Typically 10 to 20 percent less energy is consumed by lighting in laboratory-type facilities than by the HVAC system. Nonetheless, efficient lighting systems provide significant energy savings. Efficient lighting design begins with understanding the tasks to be performed in the laboratory. A design that incorporates both dedicated task illumination and general ambient lighting is most energy efficient. High-efficiency lighting components, such as T8 fluorescent lamps and electronic ballasts, are the starting point in energy-efficient lighting designs. Lighting energy is also dramatically reduced by control systems that turn off lights based on occupancy or adjust lighting in response to available natural light. In some laboratories, a remote lighting system provides the benefit of isolating a large portion of the lighting system from the laboratory space.

\subsection{Lighting Design}

\section{Energy Efficiency and Lighting Design}

Efficient laboratory lighting design first considers the task that occupants will perform in the space. We review two lighting design approaches: general lighting and task-ambient lighting. The lighting design approach determines the type of lighting calculation used. Lighting design affects other energy-consuming systems in the facility. For instance, in cleanrooms, large ceiling luminaires reduce ceiling area for HEPA filters. As filter area is reduced, filter exit velocity increases, increasing the static pressure within the system, which causes fans to consume more energy. Finally, all heat generated by the luminaires and the harder working fans affects cooling equipment sizing. \{Mcllvaine, 1992; Eley et al., 1993\}

\subsubsection{Task identification}

All lighting design projects begin with one crucial question: What are the tasks performed in the space? Light designers should remember that people are more valuable than energy; businesses typically spend about $\$ 100$ per square foot on salaries and benefits while the average cost of energy is about $\$ 1.00$ per square foot. In laboratorytype environments, the costs may be higher, but the ratio is similar

All areas require some form of lighting. Most areas will house specific tasks that necessitate dedicated lighting sources, such as desk lamps for augmenting low ambient lighting in an environment filled with computers, or a highwattage, high-lux, indirect lighting source in areas where drafting work is performed.

Eley et al. (1993) also notes that "If the task location in a room is likely to vary widely, or if the space is likely to be frequently re-configured to accommodate changes in work groups (such as a company that will be adding staff and moving work stations around a couple of times per year), then it may be advisable to design for task levels of luminance everywhere in the room."

\subsubsection{General lighting design}

According to Eley et al. (1993), "The general lighting design approach is a common strategy used to provide a fairly uniform amount of light throughout a room." This approach usually results in a regular pattern of light fixtures that produces very even light levels, slightly higher than the average value in the center of the room, and slightly lower in the outer corners of the room. 
The Handbook of Facilities Planning (1990) notes that the "Lighting requirements in a laboratory environment generally are the same as for an office: $75-150$ foot-candles [fc or lux] at the bench top [usually 30 inches or 760 $\mathrm{mm}$ from the floor]. However, some lab functions require higher or lower levels." One hundred fc usually requires an energy expenditure of approximately four watts/square foot. Most of that energy is ultimately converted to heat in the laboratory. The required color of the light (in terms of wavelength in nanometers) should also be considered. [Mcllvaine, 1992; Handbook of Facilities Planning, 1990]

With the diversity of tasks performed in any given space of a research facility, standard practice has been to design the general lighting system to a 500-lux maintained level of illumination. This lighting is typically provided by $2 \times 4$ lens troffers installed in a uniform grid pattern. This pattern is easiest to install and least expensive in terms of first cost. If the space configuration remains the same with no modifications to work stations, no repositioning of walls and modular furniture, and the same task being performed throughout the space, this lighting system will perform adequately.

Although this design provides sufficient light for most clerical-type tasks, it often interferes with computer station operation. The disruption is a result of glare on VDTs, produced by the ceiling-mounted fluorescent fixtures. Individual requirements of the occupants of the space are also not considered. The brightness and intensity of lighting that an occupant requires is contingent on the particular task being performed, the occupant's age, and the overall reflectivity of the space. Simply installing a fluorescent troffer system with a $50-\mathrm{fc}$ maintained light level is not an acceptable choice for laboratory lighting designers.

The general lighting design described above may also require additional fixtures where instruments and specialized equipment require higher ranges of illumination, such as in a gross tissue review room or a chemistry room. A more efficient design might be to examine the potential for using both low ambient and specific task area sources to provide the levels of illumination required.

\subsubsection{Luminance levels}

Industry standards currently allow for 500 lux maintained for general office and clerical tasks. Classrooms and general lecture halls also are included in this category. [Lindsey 1991]

The Illuminating Engineering Society (IES) of North America (1993) lists recommended lux for a number of laboratory tasks. These levels represent general ranges of luminance required for optimal total performance. These recommended levels should be provided directly on the individual task area as sown in the following Table 9-1.

It is important for designers to keep in mind that other factors should weighed as part of the design process: contextual data such as the age and physical abilities of the occupants of the space; reflectivity of the walls, ceiling, floor and furniture; and the amount of daylight that is available. [IES, 1991a]

Today's business climate stresses the importance of energy efficiency. Most laboratory lighting systems can be designed to have less than 1.0 watt/sq.ft. of electric load, with specific task areas sometimes requiring luminance that could have an energy requirement of up to 4.0 watts/sq.ft. Utilizing a combination of low ambient and high task area lighting can minimize the energy load.

Certain design issues should be considered for research laboratories. The design plan must account for the fact that the same space may require a number of varied lighting systems to accommodate computer VDT's, general ambient task lighting, and high-contrast, high-lux-level lighting for drafting or close-up, fine detail projects. In addition, laboratory environments tend to be reconfigured on a regular basis, so the lighting designer must attempt to predict and understand long-term needs. [IES, 1991a; IES, 1993; Lighting Design Practice, 1990]

While all these issues and considerations seem a bit overwhelming, technology has provided the tools that reduce this formidable task to one of manageable dimensions. 
Table 9-1

$\begin{array}{lr}\text { Specimen Collecting } & 500-1,000 \mathrm{lux} \\ \text { Tissue laboratories } & 1,000-2,000 \mathrm{lux} \\ \text { Microscope reading room } & 200-500 \mathrm{lux} \\ \text { Gross specimen review } & 1,000-2,000 \mathrm{lux} \\ \text { Chemistry rooms } & 500-1,000 \mathrm{lux} \\ \text { Bacteriology rooms } & \\ \quad \text { General } & 500-1,000 \mathrm{lux} \\ \quad \text { Reading culture plates } & 1,000-2,000 \mathrm{lux} \\ \quad \text { Hematology } & 500-1,000 \mathrm{lux} \\ \text { Drafting } & \\ \quad \text { Blueprints } & 500-1,000 \mathrm{lux} \\ \text { Light Table } & 100-200 \mathrm{lux} \\ \quad \text { Vellum } & \\ \quad \text { High Contrast } & 500-1,000 \mathrm{lux} \\ \quad \text { Low Contrast } & 1,000-2,000 \mathrm{lux} \\ \text { Reading } & \\ \text { CRT Screens } & 50-100 \mathrm{lux} \\ \text { Handwritten (\#3 pencil) } & 500-1,000 \mathrm{lux} \\ \text { Chalkboards } & 500-1,000 \mathrm{lux}\end{array}$

\subsubsection{Task-ambient lighting}

Eley et al. (1993) provides the following discussion of task-ambient lighting in the Advanced Design Guidelines Manual:

Task-ambient lighting refers to designs in which a general uniform lighting system is supplemented with local task luminaires. Task-ambient design approaches save energy when compared with most general lighting strategies, because higher light levels are provided for the task areas only. For example, in a task-ambient design, lighting fixtures might be concentrated primarily over work areas, while an indirect lighting system provides relatively low levels of general (ambient) illuminance. Thus, when compared to a more traditional design, which might rely on a uniform layout of direct lighting luminaires, the average light level for the room may be lower, and the number of required light fixtures may be reduced. This design strategy usually requires point calculations to insure that luminaires are correctly located to produce the lighting level and quality necessary for performing visual tasks at the needed locations.

General lighting is still the most widely practiced lighting design approach, due to the perception that task-ambient lighting equipment is more expensive, the assumption that point calculations are expensive and difficult to perform, and the belief that task-ambient 
strategies create an inflexible interior space. However, task-ambient systems are becoming more attractive with the development of new lighting equipment and easy-touse point calculation computer programs, and with rising electrical energy costs.

Information that will assist the designer is selecting the most appropriate task lighting source includes:

- the nature of the visual task(s) being performed in the space to be lighted;

- the contextual data relating to the space, which includes information about the reflectivity of the walls, ceiling, floor and furniture;

- factors that might affect visual comfort, such as direct glare from windows, existing lighting fixtures, or other internal sources; and

- age(s) of the occupant(s) of the space and the level of illumination required for the tasks being performed regularly;

Task ambient lighting provides the exact amount of lighting required to perform a specific task as well as the most energy-efficient lighting available. In a research lab, this could mean lighting fixtures concentrated directly over the work space, providing the lighting levels required for the tasks being performed, while an indirect lighting system provides relatively low levels of ambient (general) illuminance for the remainder of the space. If the average light level were to be calculated for this space, it would be lower than in a traditional design, but the occupants would most likely report a high level of satisfaction with the system.

\subsubsection{Lighting calculation methods}

Eley et al. (1993) describe the following lighting calculation methods:

The skilled application of computerized point lighting calculations can optimize lighting levels in both the task and ambient domains in order to minimize energy consumption. The lighting professional should consider the use of point lighting calculations, both to design more energyefficient spaces, and to create spaces with more drama and visual interest.

Point calculations are an exceptionally accurate way to compare general lighting systems. While the easier lumen method allows the comparison of average illuminance, point calculations permit the comparison of uniformity of light on the work plane, the patterns of light produced on ceilings and walls, and task contrast rendering. More specifically, point calculations allow consideration of the effects listed below.

- Effect on Room Surfaces. By evaluating the patterns of light on a wall caused by a row of compact fluorescent down lights, an aesthetic evaluation can be made. Artwork locations may be selected or lighting may be designed to highlight artwork. It may also be possible to determine whether the pattern created on a wall will produce luminance extremes that will cause glare or reflections in VDT screens.

- Indirect Lighting Effects on Ceiling. When they are too close to the ceiling, indirect lighting systems may create definite stripes or pools of light on the ceiling that are distracting and that may image in VDT screens. Careful ceiling luminance calculations can help identify the problem, and allow comparison of lighting products with various optical distributions and suspension lengths to reduce the effect. Gray-scale printouts or shaded VDT screen output of luminance make visual assessments possible. 
- Interior Task-Ambient Lighting. Point calculations should be used for any type of lighting design where the task locations and types are well known and are unlikely to move without a lighting redesign. They may also be used for lighting designs where tasks that move end up in predefined locations.

Cautions for Point Calculations. In the case where a task light is used, or where an indirect fixture is mounted within 12 inches of the ceiling, point calculations are not always appropriate. In general, if the luminaire is close to the surface where lighting patterns are to be evaluated, a near field situation exists. A shortcoming of the mathematics used in point calculations is that these near field calculations are comparatively inaccurate unless near field photometric data is available from the luminaire manufacturer, or the computer program is capable of adjusting the characteristics of the luminaires to improve the accuracy of the results. Otherwise, it may be more accurate to evaluate the light patterns from the task light or indirect fixture empirically.

\subsubsection{Lighting quality computations}

According to Eley et al. (1993):

The emphasis of most lighting calculations is to predict illuminance levels in lux or foot-candles. In addition, it is possible to calculate more specific lighting quality measures, which take many other factors into consideration. Relative Visual Performance (RVP) and Equivalent Sphere Illumination (ESI) are measures of visibility and visual performance that measure a person's ability to perform visual tasks under specific lighting conditions. Visual Comfort Probability (VCP), on the other hand, addresses visual comfort and the presence or absence of discomfort glare. These visual quality measures have certain lighting design applications (as well as limits) and are features of many lighting analysis programs.

\subsubsection{Inputs for lighting quality computations}

Eley et al. (1993) further point out that:

ESI, RVP and VCP values are all influenced by factors other than lighting system illuminance. Factors may include task type, age of the observer, angle of viewing the task, and lighting system characteristics. In order to use lighting quality metrics effectively, the designer must know all the factors listed below with absolute certainty. This will allow the designer to calculate these values accurately for specific types of tasks and task locations.

- Task Type

Different ESI and RVP values will result in the same room and lighting system for different tasks. Values will not only be higher or lower, but a wider range will be evident with veiling reflectionsensitive tasks. The size of the task must be known (such as the solid angle of the letter " $e$ " on this page).

- Reflectance of Task and Room Surfaces

Significant differences in luminance between the task and surrounding room surfaces may have a profound effect on task visibility and/or visual performance. This is particularly relevant for work spaces containing VDT terminals. 
- Task Orientation

Exact viewing direction and angle of the task must be known within a few degrees. The same task may have widely different ESI and RVP values depending on the angle from which it is viewed in the room.

\section{- Luminaire Photometry and Room Geometry}

The room under study must be described exactly and the photometric data of a specific luminaire must be used in the study. This can be a limitation if, for instance, the computer program is unable to include the effects of partitions or task lights.

- User Age

Human visual systems deteriorate with age, and older eyes allow less light to reach the retina than do younger eyes. Therefore, in order to predict how visible a task will be, it is necessary to account for this reduction. RVP requires a user age input and applies an average light reduction for that age group.

Visual performance computations, when performed properly, are much more accurate indicators of the visibility of visual tasks than are simple illuminance measures. The IES has announced that in the future, visual performance will replace illuminance level computation as the standard for lighting design. Computation of visual performance metrics is fairly easy to perform, given the right computer program. However the application of ESI and RVP metrics is relatively limited unless the designer or engineer is experienced with the technology and its limitations, and is cautious with its application. Formal training is available and highly recommended for those desiring to employ visibility metric analysis.

- Comparing Different Lighting Systems

ESI, RVP, and VCP are useful at comparing competing lighting systems and designs on a statistical basis when specific tasks and locations are unknown. As long as reasonable assumptions are made in regard to possible tasks, viewing directions, viewing angles, and task locations, the probability that one system will provide superior performance over another may be ascertained, assuming the analyst respects the statistical significance of the results.

\subsubsection{Point calculation considerations}

A design strategy that takes advantage of both general and task lighting opportunities usually requires point calculations if task lighting requirements are being met by luminaires. Point calculation methods predict illuminance at a specific location. Indoor applications, which will account for the majority of laboratory lighting requirements, consist of two components, direct and reflected.

The direct component is light is delivered directly from the luminaire to the point; the reflected component is light reflected to the point by room surfaces. A computer assisted point calculation program can insure that the luminaires are situated to produce the lighting level and quality necessary for the tasks being performed. [IES, 1991b; IES, 1982; Lindsey, 1991; IES, 1993]

\subsubsection{Lighting calculation programs and resources}

As noted by Eley et al. (1993): 
Each year, the illuminating Engineering Society publishes a lighting software survey in its monthly Lighting Design + Application. Products are surveyed in many areas, including hardware requirements, analysis features, applications, types of output, user features, and price. At the time of the printing of the 1993 Advanced Lighting Guidelines, the IES survey was the most up to date and complete source of information on lighting software on the market. The following list attempts to list some of the more advanced software available at the time of this printing. For additional information, consult the June 1992 edition of Lighting Design + Application.

- Interior Lighting Programs

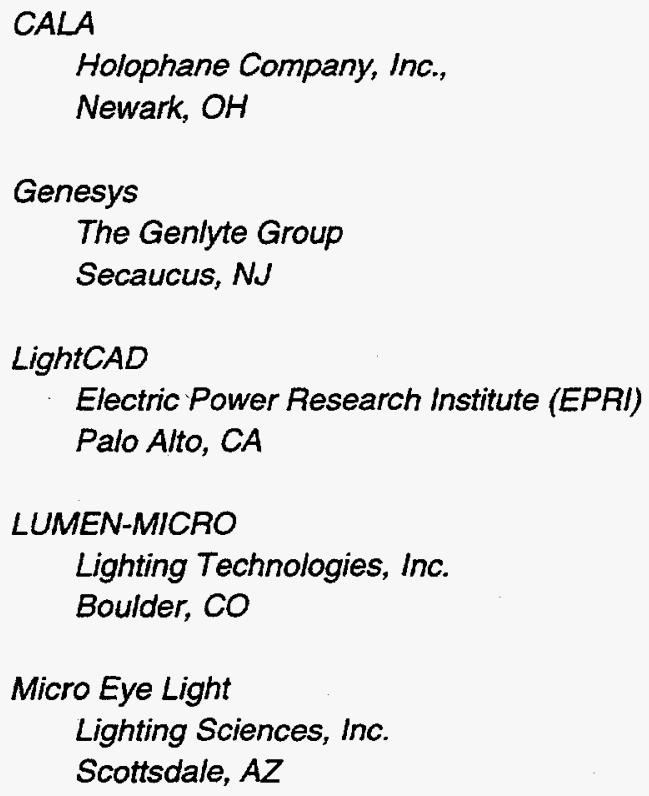

- Synthetic Photography Ray-Tracing Programs

\section{LUMEN MICRO}

Lighting Technologies, Inc.

Boulder, CO

\section{RADIANCE}

Lawrence Berkeley National Laboratory

University of California

Berkeley, CA

- Exterior Lighting Programs

\section{AUTOLUX}

Independent Testing Laboratories, inc.

Boulder, CO

\section{AUTO-SITE-LITE \\ Lighting Sciences, Inc. \\ Scottsdale, $A Z$}

\section{CALA}

Holophane Company, Inc.

Newark, $\mathrm{OH}$ 


\author{
Genesys \\ The Genlyte Group \\ Secaucus, NJ \\ ICON II \\ Cooper Lighting, inc. \\ Elk Grove, IL \\ LUMEN-POINT \\ Lighting Technologies, Inc. \\ Boulder, CO

\section{SPAULD} \\ Spaulding Lighting, Inc. \\ Cincinnati, $\mathrm{OH}$
}

\title{
9.1.3.6 Task/ambient lighting example
}

One example of task ambient lighting is for a 20 foot $x 40$ foot room where the primary tasks are drafting and design of printed circuit boards. The drafting and design area is located in the center of the room, occupying about a quarter of the available space. Recommended levels of illumination are 1,000-2,000 lux. The staff in this area have requested that the higher levels of illumination be provided as there have been reports of difficulty in performing some required visual tasks.

Standard design practice would be to design the entire room to the 2,000 lux level, which would require $322 \times 4$ troffers with four $32 W T 8$ lamps in each fixture. This standard design assumes reflectance of 80 percent ceiling, 50 percent walls, and 30 percent floors. This standard layout will provide the required 2,000 lux; the luminance range will average 2,090 lux and have a minimum level of approximately 920 lux.

The energy density of the space would be 4.4 watts/sqft.

Calculation:

$$
\begin{array}{lll}
32 \mathrm{~W} \text { (8 with 4-light electronic ballast } & = & 27.5 \text { watts (including ballast loss) } \\
32 \text { troffers with } 4 \text { lamps each } & =128 \text { lamps } \\
128 \text { lamps } \times 27.5 \text { watts } & =3,520 \text { watts } \\
\text { Room size } 20 \times 40 & =800 \text { sqft } \\
\text { Energy density } & =4.4 \text { watts/sqft }(3,520 \text { watts } / 800 \text { sqft) }
\end{array}
$$

If a lighting designer decided to use the ambient task lighting approach discussed above, the layout would be much different. Placing six $4 \mathrm{ft} \times 4 \mathrm{ft}$ troffers, each with eight $32 W T 8$ lamps, over the center area of the lab would provide the luminance desired for the drafting and circuit design tasks being performed. There would be an average of 2,050 lux delivered to the work surface over the task area, meeting the needs of the space. The light levels would drop off in the general areas to an average of about $300 \mathrm{lux}$, which will be more than enough light for the occupants to navigate through the space. 
Calculation:

32WT8 with 4-light electronic ballast

$=$

Six troffers with 8 lamps each

$=48$ lamps

48 lamps $\times 27.5$ watts

$=1,320$ watts

Room size $20 \times 40$

$=800$ sqft

Energy density

$=1.65$ watts/sqft (1320 watts/800sqft)

\subsection{High-Efficiency Lighting Components}

\section{Energy Efficiency and Lighting Components}

A number of lighting system components are available for installation in research laboratories. This section will review the various lamps, ballast, and fixtures that are typically utilized to provide general space illumination, with particular attention to the efficacy of specific lamp and ballast combinations. Components designed to provide task lighting will also be examined, including discussions of the relative efficiency of various products.

According to Eley et al. (1993),

There are three primary means of improving the efficiency of a fluorescent lamp-ballast system:

- Reduce the ballast losses.

- Operate the lamp(s) at a high frequency.

- Reduce losses attributable to the lamp electrodes.

\subsubsection{Lamps}

Eley et al. (1993) note that, "Fluorescent lamps are reasonably efficient at converting input power to light. Nevertheless, much of the power supplied into a fluorescent lamp-ballast system produces waste heat energy."

In the history of lighting, the combination of the 32 WT8 lamp with the high-frequency electronic ballast produced a fluorescent lamp that was energy efficient, offered a high lumen and Color Rendering Index (CRI) package, and had very attractive economics. A brief technical review of the T8's operating characteristics will show the reasons for the lamp's superior performance.

- The lamp is 8-1/8 inches in diameter, providing the opportunity for more light to be delivered from the fixture than is possible from a T12 lamp. Fluorescent lamps operate best when the average bulb-wall temperature is at 100 degree $\mathrm{F}$. Given the smaller diameter of the T8 lamp than that of its predecessors, there is a measurable reduction of thermal buildup between lamps, which positively affects lamp performance.

- The T8 lamp and its electronic ballast are matched, operating at the same capacity whereas T12 lamps rarely operate at the same capacity as their ballasts.

- T8 lamps use combinations of rare earth phosphors, which produce high concentrations of light at the peak sensitivity regions of the human eye: red, green, and blue. The eye blends these colors to produce other colors; the result is good color rendering. The energy efficiency improves 
because the eye can see easily with these "tri-phosphors," so less light is required to accomplish a given task than is needed with other types of lamps. [Lindsey, 1991; Eley et al., 1993; IES, 1993] •

The T8 lamps, when operated by an electronic ballast, demonstrate an improved efficiency of around 11 percent over the T12s. [Lindsey, 1991]

- The T8 lamp, when operated for an average of eight hours per start, will have an expected lamp life of 28,000 + hours versus a shorter life for the T12 lamp.

- The T8 lamp has a much slower depreciation curve than the $34 W F 40$ lamp, which will provide less light loss and color shifts over the life of the lamp than a T12.

\subsubsection{T-8 Jamp retrofits}

The $265 \mathrm{~mA} T-8$ fluorescent lamp-ballast system is a relatively recent energy-efficient lighting product. Introduced to the American market in 1982, it is now made by all major U.S. lamp manufacturers. Straight T-8 lamps have the same medium bi-pin bases as T-12 lamps, so they can fit the same sockets (this is not true for the U-bent T-8 lamps, which have different leg spacing than their T-12 counterparts). However, T-8 lamps have different electrical characteristics than T-12 lamps, so T-8s may not use a standard F40T12 type lamp ballast designed for 430 milliampere operation. The standard T-8 lamp family is designed for $265 \mathrm{~mA}$ operation, but T-8 lamps are also being designed to operate with special ballasts at substantially higher power levels. There is only a small cost difference between a standard T-8 lamp-ballast system and a standard F40T12 lamp-ballast configuration.

Based on efficacy alone, T-8 lamps are generally superior to any T-12 technology. A T-8 system with magnetic ballasts will typically provide 8 percent to 9 percent more light at 4 percent to 9 percent fewer watts than a system using F40T12/ES lamps with equivalent color rendering capabilities. Efficacy is further increased with electronic ballasts. The lamp cost for $T-8$ lamps in large commercial projects in major metropolitan areas is about the same as for T-12 lamps.

\subsubsection{History and problems of T12 fluorescent lamps}

The fluorescent lamp that is most often used for both general ambient and specific task lighting is the "energy saver" four-foot, cool white, fluorescent tube (F40T12/CW/SS).

In the current trend to install new fluorescent lamps that are significantly more efficient in light output and energy consumption, F32T8 fluorescent lamps are generally used as replacements for F40T12 lamps. The T8 lamp, combined with a high-frequency electronic ballast, provides a rich source of lighting that delivers a high iumen package, a high CRI (color rendering index) rating and exceptional energy efficiency. [Eley et al., 1993; IES, 1993]

A brief comparison of the two lamps will demonstrate their different operating characteristics and performance. Understanding their technical differences will help the laboratory lighting designer to select the appropriate lamp to install for a particular use.

The 34WF40T12 lamp was originally produced in response to demand for a more energy-efficient fluorescent lamp during the "energy crisis" of the 1970s. Krypton was addedas a fill gas to the standard F40 lamp, creatingthe socalled energy-efficient fluorescent lamp. Today, standard lamps typically employ neon, argon, and sometimes xenon as a fill gas. Because krypton altered the standard F40 lamp's electrical operation just enough to produce measurable energy saving, it was embraced by the lighting community as the panacea for energy problems. [Lindsey, 1991; IES, 1993]

Unfortunately, time and experience revealed reduced lamp life, poor color rendering, and low light output resulting from the following technical problems: 
- The lamps were designed to operate at a 465ma current level; however, the magnetic ballasts that operate the lamps were designed for $430 \mathrm{ma}$ lamp operation. This caused the lamp to be "underdriven," which saves energy (about six watts per lamp) but has some negative effects on the overall lighting system.

- The negative effects of underdriving of the lamps include some color shifts, which reduce the rated color rendering index (CRI). Underdriving causes effects similar to those observed when incandescent lamps are dimmed: reduced light output and "duller" color.

- The lamps typically have an initial rating of around 2,750 lumens, which seems to be a reasonably good lumen package. However, the ballast factor reduces the lamp's performance. Ballast factor can be simply defined as the lumens a particular lamp can be expected to produce when operated by a specific ballast. Thus, a ballast with a ballast factor of 95 percent would produce about 95 percent of a compatible lamp's rated lumens. The ballast factor for the electromagnetic ballast that operates the 34 WF 40 is typically about 85 percent, which would mean that about 2,340 lumens would be available from a lamp; this is an almost 20 percent reduction of the initial rated lumen package, which is a significant loss. [Lindsey, 1991]

- There have been numerous reports of shortened lamp life, most likely caused by sputtering of the cathodes due to the variancein operating currents.

- The lamp requires a 60 degree $F$ ambient temperature for proper starting, which is at least 10 degrees warmer than the temperature required by the 4OWF40 and the 32WT8 lamps. [Lindșey, 1991]

- More lamps and fixtures are usually needed than were required using old 40WF40 lamps. The costs for additional lamps and fixtures generally offsets energy savings and certainly affects a project's economics unfavorably.

$\begin{array}{lll} & \text { F40T12SS } & \text { F32T8 } \\ \text { Rated lamp wattage } & 34 \mathrm{~W} & 32 \mathrm{~W} \\ \text { Actual energy use } & 37 \mathrm{~W} & 29 \mathrm{~W} \\ \text { Effective lumens ** } & 2,376 & 2,668 \\ \text { Lumens per Watt } & 64.2 \mathrm{LW} & 92.0 \mathrm{LW} \\ \text { Rated Life } & 20,000 \mathrm{hrs} . & 20,000 \mathrm{hrs} .\end{array}$

One laboratory situation particularly demands T12 lamps. If there are E-Prom or computer chip boards being manufactured or assembled in a laboratory, it is critical that lamps be ultraviolet shielded. An F40T12 Gold lamp is available that emits virtually no UV; unfortunately, this lamp has a very low lumen rating, with effective lumens around 1,800 lumens/watt. This low rating will necessitate a larger number of lamps to meet the luminance requirements of the area than would be needed if another type of lamp was used; however these T12 lamps insure that there will not be any damage to the components being assembled.

More efficient T8 lamps could be used in this specialized environment; however, the extra cost for installing fixtures with UV shielded lenses might offset the energy savings from using the more efficient T8 lamps.

** Effective lumens are determined by multiplying the rated lumens of a lamp by the ballast factor or the particular ballast that is operating the lamp.

The 34WF40T12/CW lamp has an initial rating of about 2,750 lumens. The magnetic core and coil energy-efficient ballast operating this lamp has a ballast factor of 0.88 : 
This equation tells the designer that the lamp/ballast combination will produce about 2,376 lumens. Rule of thumb indicates that only about 50 percent of this light will reach the work surface.

The F32T8 lamp has an initial rating of about 2,900 lumens. The electronic ballast has a ballast factor of 92 percent::

$$
0.92 * 2,900 \text { lumens }=2,668 \text { lumens. }
$$

\subsubsection{Electronic ballasts}

According to Eley et al. (1993):

Newer, more energy-efficient [electronic] ballasts...improve lamp-ballast system efficacy, measured in lumens per watt. The losses in magnetic ballasts have been reduced by substituting copper conductors for aluminum and by using higher grade magnetic components. Ballast losses may also be reduced by using a single ballast to drive three or four lamps, instead of only one or two. Careful circuit design increases efficiency of electronic ballasts. In addition, electronic ballasts, which convert the $60 \mathrm{~Hz}$ supply frequency to high frequency, operate fluorescent lamps more efficiently than is possible at $60 \mathrm{~Hz}$. Finally, in rapid start circuits, some magnetic ballasts improve efficacy by removing power to the lamp electrodes after starting.

The electronic ballast is rapidly becoming the standard in the lighting industry. It produces significant energy and dollar savings in nearly every application for full-sized fluorescent lamps. The ballast is flicker free and produces virtually no noise or hum. [Eley et al., 1993]

In addition to the benefits of electronic ballasts already mentioned (which significantly enhance T-8 lamp operation), the electronic ballast with dimming capabilities is an integral component of any daylight harvesting or lumen maintenance strategy. These options will be discussed in detail later in the Controls section. The laboratory lighting designer may select electronic ballasts with complete confidence for most applications.

\subsubsection{Ballast factor}

According to Eley et al. (1993),

One of the most important ballast parameters for the lighting designerlengineer is the ballast factor. The ballast factor is needed to determine the light output for a particular lamp-ballast system.

Ballast factor is a measure of the actual lumen output for a specific lamp-ballast system relative to the rated lumen output measured with a reference ballast under ANSI test conditions (open air at $25^{\circ} \mathrm{C}\left[77^{\circ} \mathrm{F}\right]$ ). An ANSI ballast for standard 40-watt F40T12 lamps requires a ballast factor of 0.95; the same ballast has a ballast factor of 0.87 for 34-watt energy saving F40T12 lamps. However, many ballasts are available with either high (conforming to the ANSI specifications) or low ballast factors ( 70 to $75 \%$ ). It is important to note that the ballast factor value is not simply a characteristic of the ballast, but of the lamp-ballast system. Ballasts that can operate more than one type of lamp (e.g., the 40-watt F40 ballast can operate either 40-watt F4OT12, 34-watt F40T12, or 40-watt F40T10 lamps) will generally have a different ballast factor for each combination (e.g., $95 \%,<95 \%$, and $>95 \%$, respectively). 
Ballast factor is not a measure of energy efficiency. Although a lower ballast factor reduces lamp lumen output, it also consumes proportionally less input power. As such, careful selection of a lamp-ballast system with a specific ballast factor allows designers to better minimize energy use by "tuning" the lighting levels in the space. For example, in new construction, high ballast factors are generally best, since fewer luminaires will be required to meet the light level requirements. In retrofit applications or in areas with less critical visual tasks, such as aisles and hallways, lower ballast factor ballasts may be more appropriate.

To avoid a drastic reduction in lamp life low ballast factor ballasts $(<70 \%)$ should operate lamps in rapid start mode only. This is particularly relevant for 32-watt F32T8 lamps operated at high frequency.

Finding the ballast factor for lamp-ballast combinations may not be easy, as few ballast manufacturers provide this information in their catalogs. However, if the input power for a particular lamp-ballast system is known (usually found in catalogs) an estimate of the ballast factor is possible. [See Eley et al. 1993 for details on estimating ballast factors.]

- Lamp-Ballast System Efficacy

The efficiency of a fluorescent lamp ballast changes depending on the type of lamp operated. Similarly, lamp efficacy is affected by ballast technology: the same lamp will perform differently when operated by a heater cutout ballast than it will when operated at high frequency. As a consequence, the only meaningful comparison between lamps or ballasts is the lamp-ballast system efficacy. The system efficacy can be calculated as follows:

$$
\text { System Efficacy }(\text { lumens/watt })=\frac{\text { Rated Lamp Lumens }}{\text { Input Power }(\text { Watts })} \text { Number of Lamps } \infty \text { Ballast Factor }
$$

\subsubsection{Rapid-start ballasts}

After a lighting designer has selected electronic ballasts, the next decision is between rapid and instant start. The standard T8 lamp, the F32T8, is a rapid-start lamp, so the optimal choice would be a rapid-start ballast. However, this is only absolutely required when system dimming is occurring. Rapid-start ballasts are also strongly recommended when the average "on" time for the lamps is under three hours per start, for example where occupancy sensors have been installed.

The reasons for choosing rapid-start ballasts in these two cases are:

- A rapid start ballast will start a lamp by first heating the cathode and will maintain a constant arc across the cathode to maintain the heat necessary for proper operation. This is mandatory for any dimming operation. Dimming is impossible using an instant-start ballast.

- The rapid-start ballast is easier on the cathode in the starting mode; when there are many on-off cycles because occupancy sensors control the lights, lamps tend to be longer lived with rapid-start ballasts. Instant-start ballasts, in this situation, are believed to cause premature failure of the lamps because of the high voltage they use to "jump start" the lamps. This high-voltage blasting of the cathode causes sputtering-clumps of tungsten are blown off the cathode and coat the ends of the lamp, causing them to appear black. This blackening occurs with all lamps as they age, but it occurs more rapidly when an instant-start ballast is in operation and the lamp is turned off and on many times a day. 


\subsubsection{Instant-start ballasts}

There are some very persuasive arguments for the use of instant-start electronic ballasts; the laboratory lighting designer should consider them before deciding which electronic ballast to specify.

- The instant-start ballast is more economical-5 to 10 percent less expensive-than the rapid--start ballast. This can become a significant difference given the numbers of ballasts required to operate an entire lab complex. The instant-start ballast will also provide greater energy savings of about two watts per lamp. The rapid-start ballast uses more energy because it must maintain current to the cathode to maintain cathode heat; the instant-start ballast essentially blasts the cathode into operation, so it does not require constant current to maintain lamp operation. Two watts per lamp multiplied by thousands of lamps in a laboratory can have a significant impact on energy use.

- In typical settings, lamps are on for periods of time greater than three hours per start. Lamp life tends to even out between the lamps driven by rapid-and instant-start ballasts after about eight hours of continual operation, so reduced lamp life resulting from instant ballasts becomes irrelevant under these conditions.

Designers should be aware that both types of ballasts are reliable and proven technologies. The particular areas where instant-start ballasts may not be used are defined clearly. All major ballast manufacturers produce both rapidstart and instant-start ballasts, so designers can easily select the product most applicable for a particular facility.

\subsubsection{Harmonic distortion and electronic ballasts}

As noted in Eley et al. (1993),

When electronic high-frequency ballasts were first introduced in the early 1980s, some models generated relatively high line harmonics. Nevertheless, at that time, harmonic currents produced by lighting equipment and other electronic systems were not, as yet, a utility issue. However, by the mid-1980's, utilities and power engineers were becoming increasingly more concerned about power equipment that generated line harmonics.

The harmonics issue first surfaced as a concern to the professional lighting community when a major utility announced that electronic ballasts were required to have total harmonic distortion (THD) of less than $20 \%$ of the fundamental in order to qualify for their rebate program. Electronic ballast manufacturers responded to the utility's requirement by employing passive filtering that met the $20 \%$ limit at a slightly higher cost to the end user.

The laboratory lighting designer certainly should be aware of reports of harmonic distortion and electrical equipment interference from electronic ballasts. However, we know of no documented instances of severe electrical problems occurring in any laboratory environments due to Total Harmonic Distortion (THD) problems caused by the installation of electronic ballasts.

The installation of electronic ballasts will generally reduce the overall load on a circuit by reducing energy demand. All of the major ballast manufacturers produce products that are $<0.20 \mathrm{THD}$, and $<0.10 \mathrm{THD}$ ballasts are available for a premium cost. The standard magnetic ballasts that have been replaced by electronic ballasts usually have a THD of 0.25 or greater. These magnetic ballasts also consume on the average 2-6 watts more energy that their electronic replacements.

Radio frequency interference, while rare, is possible when electronic ballasts are installed in areas where equipment operates on the same frequency as the ballast. If problems involve masking of signals rather than actual damage to the equipment, there is a very simple solution: replace the electronic ballast with a hybrid ballast. This product is aimost as efficient as the electronic ballast but does not operate at the same high frequency and will not cause interference with sensitive equipment. 


\subsubsection{Reliability of electronic ballasts}

Eley et al. (1993) report that,

The reliability of electronic ballasts has been questioned since their introduction in 1981. Some manufacturers' initial products failed prematurely. Those manufacturers who were unable to improve their products are no longer producing electronic ballasts. Other manufacturers have been in production over ten years with documented ballast failure rates of less than $1 \%$ after five years of operation. At this time, it is apparent that long term usage has demonstrated the reliability of electronic ballasts.

\subsubsection{Electronic vs. Magnetic ballasts}

Eley et al. (1993) describe the advantages of electronic ballasts:

Electronic high-frequency ballasts increase lamp-ballast efficacy, leading to increased energy efficiency and lower operating costs. Electronic ballasts operate lamps using electronic switching power supply circuits. Electronic ballasts take incoming $60 \mathrm{~Hz}$ power (120 or 277 volts) and convert it to high-frequency $A C$ (usually 20 to $40 \mathrm{kHz}$ ). Electronic ballasts are more efficient than magnetic ballasts in converting input power to the proper lamp power, and their operating of fluorescent lamps at higher frequencies reduces end losses, resulting in an overall lamp-ballast system efficacy increase of $15 \%$ to $20 \%$.

Electronic ballasts have a number of other advantages over magnetic ballasts. Electronic ballasts are readily available that operate three or four lamps, allowing the use of a single ballast in 3-lamp and 4-lamp luminaires. This reduces both installation and field wiring labor costs, and may negate the necessity of tandem luminaire wiring as required by the 1992 Energy Efficiency Standards for Residential and Nonresidential Buildings (Title 24). Electronic ballasts are designed to operate lamps in either series or parallel mode. The advantage of the parallel mode of operation is that a single lamp failure will not affect the operation of the remaining lamps controlled by the same ballast. However, ballast losses will increase slightly in the parallel mode. Other advantages of the electronic ballast include reduced weight, quieter operation, and reduced lamp flicker. Electronic ballasts are directly interchangeable with magnetic ballasts, and they are available to operate most full-size and compact fluorescent lamps.

\subsubsection{Fixtures}

While the selection of the proper lamps and ballasts is important, the laboratory lighting system designer must also insure that fixtures are optically and thermally efficient. The design of a particular fixture will determine how much light is delivered to the working surface, how efficiently the lamps and ballasts operate in that fixture as a result of thermal load factors, and even how many fixtures will be required to meet the design lighting level criteria.

The laboratory environment, for the most part, utilizes the same types of fluorescent, high-intensity discharge (H.I.D.), and incandescent fixtures as are available off the shelf for all types of facilities. If a designer pays attention to the efficiency and thermal factors of a fixture's performance, the probability of specifying an energy-efficient and optimally performing system is very high.

There are only a few areas where this broad rule of thumb is not applicable. If there is any concern for Radio Frequency Interference (RFI), fixtures are available that are designed to block RFI emissions; a metal grid is embedded in the lens, which, in turn, is grounded externally. Ultraviolet shielding may also be necessary in special cases. One solution is to employ the Gold fluorescent lamp. Should this option not meet the designer's requirements, fixtures that have UV shield lenses are available, for a premium price. 


\section{- Compact fluorescent lighting}

One approach employs compact fluorescent lighting sources, normally either table lamps or task lighting systems that can be positioned on the work surface or near the area where a task is performed. In this scenario, designers should consider using single or multiple compact fluorescent lamps housed in a dedicated fixture operated with electronic ballasts. A fixture that is designed exclusively for the use of a compact fluorescent lamp and that is not able to operate any other lighting source is considered to be dedicated to the operation of a compact fluorescent lamp. A wide selection of fixtures is now available, so it should prove relatively easy to locate the exact fixture desired to meet a designer's functional and esthetic criteria. Once a fixture type is selected, inputting photometric data into a point calculation program will determine the number and location of the fixtures required to perform the task.

\subsubsection{Cleanroom fixture considerations}

Mcllvaine et al. (1992) describe issues related to lighting fixtures in cleanrooms:

Companies are making lighting more convenient and more adaptable to a user's needs. In order not to disturb the laminar air flow, tear-drop strip light fixtures mount directly to the T-Frame Suspension System and allow for 100 percent HEPA filtration coverage throughout the entire ceiling system. For Class 100 and better cleanrooms, integral fiter-luminaire modules may be needed, or teardrop luminaires that are mounted to the grid support.

[Another firm] also manufactures fixtures to accommodate HEPA filters. The latest development is a fixture for the $2 \times 2$ filter design. Also about to be introduced is a new gel seal design. Integration of the lighting system with the filter as part of one module is an improved concept which allows higher lighting levels than with the older design in which tear drop lights were hung from the $T$ bars. Fixtures should be flush-mounted in the ceiling with the smooth side down and sealed to prevent air leakage.

\subsubsection{Animal room fixture considerations}

The Handbook of Facilities Planning (1990) describes special considerations for lighting fixtures in a laboratory that houses animals:

Animal rooms require a two-level lighting arrangement. Since most laboratory animals are nocturnal, a night cycle of $0-1$ foot-candles and a day cycle generally of 30-50 foot-candles with a wide-spectrum fluorescent light source and a cleaning cycle with 70-100 foot-candles are required. Night levels should be as low as possible, with as few light leaks as possible from corridors or adjacent rooms.

The lighting control for the animal rooms has been a local time clock-controlled system. This, however, is being replaced with a more sophisticated, computer-controlled system. The reason for this is that a central control point for all rooms provides accurate logs for documentation purposes.

\subsection{Lighting Control}

\section{Energy Efficiency and Lighting Control}

Lighting controls are necessary in any lighting system; without controls, it is impossible to turn lights off or on, or to change the lighting levels. Controls are either manual, such as a single pole switch or a residential type dimmer for incandescent lamps, or automatic, such as a time clock or photocell. Included in the automatic category are occupancy sensors that detect movement or heat and turn lights on when a space is occupied and off when it is 
vacant, and computerized energy management systems that are programmed to operate lighting systems on a predetermined schedule. [Lindsey 1991; IES, 1993]

Mcllvaine et al. (1992) explain the advantage of programmable control systems in cleanrooms.

Significant savings in cost can be achieved if the lights are turned out in the cleanroom when it is not in use. A programmable control system can be readily applied to lighting loads with a payback period of less than one year, depending on actual usage. Obviously, the same savings can be achieved by merely turning off the switch at the end of the day's operation. The programmable control system, however, will rarely forget to turn off the lights.

The next sections will address a few energy-efficiency strategies that are considered cutting-edge, state-of-the-art technologies yet are also reliable and have proven track records.

\subsubsection{Occupancy sensors}

Occupancy sensors should be a part of any research laboratory lighting system, mainly because many offices attached to labs are left unoccupied for a significant amount of time each day, typically with the lights on. Reducing this load will result in measurable savings. If a laboratory does not "sweep" lights off during nighttime hours, weekends and holidays, the sensor will ensure that the lights are off when the space is unoccupied. It is probable that more energy savings will be derived from having the lighting system turned off by sensors at these times than will be realized during normal working hours.

The occupancy sensor is an energy-saving control device that turns lights on and off depending on the occupancy of the space being controlled. When people are in the room, the lights are enabled on, and when the room is vacated for a set period of time (usually 15 minutes) the device turns off the lights. This provides energy savings ranging from 10 percent to 50 percent, depending on the habits of the occupants of the space.

Occupancy sensors have been available for laboratory installation since the late 1970s. The technology uses both passive infrared (PIR) and ultrasonic (US) detectors. New, hybrid products are now being manufactured that employ both PIR and US technologies. The designer may select either technology. As a rule of thumb, PIR is most efficient in small areas, such as individual offices or supply rooms, and US is most effective in large spaces, such as a lab or classroom. Dual technology sensors, composed of both the passive infrared and ultrasonic technologies, are triggered by either heat or motion but require the absence of both to shut off, alleviating false triggering problems. Hybrid sensors are more expensive initially but may prove more efficient and cost effective over the life of the system than a single technology sensor. An occupancy sensor specialist can be consulted to determine which type of sensor will provide optimal performance and to select locations for mounting.

Designers must account for false triggering of sensors, which could occur when someone walks past the door of a controlled room and is "picked up" by the sensor, or when a sensor turns off lights in an occupied room where the occupant has remained still for the sensor's shutoff time period.

The laboratory lighting system designer should rarely if ever experience a problem involving interference with sensitive equipment from lighting sensors. There have been some isolated reports of interference with laboratory equipment, particularly in the 27 -kilohertz range, but these problems have been solved by simply changing the frequency of the sensors to a higher range, usually 40 kilohertz or higher. 


\subsubsection{Dimmable ballasts}

In some situations, it is necessary to control the fluorescent lighting system, usually to dim the lights for various tasks. Conference rooms will often utilize dimming for presentations, and certain work stations need to reduce ambient light for certain tests and equipment operation.

A variety of dimming electronic ballasts are available on the commercial market with dimming ranges of $<20$ percent, $<10$ percent, $<5$ percent and $<1$ percent. The lower the levels of dimming possible the more costly the ballast. The laboratory lighting designer needs to carefully consider the actual ranges of dimming necessary before specifying which ballast to install.

Laboratory lighting designers must also be aware of the requirements for dimming ballasts in all fixtures that are to be part of a daylight harvesting strategy. Designers should work closely with the manufacturer of photoreceptors to insure that receptors are installed in the proper locations and calibrated to the exact range of illumination desired. Typically, zones that will be effective for daylighting are within 16 feet of window(s). Effective areas for skylighting zones should be determined on a case-by-case basis.

\section{- Daylight harvesting}

Daylight harvesting takes advantage of available daylight to augment electric lighting systems. Dimming ballasts and photoreceptors can reduce electric lighting loads proportional to the amount of daylight that enters the space. The more usable daylight entering the space, the more the electric lights can be dimmed, resulting in significant energy savings - as much as 60 percent of the connected lighting load to the space. [IES, 1993]

Laboratory lighting designers will find that open ballroom-type areas and large offices that have sufficient daylight are the most cost-effective areas for daylight harvesting. Small offices with only one or two fluorescent fixtures, viewed individually, are usually not cost-effective areas for daylighting. However, if an entire laboratory lighting system is viewed as a whole, daylight harvesting in several small spaces may add up to be cost effective.

\subsubsection{Lumen maintenance}

Lumen maintenance strategies have only recently become economically viable for general use. Conventional lighting systems are designed to provide more than the required levels of illumination when new; lighting levels gradually drop as the system ages until somewhere in the middle of the effective life of the lamps, the "maintained" lux level of the system is (temporarily) achieved. This overdesign has historically been based on the popular philosophy that being overlighted for part of the time is better than being under lighted.

Fortunately, with the development of dimming electronic ballasts that are competitively priced, systems that take advantage of lumen maintenance techniques can be designed.

The strategy is straightforward: design the system in the standard manner, slightly overlighted initially; then, tune the system to the exact lux level desired. This design requires dimming ballasts in all fixtures that are included in the lumen maintenance zone and a control system that will allow ballasts to increase output as necessary. As the system ages and lamps begin to degrade, the ballast increases voltage to the lamp, which causes the lamp to produce more light.

The energy efficiency of this procedure is exceptional, with initial savings of 50 percent being realized in many instances in comparison to traditional lighting designs. The savings over the life of the lamp are expected to be significant; exact numbers are not available to date. Lawrence Berkeley National Laboratory's lighting research group is currently conducting studies to determine actual savings and effects on lamps and ballasts operated over time in this mode. It is hypothesized that lamps will have longer useful lives and that savings over time could be as high as 40 percent. 
There are a number of methods for controlling lumen maintenance areas. They are:

- Installing photoreceptors tied directly to ballasts, controlling the voltage output to the lamps based on the set level of luminance.

- Connecting dimming ballasts directly to an energy management system that has been programmed for the expected depreciation of the lamps; the energy management system directs the output of ballasts as necessary to maintain required lighting levels over time.

- Manually verifying lighting levels in a space by using photometers in specific locations, and then manually setting the system to meet lighting requirements.

Each of these options provides reliable technologies that enable successful lumen maintenance strategies. Designers must select the most appropriate control device for a laboratory's particular needs.

\subsection{Remote Lighting Systems}

\section{Energy Efficiency and Remote Lighting Systems}

Some laboratory situations require isolating the lighting system from a specific task or functional area. These areas can be very small, such as fume hood setups, or large, such as cleanrooms. A remote location light source is coupled to a distribution optic that effectively conveys light to the task within the space. This separation of source and distribution is typically used in applications that require electrical isolation because of safety, electrical interference, or spark hazard concerns.

Remote lighting systems can be used in laboratory spaces where light sources must be isolated because of:

- EMI (electrical/magnetic interference),

- solvents or flammable materials that may present fire hazard,

- extreme temperatures,

- ultraclean conditions,

- areas that cannot be easily maintained, and

- large quantities of particulate material.

\subsubsection{Remote lighting systems}

All remote lighting systems consist of a light source, optical coupling system, and distribution optic. Light sources for these systems can be any type from incandescent to HID (high-intensity discharge) lamps. The optical coupling system usually involves reflective (e.g. reflector) or refractive (e.g. lens system) optics, or a combination, to channel light from the source to the distribution system. These flux coupling devices also provide the proper spatial and directional properties of the input flux required to achieve high efficiency and desired distribution. The distribution optic conveys light to the task area. Remote lighting systems allow light sources to be placed in a space separate from the application or task area. 


\subsubsection{Remote lighting sources}

The main criteria to be considered in selecting remote lighting sources are:

1. size of the lumen package,

2. efficacy,

3. color, and

4. compatibility with distribution method.

More commercial opportunities currently exist for integrating a broad range of sources inside linear hollow light guide systems than using fiber optic systems. Virtually any type of compact source can be directly employed in a hollow light guide system using standard, commercially available reflector geometries. The lamp of choice for hollow light guides is a metal halide in the 250-500 watt range. Recent developments have produced metal halide lamps with good color rendition and high efficacy (in the range of 90-100 lumens per watt). Emerging sources like sulfur lamps will be usable in the future.

In fiber optic systems, sources are limited to incandescent, tungsten halogen, or small wattage metal halides. The critical barrier to using higher wattage systems has been the problem of effectively coupling large lamp geometries using fiber optic bundles. Considerable effort is under way to increase the effective coupling of larger wattage lamps. System efficacy for common fiber optic sources is in the range of 70 lumens per watt.

\subsubsection{Future remote lighting sources}

The article "Sun on Earth" (1994) describes sulfur microwave lamps of the future.

On October 20,1994, the U.S. Department of Energy (DOE) and the U.S. manufacturer Fusion Lighting presented a new light source with great fanfare. This so-called sulfur microwave lamp represents a totally different approach in lamp technology. The principle behind the lamp could, in very simplified terms, be described as follows: Sulfur and argon in a small, electrode-less glass bulb are turned into plasma by microwave energy at $2.45 \mathrm{GHz}$. The physical properties of the excited sulfur atoms ensure that most of the microwave energy is converted into light while little energy is emitted as ultraviolet or infrared radiation.

The first lamps are prototypes with an input power of $5.9 \mathrm{~kW}$. Fusion is developing a lower power version under the project name Solar 1000... Fusion is presently not willing to provide any data on the Solar 1000 lamp, but say that the lamp is expected to be the most efficient light source on the market (excluding monochromatic light sources such as low-pressure sodium lamps). If this holds true, the system efficacy (including power supply and magnetron) will have to be well above 110 lumens/watt. (Good high-pressure sodium lamps have a system efficacy of -110 lumens/watt and the best metal-halide lamps a system efficacy of $~ 100$ lumens/watt.)

Optical Qualities: The small size of the bulb makes it easier to design optically efficient reflectors, and the stable plasma makes it easier to predict the outcome of a given design. (The purpose of rotating the bulb is to stabilize the plasma.) In a metal-halide lamp, for instance, the arch between the electrodes moves continuously which may pose a problem when using advanced reflectors with low optical tolerance.

Spectral Qualities: Almost $75 \%$ of the energy emitted from the bulb is emitted as light in a fullcolor continuous spectrum. (About $50 \%$ of the energy emitted by a metal-halide lamp is in the form of light, whereas the corresponding value for an incandescent lamp is about 10\%.) Fusion 
says that the technology allows for lamps with a correlated color temperature in the range 4000$9000 \mathrm{~K}$. The lower temperature will be achieved at the cost of reduced efficiency.

Other Features: The lamp starts within seconds, even at low ambient temperatures. The restrike time is also just a few seconds, and the lamp can be dimmed. Since there is only sulfur and argon in the fill-both non-toxic materials-their disposal does not pose an environmental problem.

\subsubsection{Remote lighting optics and distribution}

Light guides for remote applications can be classified into two distinct types, hollow and solid.

- Solid light guides are typically known as fiber optic systems and include glass or plastic fibers. Single or multiple fibers are optically connected to a single source and then distributed throughout a space to provide illumination.

- Hollow light guide systems utilize hollow channels, lined with reflective optical media, that guide light from source to task.

Both these systems rely on the efficient transport of light flux from a source through a distribution system. Transport is usually achieved through a process known as total internal reflection (though metallic reflection and lens refraction can also be used). These optical guides allow for the fundamental separation of the physical light source and from the distribution of the source's flux.

Fiber optic lighting systems are generally better suited to task lighting applications involving illumination of highly specific areas within a space. These areas need to be relatively small, such as a series of laboratory benches or fume hoods. However, continuous light-emitting fiber optic systems can light larger areas and will become more common in the future.

For large open areas that require a general illuminance level, hollow light guides offer more potential because they can integrate higher wattage lamps and the ability to distribute flux over a large area.

\subsubsection{Hollow light guides}

A hollow light guide is an optical channeling system similar in concept to fiber optics, except that the most of the light transport occurs in air rather than within the solid core of a fiber optic. Each guide includes a channel with a cross section specially designed for the particular application. This channel has internal optical material that reflects light in a specialized manner. The surface material often utilizes the concept of total internal reflection, allowing the guide to efficiently reflect light down its length. Portions of the channel surface, usually the bottom, are patterned with transmitting sections that allow incident light to pass out of the channel and down to the task plane below. Special transmitting films are often used in this process, so that refraction or diffusion can be used to control glare and output distribution.

Light from a small, intensely bright light source is focused by a reflector so that it enters the light pipe within a specified angular acceptance cone. Light travels down the pipe, reflecting off the prismatic film that lines the outer acrylic tube. Several types of films and reflective material can be used in the lining of the tube. The prismatic film reflects the light via total internal reflection, an intrinsically efficient process. Some of the light striking the film is not reflected and "leaks out" of the pipe walls, giving the pipe a glowing appearance. A light ray that travels all the way down the pipe will strike a mirror at the end and return up the pipe. A special light-extracting surface (achieved with other films) is used to draw the light out of the pipe in a controlled manner to where it is most needed.

Hollow light guide distribution systems typically involve the use of long liner tubes constructed from acrylic tubing with either circular or rectangular cross sections. These linear elements are typically six to eight inches wide and 
can be manufactured for almost any common length. Most commercial systems are either "single-loaded" or "double-loaded," which describes the integration of the light source with the tube. In a single-loaded linear light guide, the source and reflector feed a single light tube at one end. Light is then guided down the length of the space and evenly distributed. In a laboratory application the source and optic coupling box would be positioned outside the room either within the wall or on the other side of the wall in an adjacent space. In a double-loaded system, the source and reflector system feeds two linear guides that then extend away from the source system. In a laboratory application this system would be positioned between two rooms with the source mounted into the common wall or ceiling. These sections can be ceiling integrated like typical $2 \mathrm{ft} . \times 4 \mathrm{ft}$. recessed troffers or they can be pendant mounted within a space. The light-emitting portion can have a luminous distribution characteristic similar to that of typical lens fixtures. This distribution of a linear section of light can be expressed as a candlepower distribution and can be used to do point-to-point calculations for estimating illuminance.

Candlepower distributions for the light guide can be designed that will direct flux in an asymmetric pattern for specialized horizontal or vertical applications.

\subsubsection{Hollow light guide test installations}

The article "A Systems Approach to Remote Light Sources" describes the use of hollow light guides in a museum:

In one of the large halls at the National Air and Space Museum, full of rockets and satellites, changing lamps and maintaining the luminaires in the ceiling always were very expensive and time-consuming tasks, and thus much neglected.

Here, the 94 high-intensity discharge (HID) lamps have been replaced by three sulfur-lamp units used in combination with three 30-m hollow light guides ("light pipes"). These light pipes are intemally clad with a highly reflective optical film that transports and distributes the light evenly towards the floor from over their entire length. Each sulfur lamp unit feeds light into a pipe from an easy-to-access catwalk at the side of the room. The rail-mounted pipes are divided into three sections and can be rolled back to the catwalk for cleaning and repair. The system offers improved color and reduced shadowing. Moreover, unwanted UV radiation was cut by half, an important feature for a museum.

The efficiency of hollow light guides is a much-debated issue: The above installation appears to be very efficient, with lighting levels increased three-fold and energy use cut by 1/3. Although a modern HID-lamp system also would have increased efficiency, the maintenance problems would have been the same, with the luminaires getting more and more dirty. Here, it appears that it is the combination of efficient light distribution (the light pipes in this case both transport the light over a long distance and distribute it evenly) and the easy-to-maintain feature that accounts for the savings.

A similar explanation also must be sought at the U.S. Department of Energy's Headquarters (the Forestall Building) where an 80-meter-long outdoor light pipe installation is fed by one sulfur-lamp unit at each end. These two lamps replaced 240 old luminaires with 175-W, conventional, HID lamps. Light levels were increased fourfold, while power requirements decreased by $2 / 3$.

\subsubsection{Refiector-based distribution test installation}

The article "A Systems Approach to Remote Light Sources" describes the use of a reflector distribution system in a hospital:

If the purpose is to move light without providing illumination at the same time, a reflector-based system may be cheaper and more efficient. Since the sulfur lamp provides extremely stable light from a point source, an efficient reflector in the lamp unit can "collect" the light into a narrow beam 
that moves from the lamp, via reflectors placed outside the lamp unit. If the air is clean, very little light is lost between the lamp unit and the reflectors.

At the University Hospital in Lund, Sweden, the sulfur lamp is being used in combination with reflectors made of microprismatic optical materials. This hospital, typical of those constructed during the building boom in the Nordic Countries in the 60's and 70's, has large areas where daylight has little or no access. Moreover, the present lighting systems are inefficient, and it is believed that the large, dark areas adversely influence the well being of humans. Although this is still a somewhat controversial issue, the hospital authorities believe that more sunlight-like light could have positive biological effects. The ability to achieve higher lighting levels while reducing energy costs and cooling loads is another advantage.

The building housing the first prototype installation was erected in 1967. The original intentions of the architects were to create a soft and welcoming atmosphere in the entrance area by allowing natural light to enter through the glass facade. However, the facade didn't let in as much sunlight as had been hoped, and the inner parts of the entrance area were found to be very dark. Here, two parallel sulfur lamps with custom-built reflectors have been arranged in a way that directs the light upwards. A system of reflectors (not light pipes) in the ceiling distributes the light over the entrance area. Thus, the light is transmitted from the lamp unit via a primary reflector in the ceiling, as beams through the air, to a number of secondary reflectors that direct the light down towards the flow. The reflectors are clad with highly reflective films, but shaped so as to avoid any glare. Moreover, since these films have a microprismatic surface structure that "splits up" the beams, the risk of glare problems is further reduced. The fact that the reflectors "move" the light source far away from the eye of anyone that would happen to look into them helps to further eliminate glare problems.

Similar installations are planned for three more hospitals in southern Sweden. For instance, for the first time an underground radiotherapy clinic will be bathed in sunlight, albeit artificial.

\subsubsection{Fiber optic systems}

Most fiber optic systems consist of a light source, a coupling system, and a length of fiber optic material that emits light either where it terminates or continuously along its length. In fiber optic systems the coupling system, with an integrated source and ballast, is housed in what is called the illuminator. The illuminator can be located anywhere within reasonable proximity to the task requiring lighting. Single or multiple solid optical channels are distributed to provide illumination throughout the space or application area. Illuminators can be installed within the ceiling plenum, within a wall, or anywhere else within the space. Most commercial illuminators range in volume from approximately 1 to $2 \mathrm{ft}^{3}$ and therefore can be mounted easily under a laboratory bench or adjacent to a task surface.

Fiber optic lighting systems can be divided into three types:

- End emitting,

- Continuous-emitting, and

- A series of discrete emitters.

1) End-emitting - this type of system uses flux that exits the fiber optic where it terminates, to spot light a surface or a specific task area. Single or multiple fibers can be connected to a single illuminator. At the terminal end of the fiber system, an optic head distributes light to the task area. Commercially available systems allow designers to achieve very tight distribution for spot lighting small areas. Designers can also use wide distribution systems for lighting large areas. 
End-emitting systems are particularly suited for environments where the demand for light is highly specific or task oriented; the end-emitting portion of the fiber can placed in direct proximity to the task. These systems are particularly useful for very detailed tasks that require high illumination levels. End-emitting systems are energyefficient alternatives to using high levels of general illumination provided by ceiling integrated fluorescence.

Specific tasks that can efficiently employ fiber optic task lighting include:

- detailed inspection/assembly tasks,

- microscope tasks,

- assembly and inspection tasks in micro-chip labs,

- detailed measurements, and

- cold room applications.

Open laboratory environments that combine a general level of illumination using traditional ceiling integrated fluorescents with task lighting can use fiber optic systems efficiently to provide the task lighting. This lighting approach provides a low level of ambient illuminance over the entire space using an indirect lighting system with fixtures in a uniform grid; these fixtures are suspended from the ceiling and direct light up toward the ceiling, which evenly distributes the light down toward the task. Target illuminance would be between 30-50 foot-candles (considerably lower than the conventional 75-100 foot-candles one would encounter in a typical $2 \mathrm{ft} \times 4 \mathrm{ft}$. lens troffer layout). This indirect approach provides lighting for general functions, including occupant circulation, and provides a glare-free environment for visual display terminal (VDT) applications. At individual and multi-task areas, a series of fiber optic illuminators can be mounted onto benches to provide individual task illumination.

2) Continuous-emitting - this system relies on a fiber that emits light continuously along its length in an isotropic or a directional pattern. An optical interruption to the total internal reflection process on the fiber optic surface allows for light scattering and then for emission along the length the fiber. Continuous-emitting fiber optic lighting systems will see greatly increased use in specialized laboratory spaces that require remote light sources applications. Continuous fiber optic systems allow for a narrow diameter fiber to be placed in a room as an extended light source, which can act just like a continuous row of fluorescent lamps placed end to end. Continuous-emitting systems are well suited to lighting larger areas in laboratory spaces, particularly for tasks that are long and linear in nature.

3) Series of discrete emitters - this system uses fibers that have small surfaces positioned along a length, emitting light at regular intervals. Specialized surfaces are positioned at regular intervals to interrupt the total internal reflection process, allowing for light to be emitted at that point along the fiber.

\subsubsection{Remote lighting applications}

\section{- Hollow light guides}

Manufacturers of hollow light systems have generally followed the same design protocols as for standard lighting systems. Information is available that uses the typical coefficient of utilization (CU) procedure, which allows a designer to determine illuminance within a space. To use these systems, an engineer needs to know the illuminance required for a specific space in order to determine the size and number of separate lighting systems needed. The basic zone cavity or lumen method design procedures, described by the Illuminating Engineering Society of North America (IESNA), uses published manufacturer data for light guide materials and systems. The basic procedure involves:

1. determining required illuminance level using IES recommendations;

2. determining the area of the space to be lighted; 
3. defining room characteristics, including surface reflectance;

4. determining the number of systems for supplying illuminance, using published CU data; and

5. producing a uniform layout using multiple fixture systems, based on spacing/mounting height criteria data.

\section{- Fiber optic systems}

Designers who use fiber optic light delivery systems are mainly interested in supplying a particular quantity of light to a task. A primary objective in a lighting design is providing illuminance. Illuminance is flux density on a surface, expressed as lumens (light flux) per square foot, typically known as a foot-candle. Consensus recommendations for appropriate foot-candle levels for particular tasks can be found in a variety of industry guidelines and lighting handbooks. Illuminance can be estimated or calculated using some basic principles in conjunction with published photometric performance data for a particular lighting system. The first step is to determine the amount of light flux, measured in lumens, that is produced by a source. If the source is incandescent, the rated lumens are typically what is available to the system. If the system is using an HID (high-intensity discharge) lamp, such as a metal halide, the designer needs to determine system lumens. System lumens are a product of the rated lumens of the lamp and the relative ballast factor of the ballast designed to operate the lamp. Ballast factor accounts for the difference between the lumens obtained with a reference ballast in the laboratory and the lumens available with a commercial ballast. Typical ballast factors can range from 0.7 to 1.2. (See Eley et al. 1993 for a discussion of determining ballast factor.) The designer must also consider a source's lumen maintenance, the light output characteristics over the source's life. This information is typically available from the lamp manufacturer.

Not all of the lumens from a particular source are available. All fiber optic systems use optic coupling systems that direct flux into a fiber optic material using complex reflectors, lenses, or other optical techniques. Total lumens of a fiber optic system can be determined from the coupling efficiency of the system. The coupling efficiency is simply the quotient of total lumens produced by the lamp and the total lumens accepted by the fiber. Coupling efficiency is measured under laboratory conditions and is usually published. This efficiency factor accounts for losses that occur through the reflector or lens system as well as reflection losses that occur at the face of the fiber optic bundle itself. Coupling efficiencies typically range from 50 to 80 percent, depending upon the structure of the coupling system. Light that enters the fiber optic system within a given critical angle with respect to the face of the fiber is efficiently transmitted to the terminal end via total internal reflectance. Typically, a fiber optic system absorbs a small amount of the light flux along its length. This loss is called attenuation and is a function of the fiber optic material and the distance that the flux travels.

In order to determine the total available flux provided by an end emitter, the engineer needs to know the length of the fiber and the attenuation per unit length. Attenuation refers to the percent of light that is absorbed per unit length of fiber optic. If attenuation is 2 percent per meter, then each meter length transmits 98 percent (100 percent-2 percent) of the flux entering that length. This number in known as transmittance.

\subsubsection{Fiber optic flux calculation}

In a three-meter fiber optic with 2 percent (0.02) attenuation per meter, the first meter transmits 98 percent of the Entrance Flux. This transmitted flux, represented by $0.98 \times$ Entrance Flux, is then passed on to the second meter of fiber, which in turn undergoes the same attenuation, $0.98 \times(0.98 \times$ Entrance Flux). Similarly, the flux emerging from the third meter of fiber optic is given by $0.98 \times 0.98 \times 0.98 \times$ Entrance Flux. This repeated multiplication by the transmittance per unit length can be mathematically simplified by using an exponent function (e.g. $0.98 \times 0.98 \times 0.98$ $=0.98^{3}$ ). To calculate the total transmission, for any length of fiber optic, the following formula can be used: 
Total flux transmitted $=$ Entrance Flux $x t^{N}$

where,

$t=$ transmittance per unit length in decimal form (this can be determined by one attenuation per unit length), and

$N=$ number of unit lengths, which is simply the length of the fiber optic given in the same units (e.g. feet or meters) as the units used for transmittance and attenuation.

\section{- Example problem}

Example: 1,500 Lumens of flux enter a fiber optic. The fiber optic is 2.5 meters long and has an attenuation of 3.4 percent per meter. How many lumens exit from the terminal end?

Solution: First the transmittance is determined. Transmittance $=1$ - Attenuation. Thus the transmittance is 0.966 per meter (1-0.034). The total flux transmitted is then given by 1,500 Lumens $\times(0.966)^{2.5}$, which is 1,376 Lumens.

The above factors and considerations tell a designer how much flux will exit an end-emitting fiber optic system. To calculate or estimate illuminance on a surface from a particular source, information is needed on the direction of the light output from the fiber. Conventional lighting system design relies on measuring candlepower distributions under laboratory conditions, which indicate both the intensity and direction of light emission. These measurements can be used to generate coefficients of utilization, which are published factors that tell a designer how much light actually arrives at a work plane given particular conditions (room dimensions and surface reflectance). Designers can also use distribution information for a conventional light source, typically expressed as a candlepower distribution. These same photometric approaches can be applied effectively to fiber optic lighting systems.

As fiber optic systems become more common, "coefficients of utilization" will become available based on measured candlepower distributions. At this time, designers need to rely on published or measured candlepower distributions and to use point-to-point illuminance calculation techniques.

To determine actual illuminance at a given point using any of these fiber optic lighting systems, a designer needs to know the light distribution characteristics for each light-emitting component of the system. All three systems can be easily characterized, resulting in standard candela plots of the light-emitting portion of the fiber optic. For end emitters, a generalized candela plot can be measured for each distinct type of end emitter connected to the central illuminator or light source. These characterizations can be generated by a photometric test laboratory or by the manufacturer of the optical distribution head, and can be published so that they are available to designers.

Standard photometry techniques generate a spherical characterization of the light-emitting section of a fiber. This characterization, expressed in candelas, represents the candlepower of the emitter as measured in a particular direction. This technique usually involves measuring the illuminance under laboratory conditions over a large extended spherical area surrounding the source. From these measurements, a candlepower plot is generated and expressed in luminous intensity over an entire 360-degree vertical plane. Multiple planes can be measured, depending on the degree of the area's asymmetry. For rotationally symmetric emitters like fiber optic end emitters, a single plane of measurement will be appropriate for most calculations. This calculation generates a distribution of intensity as a function of direction, expressed in candelas. This characterization allows a designer to calculate illuminance at any point within the space, based on the geometric relationship between task and source.

Using published candlepower distributions, a designer can easily determine illuminance at a surface using a point-topoint illuminance calculation. 
Illuminance is calculated using the basic equation:

$$
E=/ / D^{2}
$$

where

$$
\begin{aligned}
& E=\text { illuminance (in foot-candles), } \\
& I=\text { intensity directly under the source (in candelas), and } \\
& D=\text { is the distance from source (in feet). }
\end{aligned}
$$

This relationship can only be used when surface is directly under the source and normal (perpendicular) to the light ray.

For all other positions a more generalized formula is:

$$
E=1 \times \cos \varnothing / D^{2}
$$

where

$$
\begin{aligned}
& E=\text { illuminance (in foot-candles), } \\
& I=\text { intensity of the source (in candelas) in the direction toward the point on the illuminated surface, } \\
& \varnothing=\text { the angle between the line joining the source to the point on the illuminated surface and a line normal } \\
& \text { (perpendicular) to the illuminated surface. }
\end{aligned}
$$

This can also be expressed as the angle between the light ray and a vertical through the center of the source known as the nadir.

$$
\begin{aligned}
& \cos =\text { the trigonometric cosine function (found on most all hand calculators). } \\
& D=\text { distance between source and task point. }
\end{aligned}
$$

If multiple sources are used, the illuminance contributed by each emitter must be determined and then summed. For continuous emitters or series emitters, the designer must use the candlepower for each section and then conduct a summation for total illuminance. In continuous, light-emitting fiber optic systems, light is emitted along the entire length of the fiber optic. In order to characterize this type of system photometrically, one practical approach is to break the entire length into smaller unit lengths and conduct photometric measurements to generate a series of unique candlepower distributions for each length. This approach is particularly useful because the luminous intensity down the length of the fiber optic may vary. The unit characterization and resulting candlepower distributions would be done in a photometric testing laboratory. The resulting candlepower distribution could then be used by a designer for any type of application. These calculations that use simple point-to-point estimates do not include reflectance effects from secondary sources such as walls or adjacent surfaces. For more detailed estimates, a designer can take the candela power distribution and use computer-based calculations to determine illuminance at a point from single or multiple fiber optic point sources.

\section{References}

"A Systems Approach to Remote Light Sources." Borg, Nils, ed. International Association for EnergyEfficient Lighting Newsletter Vol. 3, No. 9, April 1994. 
Eley, C., T.M. Tolen, J.R. Benya, F. Rubinstein, R. Verderber, principal investigators. Advanced Lighting Guidelines: Final Report. Prepared for the U.S. Department of Energy, California Energy Commission, and Electric Power Research Institute, 1993.

Handbook of Facilities Planning, Vol. One, Laboratory Facilities. Ruys, Theodorus, AIA, ed. New York: Van Nostrand Reinhold, 1990.

Illuminating Engineering Society (IES) of North America. Calculating Coefficients of Utilization, Wall and Ceiling Cavity Exitance. IES LM-57, 1982.

Illuminating Engineering Society (IES) of North America. The Determination of Illuminance at Point in Interior Spaces. IES LM-43, 1991b.

Illuminating Engineering Society (IES) of North America. Lighting Handbook, Reference \&_Application, $8^{\text {th }}$ Edition. 1993.

Illuminating Engineering Society (IES) of North America. Outline of a Standard Procedure for Computing Visual Comfort Ratings for Interior Lighting, IES LM-42-72, 1991a.

Lighting Design Practice. California Energy Commission, editors, Advanced Lighting Technologies Application Guidelines, March 1990.

Lindsey, Jack l. FIES. "Applied Illumination Engineering." Lilburn, GA: Fairmont Press, 1991.

Mcllvaine, Robert W. "Chapter 1, Rooms; Chapter 4, Engineering \& Design." Cleanrooms - 1992-2000, Rooms and Components Vol. Three. Mcllvaine, Robert W., Sally Halderman, Alpa Bagga, and Joseph Schwartz, eds. City, State: The Mcllvaine Co., 1992.

"Sun on Earth." Borg, Nils, ed. International Association for Energy-Efficient Lighting Newsletter, Vol. 3, No. 8, March 1994. 


\title{
10. COMMISSIONING
}

\author{
By Geoffrey C. Bell, P.E. and Mary Ann Piette*
}

\section{Abstract: Energy Efficiency and Commissioning}

A laboratory facility will waste energy if the process of commissioning does not ensure efficient operation. Although commissioning may be thought of as a final step, it actually begins when the first new or retrofit construction design concept is formulated with a commissioning plan. Commissioning continues during construction with equipment submittal reviews and system installation verifications. These phases of the commissioning process occur even before building systems are functional. The next phases are calibrating each energy-consuming system to operate reliably at minimum levels that meet design criteria, and measuring performance in all modes of operation. Fine tuning and eliminating crosscontrol inefficiencies that increase the facility's energy demand and consumption are also steps in the commissioning process. The rewards of good commissioning can be seen when a facility's energy consumption is rechecked after one year of operation. An ongoing efficiency assurance program for the facility's life pays for itself in saved energy and reduced maintenance costs. Commissioning costs should be automatically included in a facility's capital costs to ensure that the facility is fully functional at the time of occupancy. [Heinz and McCray, 1996]

\subsection{Introduction to Commissioning}

This section provides an overview of commissioning: what it is, why it is done, how it is structured, what methods and procedures are used, and who does it today. Commissioning is not common, yet it is becoming more frequent as building owners and others recognize that buildings and energy-using systems often do not perform as well in practice as designers predict. Although commissioning has many definitions, one simple one is "a set of procedures, responsibilities, and methods to advance a system from static installation to full working order in accordance with design intent" (Yoder and Kaplan, 1992).

Definitions vary according to the scope of commissioning and the activities related to it. Some commissioning projects begin early in the design stage and continue through ongoing operations and maintenance.

Commissioning of building systems has its roots in shipbuilding where the term was first used to describe the process to ensure a ship was seaworthy and ready for service. Commissioning is common today in industrial plant control systems. The principles behind commissioning are similar to those of "total quality management" (TQM). In TQM one attempts to establish criteria that can be tracked and evaluated to determine whether the quality of a desired activity or system meets expectations; for example, TQM practitioners might attempt to measure continuous improvements in employee productivity.

Some of the primary reasons that the buildings industry has begun to pursue commissioning are: first, building systems are more complex and dynamic than ever; Energy Management Control Systems, dynamic daylighting, direct-digital controls, variable frequency drives, and thermal-energy storage systems are just a few technologies that confuse building operators and need to be carefully tuned during installation. A second reason for commissioning is that demand-side management evaluations of energyefficiency measures have shown that many measures do not perform as well as intended; a key reason is

\footnotetext{
*Introduction to Commissioning, Sec. 10.1 authored by Mary Ann Piette
} 
that the systems have not been commissioned properly (Piette et al., 1995). Many building owners have a growing awareness of the need to track buildings' energy performance, and commissioning is seen as a way to establish proper operations during start-up. A third factor in the increased awareness of commissioning is that building designers, both architects and engineers, are less involved today than in the past in ensuring that a building they have designed actually works as intended. This lack of involvement results in a knowledge gap. The designers often do not understand how the systems they design actually function in practice. The focus on minimizing first costs, especially in speculative construction, means that little effort is placed on activities after a building's initial start up, so little attention is given to bringing building systems into operation with optimal energy efficiency, good indoor air quality, and realistic procedures for operation and maintenance.

\section{- Costs and Benefits of Commissioning}

The most common question after "what is commissioning?" is "how much does it cost, and what are the benefits?" There are two ways to answer this question. Case studies of commissioning that describe how much was spent and quantitative assessments of the benefits would be an ideal approach; unfortunately, such case studies are limited, especially in how well they quantify the benefits of commissioning. A second way to determine the costs and benefits of commissioning is to examine hidden costs involved in not commissioning. Benefits from commissioning include improved energy efficiency, better operations and maintenance, fewer change orders, and improved air quality.

A discussion of the costs for commissioning of laboratory buildings is included below in section 10.1.1.2. This discussion draws on case studies from complex university laboratories. The paper cited is an excellent discussion of how the university engineering staff improved the commissioning process as they progressed through four building projects. Heinz and McCray (1996) suggest that the costs to commission a building are far less than the hidden costs that occur in cases where buildings are not commissioned.

One study on utility-funded commissioning of energy-efficiency measures in new buildings focuses on the energy savings from commissioning (Piette and Nordman, 1996). This study found that, on average, commissioning costs of about $\$ 0.20$ /sqft were marginally cost effective in energy savings alone. These low commissioning costs are based on limiting the scope of commissioning to energy-efficiency measures only. Whole-building commissioning of all major energy-using systems is likely to be more cost effective.

Improvements in indoor air quality and other non-energy benefits may be more important than the energy savings benefits from commissioning. Proper air flow in a building influences the health, safety, and productivity of the occupants (Sterling and Collett, 1994). Energy costs in office buildings are around $\$ 1$ to $\$ 2$ per square foot year while salaries of employees are two orders of magnitude greater, so health and productivity of employees is a much larger cost item. Showing occupant productivity gains in a well commissioned building versus a building that is not commissioned is extremely difficult. However, many case studies have shown that the types of problems found during commissioning, left uncorrected, result in suboptimal building performance, which could lead to suboptimal employee performance.

The bottom line is that a building that is properly commissioned is likely to have fewer complaints from occupants, lower energy costs, and improved equipment maintenance. Therefore, life-cycle costs are minimized by attention to proper start-up and commissioning.

\section{- The Commissioning Process}

There is no universal or even dominant approach used for commissioning. The American Society for Heating, Refrigeration, and Air-Conditioning Engineers is currently updating their commissioning guidelines (ASHRAE, 1989), which are probably the most widely used on the subject in the U.S. The ASHRAE guidelines focus on HVAC commissioning, but many commissioning projects involve building systems beyond HVAC. ASHRAE suggests the term "Commissioning Authority" be used to describe the 
person who leads the commissioning effort. ("Commissioning Agent" has been the most common term to date, but legal advisors to ASHRAE suggest that using the term "Agent" is more legally binding and potentially problematic.)

Three other commonly referenced commissioning documents include:

- HVAC Systems-Testing, Adjusting, and Balancing (SMACNA, October, 1994)

- Procedural Standards for Buildings Systems Commissioning (NEBB, 1993), and

- Building Commissioning Guidelines (PECI, 1992).

Although the details of commissioning procedures vary among these guidelines, most descriptions include the following three general steps:

- Develop Commissioning Plan. The Commissioning Authority develops a commissioning plan that includes items such as the project schedule, construction contractor responsibilities, outstanding information requirements, equipment and system test procedures, monitoring plan (if any), and building operator training.

- Execute Commissioning Tests. The testing activities typically begin with precommissioning or inspection tests to verify that equipment and controls are installed as specified. These inspections are followed by more sophisticated functional performance tests. Functional tests, often seen as the heart of commissioning, are intended to determine whether the installed system is adequate, controls are properly calibrated, control sequences are correct, and proper responses occur to predefined stimuli. Commissioning tests are sometimes referred to as acceptance tests.

- Operations and Maintenance Summary and Training. The Commissioning Authority reviews the training procedures and O\&M manuals to ensure that proper attention is given to key issues. This may include periodic inspections and tests similar to those performed during commissioning.

In general, the earlier that the Commissioning Authority is selected and brought into the job, the more. effective the Authority's role will be. One common problem in commissioning is to bring the Authority in late during the design or early in construction. This makes the collection of information (such as design specifications and drawings) needed to perform commissioning more difficult than it would be otherwise. It is also more difficult, and therefore expensive, to schedule the tests into a typically rushed construction and start-up schedule.

\section{- The Scope of Commissioning}

The discussion of commissioning in this chapter focuses on commissioning of research laboratories. It does not provide details on the full scope of building commissioning, which should be explored if a laboratory is being designed along with an entire new building project. The most critical items in commissioning are the dynamic systems, especially controls, and other HVAC equipment. Lighting controls are equally important. Some Commissioning Authorities and building owners include additional systems (such as envelopes, as well as non-energy systems such as plumbing, and fire, life, and safety equipment) in commissioning.

Most of the current discussion about commissioning is concerned with new construction. Many of the same principles and methods are equally relevant to commissioning a retrofit or tuning up an existing building. In an existing building, procedures can be modified to focus on identifying major O\&M problems, or there may be an extensive "recommissioning." One caution in use of the latter term is that 
most buildings were not "commissioned" to begin with, so recommissioning generally means a systematic review of building systems to ensure they perform as desired.

\section{- Who Should Commission a Building?}

In addition to the important questions of "what is it?" and "how much does it cost?" a common question about commissioning is, "who is qualified and who should do it?" The most common method for commissioning today is to hire an independent, third-party Commissioning Authority. The independence allows the Commissioning Authority to maintain neutrality that is difficult to bring to the job if the work is done by the design team.

Many design engineers argue that they are best qualified to conduct commissioning because they are closest to the design, they understand its functional intent, and they should define and perform test sequences. However, the design team is less interested in uncovering design problems than an independent party. Even when the Commissioning Authority is an independent third party, the job is complicated when design problems are exposed. The Commissioning Authority is in a difficult position when an installed system functions in an optimal fashion but was a poor design choice in the first place. Commissioning Authorities are not usually responsible for the design. However, as mentioned earlier, the lack of feedback on how building systems actually perform is one of the driving factors pushing the buildings industry into commissioning. Improving feedback on building designs is a welcome addition to the information flow that will improve in building design and performance over time.

\section{- Summary}

In summary, commissioning is a process that is in a developmental stage. There is growing interest in commissioning by building owners, architects, engineers, and facilities managers. Each party stands to gain by an investment in careful commissioning. How commissioning is done, documented, and evaluated needs to be tracked and shared with others in the buildings industry to promote common methods and robust, cost-effective, and efficient procedures. One of the keys to successful development of commissioning procedures is educating building owners about the value and benefits of commissioning. Commissioning does increase the costs of getting a building built and operating, but it generally pays for itself several times over by helping to ensure that the facility not only meets, but hopefully exceeds the owner's expectations.

\subsubsection{Commissioning Overview}

As pointed out by R.J. Flaherty and R. Gracilieri (1994), "The commissioning of laboratories is an ongoing process that begins during the initial conceptual design and continues during construction, ultimately evolving into a continuing periodic reinspection and certification of the working laboratory." Complex laboratory HVAC systems require commissioning to ensure that they operate safely and efficiently and maintain the space conditions and air quality requested by the facility owner and occupants. The commissioning process typically begins during the facility's conceptual design phase by including a commissioning plan in the design-basis documents (sometimes referred to as "design-intent" documents) and ideally continues throughout the life of the facility. Some commissioning tasks can be performed concurrently; others must be completed sequentially. [Flaherty and Gracilieri, 1994; Heinz and McCray, 1996; Rizzo, 1994; Farquharson, 1988]

Commissioning $(\mathrm{Cx})$ is a highly discipline-interactive process that requires a great deal of communication and cooperation among engineers, contractors, users, and owners. Everyone involved must have a strong commitment to the goal of a fully commissioned facility. "Tuning" complexities presented by the intricate environmental conditioning systems laboratories require an iterative problem-solving approach. Therefore, ample time must be scheduled throughout the project to allow for solving complex problems, especially towards the end of construction. [Flaherty and Gracilieri, 1994] 
The owner and users should work with the design team to develop a comprehensive commissioning plan and incorporate it into the design specifications. A laboratory facility commissioning plan has four recommended phases:

- Installation Verification -- includes a commissioning plan, submittal reviews, construction inspections, as-built drawing creation, and pre-start inspections and reports. (Is the right stuff in the right place?)

- Operational Assessment -- begins when power is applied to system components and devices, and the EMCS, including airflow dampers, actuators, fans, fume hoods, pumps, analog controls and discreet alarms. (Is it all hooked up correctly?)

- Performance Measurement -- demonstrates that the entire facility's systems interact to provide a safe, stable, reliable conditioned environment that complies with required design performance criteria and control ranges. (Does it perform and condition as required?)

- Efficiency Assurance -- insures that energy efficiency is maintained to provide life-cycle cost paybacks on energy-efficiency measures included in the design. (Is continuing to perform?)

\subsubsection{Related Commissioning Programs}

The U.S. Food and Drug Administration (FDA) criteria for commissioning or "validating" a system are that the system must meet current Good Manufacturing Practices (CGMP) and Good Laboratory practices (GLP) guidelines. Although the FDA has been "primarily concemed with the pharmaceutical, medical, and emerging biotechnology industries" when it developed the CGMP/GLP guidelines, these principles and procedures are essential in commissioning any laboratory HVAC system. [Flaherty and Gracilieri, 1994]

\subsubsection{The Cost of Commissioning}

Flaherty and Gracilieri, in their paper "Documentation Required for the Validation of HVAC Systems" (1994), discuss preparing for the cost of commissioning of a project.

The budget for the commissioning portion of the project is commensurate with the complexity of the system installed. For instance, a single-zone, constant-volume system will cost less to commission than a multizone variable-volume system. As a general rule of thumb, the commission effort will be 5 percent to 10 percent of the project cost. Some of this value is typically included in the subcontractor's pricing; for example, the controls contractor should calibrate all instrumentation as part of his contract. [Flaherty and Gracilieri, 1994]

Heinz and McCray (1995) describe the costs and bnefits of commissioning of four science buildings on the University of Washington (UW) campus.

Before proceeding to the savings and benefits I should address the inevitable question "What is the cost of commissioning?" Unfortunately, there is no good answer to the question. In one sense it can be anything you want it to be. It is all dependent upon the scope of commissioning and where the costs accumulate (or othenwise appear). In the case of the four science buildings the contracts with the commissioning firms were in the amount of: $\$ 85,000, \$ 450,000, \$ 117,000$, and $\$ 177,000$. But that is not the cost of commissioning. To varying degrees there were costs incorporated in the construction contracts, depending on the degree of specification provided and the contractor's evaluation of the cost impact. Further, there are costs which accrue to the owner based upon staff participation, some of which is paid from the capital project budget and some of which is absorbed as orientation and training, which has traditionally been absorbed by the maintenance and operations program. 
Now that commissioning is becoming better understood by UW contractors and vendors, and they are realizing some of the benefits they derive from a better managed and scheduled construction program induced by commissioning requirements, they are indicating that resulting construction efficiencies are beginning to offset what othenwise might have been considered added cost to the projects. So, as the program is maturing the costs are coming down.

In any event, for budget projection purposes, the UW is suggesting consultants include in their estimates two percent of the mechanical construction cost and one percent of the electrical construction cost for the cost of commissioning. If it is a very complex science facility, then it might be appropriate to add one-half percent in each case. Because our specifications require the prime contractor to take full responsibility for commissioning the equipment, components, and systems (under surveillance of the owner's commissioning agent), then about seventy-five percent of the commissioning cost is contained within the construction contract and about twenty-five percent is the amount required for the commissioning agent's oversight of the commissioning program. We are aware of a number of studies documented by other owners which indicate similar results.

The final, most important consideration is that for the four science buildings in this discussion, the cost of commissioning is less than the cost of NOT commissioning. That is a fact that has also been proven by analyses done by other owners. The detailed are too lengthy to present herein but are recorded by others and can be projected for the UW projects.

\subsubsection{Commissioning Mockups}

Rizzo, in his article "Commissioning of Laboratories: A Case Study" (1994), describes the building of a full-scale mockup as part of a project to renovate and add to a research building and pediatric teaching hospital in Massachusetts.

It is known that the performance of laboratories and laboratory fume hoods is affected by the placement of ventilation outlets, the orientation of the hoods with respect to those outlets, physical obstructions, and the performance of the system controls. From this, the design team, consisting of an architect, an engineer, and the hospital's engineering, planning, and safety department, decided to build a full-scale mock-up of the laboratory. The mock-up included a working fume hood used to evaluate design assumptions.

While the architect and the construction manager were finishing the mock-up, a smaller group met to review control schemes. This group consisted of the hospital's automation manager, the building's engineering manager, the hospital's project manager, the control contractors, and the designer. Based on the hospital's experience with direct digital control (DDC) systems, it was desirable that the new system be entirely DDC from the central station air units to the room temperature controls. In the interest of conserving energy, a variable-air-volume (VAV) system, with heat recovery, was to be included.

Coogan in 1994 describes the benefits and general characteristics of mockups used as part of the commissioning process.

It is common practice in laboratory construction (or retrofit) to use a mock-up or other qualification test. Frequently, this is done before the control contracts are let. It is often done before the mechanical design is approved. One of the benefits is that the commissioning agent gets the chance to flesh out and prove a test plan. Typically, the plans change at the mock-up stage, when everyone learns which tests work. Another important benefit is that the owner, the commissioning agent, and the contractors all see exactly what is and is not to be accepted. The contractors' job is eased greatly when they know exactly what is to be accomplished. Job specifications are never as explicit as the test criteria that the commissioning agent develops. 
Usually the mock-up covers only one laboratory room with one or two fume hoods. It typically includes fume hood control and room pressurization. Often temperature control is ignored in the mock-up; it is occasionally intended to be included, but it is dropped. In elaborate cases, a separate data acquisition system is used to check the control equipment; typically the control system is used for data acquisition.

Rizzo, in his case study of the construction at a Massachusetts research building and hospital, describes the effect of using a mockup on the commissioning team's decisions about using VAV technology in fume hoods.

As the controls group was finalizing its criteria, the mock-up was completed. The hood in the mock-up was balanced at $100 \mathrm{fpm}$ with the sash at 14 inches above the airfoil sill. Airflow into the hood was then observed using smoke candles to test the room architecture.

These observations determined that the two-way blow diffusers, initially installed, were interfering with the hood. Causing turbulence at the sash, these were changed so that the throw of air entering the room would be away from the hood. The observations also indicated that the side of the hood must not be closer than 12 inches to any perpendicular obstruction, such as a wing wall. However, the wing wall provided a physical obstruction, preventing people from passing too closely to the front of the hood and thereby disrupting the airflow. These cross-purposes were resolved by cutting a slot in the wall to allow air to enter the hood unobstructed while at the same time maintaining the physical barrier....

The results of the mock-up testing provided the team with the confidence to apply the new variable-volume technology to the hood applications in the expansion project. While it was not always possible to apply each recommendation exactly, the mock-up allowed for informed choice in the inevitable compromises inherent in any project.

At the same time, the team met to discuss the protocols to be applied to the commissioning of the laboratory systems. On reviewing the known information, including the testing accomplished by others, the team developed a protocol ... for the certification of the laboratories. Since the system was designed as a variable-volume (constant face velocity) system, the team deemed it necessary that the system perform to specification during a static test and a dynamic test.

Once the protocol was designed, it was distributed to the control contractor and the testing and balancing contractor. Each was instructed to use the protocol as a guide in the initial start-up of the systems. The protocol was not used as a substitute for the normal testing and balancing and control specifications.

In his article Grossman (1995) describes some of the qualities of a valid mock-up of air-flow conditions.

To achieve valid comparisons between systems, in either a working laboratory or a mock-up facility, it is important to have at least two rooms available: one to serve as the "laboratory," and the other to be the "corridor." The laboratory should resemble the actual design as much as possible, with several fume hoods connected to a single manifold, as well as a general exhaust device and air-supply system.

From a functional point of view, it is important that the equipment be able to create a range of mild and severe inlet-outlet conditions, and variations in system static pressure. Also, the rooms should be reasonably "tight" in order to maintain and test pressurization reliably. 


\subsubsection{Commissioning (Cx) Team}

Good commissioning involves planning, coordination, and proven efficient procedures implemented by a team with personal commitment to excellence. The facility design team is responsible for designating the commissioning team. The commissioning team typically includes the following representatives: owner (which includes the operation and maintenance staff); researcher; architect; electrical, energy, and mechanical engineers; balancing, controls, electrical, and mechanical contractors; the general contractor; and, for large VAV laboratory projects, a commissioning agent. The commissioning agent has the overall responsibility to coordinate and manage the commissioning process. It is important that the commissioning team members understand their responsibilities and procedures during the submittal process, well before construction begins. [Coogan, 1994; Flaherty and Gracilieri, 1994]

\subsubsection{Cx Team Commitment, Responsibility, Oversight - case study}

In their presentation on the design, construction, and commissioning of four science buildings at the University of Washington, Heinz and McCray (1996) describe details of the commissioning team's commitment, responsibilities, and oversight.

The four science buildings were well along in design before it was decided that the complexity of each was such that concern for successful start-up and operation thereafter began to mount. This evolved primarily from less than satisfactory experiences over the past ten years with other new buildings on the campus, some of which took as long as three years for staff to wring out various nagging problems, residual from the design or construction process. In most cases the maloperation of systems or equipment had a significant impact on the building occupants; either in terms of comfort and convenience or in terms of laboratory services and systems hampering or disallowing research projects to continue until corrections had been made. The impact fell upon not only the occupants but also the maintenance and operations staff who bore responsibility, when occupancy occurred, for operation of the facility.

Over a period of time, a short time in some cases, patience wore thin and attitudes became frayed when systems did not perform reliably as intended. This is not an emotional environment that can be allowed to continue. It is not an emotional environment that should be allowed to occur in the first place.

- Physics: Point-to-point tests are time consuming and boring. However, they are critical and when not done more often than not became the problem. Nonetheless, the building turned out well, with one exception.

The exception was the process cooling water system-a chiller and piped distribution system intended solely for connection of process and equipment year-round cooling requirements. Budget restrictions precluded commissioning this system. Nearly a year after completion of the building we are just about to resolve all of the difficulties encountered in startup and ongoing operation of the system. Even though the contractor acknowledges responsibility for some of the difficulties, because corrections are now being made long after the contractor has demobilized and left the job-site, it is very difficult to gain the contractor's undivided attention and to complete required corrections.

- H-Wing: The VAV fume exhaust systems were extremely difficult to commission. The primary reason was determined to be the sensing methodology provided to establish the variable air volume settings-a through-wall sensor that is influenced by too many random air streams and is also sensitive to changes in air temperature. The solution is to replace all through-wall sensors with sash-position sensors. This was not determined until after a great deal of time and effort had been expended by all parties. It became a "bitter" lesson leamed, but one that 
will not be repeated at the University of Washington. And, that is another aspect of what commissioning is all about-not only making the building fully operational, but also finding design flaws that must not be repeated in future projects.

Another lesson learned is that it is all too easy for the commissioning agent and owner's staff to get too involved with solving problems. Inherent curiosity and desire to succeed leads to this anomaly. A strict discipline must be developed that results in turning problems discovered immediately back to the contractor and design consultants to resolve. In any event, $\mathrm{H}$-Wing was the UW's first commissioning effort, was the least prepared project for commissioning, and nearly killed the program because of the problems encountered and the design/construction flaws discovered. But that is the very essence of commissioning-discovery-discovery leading to solution and, finally, successful building operation. For a long time the upper administration was concerned that commissioning was causing all of the problems. But the fact is that commissioning was discovering the problems early-on and in large numbers-problems that inevitably would have been discovered long after the contractors and designers were gone which the owners then would have had to correct at great inconvenience to the occupants and great expense to the owner.

Because commissioning became the prime contractor's responsibility, and had to be completed, for the most part, before substantial completion (occupancy), scheduling of commissioning activities was thoroughly incorporated into the construction schedule, and as early as possible in most cases. This provided adequate lead-time for failed components to be replaced without delay to the completion date.

The other problem is a complete commissioning oversight. There are a number of controlled environment chambers (cold rooms) which are specified in the general construction sections of the specifications and installed by other than the mechanical or electrical subcontractors. They were completely overlooked when the commissioning scope of work was developed. Consequently, we are now experiencing a number of operational problems, mostly having to do with control sensitivity. Gradually UW staff are solving these problems, with some help from the responsible vendor. It will take longer this way and is having some impact on the users of the equipment. Next time, commissioning will also apply to such special spaces and other equipment/system provisions which traditionally are carried in the general construction areas of the specifications.

The biggest change from what had been our original approach to commissioning is to require, via the construction contract specifications, the prime contractor (and subcontractors) to be responsible for commissioning all of the equipment, components, and systems in the project, and to schedule and coordinate the subcontractors and vendors accordingly. Further, on large projects the prime contractor is required to include a test engineer to schedule all of the tests, develop test procedures, coordinate testing with all involved, and document results. This has induced a much higher level of quality assurance in the layout and installation of the systems, all of which is to the owner's advantage. Further, by the fact that the owner has made all expectations clear and is willing to pay extra for added performance on the part of the contractors, cooperation is vastly improved and arguments regarding failures reduced to an absolute minimum.

This reduces the scope of commissioning for the commissioning agent from all of the above activity to only the activity of reviewing and approving written test procedures, witnessing and approving equipment and component tests, and witnessing and approving system functional performance tests. A commissioning agent, reporting directly to the owner, is still extremely important in order to ensure the prime contractor (and test engineer) are doing the job intended and required for the proper operation of the building. In the case of smaller projects, trained UW staff will perform in the role of the commissioning agent ...

\section{Summary}


The University of Washington has now had extensive experience with several approaches to commissioning and has learned a great deal in he process. The value of commissioning is no longer in question. It is a demonstrated fact. Accordingly, three buildings currently under construction have refined commissioning programs included in the contract documents. The EE/CSE project is by far the most refined to date. An extraordinary amount of time was spent working with the design team to consider all commissioning requirements and develop the construction documents accordingly.

\subsubsection{Operations and Maintenance Hand-off}

The Operation and Maintenance (O\&M) organization has the long-term responsibility for the facility's function and performance. All systems should be commissioned to prove proper operation before acceptance by the owner and the hand-off to the O\&M team takes place. Experience has shown that systems not thoroughly commissioned before acceptance become the owners', and eventually the O\&M team's, problem. As Heinz and McCray (1996) point out, "[the] Physical Plant [O\&M] staff [will] have ... to pick up the pieces for what appear[s] to be a dysfunctional building-dysfunctional only because it was not commissioned." [Flaherty and Gracilieri, 1994; Heinz and McCray, 1996; Rizzo, 1994]

\subsection{Installation Verification}

\section{Energy Efficiency and Installation Verification}

The installation verification phase of commissioning insures that installed equipment is in compliance with building codes, design-basis documents, and safety standards. This commissioning phase includes thorough reviews of equipment submittals, construction inspection, and other "static" reviews. The appropriateness of the equipment or system to accomplish its intended function is determined by comparing the installation with the design-basis documents, which includes an equipment submittal log. Connections to utilities, service sizing, written standard operating procedures, and preventive maintenance programs are also verified. [Flaherty and Gracilieri, 1994]

\subsubsection{Submittal review}

The installation verification phase of the commissioning plan includes a comprehensive submittal review program and an extensive submittal log, outlined in the design-basis document set. The specifications must also fully outline the participation of each design consultant and the prime and sub contractors in the submittal review process. Attention to detail at this early stage of the construction process will help avoid future problems that could result from laboratory VAV fume hood and supply air systems complexities. [Heinz and McCray, 1996]

\subsubsection{Construction inspection}

After equipment submittals have been reviewed, the next step in the commissioning process is to verify that the system is installed according to the bid-set documents, including plans and specifications. All too often, specifications are conveniently overlooked during construction. This is unfortunate because much valuable information in the specifications simplifies a contractor's work. The verification of proper equipment installation is very important in a laboratory facility so that incorrect installation can be ruled out as a cause of equipment failures, which typically result from incorrect usage or procedures by personnel who work in the laboratory. Major failures are rarely related to inadequate equipment performance or incorrect equipment design or selection. Therefore, both pre- and post-installation inspections should be conducted to confirm correct installation. [Flaherty and Gracilieri, 1994; Farquharson, 1988; Measurement and Verification (M\&V) Guidelines for Federal Energy Projects, 1996] 


\subsubsection{As-built conditions}

As-built drawings are produced by the contractor and compared with the original design documents to identify any changes made during installation that could affect the laboratory's performance. Discrepancies between the original bid-set drawings and the installation must be corrected prior to laboratory start-up and occupancy. Problems can be as minor as an incorrectly marked pipe or as major as a motor supplied with the wrong voltage. Ideally, the "as-built" verification is performed several times during construction, so that conflicts between design and installation can be resolved with minimal effect on the project schedule. [Flaherty and Gracilieri, 1994]

\subsubsection{Test reports}

According to Coogan (1994), "Test report forms are essential to successful commissioning. They help ensure that each piece of similar equipment is tested the same way. They serve as the final record of system operation." A comprehensive specification includes different forms for each type of equipment and system. Printing and distributing these forms well in advance of testing will speed the process and allow time for questions and clarification about each form.

\subsection{0perational Assessment}

\section{Energy Efficiency and Operational Assessment}

Operational assessment commissioning starts when the first device or piece of equipment is powered up. During this commissioning phase, fundamental operations such as fan rotation, valve function, and alarm systems are checked for conformance with design documents. The most valuable tool for assessing the facility's operation is the EMCS. Commissioning with the EMCS can lead to the discovery of component failures and system malfunctions. In addition, efficient commissioning requires that team members decide how to work together during operational testing. For instance, it is very important that a control contractor know how much work has been completed and what is expected to be completed in conjunction with a balancing contractor. Wasted time and "finger pointing" result when work is not coordinated. One of the most important indicators of equipment function is calibration. Operational assessment is a way to document equipment function(s) and determine the required frequency of calibration. Written calibration procedures should be included in the laboratory design specification, and all equipment must be calibrated prior to acceptance. [Flaherty and Gracilieri, 1994; Heinz and McCray, 1996; Coogan, 1994]

\subsubsection{EMCS operational assessment}

The EMCS workstation is widely recognized as the best tool for performing a wide range of laboratory operational tasks. However, it is not yet recognized as a useful commissioning tool. Unfortunately, the EMCS workstation is usually either not on the job site when the commissioning team is testing the laboratories, or it is located inconveniently for start-up and testing work. VAV laboratories' acceptance tests require monitoring of numerous variables at once with precise timing. The control contractor should have the EMCS workstation available to the commissioning team for logging data while the team manually performs and observes laboratory tests. A mobile workstation in the form of a lap-top computer will facilitate laboratory testing. [Coogan, 1994] According to Coogan (1994), the following operational assessment procedure, which involves coordination between the building contractor and commission team, generally works well:

Start up all control equipment before the balancer starts. The controls have to be "operational" without necessarily being "tweaked." All of the i/o [input and output] 
points work, the sensors register, and the actuators are effective over the whole operating range. Everything is wired and named correctly. Also, the control sequences must be completely functional. Everything is programmed and checked out.

The control contractor should not put any effort into calibrating flow sensors or adjusting the minimum or maximum flows of the room. It is a waste of time to do that without the balancer, because he/she is obliged to do it anyway.

Similarly, the contractor may choose not to carefully tune the flow control loops before the balancer calibrates the system. The trade-off between stability and speed that comes up every time a loop is tuned works differently during sensor calibration than it does during laboratory operation. When the balancer is calibrating the system, stability is valued over speed to a much greater extent than when the building is operating. Consequently, efficient balancing suggests tuning the loops for very stable operation and not tweaking them for maximum performance until the balancer is done calibrating the sensors.

Balancer trained to adjust $D D C$ system. The term "testing, adjusting, and balancing" can be a holdover from earlier types of HVAC systems. On many jobs today, the balancer does very little "adjusting" of the flow control systems. Frequently, the system is tested and left to the temperature control contractor to "adjust" until the control system reading matches that of the balancer.

On the other hand, there are many balancers who are completely capable of "adjusting" a DDC system to calibrate it.

This presents the team with a choice. They can either send a control technician around the building with the balancer, or they can train the balancer to adjust the control system. Either way works, as long as everyone knows the plan and prepares for it. If the balancer does not get the training needed, efforts to adjust the system may create more work than they accomplish. If the temperature control contractor does not plan to have a technician available, the job may be held up by a lack of personnel.

Worse than either of these is to have the balancer or commissioning agent going around the building alone measuring flows, taking notes, but not adjusting anything. $\mathrm{He} / \mathrm{she}$ might hand in a report full of discrepancies, but there is no verification of a problem, no joint resolution, and no teamwork. Worst of all is to have several different parties doing that in an uncoordinated fashion. It sounds unbelievable, but it can happen. These are the jobs where acceptance testing drags on for years or is never completed to the owner's satisfaction.

\subsubsection{Operational testing}

Generally, Farquharson (1988) advises that laboratory operational testing should include the following operational tests to evaluate the laboratory's environmental performance:

- Air flow, volume, and distribution test;

- Temperature test;

- Humidity test;

- Fume hood face velocity recovery test; 
- Main air supply and make-up supply volume and reserve capacity test;

- Lighting level test; and

- Laboratory Pressurization Control test.

\section{- Fume hood testing}

The balancing contractor performs fume hood face velocity tests and ensures that fume hood flow is correct, using flow measurements in the exhaust dust or a grid of face velocity measurements or both. Local face velocity sensor calibration is also verified. Once the balancer is assured that a fume hood has the correct flow and face velocity values, it is necessary to check the hood's dynamic response to sash movements. The response to sash movements is the control contractor's responsibility; the balancer or commissioning agent is responsible for verifying the hood's dynamic response. Coogan (1994) suggests that, "It is most effective if the control contractor sets [the hoods] up alone and accompanies the balancer when the performance is verified." [Coogan, 1994]

\section{- VAV system testing}

Prior to its acceptance, the VAV laboratory system must be tested to check how well the fume hood, supply, and general exhaust dampers track. The system's control repeatability should be limited to \pm 5 percent of full range flow. All damper and control valves should be cycled sufficiently to detect any transducer drift off zero, span shifts, or inconsistent operation (usually a result of inferior mechanical linkage). [Richardson, 1994]

\section{- Alarm testing}

Alarms are an extremely important feature in a laboratory control system. Typically, alarm systems are tested by inputting set point values that exceed safe operating parameters and monitoring the subsequent reports. Some alarms report to separate safety subsystems; other alarms report to the central EMCS console(s). An alarm associated with the EMCS workstation should an generate a visual and an audible report. The most important alarms should "take over" the EMCS workstation screen and require acknowledgment so that they cannot be missed or ignored. [Flaherty and Gracilieri, 1994; Coogan, 1994]

The best alarm test initiates an alarm that must be verified at a specified reporting station. A sequential group of alarms can be tested by turning off equipment such as exhaust fans. However, if an individual alarm point is wired or addressed incorrectly in this group, it may not be detected or go off at its correct level. An alarm must trip when a flow is unsafe, not just when a device fails. The EMCS provides a number of convenient ways to override controls and create an alarm condition. Each alarm must be tested and documented during laboratory commissioning. Coogan (1994) stresses, "Spot checks are not suitable for safety alarms." [Flaherty and Gracilieri, 1994; Coogan, 1994]

\section{- Filter testing}

Filter integrity tests are performed during operational assessment. Filter tests are particularly important in laboratory HVAC systems that include high-efficiency particulate air (HEPA) filters. Flaherty and Gracilieri(1994) reminds us that, "Although most suppliers of HEPA filters include test data (efficiency, static pressure loss at a specified flow rate), damage to the filter media may have resulted during shipment. Also, by performing an in situ test, the integrity of the filter, frame, and housing are evaluated as a unit." 


\subsubsection{Operational Testing - case study}

Rizzo's case study on the commissioning of a hospital laboratory (1994) explains the steps in the commissioning process, problems encountered, and the benefits of re-certification after the laboratory was opened. This project involved a building expansion followed by the renovation of an existing laboratory.

\section{- Commissioning}

The first stage in the actual start-up of the systems was to determine that the main air-handling equipment was performing as required. This was done using the normally prescribed methods. Each fan was tested for performance and compared to its fan curve. Control devices were tested and verified using trend logs, thermometers, flow meters, etc. Heating and cooling systems, both primary and secondary, were balanced and tested.

From there, it was a matter of proceeding methodically from room to room to verify the remaining control points. With 439 supply and exhaust terminals and 54 fume hoods, it was a daunting task. As the rooms were certified complete by the construction manager, the verification group, made up of the owner, engineer, and contractor, would verify the work using the method described in the protocol. Tracking this work was done on the construction manager's log sheet...

Room-by-room verification was performed at three different levels: (1) room temperature controls, (2) central communication network, and (3) room airflow controls, including fume hood certification. Most of these levels were done concurrently where possible. For example, the temperature and aifflow of an office or similar space would be checked at the same time.

\section{- Problems}

False starts were the rule for the first few verification attempts. Even though the construction manager declared an area complete, the verification group would inevitably find an error in wiring, network address, programming, or air balancing. Sometimes the problems had a combination of causes. During this process, a large number of failures were noted with the hood damper motors. These were all replaced. During this first pass at commissioning, the system failure rate among the DDC components ran at approximately 30 percent.

The second round of verification was more successful. Failure rates fell to approximately 10 percent at the room level. At this point, no attempts had been made to verify any fume hoods. The team was still working to accomplish temperature stability at the room level, which was done in short order.

One fume hood was verified as working properly. This hood, located on the ninth floor of the building, was considered representative and was used as a "testing" mock-up. Since most of the systems were functioning well for volume and temperature control at the room level, it was felt that this hood could be used to test the control loops for the local room control system. Using trend logs and visual observation, we were able to refine the timing and the accuracy of the controls, limiting hunting and the effects of other system variations.

For example, the controls used were of the "step and wait" type. We found that with two-way valves on the reheat coils, the water temperature in the loop on the floor would cool due to the lack of continuous flow. This delayed the arrival of hot water and caused the controls in the room to overshoot to full heat. When the hot water finally arrived at the coil, the room temperature would rise quickly, causing the control to go to full cooling.

This "rocking" phenomenon was resolved by adding small bypasses in the reheat piping loop on each floor, thereby maintaining loop temperatures, and by removing the water temperature 
compensating feature from the hot water system. The water temperature now circulates through the system at 170 degrees minimum. Done at the cost of standby losses, system performance was greatly improved.

While trends were being studied on the ninth floor hood, attempts were made to verify the communications network. This turned out to be the most difficult portion of the commissioning process. the room controls generally were working, but communication with the controllers from the central system was intermittent at best. Many theories were fonwarded as possible reasons for the difficulties. However, most of the problems were caused by loose or improper wiring and by improper network addressing. Although it sounds simple, these problems caused the commissioning process to take one year.

As strenuous as this was, the perseverance of the commissioning team paid off. The network was finally signed off one year after it was first tumed on. Given this setback, it was imperative that the hoods be verified as quickly as possible. We decided to verify the hoods locally first and then verify the alarms at the central network. This allowed us to continue commissioning the building while repairs were completed on the network.

Following the lessons learned at the ninth floor "testing" mock-up and using the verification protocol, the 54 fume hoods were verified and declared working. As this verification was being completed, the network repairs were finalized. The last step in the commissioning process could now proceed, i.e., to verify the fume hood alarms. This was done within two weeks.

At the end of the commissioning process, the DDC component failure rates had dropped to less than 1 percent.

\section{- Recertification}

Since the building opened, the hood/laboratory systems have been recertified twice using the protocol as the guideline. It has been found that the DDC component failure rate remains at less than 1 percent of the total system components. The system is reliable and energy efficient and provides a safe working environment for the laboratory occupants.

\section{- Lessons Learned}

Enough time had passed between the purchase of the system in the expansion project to the renovation project that a new generation of control devices became available. Working again with the same team from the expansion project helped avoid the earlier start-up problems. By comparison, the commissioning of the old building's new system took only four months following the same procedures as those used in the expansion project.

This system consolidated all terminal electronics onto a single board, allowing for a cleaner installation and less time spent diagnosing problems. The network addressing of each box was done via switches in lieu of software. This allowed for a more positive address and avoided the problems caused by duplicate address on the same local area network (LAN). LANs were limited to one floor, simplifying diagnostics and limiting problems to a more easily defined area. Each LAN was then connected to a host computer for central monitoring.

Another lesson learned-not as part of the commissioning process but later during recommissioning - was the operational differences between the types of control at the fume hood. The device used for measuring the face velocity at the hoods on the project was a pressure differential type. This was in lieu of the sash position sensor. During the initial selection, it was felt that both would serve our application well. At the time, the team actually preferred the sash position sensor due to the perceived potential of the bypass sensor to become blocked. 
Fortunately, the bypass sensor was used. This choice was finally made by default, since the low bidder used that sensor. Going back to certify the hoods, the technicians noticed that a number of hood sashes were left open. Questioning the researchers about this, it was discovered that a number of the occupants do low-level radioactive work in the hoods. The work requires the use of a vertical acrylic plastic shield placed at the sash, forcing the sash to remain open. Airflow readings taken around the free area of the hood with the shield in place showed the volume reduced from what it should have been with an open sash. However, the velocity of the air at the instrument showed that the setpoint was satisfied. Further readings showed that the bypass-type sensor automatically adjusted for the occlusion caused by the shield. Also, the air velocity at the free openings on either side of the shield remained at $100 \mathrm{fpm}$. If sash position sensors had been used in this case, the velocities and volumes would have been much higher. A sash position sensor cannot adjust for this type of blockage. This finding caused the hospital to request that all future hood control systems be fitted with bypass sensors, including those in the retrofit of the old building.

\subsubsection{Operational balancing}

Operational assessment includes balancing of air and heat transfer fluids, e.g., hot and chilled water. This operational balancing insures design air distribution and flow throughout the laboratory and the supply air temperatures necessary to maintain design conditions. Adequate amounts of heat transfer fluids must be verified from the facility's central plant and utility services to and from boilers, chillers, and cooling towers. Proper connections to the equipment are checked at the point of use during balancing. [Flaherty and Gracilieri, 1994]

\subsubsection{Operational calibration}

Operational calibration assesses the laboratory systems and set points according to the design requirements and sequence of operations to determine proper system responses. Damper and control valves, alarms, and safety devices are verified using automated or manual simulation. Deviations from operating set points are observed and documented. During this phase of operational assessment, the range, span, and zero-set of analog output devices is determined. The EMCS is not fine tuned. Operational calibration verifies that a valve that is supposed to close during set point deviation actually does so. The rate of the valve's operation is verified in the Performance Measurement phase of commissioning, discussed below. [Flaherty and Gracilieri, 1994]

\subsubsection{Operational Assessment Process}

Coogan, in (1994) describes the general approach to operational assessment of a VAV laboratory.

...the commissioning agent usually has a plan to bring the equipment into operation in a certain order.... An example is the case of fume hood and room supply airflow. The hoods may not work properly until the room supply is stable and the diffusers are balanced, or they may not work if the pressurization is way off. On the other hand, the room air controls are driven directly by the hoods, so the room may not work until the hoods are right.

...It is possible to get one system working roughly ...then come back and fine tune the first system without losing the work on the second. The goal is to avoid tweaking the same component twice.

The approach described next is compiled from experiences with various jobs. Successful teams often follow roughly this sequence:

1. fume hoods 
2. room supply and exhaust flows

3. room pressurization

4. alarms.

There is plenty of room for variety in the sequence... Many find it more efficient to separate the tasks of calibrating sensors from documenting room performance....

The flow controllers do not work without the fan; the fan control is affected by the operation of the flow controis.

Coogan recommends the following method for operational assessment:

1. Start up flow control equipment, but do not adjust. The flow control equipment only needs to be minimally functional to get to the next step. The damper has to move, and the sensor has to respond and be reasonably accurate. Putting off the detail work helps make sure it is not done twice.

2. Set up and adjust fan controls. The first step is to set the fan speed to get the required flow. Then select the duct static pressure setpoint according to the actual pressure at design flow. This step is usually performed by a representative of the owner, such as the commissioning agent or air balancer. The mechanical contractor or the design consultant may oversee the work.

3. Calibrate and document flow measurements. This was already described.

4. Fine tune the flow controls. It is best to fine tune the flow controls after the sensors are all calibrated. This is a step the contractor does alone, and then the commissioning agent verifies and documents it.

5. Test and document dynamic performance. Some of the testing is described here.

\subsubsection{Accurate Airflow Sensing}

Regarding airflow sensing, Coogan (1994) points out that:

Supply and exhaust duct sizing is sometimes controversial in VAV laboratory jobs. All kinds of buildings have supply and exhaust ducts, and mechanical consultants are used to sizing them for a variety of issues (noise, air volume, energy consumption, construction cost, etc.). The special issue in VAV laboratories is that the ducts must also be sized to accommodate highly accurate airflow sensing. Typically, this means that engineers must use a smaller cross section than they otherwise would in order to get velocities high enough for accurate measurement. Frequently, a short section of small duct is used for the measurement station with transition pieces at each end to mate with a duct size preferred for other considerations.

This is a major commissioning issue and a great example of the need to get the whole team communicating as soon as possible. If the control contractor does not check the ducts until they are built, it is extremely expensive to modify the sheet metal. If the control contractor gets his/her requirements in before the ducts are fabricated, it saves a lot. If he/she gets them in before the ducts are designed, it is less work for everyone (consultant, duct designer, sheet metal contractor, control consultant, commissioning agent, and, ultimately, the owner). 


\subsection{Performance Measurement}

\section{Energy Efficiency and Performance Measurement}

Laboratory facilities are unique environments that require dynamic operation of various interactive systems, in contrast to standard office buildings. These dynamic, interactive systems can include variable air volume (VAV) supply, fume hoods, and exhaust systems that require positive and negative pressure differentials between laboratories and support spaces. Therefore, commissioning should evaluate and measure the entire facility's performance. The Performance Measurement phase of commissioning assesses the system's actual performance and functioning status and compares the results with the design specification. Baseline performance data are compiled to verify the design performance predictions and to assist in the efficiency assurance commissioning phase, described in the next chapter. All critical components are tested to determine their performance, suitability, and reliability. "Stress conditions" are created to determine the laboratory systems' control ranges. A fundamental concern is to determine the facility's stability and ability to recover from periods of transition and emergency. Therefore, control sequences, room pressure control, and fume hood containment systems are closely and thoroughly verified. [Heinz and McCray, 1996; Flaherty and Gracilieri, 1994; Farquharson, 1988]

\subsubsection{Design compliance}

Before a building is turned over to the occupants, baseline data are collected that consist of temperature and humidity profiles, pressure differentials, and other performance criteria stipulated in the design specifications. All performance measurements must meet or exceed the criteria defined during the project's programming and design stages. During data collection, all pieces of laboratory equipment should be operating so their effect on the laboratory's measured performance can be determined. Laboratory fume hoods should be rechecked for design air flow as part of performance measurement commissioning. [Flaherty and Gracilieri, 1994]

\subsubsection{Dynamic measurements}

Dynamic measurement tests for correct air flow volume, response speed, and stability are performed to establish minimum, median, and maximum levels of laboratory performance. The laboratory environmental conditioning should meet design criteria with no more than a 5 percent variance from the set points. These performance measurements need to be made while the fume hoods and air supply and exhaust devices are functioning under conditions similar to those of actual laboratory occupancy. These tests should be conducted several times to ensure repeatability. The commissioning team should be reminded that laboratory configurations include many air-flow control devices, some of which operate independently of the EMCS. Individual fume hood exhaust controllers interact with each other and with main VAV supply and exhaust systems. Grossman (1995) stresses that, "...system comparisons should include a test focusing on these interactions (intersystem stability), using a laboratory configuration with multiple fume hoods on a single manifold." Before the dynamic measurement tests are complete, laboratory safety levels under emergency conditions must be measured. These tests should compare fume hood containment and room pressurization under various power loss conditions. Finally, the performance measurement commissioning phase addresses the issue of system noise, including all device noise characteristics and resulting sound pressure levels in the laboratory. [Grossman, 1995; Farquharson, 1988]

\subsubsection{Measuring equipment}

Farquharson, in (1988) describes correct procedures for using measuring equipment in the commissioning process. 
The definitions of the various measuring apparatus are given in the definition section, and uses are indicated in the protocols for performance testing.

Every measuring device is a comparison element. Comparison is made against a reference standard, in the process known as calibration. Calibration needs and procedures also vary, therefore every time a piece of equipment is used during the validation procedures, compliance with calibration requirements is to be verified before starting. Lack of adequate documentation could in many cases render the validation procedure invalid.

Adequate knowledge of the operation capabilities of the system is also fundamental. Inadequate location for sampling processes, such as badly placed particle counters, can render confusing and inaccurate results. A comprehensive training program should be in place for new operators and a minimum of qualifications should be demanded prior to acceptance of a candidate.

\subsubsection{Performance challenge}

A challenge of the laboratory's environmental conditioning system is integral to the performance measurement commissioning phase. Farquharson (1988) states the concept concisely:

In a ... [commissioned] system, output parameters, aside from being equal or better than the original design parameters, must be maintained continuously during environmental control system operation. To determine this, the system must be challenged or put in situations representing the possible standard and non standard operating conditions that may be encountered during everyday operation. The idea of challenging the system under unlikely but possible conditions is to determine the degree of change in the environmental parameters, and [the system's] recovery capabilities. A fundamental aspect of the ... [commissioning] process is to substantiate the constant and sustained operation of every component of the environmental control system at all times within the specified parameters. The testing and measuring procedures of environmental control parameters are universal; nevertheless, every system is unique and creates a need for specific challenges to assure that system's proper and continuous operation. The type of system will affect the testing methodology.

\subsubsection{Fume hood containment verification}

A fume hood's containment must be verified during the dynamic performance measurement commissioning phase. This dynamic containment performance may be defined in terms of a measured response time, or it may be defined in terms of containment of vapors under specified conditions. Response time measurements are required for each fume hood because of the interaction of dedicated fume hood velocity controllers, as noted above. However, containment tests may only be required for some representative sample of hoods because of uniformity of the design and installation. [Coogan, 1994; Rizzo, 1994]

The following fume hood containment criteria were developed for design specifications from meetings of five manufacturers of fume hood control and monitoring devices and have been repeated here, as presented by Rizzo (1994) in an analysis of a research building and hospital construction and renovation project.

- Constant fume hood face velocity should be maintainable within a tolerance of 10 percent given any operating condition. 
- The reaction time for the controls must be within 30 seconds from minimum to maximum.

- Control could be either bypass sensor type or sash position sensor type.

- Hood-mounted displays should be simplified to provide status lights indicating "danger," "caution," "safety," and "high" velocities. Meters indicating actual velocity were considered unnecessary, as was manual adjustment of hood velocity. an override switch was provided for emergency use, and an audible alarm would indicate low velocity.

- The hood alarms and overrides were to be centrally monitored via the hospital's 24hour computer monitoring system.

- The hood system should be of the same manufacture as the room control devices.

- Room pressurization would be accomplished using air volume tracking in lieu of differential pressure devices.

- All control devices would be of the pressure independent type.

\subsubsection{Fume Hood Performance measurement example}

Grossman (1995) recommends the following for performance testing of laboratory air flow systems:

This type of performance comparison should measure accuracy, stability, tumdown, and response speed of the system in the following ways:

- $\quad$ Aifflow accuracy should be checked by measuring the airflow volume and velocity of the fume hoods and aiflow related devices.

- Fume hood face velocity should be checked in the duct with sashes open at the $20 \%, 50 \%$, and $100 \%$ positions.

- Airflow volume of the fume hood should also be checked with the sash fully closed to verify the minimum low value (turndown) of the fume hood. (For optimum results, this test should be repeated with various inlet pressures.)

After a fume hood sash is moved to the fully open position, response time for an aiflow control system is generally defined as the time it takes for the aifflow to reach -- and stay within -- $\pm 5 \%$ of full volume. For accurate results, response time should be measured simultaneously with room pressure by generating a variety of air volume changes, supply-and exhaust-duct static pressures, and duct pressure losses, along with single and multiple simultaneous movements of fume hood sashes.

While these tests are underway, it is important to measure the airflow of fume hoods and room pressurization in both adjoining rooms, monitoring and recording the maximum "overshoots" and "undershoots." This gives a fairly accurate measurement of the stability for individual airflow controllers as they respond to step changes from other controllers.

The flow sensors used in these tests need a minimum accuracy of $\pm 2 \%$ of the signal. Datalogging from these sensors should occur at intervals of $20 / \mathrm{sec}$ to correctly assess response times, while 
the room pressure sensors need a minimum accuracy of $0.5 \%$ to measure pressure between the laboratory and adjoining room or rooms.

\subsubsection{Room pressure control verification}

When all subsystems have been performance tested, the laboratory room pressurization performance is verified. There are specific criteria for room pressure response speed and accuracy, which are relatively easy to verify. The fundamental safety issue is verification of air motion at the point of entry into the laboratory. This air motion can be stated in terms of the differential pressure and the direction of air movement. Each laboratory is checked for proper pressurization; "spot checks" are not advised. VAV laboratories present a special set of problems; correct room pressure control must be verified throughout all volumes of supply and exhaust air flows. The EMCS can greatly simplify room pressure control verification. Set points can be easily.manipulated to force the conditioning system through all air flow volumes, and the results can be monitored and logged over time. Using visual indications of laboratory pressure differential are not recommended because the magnitude of changes is unknown, and brief changes will be missed. [LBNL, 1996; Coogan, 1994]

\subsubsection{VAV Flow Tracking $C x$ - case study}

Richardson in (1994) describes the steps he took in commissioning a flow tracking system in a VAV laboratory.

\section{- Testing and Commissioning}

1. For each fume hood, verify by pitot-tube traverse that the aiflow is between 100 percent and 110 percent of design. (The design aiflow is the volume of exhaust that produces the required face velocity at sash opening.)

2. For each laboratory balance, the supply aiflow should be between 90 percent and 100 percent of design. Avoid any direct velocity from the ceiling diffuser toward the fume hoods. Verify airflow measurements by establishing correction factors from pitot tube traverses.

3. Balance the general exhaust system aiflow to between 100 percent and 110 percent of design. When flow hoods are used to establish general exhaust, care should be taken when reading multiple grilles that the flow hood does not add restriction forcing the air to another grille.

4. After the correct airflow for the hood has been established and all exhaust and supply air systems have been balanced, verify that the face velocities do not fall below 80 percent of the design face velocity at any one point.

Face velocities shall be taken at equal areas over the cross section of the sash opening. (As specified in the $A A B C$ National Standards, the maximum distance between the center points of the equal areas shall not exceed 6 inches.) The face velocities shall be measured using an electronic rotating vane anemometer with a 4-inch fan, accurate to $25 \mathrm{fpm}$.

\section{- Tracking the Laboratory Control}

Track the laboratory in the following manner by establishing aifflows for each valve:

1. All hood sashes open, minimum cooling.

2. All hood sashes closed, minimum cooling. 
3. All hood sashes closed, maximum cooling.

4. Note velocity at the door during the setup of items 1 through 3 in this list.

5. Identify the point at which the hood face velocity falls below its target velocity. (Any time a minimum cfm is set, the hood will track linearly until it reaches the minimum airflow point; then the face velocity will increase.)

6. Indicate flows on a drawing of the laboratory at maximum and minimum conditions and velocities recorded at the door.

7. Track the entire exhaust system from full flow to minimum flow by observing the static pressure entering the most remote hood exhaust valve.

8. Track the entire supply system from full flow to minimum flow, observing the static pressure entering the most remote supply valve.

9. Verify stack velocity to be constant or to exceed the minimum stack velocity requirement.

\subsubsection{VAV Constant Volume Offset Cx - case study}

Atwell and McGeddy in (1989) give details of the commissioning and startup of VAV systems in a laboratory retrofit project.

The labs were maintained at constant negative pressure with a constant volume offset. Measurement and air flow was as follows:

1. Air flow from the fume hood was measured by a multipoint averaging velocity sensor and signaled to the DDC panel.

2. Space temperature was read by a temperature sensor and a signal from the DDC panel controlled the VAV terminal damper, varying the amount of conditioned air flowing into the lab. The air velocity sensor in the VAV terminal was used to allow the DDC system to calculate the exact air quantity.

3. Makeup air was then supplied to the room according to the formula:

Makeup air = Exhaust flow-Conditioned air flow-Auxiliary exhaust - 200 CFM.

4. The DDC system sent a signal to the makeup air VAV terminal for the damper to control the amount of makeup air flowing in to the lab. Again, the air velocity sensor in the terminal was used to calculate the makeup air quantity.

5. If the hoods were operating at full capacity and the space required additional cooling, thereby creating a situation requiring more supply than exhaust, the VAV terminal on the return air system was opened to maintain the 200 cfm differential.

...all flow in to and out of the room was measured. This control scheme provided a closed loop and positive method of control. VAV terminal dampers are controlled directly through the DDC system with the use of pressure transducers. The multipoint flow sensors in the terminals are used to indicate air flow back to the DDC system. Air flow in each lab is logged by the central processor and can be tracked continuously... The logged data indicates that the offset is being maintained with remarkable accuracy. In some instances the offset is larger than $200 \mathrm{cfm}$, but 
remains constant within a range. This excess air can be attributed to leakage at the VAV terminals.

In summary, the system shows repeatable and precise control. System improvements can be realized through development of lower leakage VAV terminals. The use of DDC VAV terminals is not practical because the cost of the controllers is too high and the boxes can not fail closed but fail in the position that they are in at the time of failure.

\subsection{Efficiency Assurance}

\section{Energy and Efficiency Assurance}

Energy-Efficiency Assurance is a relatively new concept in commissioning. Typically, once the first three commissioning phases (noted above) are completed and a facility is accepted by an owner, the facility is left to operate poorly or efficiently over the remainder of its life, affected only by its maintenance program. Efficiency Assurance commissioning means continuing energy-use monitoring for the facility's life. Determining the laboratory's energy savings is a function of the project's value, the energy-efficiency 'measures (EEMs) installed, and their expected cost effectiveness. Baseline performance is first accurately defined, and the potential to generate energy savings is predicted based on life-cycle cost analyses performed during right-sizing (see Chapter 3). Verifying baseline energy use and post-occupancy conditions validates that energy-consuming systems are operated in conformity with the design-basis documents. Follow-up monitoring, as part of Efficiency Assurance commissioning, involves inspections, spot measurement tests, or continual energy-use measurements. A monitoring interval is established to account for the facility's energy-use profile and installed energy-efficiency systems. Therefore, the monitoring interval varies from project to project. [Measurement and Verification (M\&V) Guidelines for Federal Energy Projects, 1996]

\subsubsection{Baseline energy use}

Energy-use baselining is rarely done as a part of commissioning. Energy-use baseline performance accurately defines the potential to generate energy savings as predicted by life-cycle cost analyses performed during right-sizing (see Chapter 3). Verifying baseline energy use and post-occupancy conditions validates that energy-consuming systems are operated in conformity with the design-basis documents.

Baselining of physical conditions such as equipment counts, nameplate data checks, and verification of proper equipment installation, is determined during the other commissioning process phases. These other commissioning phases also verify that: components or systems operate correctly, have correct energy consumption rates, and have the potential to generate energy savings.

Caution is advised when establishing a new facility's energy-use baseline since it often takes a year or more to be fully occupied and operational. System "shake-down" can take longer than expected. Therefore, the energy-use baseline period can only be estimated prior to construction and may need subsequent adjustments. [Measurement and Verification (M\&V) Guidelines for Federal Energy Projects, 1996] 


\subsubsection{EMCS and efficiency assurance}

The facility's EMCS greatly simplifies the efficiency assurance. At defined intervals during the facility's life, it is necessary to verify that the installed equipment components or systems have been properly maintained, continue to operate correctly, and generate energy savings. These data can be monitored and logged with the EMCS, and reports can be regularly produced for the facility manager to review.

The EMCS software must be reviewed from time to time because system efficiencies change from use. EMCS software, i.e., control sequences and blocks, can adapt to changing equipment efficiencies but should not adapt so much that good maintenance is avoided or preventative maintenance is ignored. Software reviews can determine the need for upgrading, changing, or adjusting the facility's devices and equipment. EMCS sequence-of-operations reviews help the facility operate at its highest energy efficiency. [Measurement and Verification (M\&V) Guidelines for Federal Energy Projects, 1996; Farquharson, 1988]

\subsubsection{Verification of EEMs}

All EEMs are verified to determine each one's energy savings potential. Verification techniques include the following: [Measurement and Verification (M\&V) Guidelines for Federal Energy Projects, 1996]

- Engineering calculations;

- Metering and monitoring;

- Utility meter billing analysis;

- Computer simulations; and

- Mathematical models.

Baseline energy use, post-installation energy use, and energy (and cost) savings are determined using one or more of the techniques described in the remaining sections of this chapter.

\subsubsection{Estimating energy savings}

As noted in Measurement and Verification (M\&V) Guidelines for Federal Energy Projects (1996), "There are numerous factors that can affect energy savings ... such as weather, operating hours, process loads and heat exchanger fouling." Baseline energy use can be adjusted up or down for factors beyond the control of the facility manager. Stipulated baseline values will need to be checked for reasonableness by comparing (a) total predicted savings (from LCC analyses) to utility energy consumption data or (b) predicted savings to actual conditions observed during monitoring intervals.

\subsubsection{Determining monitoring intervals}

A monitoring interval should take account of many factors such as the facility's expected energy use, installed EEMs, and support personnel available to produce and review energy-use reports. The facility can be monitored continuously or at regular intervals. Periodic reports present energy and cost savings, including measurement-based kWh savings data. [Measurement and Verification (M\&V) Guidelines for Federal Energy Projects, 1996] 


\subsubsection{Periodic report tasks}

The Federal Energy Management Agency (FEMP) report entitled "Measurement and Verification (M\&V) Guidelines for Federal Energy Projects" (1996) describes a procedure for monitoring and data gathering for preparing reports of a building's actual energy use. This procedure is described for federal agency buildings but is appropriate for any laboratory facility:

1. If the [Energy Service Company] ESCO is responsible for metering, it notifies the federal agency that periodic "true-up" activities are scheduled to begin. Periodic true-up metering may be conducted for a period of time required to capture all operating conditions of the projects(s) and/or affected processes. The federal agency can conduct progress inspections of metering, as required.

2. Metering and verification documentation are presented in Regular interval Reports. Federal facility personnel review and approve the report.

3. Federal facility personnel ensure the that report and verification documentation are complete and accurate and in compliance with the contract and approved site-specific M\&V plan. Based on the results, payments during the previous period are reconciled and adjusted in subsequent contract payments [to the Energy Service Company]. This payment reconciliation would not apply if fixed payments are specified in the contract.

\subsubsection{M\&V options}

FEMP (1996) describes various measurement and verification options for retrofit projects. These options are also applicable to new construction.

The Measurement and Verification guidelines contain methods for determining energy savings from energy conservation projects. All of the methods for determining energy savings are based on the same concept; namely, energy savings are derived by comparing the energy usage after the retrofit to what the energy usage would have been without the retrofit (i.e. the baseline). It is relatively easy to measure post-retrofit consumption. However, it is impossible to "measure" what the energy usage would have been, therefore it is impossible to "measure" energy savings. Energy savings can only be determined, based on assumptions about the baseline.

[The FEMP document] contains measurement guidelines grouped into three categories, Options $A$, $B$ and $C$. These options are consistent with those defined in the North American Energy Measurement and Verification Protocols (NEMVP). Three options are provided in order to provide flexibility in determining energy savings. A particular option is chosen based on the expectations of the agency and on site specific features.

The options differ in their approach to the level and duration of the retrofit verification measurements. For instance, Options $A$ and $B$ both focus at the system level, while Option $C$ uses measurements taken at the whole-building, or whole-facility level. Option $A$ uses short term measurements, while Options $B$ and $C$ use continuous or regular interval measurements during the term of the contract.

None of the options are necessarily more expensive or more accurate than the others. Each has advantages and disadvantages based on site specific factors and the needs and expectations of the agency. 
As mentioned above, the M\&V options have been defined to help organize the selection of an appropriate M\&V plan for each ESPC [Energy Savings Performance Contract] project. Table [10.1] is a quick overview of the three options.

Table 10.1

M\&V Options Summary

\begin{tabular}{|c|c|c|c|}
\hline M\&VOption & $\begin{array}{l}\text { Verification of } \\
\text { Potential To } \\
\text { Perform } \\
\text { (and generate } \\
\text { savings) }\end{array}$ & $\begin{array}{c}\text { Verification of } \\
\text { Performance } \\
\text { (savings) }\end{array}$ & $\begin{array}{c}\text { Performance } \\
\text { Verification } \\
\text { Techniques }\end{array}$ \\
\hline $\begin{array}{l}\text { Option A } \\
\text { Verifying that the measure has } \\
\text { the potential to perform and to } \\
\text { generate savings }\end{array}$ & Yes & Stipulated & $\begin{array}{l}\text { Engineering } \\
\text { calculations } \\
\text { (possibly including } \\
\text { spot measurements) } \\
\text { with stipulated } \\
\text { values }\end{array}$ \\
\hline $\begin{array}{l}\text { Option B } \\
\text { Verifying that the measure has } \\
\text { the potential to perform and } \\
\text { verifying actual performance by } \\
\text { end use }\end{array}$ & Yes & Yes & $\begin{array}{l}\text { Engineering } \\
\text { calculations with } \\
\text { metering and } \\
\text { monitoring } \\
\text { throughout term of } \\
\text { contract }\end{array}$ \\
\hline $\begin{array}{l}\text { Option } C \\
\text { Verifying that the measure has } \\
\text { the potential to perform and } \\
\text { verifying actual performance } \\
\text { (whole-building analysis) }\end{array}$ & Yes & Yes & $\begin{array}{l}\text { Utility meter billing } \\
\text { analysis, possibly } \\
\text { with computer } \\
\text { simulation }\end{array}$ \\
\hline
\end{tabular}

FEMP. 1996

\section{- Option A}

Option $A$ is a verification approach that is designed for projects in which the potential to perform needs to be verified, but the actual (sic) [energy use] can be stipulated based on the results of the "potential to perform and generate savings" verification and engineering calculations. Option $A$ involves procedures for verifying that:

- Baseline conditions have been properly defined;

- The equipment and/or systems that were contracted to be installed have been installed;

- The installed equipment components or systems meet the specifications of the contract in terms of quantity, quality, and rating;

- The installed equipment is operating and performing in accordance with the specifications in the contract and meeting all functional tests; and 
- The installed equipment components or systems continue, during the term of the contract, to meet the specifications of the contract in terms of quantity, quality and rating, and operation and functional performance.

Option $A$, therefore, enables the contracting parties to confirm that the proper equipment components or systems were installed and that they have the potential to generate the predicted savings. Achieving this level of verification is all that is contractually required for certain types of performance contracts. For example, baseline and post-installation conditions (e.g., equipment quantities and ratings such as lamp wattages, chiller $\mathrm{kW} /$ ton, motor $\mathrm{kW}$, or boiler efficiency) represents a significant portion of the uncertainty associated with many projects.

Verification of the potential to perform may be done with inspections and/or spot or short-term metering conducted right before and/or right after project installation. Annual (or some other shorter, regular interval) inspections may also be conducted to verify the ECMs' [Energy Conservation Measures] continued potential to perform and generate savings.

With Option $A$, actual achieved energy or cost savings are predicted using engineering or statistical methods that do not involve long term measurements. All end-use technologies can be verified using Option A. Within Option $A$, various methods and levels of accuracy in verifying performance are available. The level of accuracy ranges from an inventory method of ensuring nameplate data and quantity of installed equipment to short-term measurements for verifying equipment ratings, capacity and/or efficiency.

Performance can be quantified using any number of methods, each depending on the accuracy requirements of the contract. Performance of equipment can be obtained either directly, such as actual measurement, or indirectly, such as the use of manufacturer data. There may be sizable differences between published information and actual operating data. Where discrepancies exist, or at least are believed to exist, field operating data should be obtained. These data could take the form of a spot measurement for a constant load application. Short term M\&V can be used if the application is not proven to be a constant load.

Verification of baseline and post-installation equipment should occur at the same level of thoroughness. Either formally or informally, all equipment baselines should be verified for accuracy and for agreement with stated operating conditions. Actual field audits will almost always be required.

\section{- Option B}

Option $B$ is for projects in which:

(a) The potential to perform and generate savings needs to be verified; and

(b) Actual performance during the term of the contract needs to be measured (verified).

Option $B$ involves procedures for verifying the same items as Option A [see bullets on previous page] plus verifying actual achieved energy savings during the term of the contract. Performance verification techniques involve engineering calculations with metering and monitoring.

Option B M\&V involves:

- Confirming that the proper equipment/systems were installed and that they have the potential to generate the predicted savings, and 
- Determining an energy (and cost) savings value using measured data taken throughout the term of the contract.

All end-use technologies can be verified with Option B; however, the degree of difficulty and costs associated with verification increases exponentially as the complexity of the metering increases.

How accurate the energy savings value must be is defined by the federal agency or negotiated with the ESCO. The steps used in measuring or determining energy savings can be more difficult and costly than those used in Option A; however, the results will typically be more precise.

Methods used in this option will involve long term measurement of one or more variables. Long term measurement accounts for operating variations and will more closely approximate actual energy savings than the use of stipulations as defined for Option A. Long term measurements do not necessarily increase the accuracy.

Measurement of all end-use operating systems may not be required if a statistically valid sampling method is used to select a sub-set of operating systems. Examples of this include measurement of operating hours for a selected group of lighting fixtures or power draw of certain motors which have been pre-determined to operate in a similar manner....

\section{- Option C}

Option $C$ is also for projects in which (a) the potential to perform needs to be verified and (b) actual performance during the term of the contract needs to be verified. Option $C$ involves procedures for verifying the same items as Option A plus veritying actual achieved energy savings during the term of the contract.

Performance verification techniques involve utility whole building meter analysis and/or computer simulation calibrated with utility billing data. As such Option $C$ is the one M\&V option that addresses aggregate, coincident demand and energy savings from multiple resources at a single site. Option $C$ also provides procedures for determining and verifying the impact of ECMs which are not directly measurable, or affect loads indirectly, such as increasing building insulation, or installing low-e windows.

Option C M\&V involves:

- Confirming that the proper equipment/systems were installed and that they have the potential to generate the predicted savings, and

- Determining an energy savings value using measured utility meter data taken throughout the term of the performance contract.

All end-use technologies can be verified with Option C. This option would be used when there is a high degree of interaction between installed energy conservation systems and/or the measurement of individual component savings would be difficult. Accounting for changes other than those caused by the ECMs is the major challenge associated with Option $C$-particularly for long term contracts.

\subsubsection{M\&V activities}

FEMP offers the following overview of general procedural steps and submittals.

Expected M\&V activities can be broken down into the following items: 
- Define M\&V requirements for inclusion in the contract between the federal agency and ESCO [Energy Savings Contractor] based on the federal ESPC M\&V guidelines in this document.

- Either before or after the contract is signed, define a site-specific M\&V plan for the particular project being installed once the project has been fully defined.

- Define the pre-installation baseline, including (a) equipment/systems, (b) baseline energy use (and cost), and/or (c) factors that influence baseline energy use. The baseline can be defined through site surveys; spot, short term, or long term metering; and/or analysis of billing data. This activity may occur before or after the contract is signed.

- Define post-installation situation, including (a) equipment/systems, (b) post-installation energy use (and cost), and/or (c) factors that influence post-installation energy use. Site surveys; spot, short term, or long term metering; and/or analysis of billing data can be used for the post-installation assessment.

- Calculate energy savings for the first year of the contract.

- Conduct annual M\&V activities to (a) verify operation of the installed equipment/systems, (b) calculate current year savings, and (c) estimate savings in subsequent years.

\section{References}

ASHRAE, ASHRAE Guideline 1-1989. Commissioning of HVAC Systems: American Society for Heating, Refrigeration, and Air-Conditioning Engineers, 1989.

Atwell, Cindra M. and Donald McGeddy, P.E., P.C. "Variable Air Volume Retrofits for Hospitals and Laboratories." Energy Technology Conference, Proceedings, November 1989.

Coogan, J.J. "Experiences with Commissioning VAV Laboratories." ASHRAE Technical Data Bulletin, Vol. 10, No. 1, Jan. 1994.

Farquharson, G.J. "Design, Installation, Commissioning, Testing and Validation of Pharmaceutical Clean Rooms." IMechE, 1988.

Flaherty, R.J., PE., R. Gracilieri, P.E.; "Documentation Required for the Validation of HVAC Systems." ASHRAE Technical Data Bulletin, Vol. 10, No. 1, 1994.

Grossman, Irwin. "Troubleshooting Lab Systems: Comparing Laboratory Airflow Control Systems: A practical guide to a complex subject." Engineered Systems, September 1995.

Heinz, J.A. and J.M. McCray. "University of Washington Science Buildings" University of Washington Science Building Commissioning. Presented at the Federal Energy Management Program (FEMP) Building Commissioning Demonstration Workshop, January 1996.

Measurement and Verification (M\&V) Guidelines for Federal Energy Projects. Federal Energy Management Program (FEMP), DOE/GO-10096-248, January 1996.

National Environmental Balancing Bureau (NEBB). Procedural Standards for Buildings Systems Commissioning, Rockville, MD, 1993.

Piette, M. A., and B. Nordman. "Costs and Benefits of Utility Funded Commissioning of EnergyEfficiency Measures in 16 Buildings", ASHRAE Transactions, Vol. 102, Pt 1. Feb. 1996. (LBNL-37823) 
Piette, M.A., and B. Nordman, O. deBuen, R. Diamond. "Findings from a Low-Energy New Commercial Buildings Research and Demonstration Project." Energy - The International Journal, Vol. 20, No. 6, 1995: 471-482. (LBNL-36506)

Portland Energy Conservation Incorporated (PECI), Building Commissioning Guidelines, Second Edition Report to the Bonneville Power Administration, November 1992.

Richardson, G. "Commissioning of VAV Laboratories and the Problems Encountered." ASHRAE Technical Data Bulletin, Vol. 10, No. 1, 1994.

Rizzo, S.P., PE. "Commissioning of Laboratories: A Case Study." ASHRAE Technical Data Bulletin. Vol. 10, No. 1, 1994.

Sheet Metal and Air Conditioning Contractors National Association (SMACNA). HVAC Systems Testing, Adjusting, and Balancing, Chantilly, VA, October, 1994.

Sterling, E. and Collett, C., "The Building Commissioning Quality Assurance Process in North America," ASHRAE Journal, Vol. 36, Number 10, October 1994.

Yoder, R. and Kaplan M., "Building Commissioning for Demand-Side Resource Acquisition Programs," Proceedings of the ACEEE 1992 Summer Study on Energy Efficiency in Buildings, Vol. 5, American Council for an Energy-Efficient Economy, Washington D.C., August 1992. 


\section{DISCLAIMER}

While this document is believed to contain correct information, neither the United States Department of Energy (DOE) nor any agency thereof, nor The Regents of the University of California (The Regents), nor the California Institute for Energy Efficiency (CIEE), nor any of CIEE's sponsors or supporters (including California electric and gas utilities), nor any of these organizations' employees, make any warranty, express or implied, or assume any legal liability or responsibility for the accuracy, completeness, or usefulness of any information, apparatus, product, or process disclosed, or represent that its use would not infringe on privately owned rights. Reference herein to any specific commercial product, process, or service by its trade name, trademark, manufacturer, or otherwise, does not necessarily constitute or imply its endorsement; recommendation, or favoring by DOE or any agency thereof, or The Regents, or CIEE, or any of CIEE's sponsors or supporters. The views and opinions of the authors expressed herein do not necessarily state or reflect those of DOE or of any agency thereof, of The Regents, of CIEE, or any of CIEE's sponsors or supporters, and the names of any such organizations or their employees shall not be used for advertising or product endorsement purposes.

This report has been reproduced directly from the best available copy.

Available to DOE and DOE Contractors

from the Office of Scientific and Technical Information

P.O. Box 62, Oak Ridge, TN 37831

Prices available from (615) 576-8401

Available to the public from the

National Technical Information Service

U.S. Department of Commerce

5285 Port Royal Road, Springfield, VA 22161

Emest Orlando Lawrence Berkeley National Laboratory is an equal opportunity employer. 